\title{
Analysis of coiled coil domain containing 33 protein (CCDC33) and determination of infertility causes in mutant mouse line with the deletion of six germ cell-specific genes
}

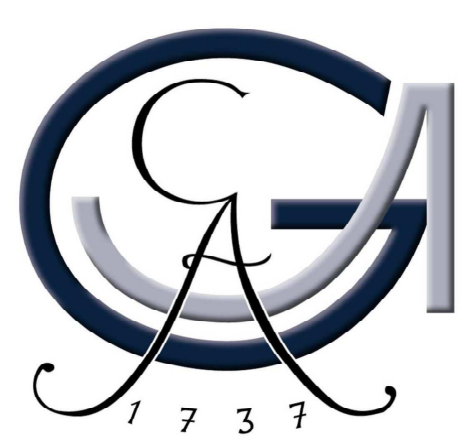

Dissertation

zur Erlangung des Doktorgrades

der Mathematisch-Naturwissenschaftlichen Fakultäten der Georg-August-Universität zu Göttingen

vorgelegt von

Krzysztof Wieczerzak

aus Kraków, Polen 
D7

Referent:Prof. Dr. med. Dr. h. c. Wolfgang Engel

Korreferent:Prof. Dr. Sigrid Hoyer-Fender

Tag der mündlichen Prüfung: 
Dedicated to my family. 


\section{Table of contents}

Table of contents 1

$\begin{array}{lr}\text { Abbreviations } & 6\end{array}$

1. INTRODUCTION 12

1.1. Role of $C c d c 33$ in spermatogenesis 12

1.2. Determination of infertility causes in mutant mouse line with the deletion of six germ cells specific genes (6xKO line) 15

1.3. Aims of the study 18

2. MATERIALS AND METHODS 20

2.1. Materials 20

2.1.1. Antibodies 20

2.1.2. Chemicals 20

2.1.3. Enzymes 23

2.1.4. Radioactive substances. 24

2.1.5. Solutions, buffers and media 24

2.1.5.1. Antibiotics 24

2.1.5.2. Buffers 24

2.1.5.3. Media 29

2.1.5.3.1. Media for bacteria. 29

2.1.5.3.2. Media for yeast 29

2.1.5.3.3. Media for cell cultures 30

2.1.5.4. Sterilisation of solutions 30

2.1.6. Plasmids 31

2.1.7. Bacterial strains 31

2.1.8. Mouse strains 31 
2.1.9. Yeast strain 32

2.1.10. Synthetic oligonucleotides 32

2.1.11. Kits 35

2.1.12. Laboratory materials 35

2.1.13. Instruments 36

$\begin{array}{ll}\text { 2.2. Methods } & 37\end{array}$

2.2.1. Isolation of nucleic acids 37

2.2.1.1. Isolation of genomic DNA 37

2.2.1.2. Isolation of plasmid DNA 38

2.2.1.3. Isolation of total RNA 39

2.2.2. Determination of nucleic acid concentration 39

2.2.3. Reverse transcription 39

2.2.4. Polymerase Chain Reaction (PCR) 40

2.2.5. Quantitative Real-Time PCR 41

2.2.6. Agarose gel electrophoresis $\quad 42$

2.2.6.1. Gel electrophoresis of RNA 42

2.2.6.2. Gel electrophoresis of DNA 42

2.2.7. Purification of DNA 43

2.2.7.1. Purification of DNA from agarose gel 43

2.2.7.2. Purification of plasmid DNA prior to sequencing 43

2.2.8. Enzymatic modifications of DNA 43

2.2.8.1. Restriction digestion of DNA 43

2.2.8.2. Ligation of DNA fragments 44

2.2.9. Transformation of bacteria 44

2.2.10. Northern blot 44

2.2.11. Southern blot 45

2.2.12. Transcriptome 45

2.2.13. Protein analysis 46

2.2.13.1. Isolation of total protein 46

2.2.13.2. Determination of protein concentration (Bradford, 1976) 47

2.2.13.3. Western blot 47 
2.2.13.4. Generation of CCDC33-MBP and CCDC33-GST fusions proteins for antibody production $\quad 48$

2.2.13.5. Immunization of rabbit 49

2.2.13.6. Purification of antibodies 49

2.2.14. Yeast-two-hybrid 49

2.2.14.1. Preparation of competent yeast cells $\quad 50$

2.2.14.2. Yeasts' transformation with DNA constructs 50

2.2.15. Histological techniques 51

2.2.15.1. Tissue preparation for paraffin-embedding 51

2.2.15.2. Hematoxylin-eosin staining 51

2.2.15.3. Immunohistochemistry staining 52

2.2.16. Cell culture methods

2.2.16.1. Trypsinisation of eukaryotic cells 52

2.2.16.2. Cell transfection 53

2.2.16.3. Co-immunoprecipitation 53

2.2.16.4. Immunocytochemistry staining 54

2.2.17. Production of knockout mice 54

2.2.17.1. Electroporation of ES cells with the 4933400A11Rik knockout 57

2.2.17.2. Microinjection of ES cells into blastocysts 57

2.2.17.3. Detection of chimerism and mice breeding 58

2.2.18. Fertility test 58

2.2.18.1. Isolation of spermatozoa 58

2.2.18.2. The analysis of sperm head morphology 58

2.2.18.3. CASA $\quad 59$

2.2.18.4. Testosterone level determination $\quad 59$

2.2.18.5. Acrosome reaction $\quad 59$

2.2.18.6. Determination of spermatozoa number 60

2.2.18.7. Superovulation $\quad 60$

2.2.18.8. Analysis of embryonic development 60

2.2.18.9. In vitro fertilisation 61

$\begin{array}{ll}\text { 2.2.19. Computer analysis } & 61\end{array}$ 
3. RESULTS 63

3.1. The analysis of the CCDC33 protein 63

3.1.1. Determination of the CCDC33 domain responsible for the interaction with PXT1 63

3.1.2. Coimmunopreciptation of CCDC33-1.1 with PXT1 71

3.1.3. Functional analysis of the PXT1 sequence responsible for the interaction with the CCDC33 74

3.1.4. The analysis of the consequences of CCDC33-PXT1 interaction for $\begin{array}{ll}\text { PXT1 induced apoptosis } & 81\end{array}$

3.1.5. Generation of anti-CCDC33 antibody $\quad 84$

3.1.6. The analysis of the specificity of anti-CCDC33 antibody 88

3.1.7. Generation of $C c d c 33$ - deficient mice 95

3.2. The analysis of knockout mouse line with the disruption of 6 germ $\begin{array}{ll}\text { cell-specific genes } & 102\end{array}$

3.2.1. The analysis of fertile and infertile males from 6xKO line 104

3.2.1.1. Testosterone level in peripheral blood 105

3.2.1.2. Histological analysis of the testis from 6xKO infertile males 105

3.2.1.3. The analysis of spermatozoa of 6xKO infertile mice 106

3.2.2. Transcriptome analysis of the testes of mice of $6 \mathrm{xKO}$ infertile and $\begin{array}{ll}5 x K O \text { fertile lines, respectively } & 111\end{array}$

3.2.3. Analysis of 4933400A11Rik expression 117

3.2.4. Analysis whether sperm of $6 \mathrm{xKO}$ infertile males are able to fertilize $\begin{array}{ll}\text { oocytes } & 122\end{array}$

3.2.5. In vitro fertilization $\quad 125$

3.2.6. Generation of 4933400A11 Rik knockout mouse 126

3.2.7. Analysis of 4933400A11RIK protein 129

3.2.8. Anti-4933400A11RIK antibody test in immunostaining of $\begin{array}{ll}\text { transiently tranfected cells } & 131\end{array}$

3.2.9. Sub-cellular localization of mouse 4933400A11RIK protein 134 
4. DISCUSSION 136

4.1. Analysis of the CCDC33 protein 136

4.1.1. Identification of domains in CCDC33 and PXT1 responsible for protein-protein interaction

4.1.2. CCDC33 can inhibit pro-apoptotic activity of PXT1 in spermatocytes

4.2. Analysis of knockout mouse line with the disruption of 6 germ cell-specific genes

4.2.1. Males from $6 x \mathrm{KO}$ line are infertile

4.2.2. 4933400A11RIK protein may be responsible for the infertility of 6xKO mice males

4.2.3. 4933400A11Rik protein might regulate germ cells cytoskeleton

4.2.4. Disregulation of germ cells actin cytoskeleton reorganisation may be the underlying cause of male infertility in $6 \mathrm{xKO}$ mice 


\section{Abbreviations}

$129 / \mathrm{Sv}$

$15 \mathrm{P}-1$

$5 \times \mathrm{KO}$

$6 \times \mathrm{KO}$

aa

Acr

Amp

AP

ATP

BAG

BCIP

BCL-2

BH3

BiFC

bp

BLAST

BSA

${ }^{\circ} \mathrm{C}$

C57BL

Ccde33

CD1
$129 / \mathrm{Sv}$ mouse strain

mouse Sertoli cell line

five time germ cell-specific gene knockout mouse line

six time germ cell-specific gene knockout mouse line

amino acid

acrosin prepropeptide gene

ampicillin

alkaline phosphatase

adenosinetriphosphate

BCL-2 associated athanogene

5-bromo-4-chloro-3-indolylphophat

B-cell leukemia/lymphoma-2

BCL-2 homology domain 3

bimolecular fluorescence complementation

base pair

basic local alignment search tool

bovine serum albumin

Celsius degree

C57BL/6J mouse strain

coiled coil domain containing 33 gene

CD1 mouse strain 
cDNA

CoIP

Creb314

Cy3

DAPI

$\mathrm{dCTP}$

DEPC

$\mathrm{dH}_{2} \mathrm{O}$

DMEM

DNA

DNAse

dNTP

DPBS

dpp

DsRED

DTT

EDTA

EGFP

ES

et al.

$\mathrm{EtBr}$

Fig.

FITC

FSH

FVB complementary DNA

coimmunoprecipitation

cAMP responsive element binding protein 3 -like 4 gene

indocarbocyanine

diamidino-2-phenylindole dihydrochloride

desoxyribocytosinetriphosphate

diethylpyrocarbonate

destilled water

Dulbecco's modified eagle medium

deoxyribonucleic acid

deoxyribonuclease

deoxynucleotidetriphosphate

Dulbecco's phosphate buffered saline

days post partum

Discosoma sp. red fluorescent protein

dithiothreitol

ethylene diamine tetraacetic acid

enhanced green fluorescent protein

embryonic stem

et alii (and others)

ethidium bromide

figure

fluorescein isothiocyanate

follicle-stimulating hormone

FVB/N mouse strain 
g

GC-4

Gene ID

HCG

Hist1h1t

HPRT

$\mathrm{h}$

$\mathrm{IgG}$

IPTG

IVF

Kan

$\mathrm{kb}$

$\mathrm{kDa}$

LB

MA-10

mg

$\mathrm{ml}$

$\mu 1$

$\mu \mathrm{m}$

$\min$

$\mathrm{mM}$

mRNA

Mw

$\mathrm{NaAc}$

NBT gravity

mouse spermatocyte cell line

gene identification number

human chorionic gonadotrophin

histone cluster 1 gene

hypoxanthin-phosphoribosyl-transferase

hour(s)

immunoglobulin $\mathrm{G}$

isopropyl-ß3-thiogalactopyranoside

in vitro fertilization

kanamycin

kilobase

kiloDalton

Luria-Bertani medium

mouse Leydig tumor cell line

milligram

milliliter

microliter

micrometer

minute

millimolar

messenger-RNA

molecular weight

sodium acetate

4-nitro-blue-tetrazolium chloride 
NCBI

$\mathrm{Neo}$

ng

$\mathrm{nm}$

nt

OD

ORF

$\mathrm{p}$

PAGE

PBS

PCR

PFA

polyA, $\mathrm{p}(\mathrm{A})$

PVDF

Pxt1

RNA

RNase

RT-PCR

RT

Sc11

Sdha

SD

SDS

Tab.

Taq
National Center for Biotechnology

neomycin

nanogram

nanometer

nucleotide

optical density

open reading frame

probability

polyacrylamide gel electrophoresis

phosphate buffered saline

polymerase chain reaction

paraformaldehyde

polyadenylation

polyvinlidene difluoride

peroxisomal testis specific 1 gene

ribonucleic acid

ribonuclease

reverse transcriptase PCR

room temperature

Sertoli cell line

succinate dehydrogenase

standard deviation

sodium dodecyl sulphate

table

DNA polymerase (Thermus aquaticus DNA polymerase) 
TE

Tex22

Theg

TNF

Tnp2

Tris

U

$\mathrm{Ub}$

UTR

Vol.

VP

WT

ZP

Symbols of nucleic acids

A

C

G

$\mathrm{T}$

$\mathrm{U}$

\section{Symbols of amino acids}
A Ala
alanine
B Asx
asparagine or aspartic acid
C Cys
cysteine

tris-EDTA buffer

testis expressed gene 22

testicular haploid expressed gene

tumor necrosis factor

transition protein 2 gene

trihydroxymethylaminomethane

unit

ubiquitin

untranslated region

volume

vaginal plug

wild type

zona pellucida

adenosine

cytidine

guanosine

thymidine

uridine 


\begin{tabular}{|c|c|c|}
\hline $\mathrm{D}$ & Asp & aspartic acid \\
\hline $\mathrm{E}$ & Glu & glutamic acid \\
\hline $\mathrm{F}$ & Phe & phenylalanine \\
\hline $\mathrm{G}$ & Gly & glycine \\
\hline $\mathrm{H}$ & His & histidine \\
\hline I & Ile & isoleucine \\
\hline $\mathrm{K}$ & Lys & lysine \\
\hline $\mathrm{L}$ & Leu & leucine \\
\hline M & Met & methionine \\
\hline $\mathrm{N}$ & Asn & asparagine \\
\hline $\mathrm{P}$ & Pro & proline \\
\hline Q & Gln & glutamine \\
\hline $\mathrm{R}$ & Arg & arginine \\
\hline $\mathrm{S}$ & Ser & serine \\
\hline $\mathrm{T}$ & Thr & threonine \\
\hline $\mathrm{V}$ & Val & valine \\
\hline W & $\operatorname{Trp}$ & tryptophan \\
\hline $\mathrm{Y}$ & Tyr & tyrosine \\
\hline $\mathrm{Z}$ & Glx & glutamine or $\mathrm{g}$ \\
\hline
\end{tabular}




\section{INTRODUCTION}

Approximately 60-75\% of all cases of male infertility remain idiopathic (Wu et $a l ., 2010)$. The determination of the genes, which are involved in spermatogenesis control might help to better understand molecular pathways driving male gamete production and, consequently, the reasons of human infertility. My thesis consists of 2 parts concerning 2 different aspects of human infertility research. The first project concerns the analysis of coiled coil domain containing 33 (CCDC33) protein and its role as an interaction partner of PXT1. In the second project I have analyzed the phenotype of males from a multiple knockout mouse line with six knockouted genes: Tnp2, Hist1h1t, Theg, Acr, Creb3l4 and Tex22.

\subsection{Role of $C c d c 33$ in spermatogenesis}

The transcript of mouse coiled coil domain containing 33 (Ccdc33) gene was cloned and identified by the generation of full-length cDNA library (Carninci and Hayashizaki, 1999). Then four different alternative splicing products of Ccdc33 were detected by RT-PCR in various tissues (Kaczmarek at al., 2009). Two longer transcripts: $C c d c 33 a$ contains exons 6-25 and $C c d c 33 c$ contains exons 1-3; 7-8; 10-13 and 15-25. $C c d c 33 a$ were found mainly in testis, but weak expression was also obtained in ovary, brain and mammary gland. $C c d c 33 c$ was observed in ovary, brain and mammary gland. Both transcripts encode proteins containing 3 coiled coil domains, $\mathrm{Ca}^{2+}$-dependent membrane-targeting module (C2 domain), C-terminal located ER membrane retention signal-like motif: NNQK and putative peroxisomal targeting signals type 2 (PTS2). In addition, the CCDC33c variant contains the $\mathrm{N}$-terminal ER-retention signal: GRQK. Two shorter variants: $C c d c 33 b$ (exons 6-8a) and $C c d c 33 d$ (exons 1-5) were found only in the testis and mammary gland, respectively (Kaczmarek at al., 2009). During spermatogenesis, the expression of mouse $C c d c 33$ was detected first in primary spermatocytes. No expression was detected in the testis of $W / W^{v}$ mutants and in Leydig (MA-10) and Sertoli (15P-1) cell lines (Kaczmarek el at., 2009). These results indicate that in testis $C c d c 33$ gene is expressed only in germ cells. By yeast-two-hybrid system the 
interaction of CCDC33 and peroxisomal testis specific 1 (PXT1) protein was identified and then confirmed by bimolecular fluorescence complementation assay (BiFC) and colocalization experiments (Kaczmarek, 2009).

Pxt1 gene encodes male germ cell-specific peroxisomal protein consisting of 51 amino acids (Grzmil et al., 2007). The expression of Pxtl is developmentally regulated during spermatogenesis and it starts with the pachytene spermatocyte stage. PXT1 protein contains a functional peroxisomal targeting signal type 1 (PTS1) at the $\mathrm{C}$ terminus (tripeptide Asn-His-Leu (NHL)), and EGFP-PXT1 fusion protein co-localizes with catalase, acyl CoA oxidase and ATP-binding cassette, sub-family D (ALD), member (ABCD3, also known as PMP70), which are known as peroxisomal markers (Grzmil et al., 2007). The analysis of the function of Pxtl in mouse testis by generation of transgenic animals with the overexpression of PXT1-cMYC fusion protein under the control of the $P G K 2$ promoter showed that this protein induces apoptosis in primary spermatocytes leading to male infertility (Kaczmarek, 2009; Kaczmarek et al., 2011). In the N-terminal part of PXT1 protein a BH3-like domain was identified. The domain known as Bcl-2 Homology 3 (BH3) was demonstrated in other proteins to be responsible for the induction of programmed cell death (Wang et al. 1996; Sattler et al., 1997; Singh et al., 2002; Yang, 2010; Garrison et al., 2011; Song et al., 2011). Yeast library screening showed that PXT1 interacts with BCL2-associated athanogene 6 (BAG6, also known as BAT3). BAG6 is known as an apoptosis regulator, and it was confirmed that BAG6 can protect cells from PXT1 induced apoptosis (Kaczmarek, 2009; Kaczmarek et al., 2011).

The role of peroxisomes in spermatogenesis process is poorly understood. The patients with X-linked adrenoleukodystrophy (X-ALD) demonstrated spermatogenesis disruption due to a mutation in peroxisomal membrane ABCD1 (ATP-binding cassette, sub-family D (ALD), member 1) protein, which is involved in the transport of very-longchain fatty acids (VLCFA) into the peroxisomal matrix (Brennemann et al., 1997; Kemp and Wanders, 2007). The dysfunction of ABCD1 results in VLCFA accumulation in the cell cytoplasm resulting in the vacuolization of Sertoli cells and a spermatogenesis arrest (Powers and Schaumburg, 1981; Powers, 1985). On the other hand, severe forms of peroxisomal biogenesis disorders suggest important function of peroxisomal metabolism in the development of the testis by regulation of the androgen balance or androgen signalling (Foresta et al., 2008; Luers et al., 2009). Deficiency of the acyl-coenzyme A 
oxidase 1 (Acoxl) gene (which encodes for peroxisomal enzyme involved in $\beta$-oxidation) in mouse model results in the reduction in the number of Leydig cells as well as the arrest of sperm maturation in seminiferous tubules (Fan et al., 1996). Peroxisomal biogenesis factor 7 (Pex7) mutant mice, of which only $50 \%$ survive to adulthood, were found to present testicular atrophy and infertility (Brites et al., 2003). The analysis of Pex7/Abcdl double knockout mice showed that plasmalogen synthesis and VLCFA metabolism is important for normal spermatocyte development (Brites et al., 2008). Testicular atrophy and male infertility were observed also in mice with the disruption of peroxisomal glyceronephosphate O-acyltransferase gene (Gnpat) (Rodemer et al., 2003). Homozygous male mutant mice lacking the peroxisomal protein hydroxysteroid (17-beta) dehydrogenase 4 (HSD17B4 or multifunctional protein 2, MFP-2) exhibit strongly reduced fertility connected with a lipid accumulation within the seminiferous tubules and arrest of germ cells maturation (Baes et al., 1997; Baes et al., 2000; Huyghe et al., 2006).

Peroxisomes are cellular organelles surrounded by a single membrane, with the diameter of $0.1-1 \mu \mathrm{m}$. The most important function of these organelles includes decomposition of hydrogen peroxide by catalase and $\beta$-oxidation of very-long-chain fatty acid as well as biosynthesis of lipids (bile acids, cholesterol, phospholipids) and glycerol (Mannaerts and van Veldhoven, 1993; Wanders, 2000). They also play certain role in the degradation of amino acids and purines and in glyoxylate, dicarboxylate and retinoid metabolism (Wanders and Waterham, 2006). Despite their important role, peroxisomes were believed for a long time to be restricted to somatic cells in the testis. They were identified in Leydig cells (Fawcett and Burgos, 1960; Reddy and Svoboda, 1972; Zini and Schlegel, 1996; Baumgart et al., 1997; Reisse et al., 2001) and Sertoli cells (Lester et al., 1996). In 2000, Figureoa et al. have observed for the first time peroxisome-like structures in rat oocytes (Figuorea et al., 2000), whereas in spermatogonial cell line peroxisomes were first detected in 2003 by Luers et al. Three years later peroxisomes were detected in the spermatogonia of germinal epithelium in mouse testis, but authors suggested that they become less apparent or even disappear during spermatogenesis (Huyghe et al., 2006; Luers et al., 2006). In 2007, peroxisomes were clearly demonstrated for the first time at all spermatogenesis stages, except for mature spermatozoa (Nenicu et al. 2007). Moreover, the authors observed that during spermatid maturation, peroxisomes aggregate to large clusters - the total number of peroxisome was decreasing and the volume was 
increasing (Nenicu et al., 2007). In the same year, in our Institute peroxisomal germ cellspecific Pxtl gene was discovered (Grzmil et al., 2007). Further characterization of CCDC33 and its interaction partner PXT1 would help to better understand the physiological role of peroxisomes in spermatogenesis.

\subsection{Determination of infertility causes in mutant mouse line with the deletion of six germ cells specific genes (6xKO line)}

Genetic control of mammalian spermatogenesis is not completely understood. Therefore, a generation of mouse models with targeted disruption of particular spermatogenesis-relevant genes seems to be an attractive method to investigate this subject. A generation of several single knockouts of following genes does not result in male infertility: Tnp2 (Adham et al., 2001), Acr (Adham et al., 1997, Nayernia et al., 2002b), Histlh1t (Drabent et al., 2000), Theg (Mannan et al., 2003), Creb3l4 (Adham et al., 2005) and Tex22 (Geisler, 2004).

Transition protein 2 gene (Tnp2) participates in the replacement of histones and in chromatin condensation in elongated spermatids. TNP2 protein is subsequently replaced by protamine 1 and 2 (Reinhart et al., 1991). Premature translation of Tnp2 mRNA causes abnormal sperm head morphogenesis, reduced sperm motility and male infertility in transgenic males (Tseden et al., 2007). Nevertheless, Tnp2-/- knockout males revealed normal fertility on the mixed C57BL/6Jx129/Sv background. However, on the inbred 129/Sv background homozygous mutant males are infertile (Adham el al., 2001). In infertile males germ cells were capable to initiate chromatin condensation, but abnormal focal condensation of chromatin in step 11 to 13 spermatids was observed and chromatin condensation was still incomplete in epididymal sperms. Furthermore, in mice from the inbred background the migration of Tnp2-/- spermatozoa from the uterus into the oviduct was reduced (Adham et al., 2001). Since Tnp2 shows high similarity to Tnp1, it is possible that in fertile line the disruption of Tnp2 gene can be compensated by Tnp1 (Adham et al., 2001; Zhao et al., 2001).

Histone cluster 1 (Histlhlt) gene is a linker histone and replaces cells somatic linker histones H1.1 and H1.2 during the meiotic prophase in male germ cells (Meistrich et al., 1985; Drabent et al., 1993). Histlhlt mRNA is expressed only in the mid- and late- 
pachytene spermatogenesis stages and the protein appeared first in pachytene spermatocytes and persists until later stages from round up to elongated spermatids (Drabent et al., 1996). Mass spectrometry analysis of HIST1H1T protein showed four different phosphorylation sites and this protein can be found as mono-, di-, and triphosphorylated as well as the unphosphorylated form. The conclusion was that the number of the phosphate groups is related to the regulation of chromatin decondensation (Sarg et al., 2009). Histlhlt-deficient mice are fertile. The testicular morphology and spermatogenesis process were not different from that observed in wild type mice. Hist1h1t-/- mice showed enhanced expression of histone genes: H1.1, H1.2 and H1.4 during spermatogenesis (Drabent et al., 2000).

Testicular haploid expressed gene (Theg) is specifically expressed in spermatid cells. The expression of this gene is up-regulated by factors from Sertoli cells (Nayernia et al., 1999, Mannan et al., 2000). Two mouse knockout lines for Theg were generated. In the first line, the part of Theg gene encoding for the C-terminal region of the THEG protein was deleted, whereas in the second line the part encoding for $\mathrm{N}$-terminal domain was replaced by the neomycin casette. Males from both knockouted lines are fertile, and no abnormalities in testicular morphology or sperm properties were detected (Mannan et al., 2003).

Acrosin prepropeptide (Acr) gene encodes serine protease protein, which is located in the acrosome as a matrix protein and on the sperm membrane as a glycosylphosphatidylinositol (GPI)-anchored protein (Kremling et al., 1991, Honda et al., $2002 \mathrm{a} / \mathrm{b})$. This protein is involved in the proteolysis of zona pellucida of the oocyte (Howes et al., 2001; Honda et al., 2002a). Mice lacking ACR are fertile and yield normal litter sizes (Adham et al., 1997, Nayernia et al., 2002; Yamashita et al., 2008). The loss of ACR resulted in delayed sperm penetration of the zona pellucida (ZP) in IVF experiment. It was probably due to the delay in dispersal of acrosomal proteins during the acrosome reaction (Adham et al., 1997).

cAMP responsive element binding protein 3-like 4 (Creb3l4) gene belongs to the CREB/ATF family of transcription factors that are involved in mediating transcription. In the mouse testis, Creb3l4 is especially active in response to a variety of stress conditions; in normal testis this gene is expressed exclusively in postmeiotic cells suggesting important role in spermatid differentiation (El-Alfy et al., 2006; Stirling and 
O'hare, 2006). Human CREB3L4 transcripts are detected exclusively in the prostate and in breast. Overexpression of CREB3L4 in prostate cancer cells suggests that this gene contributes to the development of prostate cancer (Qi et al., 2002). Inactivation of Creb3l4 in mice did not influence testis development, and males lacking Creb3l4 were fertile (Adham et al., 2005).

Testis expressed gene 22 (Tex22, also known as Tep22) is predominantly expressed in spermatocytes and spermatids of the murine testis. In the testis of 15 days old mouse four Tex22 transcripts were detected (Neesen et al., 2002). Specific antibodies against TEX22 detected this protein for the first time in the testis of 18 days old animal. TEX22 protein is localized in the acrosomal region of early elongating spermatids, but during spermiogenesis the acrosomal TEX22 is reduced and this protein can be localized in cytoplasm of the midpiece and in the mitochondrial sheath of mature spermatozoa (Neesen et al., 2002). These results suggest that Tex22 is involved in the biogenesis of the acrosome and in the function of the midpiece of murine spermatozoa (Neesen et al., 2002).

\begin{tabular}{|c|c|c|c|c|c|c|}
\hline Feature & Tnp2 & Histlhlt & Theg & Acr & Creb3l4 & Tex22 \\
\hline Gene ID & 21959 & 107970 & 21830 & 11434 & 78284 & 75671 \\
\hline Locus & $\begin{array}{c}16 \mathrm{~B} 1- \\
\mathrm{B} 3\end{array}$ & $13 \mathrm{~A} 3.2$ & $\begin{array}{c}10 \mathrm{~B} 5- \\
\mathrm{C} 1\end{array}$ & $15 \mathrm{E}-\mathrm{F}$ & $3 \mathrm{~F} 1$ & $12 \mathrm{~F} 1$ \\
\hline $\begin{array}{c}\text { Genomic DNA size } \\
(\mathrm{bp})\end{array}$ & 721 & 912 & 10660 & 6259 & 6013 & 14413 \\
\hline Exons-introns & $2-1$ & $1-0$ & $8-7$ & $5-4$ & $9-8$ & $2-1$ \\
\hline
\end{tabular}

Table 1. Basic information about mouse Tnp2, Hist1h1t, Theg, Acr, Creb3l4 and Tex22 genes based on NCBI database.

In order to further analyse the synergistic function of these genes multiple knockout lines were generated in the Institute of Human Genetics, University of Göttingen. It was reported previously that generation of multiple knockout lines might provide new phenotypic evidences for the function of analyzed genes. Homozygous double knockout 
mice with targeted disruption of Histlhlt and sperm mitochondrial-associated cysteinrich protein (Smcp) were subfertile (Nayernia et al., 2002a/2003b); however, single knockout males on hybrid background were fully fertile (Drabent et al., 2000, Nayernia et al., 2002a). Double mutants Histlhlt/Smcp demonstrated spermatozoa head abnormalities, reduced sperm motility and impaired sperm-oocyte interaction (Nayernia et al., 2003b), thus the function of both genes could be better recognized. In contrast, the analysis of two lines of triple knockout mice (Tnp2/Acr2/H1.12 and Tnp2/Acr2/H1t2) showed that both lines are fertile with normal sperm parameters, which clearly demonstrates the functional redundancy of these proteins in male mouse fertility (Nayernia et al., 2003a). Other triple knockout lines, Acr/H1.1/Smcp, Acr/Tnp2/Smcp, Tnp2/H1.1/Smcp, Acr/H1t/Smcp, Tnp2/H1t/Smcp, exhibit drastic reductions in fertility on mixed genetic backgrounds as a result of impaired sperm motility. In the female tracts reduced migration and decreased fertilization efficiency of mutant spermatozoa was noticed (Nayernia et al., 2005). Four times knockout Acr/Tnp2/Hist1h1t/Theg and Acr/Tnp2/Hist1h1t/Tex22 and five times knockout Acr/Tnp2/Hist1h1t/Theg/Creb3l4 mutant males are fertile (data not published). In order to analyse whether any cumulative effect of six male germ cell-specific genes Acr/Tnp2/Hist1h1t/Theg/Creb3l4/Tex22 can be observed in mutant mouse with the disruption of all these genes in a single animal, the fertility parameters of this line were analyzed in this work. I have discovered that $20 \%$ of males from six time knockout line $(6 \mathrm{xKO})$ are infertile. The analysis of the reason of infertility was also the objective of my work.

\subsection{Aims of the study}

The aims of the present study can be summarised in two main aspects: further analysis of $C c d c 33$ gene and protein, and determination of infertility causes in mutant mouse line with the deletion of six germ cell-specific genes.

In the first part of my study CCDC33 protein and its interaction with PXT1 was studied. The analysis was focused on the determination of the part of CCDC33 which is responsible for the interaction with PXT1 and which domain of PXT1 is important for binding with CCDC33. Previously, the transcription of $C c d c 33$ gene was detected in male germ cells starting at $15 \mathrm{dpp}$. In this work the CCDC33 protein is analysed in order to 
demonstrate its translation. Pro-apoptotic function of PXT1 protein is already known, and therefore our objective was to identify whether the interaction of PXT1 and CCDC33 has any impact on PXT1 pro-apoptotic activity in transient transfected HeLa cells. Moreover, in order to closer analyse the function of CCDC33 in spermatogenesis, the knockout mouse model should be generated.

The other project involved the analysis of the phenotype of 6xKO males so that we could answer the question of how these six genes (Tnp2, Hist1h1t, Theg, Acr, Creb3l4 and Tex22) act together on male fertility, and discover the cause of male infertility. For this task, after detailed analysis of the phenotypes, the comparison of transcriptomes of the testes of 5xKO fertile and $6 x \mathrm{KO}$ infertile mice should be performed to find candidate genes which can be involved in male fertility. I have discovered that the 4933400A11Rik gene, which is expressed in testes of fertile mice, is not longer expressed in the testes of infertile males. This gene is unknown and thus a closer analysis of its expression and cellular localization has suggested bring more light to its molecular function in spermatogenesis. 


\section{MATERIALS AND METHODS}

\subsection{Materials}

\subsubsection{Antibodies}

Anti-CCDC33

Sigma, Deisenhofen

Anti-CCDC33

Santa Cruz Biotech., Santa Cruz, USA

Anti-E2 Tag Rabbit Polyclonal Antibody

Biozol, Eching

Anti-F-actin capping protein subunit alpha-1

Millipore, Temecula, USA

Anti-Gluthatione-S-Transferase (GST) Clone GST-2 (monoclonal, Mouse)

Sigma, Deisenhofeen

Anti-MBP Monoclonal Antibody (HRP conjugated, Mouse)

New England Biolabs,

Frankfurt a/Main

Anti-Mouse IgG (whole molecule) -Alkaline Phosphatase

Sigma, Deisenhofen

Anti-Mouse IgG (whole molecule) - Cy3

Sigma, Deisenhofen

Anti-Mouse IgG (whole molecule) -FITC

Sigma, Deisenhofen

Anti-cMyc Tag, (mouse)

Millipore, Temecula, USA

Anti-Rabbit IgG (whole molecule) -Alkaline Phosphatase

Sigma, Deisenhofen

Anti-Rabbit IgG (whole molecule) - Cy3

Sigma, Deisenhofen

Anti-Rabbit IgG (whole molecule) -FITC

Sigma, Deisenhofen

Anti- $\alpha$-tubulin, mouse monoclonal

Santa Cruz Biotech., Santa Cruz, USA

Anti- 4933400A11 RIK

GenScript, Piscataway, USA

\subsubsection{Chemicals}

$1 \mathrm{~kb}$ DNA-Ladder

Invitrogen, Karlsruhe

100 bp DNA Ladder

Invitrogen, Karlsruhe

5-bromo-4-chloro-3-indolylphophat (BCIP)

Biosynth, Staad, Switzerland

Acetic acid

Merck, Darmstadt

Agar-Agar, Kobe I

Roth, Karlsruhe

Agarose

Bio-Budget, Krefeld 
Albumin Fraktion Y (BSA)

Ammonium acetate

Ammonium persulfate

Ampicillin sodium salt

Ampuwa water

$\beta$-Mercaptoethanol

Bacto-Peptone

Bacto-Yeast-Extract

Boric acid

Bromophenol blue 0.02\%

Chloroform

Coomassie Brilliant Blue R-250

Diethyl pyrocarbonate (DEPC)

Dimethyl formamide

Dimethyl sulfoxid (DMSO)

Direct PCR Lyse Reagent

Dithiothreitol

dNTPs

DO Supplement (-Ade/-His/-Leu/-Trp)

Dulbecco’s Modified Eagle Medium (DMEM)

EDTA

EGTA

Ethanol

Ethidium bromide

Eukitt-quick hardening mounting medium

FCS

Formaldehyde

Freund's adjuvant, complete and incomplete

Geneticin sulphate (G418)

Gluthation

Glycerol

Glycine
Roth, Karlsruhe

Fluka, Neu Ulm

Roth, Karlsruhe Applichem, Darmstadt

Fresenius, Bad Homburg Sigma, Deisenhofen Difco, Detroit, USA Difco, Detroit, USA Roth, Karlsruhe Roth, Karlsruhe Baker, Devent Serva Electrophoresis, Heidelberg Roth, Karlsruhe Merck, Darmstadt Merck, Darmstadt Peqlab, Erlangen Sigma, Deisenhofen Invitrogen, Karlsruhe

Clontech, Heidelberg PAN-Systems, Nürnberg Applichem, Darmstadt Applichem, Darmstadt Baker, Deventer Applichem, Darmstadt Fluka, Neu Ulm PAN-Systems, Nürnberg Invitrogen, Karlsruhe Sigma, Deisenhofen Sigma, Deisenhofen Applichem, Darmstadt Roth, Karlsruhe Biomol, Hamburg 
$\mathrm{HCl}$

IPTG

Isopropanol

IVF Cook Medium

$\mathrm{KCl}$

Lipofectamine 2000 TM

Maltose

Medium M2 and M16

Methanol

$\mathrm{MgCl}_{2}$

Milk powder

Mineral oil

$\mathrm{NaCl}$

$\mathrm{NaOH}$

Nitro-blue tetrazolium chloride

NuPAGE Novex Bis-Tris 12\% and 4-12\% Gel

NuPAGE MOPS/MES SDS running buffer

NuPAGE SDS sample buffer

OptiMEM I

Paraformaldehyde

PBS

Penicillin/Streptomycin

Peptone

Phenol

Picric acid

Proteinase $\mathrm{K}$

RNA length standard

Roti®-Nanoquant

Salmon sperm DNA

SDS

SeeBlue Plus2 Pre-Stained Standard

S.O.C Medium
Merck, Darmstadt

Roth, Karlsruhe

Baker, Deventer

Cook Medical, Brisbane, Australia

Merck, Darmstadt Invitrogen, Karlsruhe Merck, Darmstadt

Sigma, Deisenhofen Roth, Karlsruhe Merck, Darmstadt Roth, Karlsruhe Sigma, Deisenhofen Roth, Karlsruhe Merck, Darmstadt Applichem, Darmstadt Invitrogen, Karlsruhe Invitrogen, Karlsruhe Invitrogen, Karlsruhe Invitrogen, Karlsruhe Roth, Karlsruhe PAN-Systems, Nürnberg PAN-Systems, Nürnberg Roth, Karlsruhe Biomol, Hamburg Fulka, Neu Ulm

Roche, Penzberg Invitrogen, Karlsruhe Roth, Karlsruhe Sigma, Deisenhofen Serva, Heidelberg Invitrogen, Karlsruhe Invitrogen, Karlsruhe 
Sodium acetate

Sodium citrate

SuperScript II

TRI reagent

Tris base

Triton X-100

TrypleTM Express

Tween-20

Vectashield (DAPI)

$\mathrm{X}$-Gal

$\mathrm{X}-\alpha-\mathrm{Gal}$

Xylene

Yeast extract

\subsubsection{Enzymes}

DNAseI

Immolase DNA Polymerase

Klenow Fragment

Proteinase $\mathrm{K}$

Platinum Taq polymerase

Polymerase Pfu

Restriction enzymes (with supplied buffers):
Merck, Darmstadt

Roth, Karlsruhe

Invitrogen, Karlsruhe

Invitrogen, Karlsruhe Applichem, Darmstadt

Serva, Heidelberg Invitrogen, Karlsruhe Applichem, Darmstadt Vector, Burlingame Biomol, Hamburg Clontech, Heidelberg Merck, Darmstadt Roth, Karlsruhe Sigma, Deisenhofen Bioline, Luckenwalde Invitrogen, Karlsruhe Sigma, Deisenhofen Invitrogen, Karlsruhe Stratagene, Waldbronn Invitrogen, Karlsruhe

$>$ AsiSI

> BamHI

$>B g l \mathrm{II}$

$>C l a \mathrm{I}$

$>D p n \mathrm{I}$

$>$ EcoRI

HindIII

$>K p n \mathrm{I}$

$>N d e \mathrm{I}$ 


$$
\text { Pst } \mathrm{I}
$$

Superscript-II

T4 DNA ligase

Trypsin
Invitrogen, Karlsruhe

Promega, Mannheim

Invitrogen, Karlsruhe

\subsubsection{Radioactive substances}

$\alpha-{ }^{32} \mathrm{P}-\mathrm{dCTP}$

Amersham, Braunschweig

\subsubsection{Solutions, buffers and media}

\subsubsection{Antibiotics}

Antibiotics were dissolved in required solvent, filtrated through sterile filters and stored at $-20^{\circ} \mathrm{C}$ (stock solutions). When antibiotics were needed, they were added to the autoclaved medium after cooling down to a temperature lower than $50^{\circ} \mathrm{C}$.

Antibiotics

Ampicillin

Kanamycin

Geneticin (Neomycine)

Streptomycin

\section{$\underline{\text { Stock solution }}$}

$50 \mathrm{mg} / \mathrm{ml}\left(\mathrm{H}_{2} \mathrm{O}\right)$

$25 \mathrm{mg} / \mathrm{ml}\left(\mathrm{H}_{2} \mathrm{O}\right)$

$10 \mathrm{mg} / \mathrm{ml}\left(\mathrm{H}_{2} \mathrm{O}\right)$

$0,1 \mathrm{mg} / \mathrm{ml}(\mathrm{PBS})$
Working solution

$50 \mu \mathrm{g} / \mathrm{ml}$

$50 \mu \mathrm{g} / \mathrm{ml}$

$200 \mu \mathrm{g} / \mathrm{ml}$

$50 \mu \mathrm{g} / \mathrm{ml}$

\subsubsection{Buffers}

All standard buffers and solutions were prepared according to Sambrook et al. (1989).

AP buffer

$100 \mathrm{mM}$ tris/ $\mathrm{HCl}(\mathrm{pH} 9)$

$100 \mathrm{mM} \mathrm{NaCl}$

$50 \mathrm{mM} \mathrm{MgCl}_{2}$

Bouin's solution

15 volume of picric acid (in $\mathrm{H}_{2} \mathrm{O}$ )

5 volumes $37 \%$ formaldehyde

1 volume acetic acid 
BCiP

Column buffer

Denaturation solution

Depurination solution

dNTP-mix

Elution buffer

Elution buffer II

$1 \mathrm{ml} 100 \mathrm{mM}$ gluthation $+9 \mathrm{ml}$ protein purification buffer

Lysis buffer (ES cells)

Lysis buffer I
$50 \mathrm{mg} / \mathrm{ml} \mathrm{BCiP}$

$70 \%$ dimethylformamide

$20 \mathrm{mM}$ tris/ $\mathrm{HCl}(\mathrm{pH} 7.4)$

$200 \mathrm{mM} \mathrm{NaCl}$

1 mM EDTA

$1 \mathrm{mM}$ DTT

$1.5 \mathrm{M} \mathrm{NaCl}$

$0.5 \mathrm{M} \mathrm{NaOH}$

$250 \mathrm{mM} \mathrm{HCl}$

$10 \mathrm{mM}$ dATP

$10 \mathrm{mM}$ dCTP

$10 \mathrm{mM}$ dGTP

10 mM dTTP
$50 \mathrm{mM}$ tris/ $\mathrm{HCl}(\mathrm{pH} 8.5)$

5 mM EDTA

$0.2 \%$ SDS

$100 \mathrm{mM} \mathrm{NaCl}$

$250 \mu \mathrm{l}$ proteinase $\mathrm{K}(10 \mathrm{mg} / \mathrm{ml}) / 25 \mathrm{ml}$

$10 \mathrm{mM}$ tris/ $\mathrm{HCl}(\mathrm{pH} 7.4)$

1 mM EDTA

$100 \mathrm{mM} \mathrm{NaCl}$

$0.1 \%$ SDS 
$2.5 \%$ glycerol

$0.5 \%$ deoxycholate sodium

1 mM EGTA

$0.1 \%$ tritonX

Lysis buffer II

$50 \mathrm{mM}$ tris/ $\mathrm{HCl}(\mathrm{pH} 8)$

$0.5 \%$ SDS

$100 \mathrm{mM}$ EDTA

Lysis buffer III

$250 \mathrm{mM}$ tris/ $\mathrm{HCl}(\mathrm{pH} 7.4)$

$100 \mathrm{mM} \mathrm{NaCl}$

$100 \mathrm{mM}$ EDTA

$1.25 \%$ deoxycholate sodium

1 protease inhibitor cocktail tablet $/ 25 \mathrm{ml}$

Lysis buffer IV

$50 \mathrm{mM}$ tris/ $\mathrm{HCl}(\mathrm{pH} 8.3)$

$150 \mathrm{mM} \mathrm{NaCl}$

$1 \%$ TritonX

1 protease inhibitor cocktail tablet/40ml

Lysis buffer V

$50 \mathrm{mM}$ tris/ $\mathrm{HCl}(\mathrm{pH} 8.3)$

$150 \mathrm{mM} \mathrm{NaCl}$

$1 \mathrm{mM}$ DTT

1 protease inhibitor cocktail tablet/40ml

Lysis buffer V I

$50 \mathrm{mM}$ tris/ $\mathrm{HCl}(\mathrm{pH} 8.3)$

$150 \mathrm{mM} \mathrm{NaCl}$

$1 \%$ TritonX

$0.1 \%$ SDS

$0.5 \%$ deoxycholate sodium

1 protease inhibitor cocktail tablet/40ml 
Lysis buffer VII

MOPS 10x

NBT

Neutralisation solution

P1 resuspension buffer

P2 lysis buffer

P3 neutralization buffer

PEG/LiAc buffer
$5 \mathrm{mM}$ MOPS (pH 7.4)

$250 \mathrm{mM}$ sucrose

$1 \mathrm{mM}$ EDTA

$0.1 \%$ ethanol

$0.2 \mathrm{mM}$ DTT

$1 \mathrm{mM}$ 6-aminocapronic acid

1 protease inhibitor cocktail tablet/40ml

41.8 g MOPS

$16.6 \mathrm{ml} 3 \mathrm{M} \mathrm{NaAc}$

$20 \mathrm{ml} 0.5 \mathrm{M}$ EDTA

Till $11 \mathrm{H}_{2} \mathrm{O}_{\text {DEPC }}$

$75 \mathrm{mg} / \mathrm{ml} \mathrm{NBT}$

$70 \%$ dimethylformamide

$1.5 \mathrm{M} \mathrm{NaCl}$

$1 \mathrm{M}$ tris/ $\mathrm{HCl}(\mathrm{pH} 7.0)$

$50 \mathrm{mM}$ tris/ $\mathrm{HCl}, \mathrm{pH} 8.0$

10 mM EDTA

$100 \mu \mathrm{g} / \mathrm{ml}$ RNase A

$200 \mathrm{mM} \mathrm{NaOH}$

$1 \%$ SDS

$3 \mathrm{M}$ potassium acetate, $\mathrm{pH} 5.5$

$1 \mathrm{ml} 10 \mathrm{x}$ TE

$1 \mathrm{ml}$ 10x LiAc

$8 \mathrm{ml} 50 \%$ PEG 
Protein purification buffer

RNA loading buffer

RNA sample buffer

$\operatorname{SSC}(20 x)$

TBE buffer $(5 \mathrm{x})$

TBST

TE buffer

1x TE/LiAc buffer

Washing buffer I
$20 \mathrm{mM}$ tris/ $\mathrm{HCl}(\mathrm{pH} 7.5)$

$500 \mathrm{mM} \mathrm{NaCl}$

$10 \%$ glycerol

2 protease inhibitor cocktail tablet/100ml

$40 \mu 11 \%$ ethidium bromide

$500 \mu \mathrm{l}$ standard loading buffer

$45 \mu 110 \times$ MOPS buffer

$75 \mu 137 \%$ formaldehyde

$180 \mu 1$ formamide

$3 \mathrm{M} \mathrm{NaCl}$

$0.3 \mathrm{M}$ sodium citrate $(\mathrm{pH} 7.0)$

$450 \mathrm{mM}$ tris base

$450 \mathrm{mM}$ boric acid

20 mM EDTA (pH 8)

$10 \mathrm{mM}$ tris

$150 \mathrm{mM} \mathrm{NaCl}$

$0.1 \%$ tween 20

$10 \mathrm{mM}$ tris/ $\mathrm{HCl}(\mathrm{pH} 8.0)$

1 mM EDTA

$0.5 \mathrm{ml} 10 \mathrm{x}$ TE buffer

$0.5 \mathrm{ml} 10 \mathrm{x} \mathrm{LiAc}$

$4 \mathrm{ml} \mathrm{dH_{2 } \mathrm { O }}$

2x SSC

$0.1 \%$ SDS 
Washing buffer II

$0.2 \mathrm{xSC}$

\subsubsection{Media}

\subsection{Media for bacteria}

LB Medium

$1 \%$ peptone

$1 \% \mathrm{NaCl}$

$0.5 \%$ yeast extracts

$(+1.5 \%$ agar for plates $)$

LB Bacto-Medium

$$
\begin{aligned}
& 1 \% \text { Bacto-peptone } \\
& 1 \% \mathrm{NaCl} \\
& 0.5 \% \text { Bacto-yeast extracts }
\end{aligned}
$$

The LB medium was prepared with distilled water and autoclaved.

\subsection{Media for yeast}

YPD Medium

$2 \%$ peptone

$1 \%$ yeast extracts

(+ $1.5 \%$ agar for plates)

Autoclave

$0.2 \%$ glucose

$10 \mu \mathrm{g} / \mathrm{ml}$ adenine

$50 \mu \mathrm{g} / \mathrm{ml}$ kanamycin

$50 \mu \mathrm{g} / \mathrm{ml}$ streptomycin

SD Medium

$1.7 \mathrm{~g}$ yeast nitrogen base

0.6 g DO supplement

$5 \mathrm{~g}$ ammonium sulfate

Till $950 \mathrm{ml} \mathrm{H}_{2} \mathrm{O}_{\text {DEPC }}$

pH 5.8 
(+ $1.5 \%$ agar for plates $)$

Autoclave

$0.2 \%$ glucose

$50 \mu \mathrm{g} / \mathrm{ml}$ kanamycin

$50 \mu \mathrm{g} / \mathrm{ml}$ streptomycin

\subsection{Media for cell culture}

HeLa/NIH3T3 medium

178 ml DMEM without L-glutamin

$20 \mathrm{ml} 10 \%$ FCS

$100 \mu \mathrm{g} / \mathrm{ml}$ penicillin/streptomycin

GC-4 medium

200 ml Dulbecco-M-Medium

$30 \mathrm{ml} 10 \%$ FCS

$100 \mu \mathrm{g} / \mathrm{ml}$ penicillin/streptomycin

\section{ES medium}

Embryonic stem (ES) cell medium:

DULBECCO’s Modified Eagles Media

(DMEM)

$1 \mathrm{mM}$ Non essential amino acids

$1 \mathrm{mM}$ sodium pyruvate

$10 \mu \mathrm{M} \beta$-mercaptoethanol

2 mM L-glutamine

$20 \%$ FCS

$100 \mu \mathrm{g} / \mathrm{ml}$ penicillin/streptomycin

\subsubsection{Sterilisation of solutions}

All heat sensitive solutions were filtered through a sterile filter $(0.2$ to $0.45 \mu \mathrm{m}$ pore size), solutions which are not heat sensitive were sterilised for $60 \mathrm{~min}$ at $121^{\circ} \mathrm{C}, 105$ $\mathrm{Pa}$ in an autoclave (Webeco, Bad Schwartau). 


\subsubsection{Plasmids}

$>\mathrm{pCMV}-\mathrm{Myc}$

$>$ pDsRed-Monomer-N1

$>\mathrm{pET}-41 \mathrm{a}$

pEGFP-C1

$>$ pGADT7

$>$ pGBKT7

$>$ pGEM-T Easy

$>$ pMAL-c $2 \mathrm{X}$

pQM-NTag/A intron vector
Clontech, Heidelberg

Clontech, Heidelberg Novagen, Darmstadt

Clontech, Heidelberg

Clontech, Heidelberg

Clontech, Heidelberg

Promega, Wisconsin, USA

New England Biolabs, Frankfurt a/Main

Abcam, Cambridge, UK

\subsubsection{Bacterial strains}

E. coli $\mathrm{DH} 5 \alpha$

E. coli BL21 (DE3)

E. coli SCS 110
K-12 strain,F- Ф80d lacZM15 endA1 recA1 hsdR17 (rk-, mk+) sup E44 thi-1 d- gyrA96 (lacZYA-arg)

Invitrogen, Karlsruhe B strain, F- ompT hsdSB(rB-mB-) gal, Dcm

Novagen, Darmstadt

rpsL (Strr) thr leu endA thi-1 lacY galK galT ara tonA tsx dam dem supE44D (lac-proAB)

Stratagene, Waldbronn

\subsubsection{Mouse strains}

Mouse strains 129/Sv, C57BL/6J, CD-1, FVB and NMRI (originated from Charles River Laboratories, Wilmington, USA) were housed in the Animal Facility of Institute of Human Genetics, Göttingen. Both mutant lines with 5 (Tnp2; Acr; H1.t; Theg and Creb3l4) and 6 (Tnp2; Acr; H1.t; Theg; Creb3l4 and Tep22) knockouted genes were generated and housed in our Animal Facility. 


\subsubsection{Yeast strain}

Saccharomyces cerevisiae AH109

Clontech, Heidelberg

\subsubsection{Synthetic oligonucleotides}

The synthetic oligonucleotide primers used in this study were obtained from Eurofins MWG Operon (Ebersberg) and dissolved in Ampuwa $\mathrm{dH}_{2} \mathrm{O}$ to a final concentration of $100 \mathrm{pmol} / \mu \mathrm{l}$.

Name

CCDC33_1F

CCDC33_1R

CCDC33_11R

CCDC33_11 CoIpF

CCDC33_11 CoIpRev

CCDC33_12F

CCDC33_12R

CCDC33_13F

CCDC33_3F

CCDC33_3R

CCDC33_4F

CCDC33_4R

CCDC33ex $23 \mathrm{~F}$

CCDC33ex24R

CCDC33del1-Fa

CCDC33del1-Fb

CCDC33del2-Fa

CCDC33del2-Fb

CCDC33del2-Ra

$\mathrm{CCDC} 33 \mathrm{del} 2-\mathrm{Rb}$

CCDC33del3-F1

CCDC33del3-F2
Sequence

5'TGGTGAATTCCCCTTGTGGAACCAGTCCTTC3'

5'ACCTATCGATCCAGTTCGTTCAGCAGTAGC3'

5'TCCTATCGATGAGGGGGCTTCTCCATTGAT3'

5'CAACGAATT CCC TTG TGGAACCAGTCCTTC3'

5'CAACGGTACCTTACGAGGGGGCTTCTCCATTGAT3'

5'TGGTGAATTCCCCCTGGGTGTATCGGTGTTA3'

5’TCCTATCGATCGCCGGTAATTGTTCATCTC3'

5'TGGTGAATTCTCCACTCAGGAAATGGAGGAA3'

5'TAATGAATTCGCAGTGTCCATGAAGCAGAAGC3'

5'TAATGAATTCGCAGTGTCCATGAAGCAGAAGC3'

5'TAATGAATTCATTCGGACAGAGCTGGAAAAG3'

5'CAACATCGATGCAGGGAGGTTTCCAGTTTC3'

5'TTCCTTGGTGGTACTTCAGACAA3'

5'AGGCTGGTCTATGATGATGGAGT3'

5'TGGTGAATTCTTCCAAGCCCGAGATG3'

5'TGGTGAATCTTCCAAGCCCGAGATGGGGCCA3'

5'TCTGCCTCAATGCAAAGCAGTGAG3'

5'AGACGGAGTTACGTTTCGTCACTC3'

5'TGTGTTCTCTGAGAAACTGGTGGC3'

5'ACACAAGAGACTCTTTGACCACCG3'

5'AAATCTCGTCTATACCACAAGATG3'

5'TTTAGAGCAGATATGGTGTTCTAC3' 


\begin{tabular}{|c|c|}
\hline \multirow{2}{*}{$\begin{array}{l}\text { CCDC33del3-R1 } \\
\text { CCDC33del3-R2 }\end{array}$} & 5'GGGCTGGTTGAGGGCCCATGGCTC3' \\
\hline & 5'CCCGACCAACTCCCGGGTACCGAG3' \\
\hline \multicolumn{2}{|l|}{ CCDC33-E6-8dsREDFP } \\
\hline \multicolumn{2}{|r|}{ 5'ATTAGAATTCGGCCACCATGGGACGACAGAAGACAAAGG3' } \\
\hline CCDC33-E6-8dsREDRP & 5'ATTAGGATCCACAGAGGTCATCGCTTGAG3' \\
\hline CCDC33-E6-8EGFPFP & 5'ATTAGAATTCGGGACGACAGAAGACAAAGG3' \\
\hline CCDC33GSTPstIRP & 5'TAATCTGCAGGTTATTCCCGTCCTGTGTCCTCT3' \\
\hline CCDC33MalEcoRIFP & 5'ATTAGAATTCCCACAGGGCCGCCTGGATAC3' \\
\hline CCDC33MalPstIRP & 5’TAATCTGCAGTTATTCCCGTCCTGTGTCCTCT3’ \\
\hline Gene5HindEGFPF & 5'CAACAAGCTTTGGCCAACCGCAAAGATAAA3' \\
\hline Gene5HindRedF & 'AACAAGCTTGCCACCATGGCCAACCGCAAAGATAAA3' \\
\hline Gene5KpnRedR & 5'TAATCGGTACCGTAGCATGTTTCAACTTGAG3' \\
\hline HPRT-For & 5'AGCCCCAAAATGGTTAAGGTTGC3' \\
\hline HPRT-Rev & 5'TTGCAGATTCAACTTGCGGCTCAT3' \\
\hline LacInZRev & 5'GTCTGTCCTAGCTTCCTCACTG3' \\
\hline mGene20F & 5'TCTCTCTTCAAGACGCTGGC3' \\
\hline mGene20R & 5'GTGTCCAGGGAAGAGGTGAA3' \\
\hline mGene25F & 5'CTGGTGGTGTCAAAAGGTTCTT3' \\
\hline mGene25R & 5'CCACAGACCACGGGAATAGT3' \\
\hline mGene27F & 5'CGATGGAATGAACGGTTGG3' \\
\hline mGene27R & 5'TCTTTGGTTCCTCCCCATGA3' \\
\hline mGene28F & 5'CTGAAGATCGCAGAGGTGTG3' \\
\hline mGene28R & 5’TGCTGGCTGTCATTTATGGA3' \\
\hline mGene4F & 5'GAATATTTCTCCCCCACAGG3' \\
\hline mGene $5 \mathrm{~A}-\mathrm{F}$ & 5'CCСТCСCATCCTTGATCACT3' \\
\hline mGene5A-R & 5'CCAАCСССТТССТССТАСАТЗ' \\
\hline mGene $5 \mathrm{~F}$ & 5'GAGGGCATCATCCTTAGCAG3' \\
\hline mGene5Fsonda & 5'ACGCCACCCTTCTAACCAG3' \\
\hline mGene5R & 5'CTTCCTTAAACTCGCCTGGA3' \\
\hline mGene 5 seqR & 5'CCTAGATGGCCATGCTCTGTA3' \\
\hline mGene 5seqF & 5'TGGAATGCTCAAGTCTCACG3' \\
\hline mGene9R & 5'GTGGAAGTATGGATACCTCATGA3' \\
\hline
\end{tabular}




$\begin{array}{ll}\text { Ndufs5FP } & \text { 5'GCAGGCGTCTGCGTCCTC3' } \\ \text { Ndufs5RP } & \text { 5'TCGCCTCATCGTTTTGTACCG3' } \\ \text { NeoInF } & \text { 5'TCATTCTCAGTATTGTTTTGCC3' } \\ \text { PCR-Pelo-F } & \text { 5'TGAGCCCAGACTGTACGTGAC3' } \\ \text { PCR-Pelo-R } & \text { 5'TCTGCACCTTAGCGTGAAGCC3' } \\ \text { pGADT7F } & \text { 5'TCGATGATGAAGATACCCCACCAAACC3' } \\ \text { pGADT7R } & \text { 5'AGATGGTGCACGATGCACAGTTGAAGTG3' } \\ \text { pMal-seqF } & \text { 5'GGTCGTCAGACTGTCGATGAAGCC3' } \\ \text { pMal-seqR } & \text { 5'GTAAAACGACGGCCAGT3' } \\ \text { pET-41a-seqF } & \text { 5'GCTAAATTCGAACGCCAGCACATGG3' } \\ \text { pET-41a-seqR } & \text { 5'TATGCTAGTTATTGCTCAG3' } \\ \text { PtproFP } & \text { 5'AACGGCATCCGTGAGAATAG3' } \\ \text { PtproRP } & \text { 5'GAGTGGGACAGGTCAGTGGT3' } \\ \text { Pxt1APGGFP } & \end{array}$

5'GAAGTCGGAGATGTGGGGGGTGGTGGTGTGGCGCTGGTGTTC3' Pxt1APGGRP

5'GAACACCAGCGCCACACCACCACCCCCCACATCTCCGACTTC3' Pxt1FGFP 5'GAGATGTGGGGGCTCCTGGTGTGGCGCTGGTGTTC3' Pxt1FGRP 5'GAACACCAGCGCCACACCAGGAGCCCCCACATCTC3' Pxt1LGFP 5'GAAGTCGGAGATGTGGGGGCTCCTTTTGTGG3' Pxt1LGRP 5'CCACAAAAGGAGCCCCCACATCTCCGACTTC3' SD 'ATGACTGCTGACTTGAGGTG3' 
TDF

TDR

TUF

TUR

$\mathrm{T} 7$
5'GCAGCTCGTTCGTTGTCC3'

5'CAGTTTGGGCCTATTGGTGTATG3'

5'CTGCGTCAGGCACTGTAAC3'

5'TTCTTCACCTGGGCTCATTC3'

5'AATACGACTCACTATAGGGCGAATTGG3'

\subsubsection{Kits}

DNAseI Amplification Grade

GeneChip Whole Transcript (WT) Sense Target Labelling Assay

Float-A-Lyzer G2

Immunoprecipitation Kit (Protein G)

Megaprime DNA Labelling System

Midi Plasmid Kit

Mini Plasmid Kit

MSB®Spin PCRapace

Pure Link TM HiPure Plasmid (Midiprep Kit)

QuikChange Site-Directed Mutagenesis Kit

QIAquick® Gel Extraction Kit
Spectrum Laboratories Inc., Greensboro, USA

Roche, Penzberg Amersham, Freiburg Invitrogen, Karlsruhe Qiagen, Hilden Invitek, Berlin Invitrogen, Karlsruhe Stratagene, Waldbronn Qiagen, Hilden

\subsubsection{Laboratory materials}

Cell culture flasks

Centrisart 1; MWCO 20 kDa

Culture slides

Filter paper 0858

Hybond C

Hybond N

Microcentrifuge tubes

Petri dishes

Pipette tips

PVDF membranes, $0.2 \mu \mathrm{m}$ pore size
Greiner, Nürtingen

Sartorius, Göttingen

BD Falcon, Heidelberg Schleicher and Schüll, Dassel Amersham, Braunschweig Amersham, Braunschweig Eppendorf, Hamburg Greiner, Nürtingen Eppendorf, Hamburg Invitrogen, Karlsruhe 
RotiPlast paraffin

Superfrost slides

Whatman blotting paper

X-ray cassette

X-ray films

\subsubsection{Instruments}

Autoclave

Centrifuge (1-15, 1-15K, 4K15)

DNA Sequencer Modell Megabace 1000

Microscope BX60

Mikrotom Jung RM 2035

Pipette

Photometer

Scale CP3202 S

SpeedVac concentrator SVC $100 \mathrm{H}$

Synergy Mx

Thermocycler

2720

ABI Prism 7900HT PCR instrument

Primus96

Thermomixer 5436

TissueLyser

TurboblotterTM

UV StratalinkerTM1800

X-Ray Automatic Processor Curix60
Roth, Karlsruhe

Menzel, Gläser

Schleicher and Schüll, Dassel

Siemens, Munchen

Amersham, Braunschweig

Webeco, Bad Schwartau

Sigma, Deisenhofen

Amersham, Freiburg

Olympus, München

Leica, Nußloch

Eppendorf, Hamburg

Eppendorf, Hamburg

Sartorius, Göttingen

Schütt, Göttingen

BioTek, Bad Friedrichshall

Applied Biosystem, Carlsbad, USA

Applied Biosystem, Carlsbad, USA

Peqlab, Erlangen

Eppendorf, Hamburg

Qiagen, Hilden

Schleicher \& Schüll, Dassel

Leica, Nußloch

Agfa, München 


\subsection{Methods}

\subsubsection{Isolation of nucleic acids}

\subsubsection{Isolation of genomic DNA}

\section{Isolation of mouse genomic DNA for PCR reaction}

Short fragment of mouse tail, $0.5 \mathrm{~cm}$ in length, was cut and incubated overnight at $55^{\circ} \mathrm{C}$ in $150 \mu \mathrm{l}$ Direct Lysis buffer (Peqlab) containing $5 \mu \mathrm{l}$ proteinase $\mathrm{K}(10 \mu \mathrm{g} / \mu \mathrm{l})$. Next day, proteinase $\mathrm{K}$ was inactivated by incubation at $85^{\circ} \mathrm{C}$ for $50 \mathrm{~min}$ and the tissue lysate was centrifuged at $12000 \mathrm{x} g$ for $10 \mathrm{~min}$. Supernatant containing the DNA was directly used for PCR.

\section{Isolation of genomic DNA for Southern blot}

Around $0.5 \mathrm{~cm}$ of mouse tail was incubated overnight at $55^{\circ} \mathrm{C}$ with $700 \mu \mathrm{l}$ of lysis buffer II containing $35 \mu \mathrm{l}$ of proteinase $\mathrm{K}(10 \mu \mathrm{g} / \mu \mathrm{l})$ in a termomixer. Next day, the cell lysate was centrifuged at $12000 \mathrm{x} \mathrm{g}$ for $10 \mathrm{~min}$. The supernatant was transferred into a new e-cup and $350 \mu \mathrm{l}$ phenol and $350 \mu \mathrm{l}$ chloroform (1:1) were added. After gently mixing ( 2 min) by inverting the tube, sample was centrifuged at $6000 \mathrm{x} \mathrm{g}$ for $3 \mathrm{~min}$ and the upper phase was transferred into a new tube. Then, $500 \mu \mathrm{l}$ chloroform was added, mixed and again centrifuged at $6000 \mathrm{x} \mathrm{g}$ for $3 \mathrm{~min}$. The upper phase was transferred into the new e-cup and DNA was precipitated by adding $50 \mu \mathrm{l}$ of $3 \mathrm{M} \mathrm{NaAc}$ and $500 \mu \mathrm{l}$ isopropanol. The sample was mixed by inverting the tube and after $1 \mathrm{~h}$ of incubation at $\mathrm{RT}$, it was centrifuged at $12000 \mathrm{x}$ g for $15 \mathrm{~min}$ at RT. DNA pellet was washed with $1 \mathrm{ml}$ of $70 \%$ ethanol, dried on air for around $10 \mathrm{~min}$ and dissolved at $60^{\circ} \mathrm{C}$ for $10 \mathrm{~min}$ in 50 $200 \mu \mathrm{l}$ of $\mathrm{dH}_{2} \mathrm{O}$.

\section{Isolation of genomic DNA from ES cells}

ES cells were incubated overnight at $37^{\circ} \mathrm{C}$ in lysis buffer (ES cells). After centrifugation at $10000 \mathrm{x}$ g for $1 \mathrm{~min}$, DNA was precipitated from supernatant by adding $500 \mu \mathrm{l}$ isopropanol. After mixing, sample was centrifuged at $13000 \mathrm{x} \mathrm{g}$ for $15 \mathrm{~min}$ at $4^{\circ} \mathrm{C}$ 
and supernatant was discarded. Pellet was washed with $1 \mathrm{ml}$ of $70 \%$ ethanol, incubated $10 \mathrm{~min}$ at RT and centrifuged at $13000 \mathrm{xg}$ for $5 \mathrm{~min}$. DNA was dissolved at $65^{\circ} \mathrm{C}$ for 10 $\min$ in $60-120 \mu \mathrm{l}$ of $\mathrm{dH}_{2} \mathrm{O}$.

\subsubsection{Isolation of plasmid DNA}

Small-scale isolation of plasmid DNA - Mini preparation (Birnboim and Doly, 1979)

Bacterial single colony was inoculated into $5 \mathrm{ml}$ LB medium containing appropriate antibiotic and incubated at $37^{\circ} \mathrm{C}$ with a shaking speed of $120 \mathrm{rpm}$ for about 15 h. To prepare bacteria stocks, $0.7 \mathrm{ml}$ of overnight culture was mixed with $0.3 \mathrm{ml} 50 \%$ glycerol and stored at $-80^{\circ} \mathrm{C}$. The rest of the culture was centrifuged at $4000 \mathrm{x} \mathrm{g}$ for 10 min. The pellet of bacterial cells was resuspended in $200 \mu \mathrm{l}$ of resuspension buffer P1 and then lysed with $200 \mu \mathrm{l}$ of lysis buffer P2. After 5 min of incubation at RT, samples were neutralized with $200 \mu \mathrm{l}$ of neutralization buffer P3. Samples were then incubated for 5 min on ice and centrifuged at $13000 \mathrm{xg}$ at $4^{\circ} \mathrm{C}$. The supernatant was transferred into a new tube and $420 \mu \mathrm{l}$ of isopropanol was added. Next, samples were incubated for $15 \mathrm{~min}$ at RT and centrifuged at $13000 \mathrm{x}$ g for $30 \mathrm{~min}$. DNA pellet was washed with $500 \mu \mathrm{l}$ of $70 \%$ ethanol. Finally, air-dried DNA was dissolved in $30 \mu \mathrm{l}$ of $\mathrm{dH}_{2} \mathrm{O}$.

\section{Large-scale isolation of plasmid DNA - Midi preparation}

Bacteria from glycerol stock $(30 \mu \mathrm{l})$ were inoculated into $25 \mathrm{ml} \mathrm{LB}$ medium with appropriate antibiotic. The culture was incubated overnight at $37^{\circ} \mathrm{C}$ with shaking speed of $120 \mathrm{rpm}$. Then sample was centrifuged at $4000 \mathrm{x} \mathrm{g}$ for $10 \mathrm{~min}$. The pellet was resuspended in $4 \mathrm{ml}$ of resuspension buffer R3 (Invitrogen). After adding $4 \mathrm{ml}$ of lysis buffer L7 (Invitrogen), samples were mixed gently by inverting the tubes and incubated for $5 \mathrm{~min}$ at RT. Then, $4 \mathrm{ml}$ of precipitation buffer N3 (Invitrogen) was added and again mixed until the mixture was homogenous. After 10 min centrifugation at $12000 \mathrm{x} g$ for 10 min at RT, the supernatant was loaded through a paper filter onto a column (HiPure Midi column, Midi Plasmid Kit, Invitrogen), equilibrated by $10 \mathrm{ml}$ equilibration buffer EQ1 (Invitrogen). The solution was drained by gravity flow. The column was washed twice with $10 \mathrm{ml}$ washing buffer W8 (Invitrogen). After second washing, DNA was eluted from 
column by adding $5 \mathrm{ml}$ elution buffer E4 (Invitrogen). Next, DNA was precipitated with $3.5 \mathrm{ml}$ isopropanol and centrifuged at $13000 \mathrm{x}$ g for $30 \mathrm{~min}$ at $4{ }^{\circ} \mathrm{C}$. The pellet was washed in $3 \mathrm{ml}$ of $70 \%$ ethanol and finally, dissolved in $125 \mu 1 \mathrm{H}_{2} \mathrm{O}$.

\subsubsection{Isolation of total RNA}

Around $100 \mathrm{mg}$ of tissue sample was homogenized in $1 \mathrm{ml}$ of TRI Reagent for 5 min by using a TissueLyser (Qiagen). Then the lysate was incubated on ice for $5 \mathrm{~min}$. To isolate proteins from cell culture $400 \mu \mathrm{l}$ of TRI reagent was added to a culture bottle and cells were homogenized with a rubber scraper. The lysate was transferred into a tube and incubated on ice for $10 \mathrm{~min}$. Further procedure is identical for RNA isolation from tissue and cell culture. After incubation, $200 \mu \mathrm{l}$ of cold chloroform was added, mixed and again cooled for $5 \mathrm{~min}$ on ice. The sample was centrifuged at $12000 \mathrm{xg}$ for $15 \mathrm{~min}$ at $4^{\circ} \mathrm{C}$. The upper, aqueous phase was carefully transferred into a new tube, where RNA was precipitated with $500 \mu \mathrm{l}$ of isopropanol followed by centrifugation at $12000 \mathrm{x} \mathrm{g}$ for $10 \mathrm{~min}$ at $4{ }^{\circ} \mathrm{C}$. Finally, the pellet was washed with $75 \%$ ethanol, dried at $37^{\circ} \mathrm{C}$ and dissolved in $50 \mu \mathrm{l}$ of $\mathrm{H}_{2} \mathrm{O}_{\text {DEPC }}$ for $10 \mathrm{~min}$ at $60^{\circ} \mathrm{C}$.

\subsubsection{Determination of nucleic acid concentration}

The concentration of nucleic acids was determined spectrophotometrically by measuring absorption at $260 \mathrm{~nm}$. The absorbance ratio measured by $260 \mathrm{~nm}$ and $280 \mathrm{~nm}$ gives the information about the purity of nucleic acids. The expected value of the ratio for sample of good quality should be between 1.7 and 2.0.

\subsubsection{Reverse transcription}

To prepare $20 \mu \mathrm{l}$ of cDNA following reagents were added:

- $\quad$ 2-3 $\mu$ g RNA

- $\quad 1 \mu 110 \mathrm{x}$ reaction buffer

- $\quad 1 \mu 1$ Amplification Grade DNAseI (Sigma)

- $\mathrm{H}_{2} \mathrm{O}$ up to $8 \mu \mathrm{l}$ 
After 15 min incubation at RT, DNAseI was inactivated by adding $1 \mu \mathrm{l}$ of stop solution and heating at $70^{\circ} \mathrm{C}$ for $10 \mathrm{~min}$. Then following reagents were added:

- $1 \mu \mathrm{l}$ oligo(dT)primer $(10 \mathrm{pmol} / \mu \mathrm{l})$

- $\quad 1 \mu 110 \mathrm{mM}$ dNTPs

Sample was denaturated for $5 \mathrm{~min}$ at $65^{\circ} \mathrm{C}$ and quick chilled on ice. Next, following reagents were added:

- $\quad 4 \mu \mathrm{l} 5 \mathrm{x}$ first strand buffer

- $\quad 2 \mu \mathrm{l}$ of $0.1 \mathrm{M}$ DTT

Sample was preincubated at $42^{\circ} \mathrm{C}$ for 2 min and then $1 \mu$ of reverse transcriptase enzyme (Superscript II, Invitrogen) was added. cDNA was synthesized $50 \mathrm{~min}$ at $42^{\circ} \mathrm{C}$ followed by the inactivation of reverse transcriptase at $70^{\circ} \mathrm{C}$ for $15 \mathrm{~min}$.

\subsubsection{Polymerase Chain Reaction (PCR)}

To perform PCR reaction, following substances were mixed:

- 10 ng DNA

- $\quad 0.5 \mu \mathrm{l}$ forward primer $(5 \mathrm{pmol})$

- $\quad 0.5 \mu \mathrm{l}$ reverse primer $(5 \mathrm{pmol})$

- $\quad 0.5 \mu 110 \mathrm{mM}$ dNTPs

- $\quad 0.75 \mu 150 \mathrm{mM} \mathrm{MgCl} 2$

- $\quad 2.5 \mu 110$ x PCR buffer

- $\quad 0.2 \mu \mathrm{l}$ Taq DNA Polymerase (5 U/ $\mu \mathrm{l})$

- Filled up to $25 \mu \mathrm{l}$ with $\mathrm{dH}_{2} \mathrm{O}$

Standard PCR program consists of:

\begin{tabular}{|c|c|c|c|}
\hline initial denaturation & $95^{\circ} \mathrm{C}$ & $5 \mathrm{~min}$ & \\
\hline denaturation & $95^{\circ} \mathrm{C}$ & $30 \mathrm{sec}$ & \\
\hline annealing of primers & $55-65^{\circ} \mathrm{C}$ & $30-60 \mathrm{sec}$ & 30-35 cycles \\
\hline extension & $72^{\circ} \mathrm{C}$ & $30-60 \mathrm{sec}$ & \\
\hline final extension & $72^{\circ} \mathrm{C}$ & 3-7 min & \\
\hline
\end{tabular}




\subsubsection{Quantitative Real-Time PCR}

\section{Genotyping of ES cells}

ES cells with targeted disruption of the $C c d c 33$ gene were genotyped using the quantitative Real-Time PCR approach to identify homologous recombinant ES cells. DNA was isolated from recombinant ES cell clones and as a control wild type DNA was used. To prepare qRT-PCR reaction, the following components were mixed:

- $5 \mu$ l of Platinum SYBR Green qPCR SuperMix-UDG with ROX (Invitrogen)

- $\quad 0.4 \mu \mathrm{l}$ of each forward and reverse primers $(10 \mathrm{pmol} / \mu \mathrm{l})$

- $\quad 2 \mu 1$ of DNA

- $\quad 2.2 \mu \mathrm{l}$ of $\mathrm{dH}_{2} \mathrm{O}$

All reactions were prepared in triplicate. The real-time PCR reactions were performed in an ABI Prism 7900HT real time PCR instrument (Applied Biosystems). The standard PCR program used in this analysis was as follows:

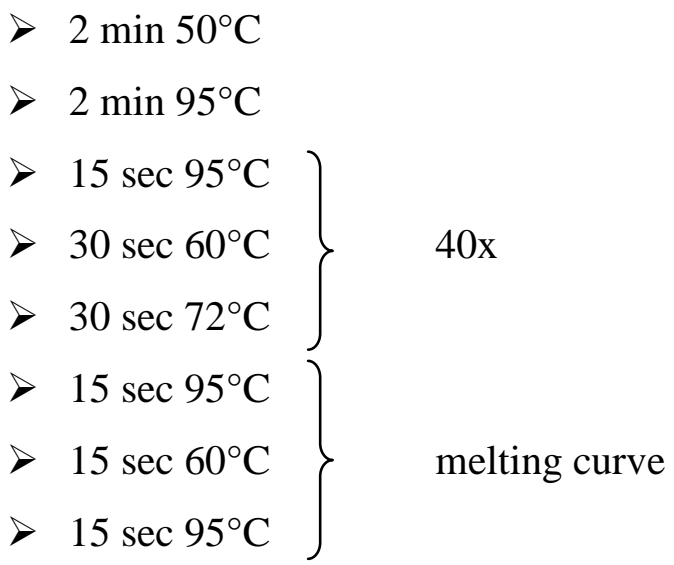

First, the series of the wild type DNA dilutions were prepared to test each primers pair used. Then, the absolute quantification (the determination of the number of alleles) was calculated based on the linear interpolation from the logarithmic standard curve, the cT values for the analysed allele $(\mathrm{Ccdc33})$ and the reference gene (Pelota) according to the method described by Boehm et al. (2004).

\section{Reverse transcription real-time PCR (qRT-PCR)}

RNA was isolated as described in section 2.2.1.3 and cDNA was prepared as described in 2.2.3. Single sample contained: 
- $5 \mu$ of Platinum SYBR Green qPCR SuperMix-UDG with ROX (Invitrogen)

- $0.4 \mu \mathrm{l}$ of each forward and reverse primers $(10 \mathrm{pmol} / \mu \mathrm{l})$

- $2 \mu \mathrm{l}$ of DNA

- $\quad 2.2 \mu \mathrm{l}$ of $\mathrm{dH}_{2} \mathrm{O}$

The real-time RT-PCR reaction was performed as described in 2.2.5. First, the standard curve for all housekeeping genes and the gene of interest were generated and the amplification efficiency of the gene of interest and the housekeeping genes were compared. Next, the value for a particular gene analysed was normalized by the values of the appropriate housekeeping gene (Hprt, Sdha or ActB) (delta cT). The expression level was demonstrated in respect to control RNA (delta delta cT method).

\subsubsection{Agarose gel electrophoresis}

\subsubsection{Gel electrophoresis of RNA}

To prepare $1 \%$ gel $2 \mathrm{~g}$ of agarose was added to $20 \mathrm{ml}$ of $10 \times$ MOPS and $148 \mathrm{ml}$ of $\mathrm{H}_{2} \mathrm{O}_{\text {DEPC }}$ and dissolved by heating in a microwave. After cooling to about $50^{\circ} \mathrm{C}, 33.2$ $\mathrm{ml}$ of $37 \%$ formaldehyde was added, mixed and spilled into a horizontal gel chamber. RNA samples (15 - $40 \mu \mathrm{g}$ of total RNA) were mixed with double volume of sample buffer, denatured at $65^{\circ} \mathrm{C}$ for $10 \mathrm{~min}$ and chilled on ice for $5 \mathrm{~min}$. Then, an equal volume of loading buffer was added and samples were loaded on the gel. Electrophoresis was run overnight at $35-45 \mathrm{~V}$ at $4{ }^{\circ} \mathrm{C}$.

\subsubsection{Gel electrophoresis of DNA}

$100 \mathrm{bp}$ to15 $\mathrm{kb}$ molecules of DNA were separated on 3 to $0.8 \%$ agarose gels, respectively. In general, to prepare $1 \%$ gel, $1 \mathrm{~g}$ agarose was added to $100 \mathrm{ml}$ of $0.5 \mathrm{x}$ TBE buffer and boiled in a microwave to dissolve the agarose. After cooling to about $50^{\circ} \mathrm{C}$ one drop of $0.07 \%$ ethidium bromide was added and the gel was placed in a horizontal gel chamber. 


\subsubsection{Purification of DNA}

\subsubsection{Purification of DNA from agarose gel}

DNA was extracted from agarose gel with QIAquick gel extraction kit (Qiagen). A fragment of gel (but not more than $400 \mathrm{mg}$ ) containing the DNA band was excised and incubated with three volumes of QG buffer at $50^{\circ} \mathrm{C}$ for $10 \mathrm{~min}$. When the gel slice was dissolved, the solution was applied to a QIAquick column. Then $100 \mu \mathrm{l}$ of isopropanol per $100 \mathrm{mg}$ gel were added and mixed very well. After centrifugation at $10000 \mathrm{x} \mathrm{g}$ for $1 \mathrm{~min}$ at RT, flowthrough was discarded and the column was washed with $500 \mu \mathrm{l}$ of QG buffer followed by washing with $750 \mu \mathrm{l}$ of PE buffer. The column was placed into a fresh tube and DNA was eluted with $50 \mu \mathrm{l}$ of $\mathrm{dH}_{2} \mathrm{O}$ by short centrifugation at $10000 \mathrm{x}$ g for $1 \mathrm{~min}$ at RT.

\subsubsection{Purification of plasmid DNA prior to sequencing}

Plasmid DNA isolated with mini Preparation method was purified prior to sequencing using the MSB Spin PCRapace kit (Invitek). $250 \mu \mathrm{l}$ of binding buffer was added to the $30 \mu \mathrm{l}$ of sample and mixed. Then, the sample was transferred into a spin filter and centrifuged for $3 \mathrm{~min}$ at $12000 \mathrm{x} \mathrm{g}$ at room temperature. The column was placed into a new tube. DNA was eluted with $30 \mu \mathrm{l}$ of $\mathrm{dH}_{2} \mathrm{O}$ by centrifugation at $10000 \mathrm{x} \mathrm{g}$ for 1 $\min$.

\subsubsection{Enzymatic modifications of DNA}

\subsubsection{Restriction digestion of DNA}

Double-stranded DNA was digested by appropriate restriction enzymes in a buffer recommended by the company. Usually, plasmid DNA digestion was done with 2-8 U of enzyme per $1 \mu \mathrm{g}$ DNA and the incubation time was $2-6 \mathrm{~h}$ at $37^{\circ} \mathrm{C} .20 \mu \mathrm{g}$ of genomic DNA was digested with $80 \mathrm{U}$ of enzyme overnight at $37^{\circ} \mathrm{C}$. 


\subsubsection{Ligation of DNA fragments}

Ligation of a DNA insert into a vector digested with appropriate restriction enzyme was performed at $4{ }^{\circ} \mathrm{C}$ overnight or at RT for $5 \mathrm{~h}$. Usually, $10 \mu \mathrm{l}$ of reaction mixture contained: $30 \mathrm{ng}$ vector DNA; $100 \mathrm{ng}$ insert DNA; $1 \mu \mathrm{l}$ of ligation buffer (10x) and $1 \mu \mathrm{l}$ T4 DNA ligase $(5 \mathrm{U} / \mu \mathrm{l})$.

\subsubsection{Transformation of bacteria}

$50-100 \mu \mathrm{l}$ of competent bacterial cells were added to the $10 \mu \mathrm{l}$ of ligation reaction, sample was gently mixed and incubated for $15 \mathrm{~min}$ on ice. After heat-shock (1 min at $37^{\circ} \mathrm{C}$ and chilled for $3 \mathrm{~min}$ on ice) $800 \mu \mathrm{l}$ of S.O.C. medium was added. The mixture was incubated in a thermoblock at $37^{\circ} \mathrm{C}, 400 \mathrm{rpm}$, for $1 \mathrm{~h}$ and then plated on LBagar plates.

\subsubsection{Northern blot}

After electrophoresis, RNA was transferred overnight onto the nitrocellulose membrane Hybond C, by using turboblotterTM. The membrane was equilibrated in $2 \mathrm{x}$ SSC and the blotting apparatus was prepared according to the manufacturer's recommendation. After transfer, the RNA was fixed by cross linking (1200 J) in UV StratalinkerTM1800. Membrane equilibrated in $2 \mathrm{x}$ SCC was pre-hybridized with $6 \mathrm{ml}$ of Rapid-hyb buffer (Amersham) and $250 \mu \mathrm{l}$ of denaturated salmon DNA for $5 \mathrm{~h}$ at $65^{\circ} \mathrm{C}$ in hybridization oven. During this time, the Megaprime DNA Labelling System (Amersham) was used for radioactive probe labeling. DNA probe was mixed with $5 \mu \mathrm{l}$ of random primer solution and the appropriate volume of water to a total volume of $36 \mu 1$ and denaturated by heating to $100^{\circ} \mathrm{C}$ for $10 \mathrm{~min}$ in a boiling water bath. After chilling on ice, $10 \mu \mathrm{l}$ of labeling buffer, $2 \mu \mathrm{l}$ of Klenow enzyme and $5 \mu \mathrm{l}$ of $\left[\alpha-{ }^{32} \mathrm{P}\right] \mathrm{dCTP}(3000$ $\mathrm{Ci} / \mathrm{mmol}$ ) were added and mixed. Then, the reaction was incubated for $1 \mathrm{~h}$ at $37^{\circ} \mathrm{C}$. [ $\alpha-$ ${ }^{32} \mathrm{P}$ ] dCTPs not incorporated were removed by using Probe QuantTM G-50 MicroCloumns (GE Healthcare). $200 \mu \mathrm{l}$ of salmon DNA was added to the labeled probe. The sample was denaturated, added to $6 \mathrm{ml}$ of the hybridization solution and hybridization was continued overnight at $65^{\circ} \mathrm{C}$. Next day, the membrane was washed 
shortly with $2 \times$ SSC at room temperature, next with $2 \times$ SSC containing $0.2 \%$ SDS at $65^{\circ} \mathrm{C}$ for $2 \mathrm{~min}$ and $0.2 \times \mathrm{SSC}$ at $65^{\circ} \mathrm{C}$ for $2 \mathrm{~min}$. The membrane was put into a X-ray cassette with $\mathrm{X}$-ray film and exposed at $-80^{\circ} \mathrm{C}$. The film was developed in X-Ray Automatic Processor Curix 60 (Agfa).

\subsubsection{Southern blot}

After electrophoresis of genomic DNA treated with restriction enzymes, the agarose gel was stained with $1 \%$ ethidium bromide in $\mathrm{H}_{2} \mathrm{O}$ and picture was taken. Then, the gel was washed with depurination buffer for $10 \mathrm{~min}$, with denaturation solution for 30 min and neutralization buffer for $30 \mathrm{~min}$. TurboblotterTM was used to transfer the DNA onto the nitrocellulose membrane. The transfer and the hybridization procedure were same as described for Northern blotting (2.2.10).

\subsubsection{Transcriptome}

The transcriptome analysis was done in the Microarray Facility, University of Göttingen. Total RNA was isolated from the testes of five fertile animals from the line with five knockouted germ cell-specific genes and from the testes of five infertile males of a line with six knockouted germ cell-specific genes with the Trizol (Invitrogen) method according to the manufacturer's recommendations. The samples were treated $20 \mathrm{~min}$ at $37^{\circ} \mathrm{C}$ with DNAse I (Sigma) to remove any DNA contamination. The quantity of RNA was analysed by Nano Drop ND-1000 Spectrophotometer. The samples were diluted to $100-200$ ng/ul. To relax secondary structures, RNA samples were heat denaturated for 2 min at $70^{\circ} \mathrm{C}$ and immediately chilled on ice. Quality of RNA was determined using the Agilent 2100 Bioanalyzer microfluidic electrophoresis (Agilent Technologies, Santa Clara, CA, USA).

Transcriptome analysis was done according to Gene Chip Whole Transcript (WT) Sense Target Labeling Assay (Affymetrix). The synthesis of double-stranded cDNA was done with $300 \mathrm{ng}$ of total RNA. This cDNA was cleaned with the Gene Chip Sample Cleanup Module (Affymetrix) and then $10 \mathrm{ul}$ were used for in vitro transcription. cRNA was purified with the Gene Chip cRNA Sample Cleanup Module (Affymetrix) and 
quantified using the Nano Drop ND-1000. From cRNA, single stranded cDNA was synthesised. Then, $1 \mu \mathrm{l}$ of RNAse was added and the sample was incubated for $45 \mathrm{~min}$ at $37^{\circ} \mathrm{C}$ to digest the cRNA. Finally, concentration of cDNA was measured by Nano Drop ND-1000 Spectrophotometer.

$5.5 \mathrm{mg}$ of single stranded cDNA was fragmented into 35-200 bases long fragments by enzymatic processes and the fragmentation degree was checked by capillary electrophoresis using the Agilent 2100 Bioanalyzer (Agilent Technologies). After fragmentation, terminal labelling with biotin labelled reagent was performed with Gene Chip WT Terminal Labeling Kit. The hybridization of biotinylated fragmented ssDNA onto the Gene Chip Mouse Gene 1.0 ST Array (Affymetrix) was performed at $45^{\circ} \mathrm{C}$ for $17 \mathrm{~h}$ at $1 \mathrm{x} \mathrm{g}$ in the GeneChip Hybridization Oven640 (Affymetrix). Washing and staining of the array with streptavidin R-phycoerythrin (SAPE; Invitrogen) was done according to the manufacturer's recommendation on the Gene Chip Fluidics Station450 (Affymetrix).

Arrays were scanned using the Gene Chip Scanner 3000 7G (Affymetrix). Data of signal intensity were extracted using the Affymetrix AGCC Software (version 2.0) (Affymetrix). The microarray data analysis consisted of following steps: between-array normalization, probe summary, global clustering, PCA-analysis and detection of differential gene expression.

\subsubsection{Protein analysis}

\subsubsection{Isolation of total protein}

\section{Protein isolation from tissue I}

$100 \mathrm{mg}$ of tissue was homogenized in $600 \mu$ lysis buffer for $5 \mathrm{~min}$ by using a Tissue Lyser (Qiagen). The samples were centrifuged at $3000 \mathrm{x} \mathrm{g}$ for $20 \mathrm{~min}$ at $4^{\circ} \mathrm{C}$. Thereafter the supernatant was centrifuged at $29000 \mathrm{x}$ g for $45 \mathrm{~min}$ at $4^{\circ} \mathrm{C}$. The supernatant was then used for Western blot.

\section{Protein isolation from tissue II}

$100 \mathrm{mg}$ of tissue was homogenized in $600 \mu \mathrm{l}$ appropriate lysis buffer for $5 \mathrm{~min}$ by using a Tissue Lyser (Qiagen). The samples were centrifuged at $13000 \mathrm{x} g$ for $10 \mathrm{~min}$ at 
$4^{\circ} \mathrm{C}$. Thereafter the supernatant I was used for western blot. The pellet was sonicated, centrifuged at $10000 \mathrm{x} \mathrm{g}$ for $10 \mathrm{~min}$ at $4^{\circ} \mathrm{C}$ and the supernatant II was used for Western blot.

\section{Protein isolation from tissue III}

$100 \mathrm{mg}$ of tissue was homogenized in $600 \mu \mathrm{l}$ lysis buffer for 5 min by using a Tissue Lyser (Qiagen). The samples were centrifuged at $1900 \mathrm{x} \mathrm{g}$ for $10 \mathrm{~min}$ at $4^{\circ} \mathrm{C}$. The pellet was resuspended in $100 \mu \mathrm{l}$ lysis buffer and recentrifuge at $1900 \mathrm{x} \mathrm{g}$ for $10 \mathrm{~min}$ at $4^{\circ} \mathrm{C}$. The supernatant was centrifuge at $50000 \mathrm{x} \mathrm{g}$ for $20 \mathrm{~min}$ at $4^{\circ} \mathrm{C}$. Then pellet was resuspended in $100 \mu \mathrm{l}$ lysis buffer and centrifuge at $50000 \mathrm{x} \mathrm{g}$ for $20 \mathrm{~min}$ at $4^{\circ} \mathrm{C}$. The supernatants from all steps were then used for Western blot.

\section{Protein isolation from cells}

$300 \mu \mathrm{l}$ of Co-IP lysis buffer (Roche) or lysis buffer I (for ES cells) were added to the $50 \mathrm{ml}$ cell culture bottle with cell confluence higher than $90 \%$, and left on ice for 10 min. Next, cell lysate was collected with a rubber scraper and incubated on ice for $30 \mathrm{~min}$ with mixing every $5 \mathrm{~min}$. Then, the lysate was centrifuged for $30 \mathrm{~min}$ at $4^{\circ} \mathrm{C}$ at $13000 \mathrm{xg}$, the protein concentration in supernatant was measured.

\subsubsection{Determination of protein concentration (Bradford, 1976)}

To determine the protein concentration, each sample was diluted 1:100 and $200 \mu \mathrm{l}$ of Roti Nanoquant was added to a $50 \mu \mathrm{l}$ aliquot of the dilution. After 5 min of incubation at RT to develop the color reaction, the absorption was measured at 590 and $450 \mathrm{~nm}$ by Synergy Mx spectrophotometer. Series of Roth Albumin Fraction V dilution was used for calibration according to the manufacturer's recommendation. Protein concentration was determined by extrapolating to this standard curve.

\subsubsection{Western blot}

NuPage 4-12\% or $12 \%$ Bis-Tris gel (Invitrogen) was used for protein electrophoresis. 50 - $100 \mu \mathrm{g}$ of protein was mixed with $2 \mu \mathrm{l}$ of 1M DTT and appropriate 
amount of $4 \mathrm{x}$ LDS loading buffer, denaturated for $10 \mathrm{~min}$ at $70^{\circ} \mathrm{C}$ and separated on the gel. Then, the gel and PVDF or nitrocellulose membrane were moistened with transfer buffer. See Blue Plus2 molecular weight standard (Invitrogen) was used to determine the size of the protein. Four sheets of Whatman paper were soaked in transfer buffer and placed on the semi dry transfer machine's lower plate. On these papers, the membrane and the gel were gently placed without any air bubbles. Next four soaked papers were placed on the gel to complete the sandwich system. Then, the upper plate was closed and the transfer was carried out at $150 \mathrm{~mA}$ for $15 \mathrm{~min}$ and $230 \mathrm{~mA}$ for next $45 \mathrm{~min}$. After blotting, the gel was stained with Comassie blue overnight at RT to control amount of protein remaining in the gel. The membrane was blocked in $5 \%$ milk/TBST on the roller for $1 \mathrm{~h}$ at RT and incubated overnight with primary antibody at $4{ }^{\circ} \mathrm{C}$. Next day, after three times washing for $10 \mathrm{~min}$ on roller with $2 \%$ milk/TBST, the membrane was incubated with secondary AP-conjugated antibody for $2 \mathrm{~h}$. Then the membrane was washed two times in $2 \%$ milk/TBST and three times in AP buffer. Finally bound antibody was visualized in $15 \mathrm{ml}$ AP buffer containing $67 \mu \mathrm{l}$ of NBT and $53 \mu \mathrm{l} \mathrm{BCIP}$ at RT.

\subsubsection{Generation of CCDC33-MBP and CCDC33-GST fusions proteins for antibody production}

Two different fusion proteins were produced for generation of anti-CCDC33 antibody. Rabbits were immunized with CCDC33-MBP (maltose binding protein) fusion protein. The same part of CCDC33 was used to generate CCDC33-GST (glutathione binding protein) fusion protein, which was used for purification of antibody from rabbit's serum. The sequence unique for mouse CCDC33 was selected using Blast-Protein program (Morgulis et al. 2008) and cloned in frame into pMAL-c2X and pET-41a vectors. To produce both CCDCD33 fusion proteins $50 \mathrm{ml}$ of LB-Bacto medium was inoculated with E. coli strain $\mathrm{Bcl} 21$ containing the appropriate plasmid, and pre-cultured overnight at $37^{\circ} \mathrm{C}$. Next day, $400 \mathrm{ml}$ medium was inoculated and incubated until $\mathrm{OD}_{600}$ reached the value of 1.0. Then, bacteria were induced with $1 \mathrm{mM}$ IPTG to produce the fusion protein. After $5 \mathrm{~h}$ incubation, samples were centrifuged at $6000 \mathrm{x} \mathrm{g}$ for $10 \mathrm{~min}$ at $4^{\circ} \mathrm{C}$. Pellet was resuspended in $15 \mathrm{ml}$ of protein purification buffer, sonicated with short pulses and then centrifuged for $20 \mathrm{~min}$ at $4^{\circ} \mathrm{C}$ at $13000 \mathrm{x}$. The supernatant was filtered 
through $0.45 \mu \mathrm{m}$ pores size filters and then applied on maltose or glutathione column. After washing twice with column buffer, the fusion protein was eluted with elution buffer I or II and dialized with Float-A-Lyzer G2 dialysis system (Spectra). Before dialysis column was washed with coupling buffer and then $2 \mathrm{ml}$ of fusion protein was added. Dialysis was done in PBS overnight at $4^{\circ} \mathrm{C}$. CentrisartI MWCO 20000 (Sartorius) ultrafiltration system was used to increase the concentration of protein by centrifugation at $3850 \mathrm{rpm}$ for $30 \mathrm{~min}$ at $8^{\circ} \mathrm{C}$.

\subsubsection{Immunization of rabbit}

Adult rabbits were immunized four times, with 4 weeks span between injections, with $500 \mu \mathrm{g}$ of native and $500 \mu \mathrm{g}$ of denaturated CCDC33-MBP fusion protein. Prior to each injection the fusion protein was diluted (1:1) in Freund's adjuvant (first immunization with complete form, later with incomplete). After $30 \mathrm{~min}$ vortexing at $4{ }^{\circ} \mathrm{C}$, fusion proteins were injected into the rabbit.

\subsubsection{Purification of antibodies}

Purification of antibodies from rabbit's serum was done with CCDC33-GST fusion protein. Hi Trap column was equilibrated with $2 \mathrm{ml}$ of ice cold $1 \mathrm{mM} \mathrm{HCl}$. Then 2 $\mathrm{ml}$ of fusion protein $(1 \mathrm{mg} / \mathrm{ml})$ was loaded onto the column and incubated overnight at $4^{\circ} \mathrm{C}$. Then, the column was washed three times alternatively with buffer A and buffer B ( 2 $\mathrm{ml}$ each) and finally with $10 \mathrm{ml}$ of PBS. 2 times diluted (PBS) rabbit's serum was filtered through $0.45 \mu \mathrm{m}$ pore size filters and applied very slowly on column. After binding of CCDC33 antibody to CCDC33-GST-fusion protein, column was washed with PBS and finally the antibody was eluted with $3 \mathrm{ml}$ of Immunopure IgG Elution Buffer (Pierce) and neutralized with $3.5 \mu \mathrm{l}$ of $1 \mathrm{M}$ tris/ $\mathrm{HCl}, \mathrm{pH} 7.5$

\subsubsection{Yeast-two-hybrid}

Yeast-two-hybrid system was used to analyse the interaction between two proteins. In this study, the Yeastmaker ${ }^{\mathrm{TM}}$ Yeast Transformation System from Clontech was used. One protein (bait) was cloned into pGBKT7 vector and expressed as a fusion 
protein with the Gal4 DNA-binding domain (Gal4-BD), while the second protein (pray) was cloned into pGADT7 vector and expressed as a fusion protein with the Gal4 activation domain (Gal4-AD). In case that both proteins interact, the Gal4-BD and Gal4$\mathrm{AD}$ are able to activate transcription of four independent reporter genes: Aur1-C, Ade2, His3 and Mel1. All of them are under the control of three heterologous Gal4-responsive promoter elements - G1, G2, and M1. AH109 strain of yeast is unable to grow on plates without the three amino acids (His, Trp, Leu) and adenine. Aurl-C and His3 are able to produce histidine. Ade 2 can synthesize adenine. Mell encodes enzyme $\alpha$-galactosidase, which turns white yeast colonies to blue in the presence of the chromogenic substrate $\mathrm{X}$ $\alpha$-Gal. As additional control of the transformation efficiency, both vectors contain genes responsible for leucine (pGADT7) and tryptophan (pGBKT7) synthesis.

\subsubsection{Preparation of competent yeast cells}

YPDA agar plate was smeared with AH109 yeast cells from a frozen stock and incubated for some days at $30^{\circ} \mathrm{C}$. Small colonies of yeast were resuspended into $50 \mathrm{ml}$ YPD medium in a sterile culture tube and incubated overnight at $30^{\circ} \mathrm{C}$ with shaking at $250 \mathrm{rpm}$. Next day, $7 \mathrm{ml}$ of the culture were transferred into $300 \mathrm{ml}$ YPD medium, incubated with shaking until the $\mathrm{OD}_{600}$ reached $0.5(4-6 \mathrm{~h})$. Then, the cells were centrifuged at $1000 \mathrm{x}$ g for $10 \mathrm{~min}$ at RT. The supernatant was discarded. Pellets of yeast were washed in $25 \mathrm{ml}$ of sterile $\mathrm{dH}_{2} \mathrm{O}$. After centrifugation, yeast pellets were dissolved in $1.5 \mathrm{ml}$ of freshly prepared $1 \mathrm{x}$ TE-LiAc buffer. After this step, cells were competent and ready for transformation.

\subsubsection{Yeasts' transformation with DNA constructs}

Competent yeast cells were immediately used for transformation. $2 \mu \mathrm{g}$ of each construct (obtained after midi preparation of plasmid DNA) were mixed with $20 \mu \mathrm{l}$ of denaturated $\left(10 \mathrm{~min}\right.$ at $\left.100^{\circ} \mathrm{C}\right)$ carrier DNA $(10 \mu \mathrm{g} / \mu \mathrm{l})$. Then, $100 \mu \mathrm{l}$ of competent cells and $600 \mu \mathrm{l}$ of freshly prepared sterile PEG-LiAc buffer were added and gently mixed. Samples were incubated for $30 \mathrm{~min}$ at $30^{\circ} \mathrm{C}$. $70 \mu \mathrm{l}$ of DMSO was added and the heat shock was done for $15 \mathrm{~min}$ at $42^{\circ} \mathrm{C}$ then, cells were placed for $2 \mathrm{~min}$ on ice. After short 
centrifugation, the pellet of cells was diluted in $300 \mu \mathrm{l}$ of $\mathrm{dH}_{2} \mathrm{O}$, dropped on two different SD plates and cultured several days at $30^{\circ} \mathrm{C}$. Transformation efficiency was tested on SD plates without leucine and tryptophan (-LT plate). Interactions were tested on SD plates without leucine, tryptophan, histidine and adenine, but containing X- $\alpha$-Gal (-LTHA, +X$\alpha$-Gal plate).

\subsubsection{Histological techniques}

\subsubsection{Tissue preparation for paraffin-embedding}

Directly after isolation tissues were fixed overnight at RT in Bouin's solution and washed next day with $70 \%$ of ethanol (overnight). The dehydration process consisted of the following washings at RT in: ethanol (70\% 1 x $15 \mathrm{~min} ; 80 \% 3 \times 20 \mathrm{~min} ; 90 \% 4$ × 20 min; $96 \% 4$ x $20 \mathrm{~min} ; 100 \% 5 \times 20 \mathrm{~min}$ ) and isopropanol (overnight at $4^{\circ} \mathrm{C}$ ). Next day, the alcohol was removed from the tissue by following incubations at RT: isopropanol xylene (75\% - $25 \%$ for $30 \mathrm{~min} ; 50 \%-50 \%$ for $30 \mathrm{~min} ; 25 \%-75 \%$ for $30 \mathrm{~min}$ ) and in xylene $\left(100 \%\right.$ overnight at $\left.4{ }^{\circ} \mathrm{C}\right)$. Thereafter, the tissues were incubated in liquid paraffin at $60^{\circ} \mathrm{C}$ for 2-3 days (with 3 to 5 changes of paraffin). Finally, the tissues were placed in embedding mold and melted paraffin was poured into the mold to form a block. Finally, paraffin blocks were stabilized in the microtome and cut in $10 \mu \mathrm{m}$ thin slides. Paraffin sections were placed on glass slides on a warm plate.

\subsubsection{Hematoxylin-eosin staining}

Tissue sections were incubated three times in xylene for 3 min each. Next, they were hydrated in: $100 \%, 96 \%, 90 \%, 80 \%, 70 \%$ and $50 \%$ ethanol (2 min in each) and washed in $\mathrm{dH}_{2} \mathrm{O}$ for $5 \mathrm{~min}$. Sections were stained for $10 \mathrm{~min}$ in hematoxylin and washed in $\mathrm{dH}_{2} \mathrm{O}$ for $10 \mathrm{~min}$. Then, tissue sections were de-stained by shortly washing five times in $\mathrm{HCl} /$ ethanol ( $1 \mathrm{ml}$ concentrated $\mathrm{HCl}$ in $400 \mathrm{ml} 70 \%$ ethanol) and two times for $1 \mathrm{~min}$ in ammonium water $(0.25 \%)$. After two times washing in $\mathrm{dH}_{2} \mathrm{O}$, sections were stained in eosin for $1 \mathrm{~min}$ and then incubated in increasing concentrations of ethanol: 50\%, $70 \%$, $80 \%, 90 \%, 95 \%$ and $100 \%$ for 2 min each. Finally, the stained slides were incubated in xylene for $15 \mathrm{~min}$ and closed with Eukitt-quick hardening mounting medium. 


\subsubsection{Immunohistochemistry staining}

Tissue sections were incubated three times for $5 \mathrm{~min}$ in xylene to remove the paraffin. Then, slides were re-hydrated in a decreasing ethanol series: $100 \%, 96 \%, 90 \%$, $80 \%, 70 \%$ and $50 \%$ for 3 min each. After washing in PBS, slides were boiled in a microwave two times for $5 \mathrm{~min}$ in $10 \mathrm{mM}$ sodium citrate (pH6.0) and then incubated with a blocking solution containing $2 \%$ sheep serum and $5 \%$ triton X-100 in PBS for $1 \mathrm{~h}$ at RT. Then, the slides were incubated with primary antibodies overnight at $4{ }^{\circ} \mathrm{C}$ in a wet chamber. Next day, slides were rinsed three times for 5 min in PBS and incubated with appropriate secondary antibody for $2 \mathrm{~h}$. Finally, the slides were washed three times for 5 min in PBS, covered with vectashield mounting medium containing DAPI (Vector, Burlingame, Calif. USA) and examined under a fluorescence microscope (BX60; Olympus).

\subsubsection{Cell culture methods}

HeLa, NIH3T3 and GC-4 cells were cultured in $5 \mathrm{ml}$ of appropriate media (2.1.5.3.3) in culture bottles in the incubator at $37^{\circ} \mathrm{C}$ and $5 \% \mathrm{CO}_{2}$. Cells were trypsinized when confluence was $90-100 \%$. All procedures of cell culture were done under sterile hood.

\subsubsection{Trypsinisation of eukaryotic cells}

Cells were washed twice with $5 \mathrm{ml}$ prewarmed, sterile PBS and then incubated in $1.5 \mathrm{ml}$ of TrypleTM Express at $37^{\circ} \mathrm{C}$ for $5 \mathrm{~min}$. Trypsin was removed by washing cells with $5 \mathrm{ml}$ PBS. Then, cells were centrifuged at $1000 \mathrm{xg}$ for $5 \mathrm{~min}$ at RT, resuspended in $3 \mathrm{ml}$ of the cell culture medium and transferred into a new culture bottle containing appropriate medium. To prepare cell stocks, aliquots of cells were mixed with freezing medium containing DMEM, 20\% FCS and 10\% DMSO and stored in liquid nitrogen. For revitalisation, frozen cells were quickly thawed and inoculated in culture medium, washed with PBS, centrifuged, resuspended in culture medium and transferred into a new culture bottle. 


\subsubsection{Cell transfection}

To check the capacity of the cells to express fusion proteinexpression of fusion proteins, they were transfected with appropriated vectors. Prior to transfection HeLa, NHI3T3 or GC-4 cells were cultured until the confluence reached 70-80\%. For the transfection in small chambers (BD Falcon Culture Slides, BD Biosciences, Bedford, USA) $1 \mu \mathrm{g}$ of Lipofectamine $2000 \mathrm{TM}$ reagent (Invitrogen) and $1 \mu \mathrm{g}$ of the endonuclease free purified (2.2.1.2) vector DNA were diluted each in $100 \mu$ l OptiMEM reduced serum medium (Invitrogen), mixed and incubated at RT for $5 \mathrm{~min}$. For the transfection in a culture bottle 5-10 $\mu \mathrm{g}$ of DNA and $10 \mu \mathrm{g}$ of lipofectamine in $400 \mu \mathrm{l}$ of OptiMEM were used. Next, both of the dilutions were mixed together and incubated for 30 min to allow formation of DNA-lipofectamine complexes. The medium on the cell culture was changed with fresh medium without antibiotics and the mixture of DNA-lipofectamine complexes was added drop by drop to the cells. Next, the cells were cultured overnight at $37^{\circ} \mathrm{C}, 5 \% \mathrm{CO}_{2}$.

\subsubsection{Co-immunoprecipitation}

For co-immunoprecipitation the Immunoprecipitation Kit (Protein G) (Roche) was used. Cells were co-transfected as described above, grown for $24 \mathrm{~h}$ at $37^{\circ} \mathrm{C}$ and collected in Lysis buffer for CoIP as described under 2.2.13.1. $3 \mu \mathrm{g}$ of anti-E2- Tag or anti-MycTag antibodies were added to $300 \mu$ of protein lysate, placed on rolling platform and incubated overnight at $4{ }^{\circ} \mathrm{C}$. Next day, $60 \mu \mathrm{l}$ of protein $\mathrm{G}$ agarose was prepared by centrifugation at $5000 \mathrm{x} \mathrm{g}$ for $20 \mathrm{sec}$ at $4{ }^{\circ} \mathrm{C}$, removing the supernatant, washing with 500 $\mu \mathrm{l}$ of lysis buffer for CoIP and centrifugation at $5000 \mathrm{x}$ g for $20 \mathrm{sec}$ at $4^{\circ} \mathrm{C}$. Then, protein $\mathrm{G}$ beads were added to the protein-antibody mixture. After at least $3 \mathrm{~h}$ incubation on roller at $4^{\circ} \mathrm{C}$, the sample was centrifuge at $5000 \mathrm{x} \mathrm{g}$ for $20 \mathrm{sec}$ at $4^{\circ} \mathrm{C}$. Pellet was washed with $500 \mu \mathrm{l}$ washing buffer I and $1 \mathrm{ml}$ of buffer II and III (accordingly to the manufacturer's instruction). Finally, beads were resuspend in $50 \mu \mathrm{l}$ of $4 \mathrm{x}$ loading solution for SDS-Page electrophoresis and boiled twice at $95^{\circ} \mathrm{C}$ for $5 \mathrm{~min}$. After adding $6 \mu \mathrm{l}$ of $1 \mathrm{M}$ DTT Western blot analysis (2.2.13.3.) was performed. Samples, which were immunoprecipitated with anti-E2-Tag antibody, were probed in Western blot with anti- 
Myc-Tag antibody. Samples precipitated with anti-Myc antibody were probed with antiE2-Tag antibody.

\subsubsection{Immunocytochemistry staining}

Cells cultured in slide chambers were washed three times in PBS and fixed in 4\% paraformaldehyde with $0.01 \%$ Tween-20 for $15 \mathrm{~min}$ at RT. After three times washing in PBS, slides were incubated in $0.01 \%$ triton X-100 (in PBS) for 15 min at RT. Then, cells were washed in PBS (3x) and unspecific binding of antibody was blocked with $5 \%$ BSA (in PBS) for $1 \mathrm{~h}$. Next, primary antibody was applied for $2 \mathrm{~h}$. Thereafter, cells were washed $3 x$ in PBS and incubated with secondary antibodies (Cy3 or FITC conjugated) for $2 \mathrm{~h}$ at RT. After three times washing with PBS the nuclei were counterstained with DAPI and the slides were analysed in Olympus BX60 fluorescence microscope.

\subsubsection{Production of knockout mice}

\section{Generation of the $C c d c 33$ knockout mouse line}

To analyse the function of the $C c d c 33$ gene, recombinant C57bl ES cells (VG13410) with targeted disruption of Ccdc33 gene were purchased from Velocigene Regeneron Pharmaceuticals Inc. (http://www.velocigene.com/komp/detail/13410). According to the knockout strategy designed by the company exons 6 to 11 of the Ccdc33 gene were replaced by the neomycin resistant gene. Figure 1 demonstrates the knockout strategy. 

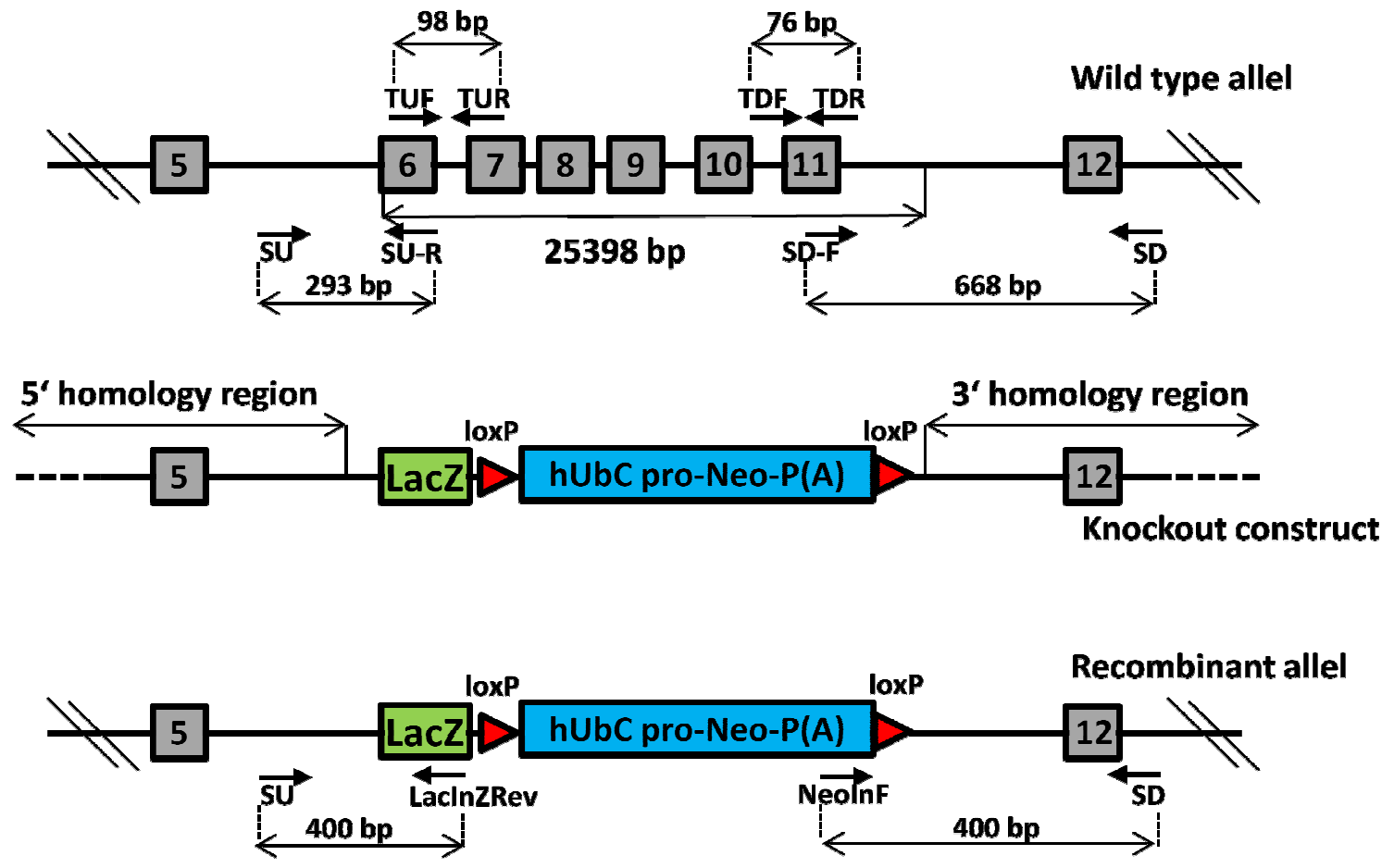

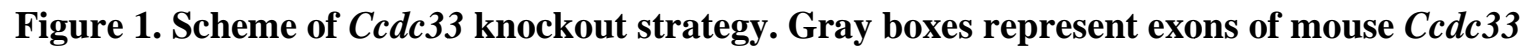
gene, green box represents $\beta$-galactosidase coding sequence, blue box stays for Neomycine cassette. Red triangles stay for LoxP sites. After homologous recombination exons 6 to 11 of the Ccdc33 gene (25398 bp) will be replaced by the neo cassette. The 5' and 3' homologous regions derived from a BAC clone and are of undefined size. The primers TUF, TUR, TDF and TDR were used for qPCR to confirm homologous recombination events in ES cells obtained from the company. Genotyping of chimeras was done with SU, SU-R and LacInZRev or NeoInf, SD-F and SD primers. PCR product sizes are given.

Prior to microinjection into the blastocysts (2.2.17.2) ES cells were tested by qPCR as described in 2.2.5.

Generation of the 4933400A11 RIKEN knockout mouse line

The knockout construct (ID79592) from International Knockout Mouse Consortium (http://www.knockoutmouse.org/martsearch/project/79592) was purchased to generate 4933400A11 RIKEN gene deficient line. The strategy designed by the company included surrounding of exon 3 of the 4933400A11Rik gene by two LoxP sites. In this 
exon the entire ORF is located. Figure 2 demonstrates schematic representation of the construct and strategy for generation of 4933400A11Rik conditional knockout line.
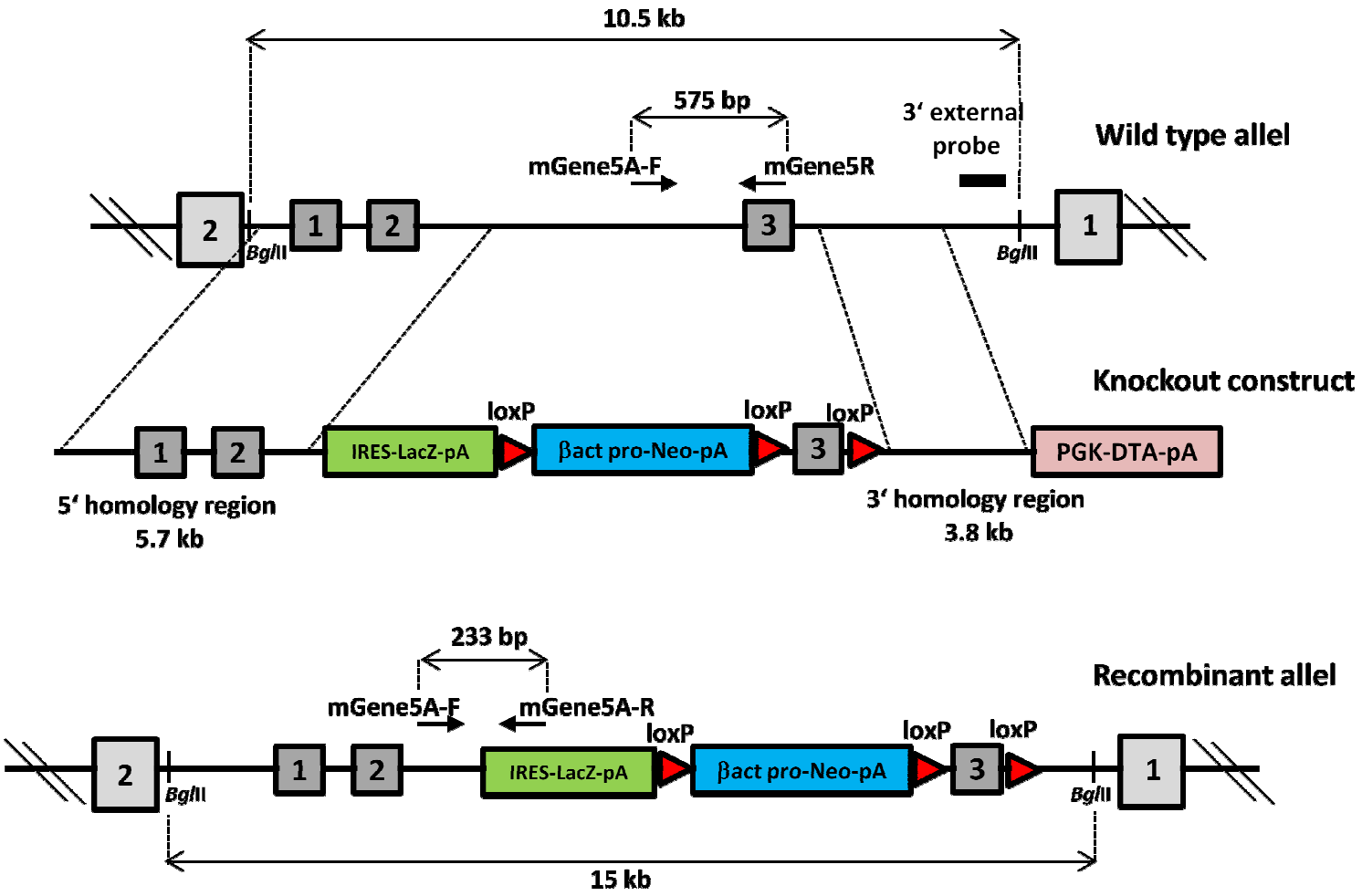

Knockout allel

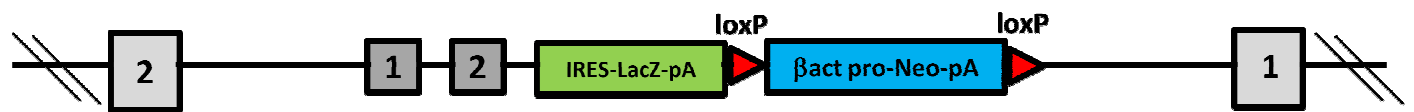

Figure 2. Scheme of 4933400A11Rik knockout's strategy. Dark gray boxes represent exons of 4933400A11Rik, light gray boxes the exons of midline 1. Green boxes stay for galactosidase coding sequence proceeded by internal ribosomal entry site (IRES), blue boxes represent neomycine cassettes, pink box represents diphtheria toxin cassette. Red triangles stay for LoxP sites. After homologous recombination exon 3 will be surrounded by two LoxP sites. Then, this conditional knockout line must be crossed with transgenic mouse carrying the Cre-recombinase gene. The deletion of exon 3 is driven by the CRE and is regulated by the particular promoter responsible for the CRE activity. To detect ES cell clone with homologous recombinant allele, the Southern blot analysis with 3' external probe was applied. Primers: mGene5A-F, mGene5A-R and mGene5R were used to genotype mutants. Significant restriction sites, restriction fragments and PCR products size are given. 


\subsubsection{Electroporation of ES cells with the 4933400A11 RIKEN knockout construct}

ES cells were cultured for two days in culture dishes (diameter $10 \mathrm{~cm}$ ). After trypsinisation, the cell pellet was washed in $20 \mathrm{ml}$ PBS, centrifuged and resuspended in 1 $\mathrm{ml}$ of PBS. $50 \mu \mathrm{g}$ of linearised DNA-knockout construct was added to $0.8 \mathrm{ml}$ of cell suspension in an electroporation cuvette. The electroporation was performed with the Bio-Rad gene pulserTM apparatus at $240 \mathrm{~V}$ and $500 \mu \mathrm{F}$. After electroporation, the cuvette was cooled on ice for $20 \mathrm{~min}$. The cell suspension was transferred into $20 \mathrm{ml}$ of ES cell medium and plated onto two $10 \mathrm{~cm}$ dishes containing feeder layers. The medium was changed every day. Selection with G418 at $400 \mu \mathrm{g} / \mathrm{ml}$ was started two days after the electroporation. ES cells, in which random integration of the knockout construct occurred, produced diphtheria toxin and degenerated. After eight days of selection, living, drug resistant colonies were picked with a drawn-out Pasteur pipette under a dissecting microscope and transferred into a 24-well plate containing feeders and ES cell medium. After two days, the ES cells were trypsinised and resuspended in $500 \mu \mathrm{l}$ ES cell medium. Half of the cell suspension in each well was transferred onto two different 24-well plates (one colony to one well on each plate). One plate contained gelatin and the other feeder cells (so called master plate). Cells growing on gelatine plate were used for DNA isolation and Southern blot analysis and the master plate was kept frozen for microinjection.

\subsubsection{Microinjection of ES cells into blastocysts}

Microinjections were done in Max Planck Institute for experimental medicine. 1020 recombinant ES cells from C57BL/6J were injected into the blastocoel cavity of recently cavitated C57BL/6J blastocysts. After injection, embryos are cultured for a short period $(2-3 \mathrm{~h})$ to allow re-expansion of the blastocoel cavity. Finally, they were transferred to the uterine horns of day three pseudopregnant females. 


\subsubsection{Detection of chimerism and mice breeding}

Both, recombinant ES cells and recipient blastocysts were from mice with C57BL background, thus a PCR reaction was applied to detect chimeras. For the genotyping of Ccdc33 KO line two different primer sets were used. SD-F; SD and NeoInF (Fig. 1), located downstream of the homologous recombination site, amplified a $668 \mathrm{bp}$ product on wild type allele and a 400 bp product on knockout allele, and SU, SU-R and LacInZRev located upstream of the homologous recombination site, amplified a $293 \mathrm{bp}$ and a $400 \mathrm{bp}$ products on WT and KO alleles, respectively. For the genotyping of 4933400A11Rik knockout line mGene5A-F, mGene5A-R and mGene5R primers were used (Fig. 2), which amplified a $233 \mathrm{bp}$ product on the KO and $575 \mathrm{bp}$ on the WT allel. The chimeras were bred with C57BL/6J to obtain heterozygous mutants.

\subsubsection{Fertility test}

Male mice were bred with wild type females for a period of three months to check the fertility. In addition, vaginal plug (VP) was controlled daily to ensure that the tested male mated with female. In case, no VP was noticed during the test period, the status of the male was marked as "unknown fertility".

\subsubsection{Isolation of spermatozoa}

Epididymides were dissected from adult males, which were not mated for at least two weeks, and placed in $400 \mu$ IVF medium, perforated with a needle and spermatozoa were allowed to swim out for $10 \mathrm{~min}$ at $37^{\circ} \mathrm{C}$. The uterus of VP positive females was closed with clips and gently dissected. After clips removing, sperm were squeezed into an e-cup.

\subsubsection{The analysis of sperm head morphology}

$20 \mu \mathrm{l}$ of spermatozoa suspension was spread on Superfrost slides, air dried and fixed for $30 \mathrm{~min}$ in ethanol : acetic acid mixture (3:1). After air drying, slides were stained overnight in $0.2 \%$ eosin. Then, they were washed in $\mathrm{dH}_{2} \mathrm{O}$ and closed with 
Eukitt-quick hardening mounting medium. About 300 spermatozoa were counted for each animal tested. Sperm head abnormalities were classified according to Styrna et al. (2003).

\subsubsection{CASA}

$13 \mu \mathrm{l}$ of epididymal spermatozoa in IVF Medium (Medicult, Jyllinge, Denmark) were put on dual sided sperm analysis chamber. Motility was analysed in computer assisted semen analysis (CASA) system using Hailton Throne CEROS software (v. 12). Sperm movement was recorded in $0.9 \mathrm{sec}$ either 20 times or until 2000 spermatozoas were captured. The following parameters were evaluated: average path velocity (VAP), curvilinear velocity (VCL), straight line velocity (VSL), straightness (STR), beat cross frequency (BCF) and amplitude of the lateral head displacement (ALH).

\subsubsection{Testosterone level determination}

For determination of serum testosterone level by radioimmunoassay (RIA), blood was collected post mortem. Serum was obtained by centrifugation for $10 \mathrm{~min}$ at $4000 \mathrm{xg}$. This analysis was done with the help of Prof. Jarry in the Department of Clinical and Experimental Endocrinology, Medical University of Göttingen using Testosterone RIA kit (Diagnostic Systems Laboratories) according to the manufacturer's instruction.

\subsubsection{Acrosome reaction}

Spermatozoa were capacitated in $500 \mu \mathrm{l}$ of PBS for $1 \mathrm{~h}$ at $37^{\circ} \mathrm{C}, 5 \% \mathrm{CO}_{2}$. Then, spermatozoa were centrifuged for $2 \mathrm{~min}$ at $3000 \mathrm{x}$ g. Next, supernatant was removed but around $50 \mu \mathrm{l}$ remained and were resuspended. To this sperm suspension $2.5 \mu \mathrm{l}$ of $10 \mathrm{mM}$ Ionophore A23187 was added. For the negative control $2.5 \mu \mathrm{l}$ of $5 \mathrm{mM}$ phosphoric acid was added instead of Inophore. After incubation for $1 \mathrm{~h}$ at $37^{\circ} \mathrm{C}$, the spermatozoa were fixed with $500 \mu \mathrm{l} 2 \%$ formaldehyde for $30 \mathrm{~min}$ at $37^{\circ} \mathrm{C}$ on warming plate. Next, spermatozoa were centrifuged for $2 \mathrm{~min}$ at $4000 \mathrm{x} \mathrm{g}$, washed twice with $15 \mathrm{mM}$ ammonium acetate and resuspended in $100 \mu \mathrm{l}$ of PBS. 20-30 $\mu \mathrm{l}$ of sperm suspension was spread on superfrost slides and air dried. The slides were stained with Comassie G-250 in 
$3.5 \% \mathrm{H}_{2} \mathrm{O}_{2}$ for $2.5 \mathrm{~min}$ and washed with water. Air dried slides were closed with Eukittquick hardening mounting medium and analysed by microscope. For a single animal three times 100 sperm were counted.

\subsubsection{Determination of spermatozoa number}

Spermatozoa were diluted 10 to 50 times. $10 \mu \mathrm{l}$ of this dilution were put into Neubauer counting chamber. Spermatozoa were counted in four fields $0.0025 \mathrm{~mm}^{2}$ under the microscope Olympus BX60. Determination of total spermatozoa was calculated as follows:

Number of sperm $=$ average of spermatozoa number per field $\mathrm{x}$ dilution $\mathrm{x} 400$ (volume of IVF medium used for sperm isolation) $\mathrm{x} 10$ (volume of sperm sample in Neubauer counting chamber).

\subsubsection{Superovulation}

Adult female mice were superovulated by intraperitoneal injections (ip) of $5 \mathrm{U}$ pregnant mare serum gonadotrophin (PMSG) followed $48 \mathrm{~h}$ later by ip of $5 \mathrm{U}$ of human chorionic gonadotrophin (HCG). Oocytes from superovulated females were isolated 15$17 \mathrm{~h}$ after HCG administration.

\subsubsection{Analysis of embryonic development}

To analyse the embryonic development, superovulated females were mated with males directly after HCG injection. Next day, vaginal plug (VP) was controlled to ensure that the tested male had copulated with the female. Embryos were flushed out from the oviduct 24h, 26h, 29h, 31h, 32h, 34h, 41h and 45h after HCG injection into M2 medium (Sigma). Finally, embryos were fixed for $15 \mathrm{~min}$ in $4 \%$ paraformaldehyde, stained with DAPI and analysed under a fluorescent microscope. 


\subsubsection{In vitro fertilisation}

For the in vitro fertilization (IVF) a fertilization dish containing four drops of IVF Cook medium (one drop of $400 \mu \mathrm{l}$, in which fertilization take place, and three washing drops of $150 \mu \mathrm{l}$ ) overlayed with mineral oil was prepared and equilibrated overnight at $37^{\circ} \mathrm{C}, 5 \% \mathrm{CO}_{2}$. Spermatozoa were isolated from epididymis, as described before (2.2.18.1), into equilibrated overnight $500 \mu \mathrm{l}$ of Cook medium overlayed with mineral oil. After isolation, 5-10 $\mu \mathrm{l}$ of the sperm suspension was transferred into $400 \mu \mathrm{l}$ of fertilisation drop and the dish was returned to the incubator until the oocytes were harvested. The oviducts from superovulated females were dissected and placed into a prewarmed $\left(37^{\circ} \mathrm{C}\right)$ PBS. Oocytes were isolated from the ampulla, washed with pre-warmed PBS and moved to the fertilisation drop containing sperm. It is important, that the time from killing female to placing oocytes into the fertilisation drop should not be longer than $5 \mathrm{~min}$. Next, IVF dishes were incubated at $37^{\circ} \mathrm{C}$ in $5 \% \mathrm{CO}_{2}$ for $6 \mathrm{~h}$. Thereafter, oocytes were washed two times in $150 \mu \mathrm{l}$ of Cook medium and incubated overnight at $37^{\circ} \mathrm{C}, 5 \% \mathrm{CO}_{2}$. Next day, 2 cell stage embryos were analysed under microscope. In case of IVF with zona pellucid (ZP) free oocytes, isolated clouds of oocytes and surrounding cumulus cells were incubated with hyaluronidase $(300 \mu \mathrm{g} / \mu \mathrm{l})$ for $10 \mathrm{~min}$ at $37^{\circ} \mathrm{C}$ on a heating plate, then acid tyrode solution ( $\mathrm{pH}$ 2.7) was used to remove ZP (usually incubated for 10-20 sec).

\subsubsection{Computer analysis}

The similarity of nucleotide or protein sequences was analysed using BLAST program (NCBI, Altschul et al. 1997; Morgulis et al., 2008). Primers specificity was checked with Primer Blast software from NCBI Data Base (http://blast.ncbi.nlm.nih.gov/). Primers were designed by Primer3 (http://frodo.wi.mit.edu/primer3) (Rozen and Skaletsky, 2000). The classification of the identified transcripts according to their biological functions and localization in cellular compartments was performed using DAVID bioinformatics tool (http://david.abcc.ncifcrf.gov/). Multiple sequence alignment was done with the ClustalW program (http://align.genome.jp). Protein structures and domains were predicted in PSORTII (http://psort.nibb.ac.jp/form.html), Motifscan (http://myhits.isb-sib.ch/cgi- 
bin/motif_scan) and SMART (http://smart.embl-heidelberg.de) programs. Statistical analysis was performed using Statistica software v.9 (StatSoft Inc, Tulusa, USA). 


\section{RESULTS}

\subsection{The analysis of the CCDC33 protein}

\subsubsection{Determination of the CCDC33 domain responsible for the interaction with} PXT1

The interaction of CCDC33 and PXT1 was identified in yeast-two-hybrid experiment using the testis cDNA library and further confirmed by co-localization, direct yeast-two-hybrid and bi-fluorescent complementation assay (BiFC) (Kaczmarek, 2009; Kaczmarek et al., 2009). The aim of this study was to identify the CCDC33 domain responsible for the interaction with PXT1.

The predicted domain composition of the CCDC33 was published previously (Kaczmarek et al., 2009). This protein contains, besides other, three coiled coil domains (CCDs) (Fig. 3). It is known that CCDs might be responsible for protein - protein interaction or heterodimerization (for review see Mason \& Arndt, 2004).

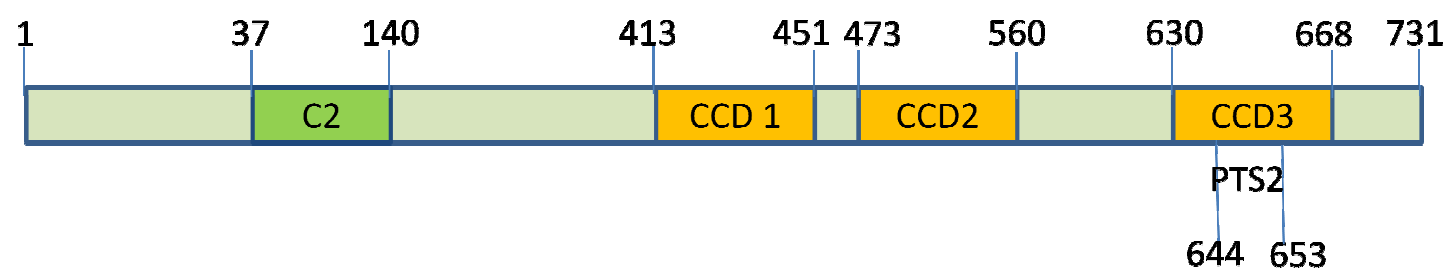

Figure 3. Schematic representation of the $\mathrm{CCDC33}$ protein. $\mathrm{CCDC33}$ protein contains three coiled coil domains (CCD 1-3), a $\mathrm{Ca}^{2+}$-dependent membrane-targeting module (C2 domain) and a peroxisomal targeting signal type 2 (PTS2) (Kaczmarek et al., 2009, modified). Significant amino acid positions are shown according to the NCBI Ref. Seq. NP_083488.

To analyse which part of the CCDC33 protein is involved in the interaction with PXT1 three constructs: pGADT7-CCDC33-1, pGADT7-CCDC33-2 and pGADT7CCDC33-3 were generated (Fig. 4). The pGADT7-CCDC33-1 construct encodes the part of mouse CCDC33 from the amino acid (aa) 261 to 481, pGADT7-CCDC33-2 and pGADT7-CCDC33-3 the parts from aa 468 to 595 and 602 to 708, respectively. First, using CCDC33_1F and CCDC33_1R; CCDC33_3F and CCDC33_3R and CCDC33_4F 
and CCDC33_4R primers and mouse testis cDNA appropriate fragments of Ccdc33 cDNA were amplified in PCR reaction. Next, purified PCR products were cloned into the pGEM-T Easy vector and sequenced. Then, appropriate inserts were isolated and subcloned in frame into pGADT7 vector using EcoRI and ClaI restriction sites. Finally, all constructs were verified by sequencing. In addition, pGADT7-CCDC33 complete (containing the nucleotides 1056-2958 of the Ccdc33 gene) and the pGBKT7-PXT1 (containing the full ORF of the Pxtl gene) constructs, kindly provided by Kaczmarek (Kaczmarek, 2009), were used. The control construct called "pGADT7-CCDC33 complete" does not contain the entire ORF of the $C c d c 33$ gene, but it has been demonstrated that the part of CCDC33 protein encoded by this construct interacts with PXT1 (Kaczmarek, 2009). Therefore this construct was used as a positive control.

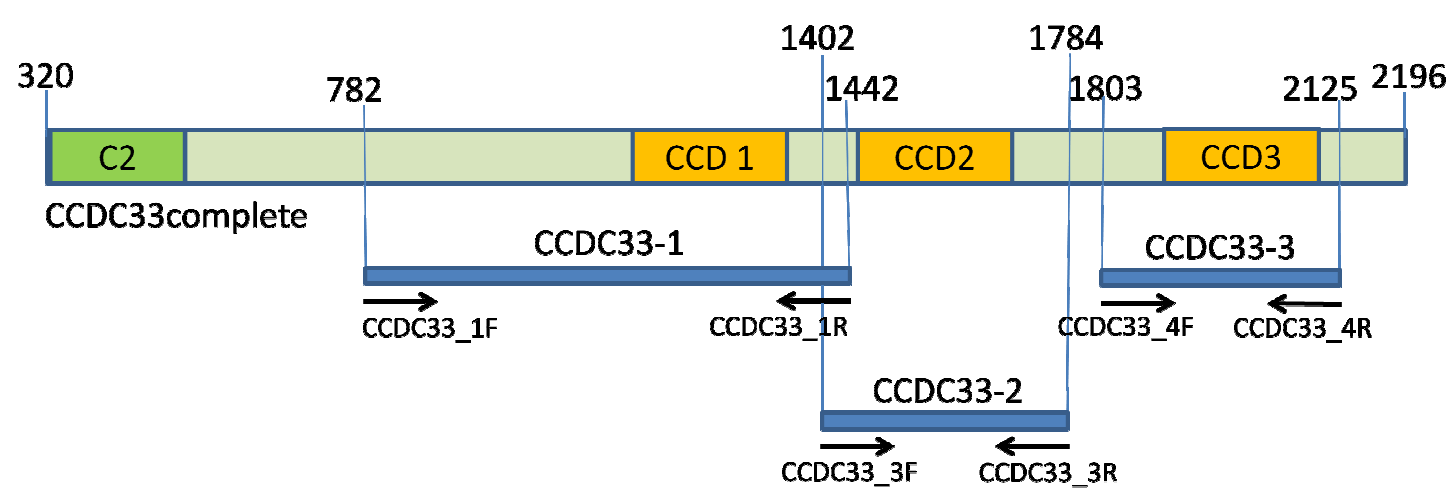

Figure 4. Schematic representation of different parts of $C c d c 33$ cDNA cloned into pGADT7 vector. These parts were used to determine the $\mathrm{CCDC33}$ domain responsible for the interaction with PXT1. C2 - $\mathrm{Ca}^{2+}$-dependent membrane-targeting module; CCD - coiled coil domain. Arrows represent primers used in the generation of constructs. Significant nucleotide positions are given according to the NCBI Ref. Seq. NM_029212.3.

Next, all constructs were used in yeast-two-hybrid system. First, to rule out the autoactivation, all constructs were co-transfected with the "empty" pGBKT7 vector (containing no insert) into AH109 yeast cells. Plates without leucine and tryptophan (-LT) served to test the efficiency of co-transfection (Fig. 5 A). No colonies were growing on medium without leucine, tryptophan, histidine and adenine and with X- $\alpha$-gal (-LTHA, $+\mathrm{X}-\alpha-$-gal), confirming that none of the tested clones undergo autoactivation (Fig. 5 B). 


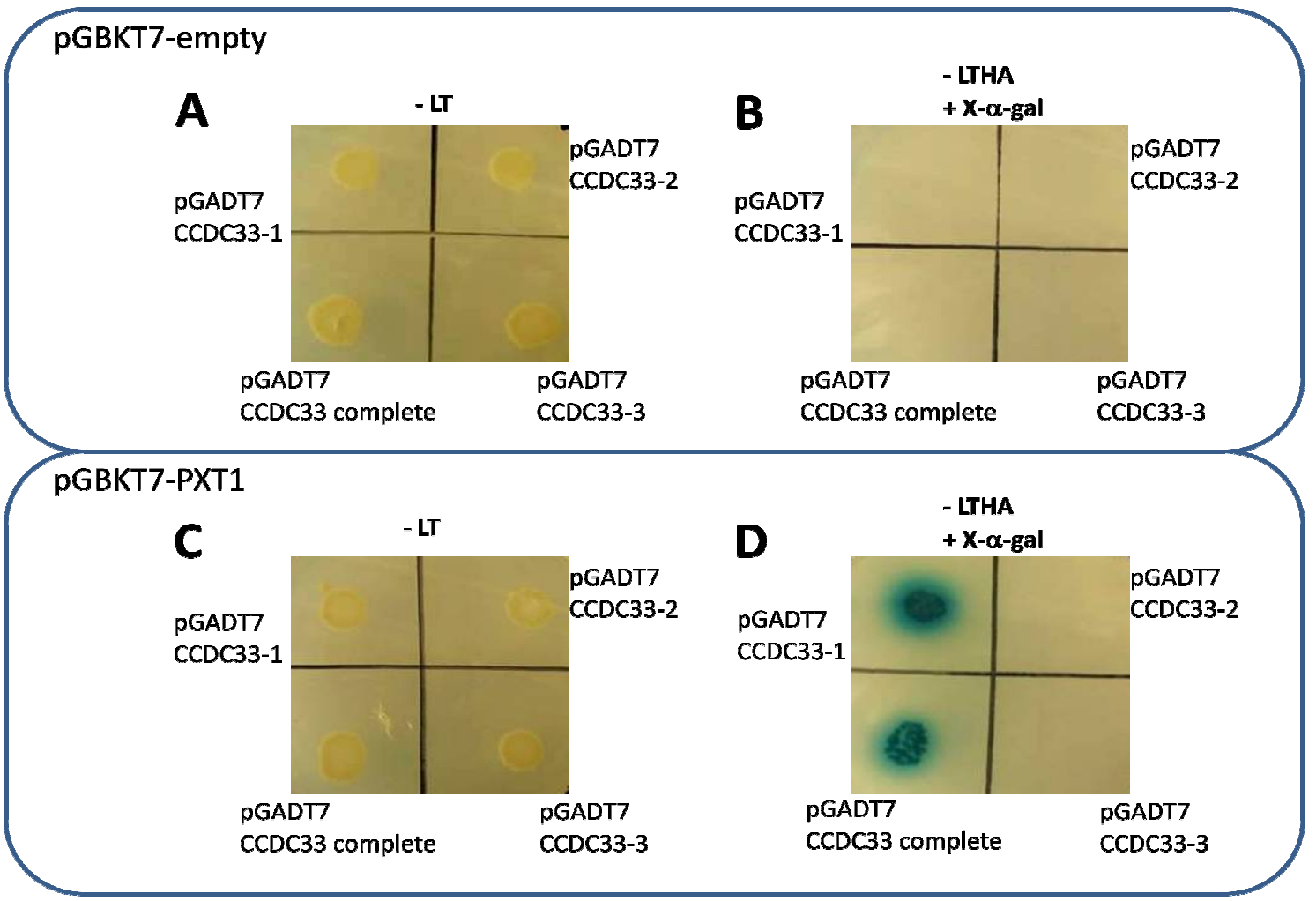

Figure 5. The analysis of CCDC33-PXT1 interaction. (A-B) Yeast cells were co-transfected with pGBKT7-empty vector and one of: pGADT7-CCDC33-1, pGADT7-CCDC33-2, pGADT7-CCDC33-3 and pGADT7-CCDC33 complete constructs. (A) White colonies on LT plates indicate successful co-transfection. (B) In contrast, no blue colonies are found on LTHA, $+X-\alpha$-gal plates, demonstrating that none of the tested constructs undergoes autoactivation. (C-D) To check which part of CCDC33 protein is involved in the interaction with PXT1 yeast were co-transfected with one of the pGADT7-CCDC33-1, pGADT7CCDC33-2, pGADT7-CCDC33-3 or pGADT7-CCDC33 complete and the pGBKT7-PXT1 constructs. (C) White colonies growing on -LT plates demonstrate successful cotransfection. (D) Blue colonies growing on -LTHA, $+\mathrm{X}-\alpha$-gal plates indicate, that the part 1 of CCDC33 protein interacts with PXT1.

Then, yeast were co-transfected with pGBKT7-PXT1 and one of pGADT7CCDC33-1, pGADT7-CCDC33-2, pGADT7-CCDC33-3 or pGADT7-CCDC33 complete constructs encoding different parts of CCDC33 protein (Fig. 5 C-D). White colonies growing on the control, -LT plates, demonstrated that the co-transfection was successful (Fig. 5 C). The interaction was tested on -LTHA, $+\mathrm{X}-\alpha-$ gal plates. Only yeast co- 
transfected with pGBKT7-PXT1 and pGADT7-CCDC33-1 was able to grow and turn blue (Fig. 5 D), thus fragment 1 of the CCDC33 protein was demonstrated to interact with PXT1. This part spans the amino acids 261 to 481, and contains one coiled-coil domain.

To further investigate the minimal region of the CCDC33 required for the association with PXT1, the CCDC33-1 fragment was divided into three smaller parts (Fig. 6). The following constructs were generated: pGADT7-CCDC33-1.1; pGADT7CCDC33-1.2 and pGADT7-CCDC33-1.3 encoding for mouse CCDC33 protein parts from amino acid position 261 to 350,305 to 421 and 402 to 481, respectively (Fig. 6).

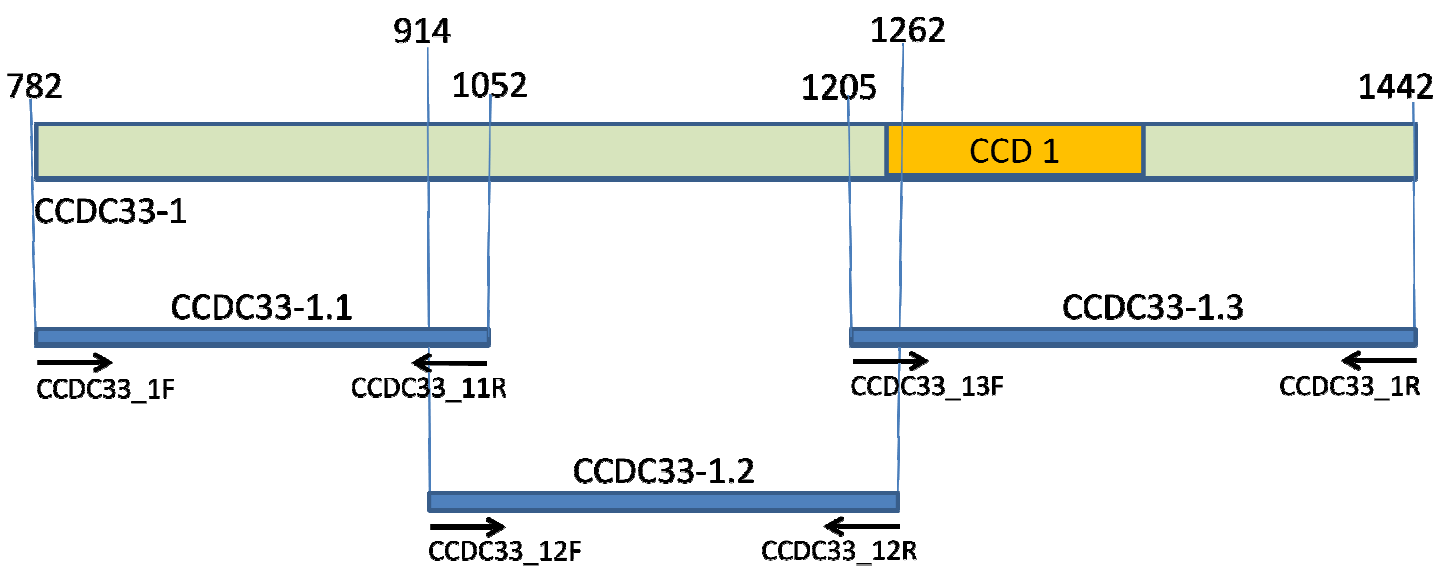

Figure 6. Schematic representation of constructs encoding parts of CCDC33-1 fragment of mouse CCDC33 protein. CCD - coiled coil domain. Arrows represent primers used in the generation of constructs. Significant nucleotide positions are given according to the mouse sequence NCBI Ref. Seq. NM_029212.3.

Appropriate fragments (Fig. 6) were amplified from mouse testis cDNA using CCDC33_1F and CCDC33_11R; CCDC33_12F and CCDC33_12R and CCDC33_13F and CCDC33_1R primers, cloned into the pGEM-T Easy vector, purified and sequenced. Next, inserts were isolated from pGEM-T Easy vector with EcoRI and ClaI restriction enzymes and sub-cloned into EcoRI/ClaI digested pGADT7 vector. To avoid the methylation of ClaI restriction site SCS110 bacteria cells lacking the DNA adenine methylation (Dam) activity were used for construct generation. After sub-cloning into pGADT7 all inserts were verified by restriction digestion and finally sequenced. Then, constructs were tested for autoactivation (Fig. 7 A-B). pGBKT7-empty vector was co- 
transfected with pGADT7-CCDC33-1.1, pGADT7-CCDC33-1.2 or pGADT7-CCDC331.3. White colonies could grow on -LT plate (Fig. 7 A), whereas no colony growth was observed on -LTHA, + X- $\alpha$-gal plates (Fig. 7 B), indicating no autoactivation activity of tested constructs. Next, yeast cells were co-transfected with pGADT7-CCDC33-1.1, pGADT7-CCDC33-1.2 or pGADT7-CCDC33-1.3 and pGBKT7-PXT1 and the interaction studz was performed (Fig. 7 C, D). Blue yeast colonies on -LTHA, + X- $\alpha$-gal indicated that the minimal region necessary for the interaction with PXT1 is located in part CCDC33-1.1 (Fig. 7 D).

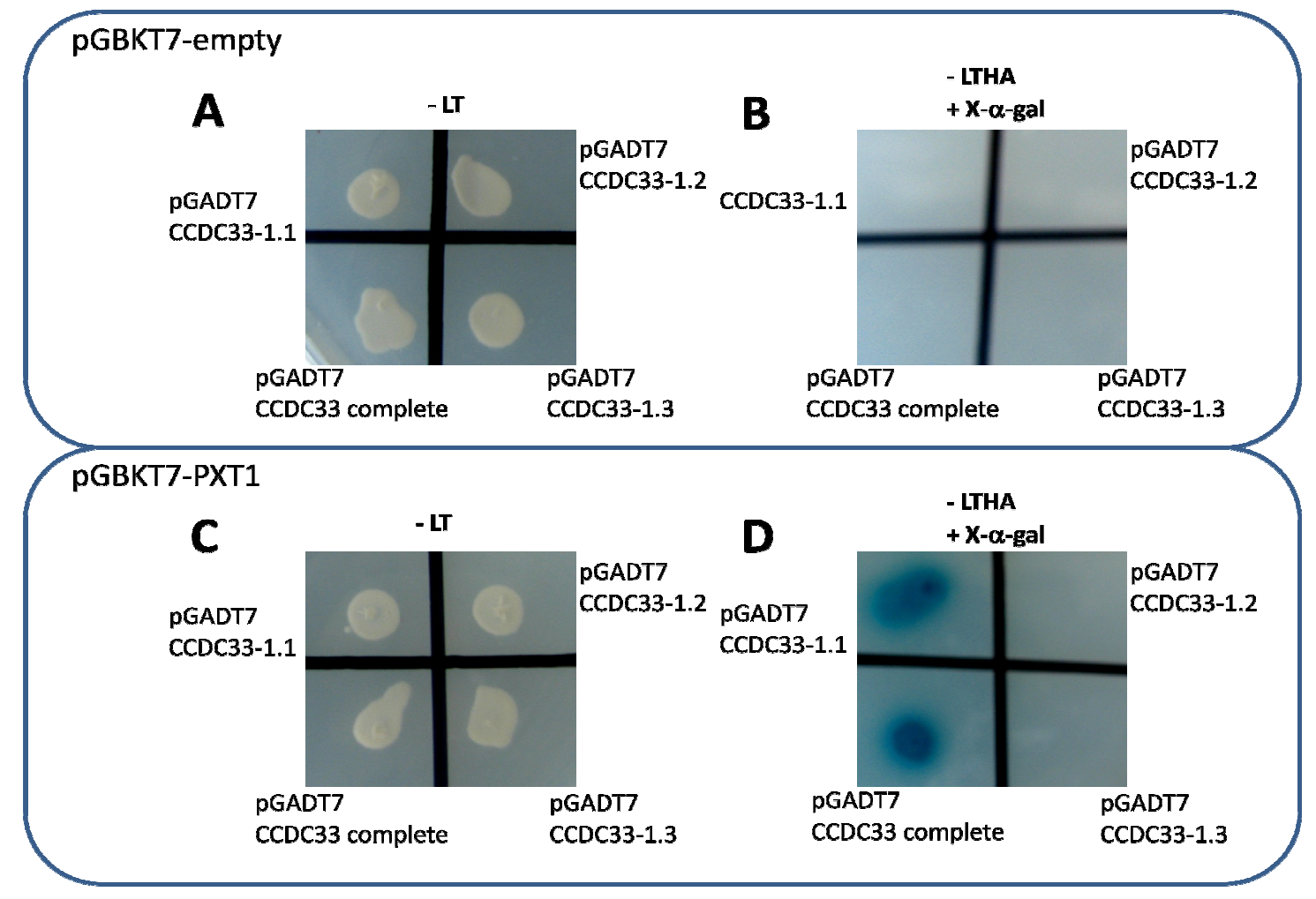

Figure 7. The analysis of the minimal region of the $\mathrm{CCDC} 33$ protein required for the interaction with PXT1. (A-B) Yeast competent cells were co-transfected with pGBKT7empty and one of: pGADT7-CCDC33-1.1, pGADT7-CCDC33-1.2, pGADT7-CCDC33-1.3 or pGADT7-CCDC33 complete. (A) The control of co-transfection was performed on plates lacking leucine and tryptophan (-LT). (B) The autoactivation was tested on plates lacking leucine, tryptophan, histidine and adenine (-LTHA), but containing X- $\alpha$-gal (+X- $\alpha$-gal). No blue colonies could be observed indicating no autoactivation. (C-D) To check which part of the CCDC33 protein is required for the interaction with PXT1 yeast were co-transfected 
with one of the pGADT7-CCDC33-1.1, pGADT7-CCDC33-1.2, pGADT7-CCDC33-1.3 or pGADT7-CCDC33 complete and the pGBKT7-PXT1 constructs. (C) White colonies growing on -LT plates demonstrated successful co-transfection. (D) Blue colonies growing on-LTHA, +X- $\alpha$-gal plates indicate interaction of part CCDC33-1.1 with PXT1.

In the part CCDC33-1.1 the coiled coil domain was not located. Moreover, no other known domain could be identified using computer domain prediction programs PSORTII, Motifscan and SMART. It is well known, that protein sequences responsible for important biological functions are highly conserved during evolution, therefore a comparison of mouse CCDC33 protein with homologous proteins from different species was performed to identify conserved regions within the CCDC33-1.1 fragment. First, NCBI data base was searched with mouse CCDC33 sequence and all similar sequences were downloaded. As demonstrated in figure 8 A mouse CCDC33 demonstrates the highest similarity to rat protein, but significant similarities were also observed with proteins of primates (marmoset, macaque and human), carnivora (panda and dog), perissodactyla (horse), didelphimorphia (gray short-tailed opossum), monotremata (platypus), amphioxiformes (lancelet), enterogona (sea squirt) and echinoida (sea urchin). Next, the alignment of CCDC33-1.1 fragment from all these species was generated with ClustalW program. Three highly conserved regions within the CCDC33-1.1 were identified after sequence alignment (Fig. 8 B). 
A

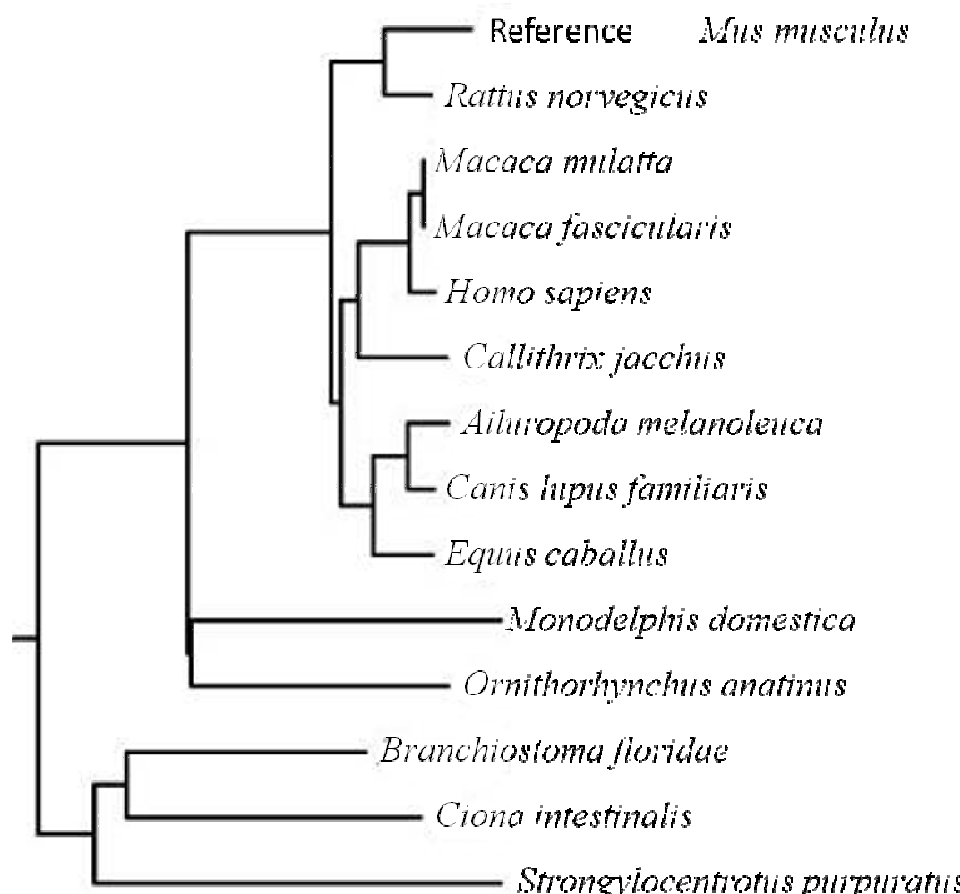

B

CCDC33-1.1

\begin{tabular}{|c|c|c|c|c|c|}
\hline Reference Mus musculus & SFI & EN & EYYP & WEFEGVSVIPT & ICGLCVERLPIIDTNLKIINGE \\
\hline Rattus norvegicus & & $=0$ & LIVIEYY & VIEI & GLCOVERLPIFDTNIRIINGE \\
\hline Macaca mulatta & PLWNCSEI & ClGRD & LILEYYS & SCXNLLDCLAGISVI & KIDGLHVERI \\
\hline Macaca fascicularis & PLWNCSEI & 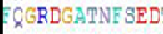 & AIVIEYYS & TIDCOAGISVIPI & Dat \\
\hline Homo sapiens & SFI & $\mathrm{CQG}$ & ALVEYYS & LNCES & CDGLA \\
\hline Callithrix jacchus & PLW. & 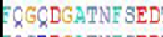 & DIVIEYY & SCRWILACETGISVLPI & ESLYRNIITGRGINGLVVECI \\
\hline Ailuropoda melanoleuca & PSWNCSEI & CيSRDG & ALIEYYS & MKGSEPWISKA LGVSVIPI & SRIYRKMIAGRGLNGIRVERLPVIDTKLKTINGE \\
\hline Canis lupus familiaris & PSWNCSFI & EGRDGP & DIVIEYY & STSMRGGEPWIISR本GVSVIPI & SRIYRRMLAGRGISGIRVERIPITDIRIRIING \\
\hline Equus caballus & PVWNCSEI & C $G R D$ & ILLEYYS & SMMRGSEPWILSR LGVSVLPI & ISRLYRKMITGRGINGIRVERLPIRL \\
\hline Ornithorhynchus anati & PVWNSSEI & Q & AIVIEYY & TTVIRNEPWNIVSI GISVIRI & INRVYRRLVASENWTGIC్VEGIPILGTLETKSD \\
\hline phis domest & PEWNMSEI & $\mathrm{K} \in \mathrm{R}$ & AILIEYYP & ITMMPARDSWNLTEA GISVVPI & INRIYRRMMSGSRI-ALHVRRIPIKRTKLRII \\
\hline sus & & & & & 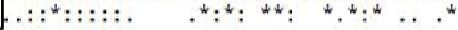 \\
\hline
\end{tabular}

Clustal Consengus

1

2

3

C

CCDC33-1.1

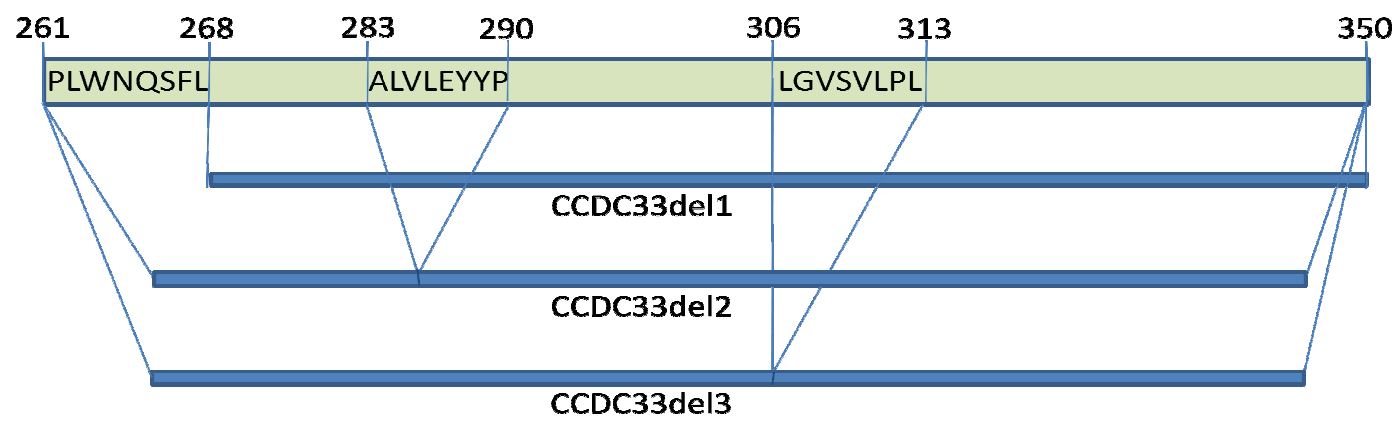

Figure 8. The analysis of evolutionary conservation of the CCDC33-1.1 protein fragment.

(A) The homology tree of CCDC33 protein sequence of different animal species was 
generated with ClustalW program. (B) The sequence alignment of the CCDC33-1.1 revealed three highly conserved amino acids sequences, which represent candidates for the minimal region required for the interaction with PXT1. (C) These parts were deleted to determine the CCDC33 domain responsible for the interaction with PXT1. Significant amino acid positions are given according to the NCBI Ref. Seq. NP_083488.

To determine whether any of the conserved regions is involved in the interaction with PXT1, three constructs (pGADT7-CCDC33del1; pGADT7-CCDC33del2 and pGADT7-CCDC33del3) were generated in which the conserved region 1, 2 or 3 was deleted (Fig. 8 C). To delete homology region 1 primers Ccdc33del1-Fa and Ccdc33_11R, amplifying a shorter fragment of CCDC33-1.1 without the N-terminal conserved region, were used. After amplification, PCR product was digested with EcoRI and $\mathrm{Cla}$ I and cloned in frame into pGADT7. To delete conserved sequences 2 and 3 (Fig. 8 B-C) a primers: Ccdc33del2-Fa, Ccdc33del2-Fb, Ccdc33del2-Ra and Ccdc33del2-Rb (to delete the region 2) and Ccdc33del3-F1, Ccdc33del3-F2, Ccdc33del3-R1 and Ccdc33del3-R2 (to delete the region 3) were applied in site-directed mutagenesis reaction. After PCR amplification and digestion with DpnI, mutated vectors were transformed into SCS110 competent cells according to protocol Quick Change SiteDirected Mutagenesis kit (Stratagene, La Jolla, CA, USA). Finally, all generated constructs harboring the deletions were sequenced.

Yeast AH109 competent cells were co-transfected with pGBKT7-PXT1 and one of pGADT7-CCDC33del1; pGADT7-CCDC33del2, pGADT7-CCDC33del3, pGADT7CCDC33complete or pGADT7-CCDC33-1.1. No colony growth on -LTHA, + X- $\alpha$-gal plate was observed for yeast cells co-transfected with pGBKT7-PXT1 and pGADT7CCDC33del3 indicating that the conserved sequence 3 in CCDC33 is required for interaction with PXT1. Efficient co-transfection was proven on -LT plate (Fig. 9). 


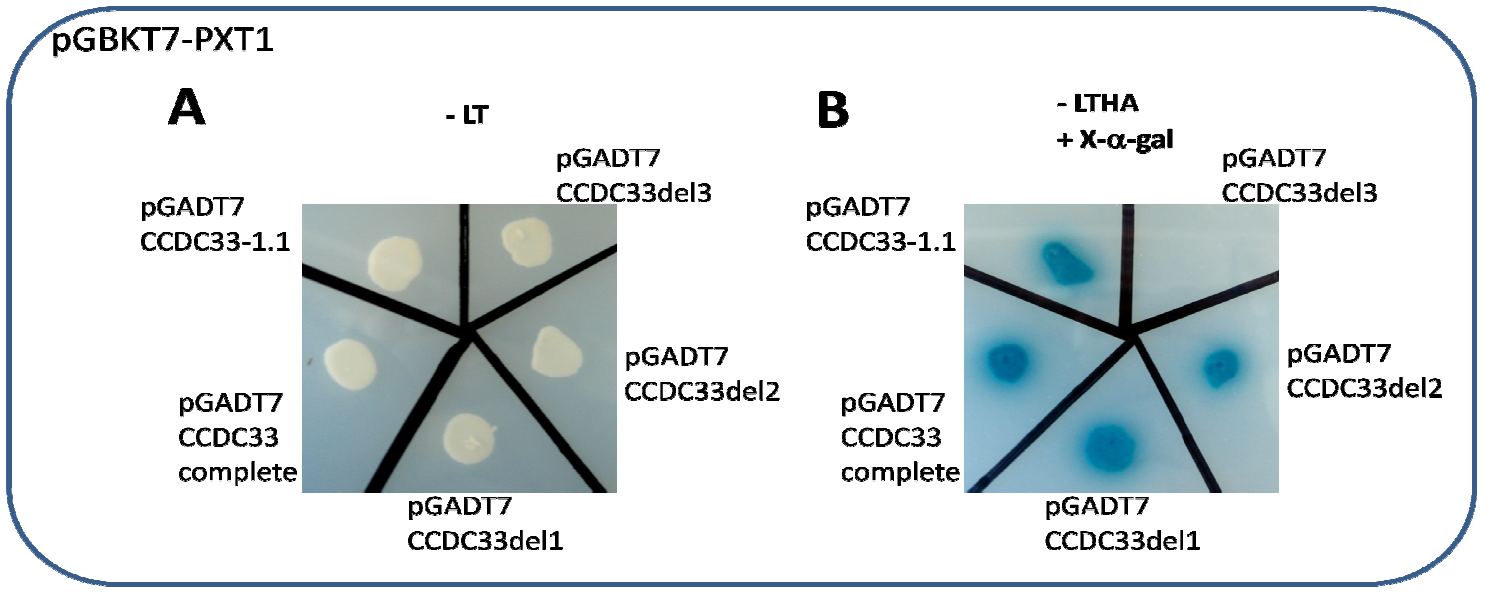

Figure 9. The analysis of conserved regions of the CCDC33-1.1 fragment. (A-B) pGBKT7PXT1 and one of pGADT7-CCDC33del1, pGADT7-CCDC33del2 or pGADT7CCDC33del3, each harbouring a deletion of one of evolutionary conserved regions identified in the CCDC33-1.1 fragment, were used in direct yeast-two-hybrid assay to analyse the interaction with PXT1. As a positive control pGADT7-CCDC33complete and pGADT7CCDC33-1.1 were used. (A) White yeast colonies growing on -LT plates showed the efficient transformation whereas blue yeast colonies (B) growing on -LTHA, +X-a-gal plate indicated interaction. The deletion of conserved region 3 (aa: 306-313) completely disturbed the interaction clearly indicating that this sequence is necessary for binding with PXT1.

\subsubsection{Coimmunopreciptation of CCDC33-1.1 with PXT1}

To analyse the physical binding between CCDC33 and PXT1 proteins coimmunoprecipitation technique was applied. For this analysis the pQM-Ntag/APXT1delBH3 (encoding for nucleotides 34-156 of the mouse PXT1) (Kaczmarek et al., 2011) was used. This vector encoding a part of PXT1 protein without the pro-apoptotic BH3 domain was taken intentionally to avoid potential degeneration of transfected HeLa cells. In the first attempt the construct pCMVmyc-CCDC33 containing exons 9-20 of the Ccdc33 cDNA generated by Kaczmarek was co-transfected with pQM-Ntag/APXT1delBH3 (Kaczmarek, 2009) into HeLa cells. Unfortunately, the amount of both isolated, E2-PXT1-BH3del and cMYC-CCDC33 proteins in supernatant (soluble) fraction was not enough for successful CoIP experiment (Kaczmarek, 2009). Therefore, after determining that shorter part of CCDC33 protein, namely CCDC33-1.1 (demonstrated in 
yeast-two-hybrid experiment to be sufficient for the interaction with PXT1), was used in CoIP attempt. This part encoding amino acids 261-350 was amplified from testis cDNA using Ccdc33_11 CoIpF and Ccdc33_11 CoIpRev primers, cloned into pGEM-T Easy and sequenced. Then, insert was isolated with EcoRI and KpnI and sub-cloned into a pCMVmyc vector. HeLa cells were co-transfected with pQM-Ntag/A-PXT1delBH3 and pCMVmyc-CCDC33-1.1 vectors. Initially both vectors were tested by immunocytochemistry. After co-trasfection HeLa cells were fixed and stained with rabbit anti-E2 (1:1000) and mouse anti-cMyc (1:1000) antibodies, followed by hybridization with anti-rabbit-Cy3 conjugated (1:500) and anti-mouse-FITC conjugated (1:500) secondary antibodies. Cell nuclei were counterstained with DAPI. Both, E2-PXT1delBH3 and CCDC33-1.1-cMyc fusion proteins could be detected in co-transfected HeLa cells (Fig. 10). It is worth to notice, that both fusion proteins co-localized in punctual-like pattern.
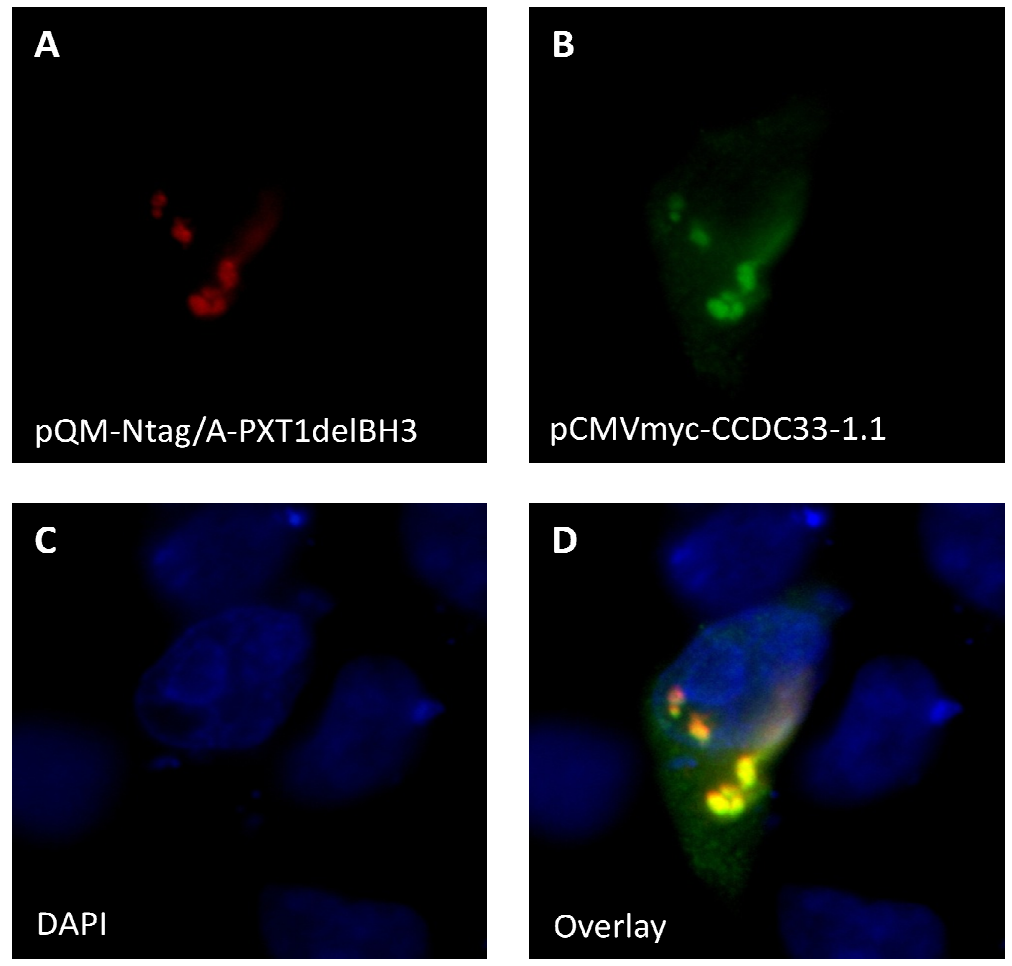

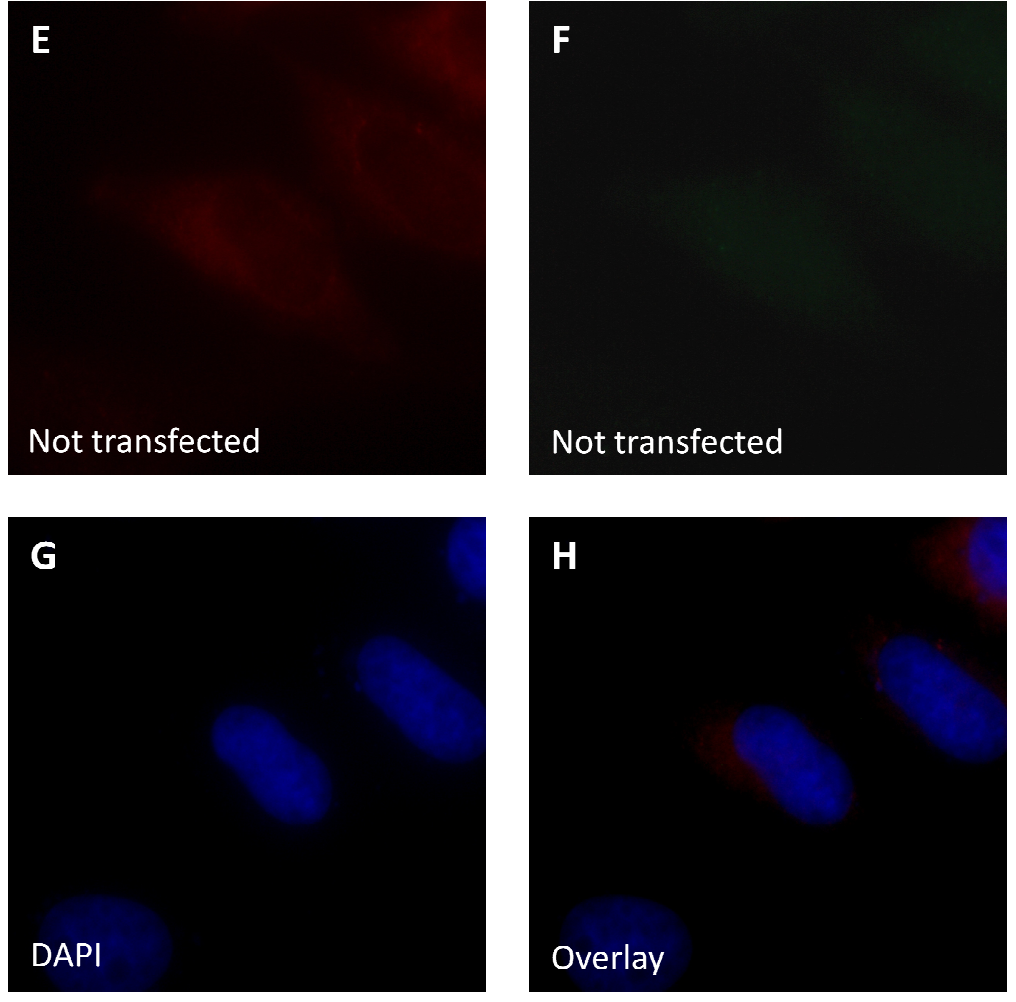

Figure 10. Co-transfections of HeLa cells with pCMVmyc-CCDC33-1.1 and pQM-Ntag/APXT1 constructs. (A) Red signals represent the E2-PXT1delBH3 fusion protein were detected by anti-E2 rabbit and anti-rabbit-Cy3 conjugated antibodies, whereas (B) green spots represent CCDC33-1.1-cMYC fusion protein stained by anti-cMyc mouse and antimouse-FITC conjugated antibodies. (D, G) Cell nuclei were counterstained with DAPI. (D) Co-localization of both proteins was observed. (E-H) Not transfected HeLa cells stained with the same concentration of antibodies were used as negative control.

Next, proteins of HeLa cells were isolated $24 \mathrm{~h}$ after co-transfection with pQMNtag/A-PXT1delBH3 and pCMVmyc-CCDC33-1.1 constructs. For coimmunoprecipitation experiment protein lysate was incubated with protein $\mathrm{G}$ and anticMyc antibody. After several incubation and washing steps, immunoprecipitated fusion proteins were analysed by Western blot incubated overnight at $4^{\circ} \mathrm{C}$ with anti-E2 antibody (1:1000) followed next day by incubation with secondary, alkaline phosphatase conjugated anti-mouse antibody (1:5000). As demonstrated in figure 11 effective immunoprecipitation of E2-PXT1delBH3 fusion protein was observed using anti-cMyc antibody. No unspecific immunoprecipitation of the E2-PXT1delBH3 fusion protein in 
HeLa cells transfected only with the pQM-Ntag/A-PXT1delBH3 vector could be observed (Fig. 11). This result clearly indicates that there is a physical binding of CCDC33 and PXT1 proteins.

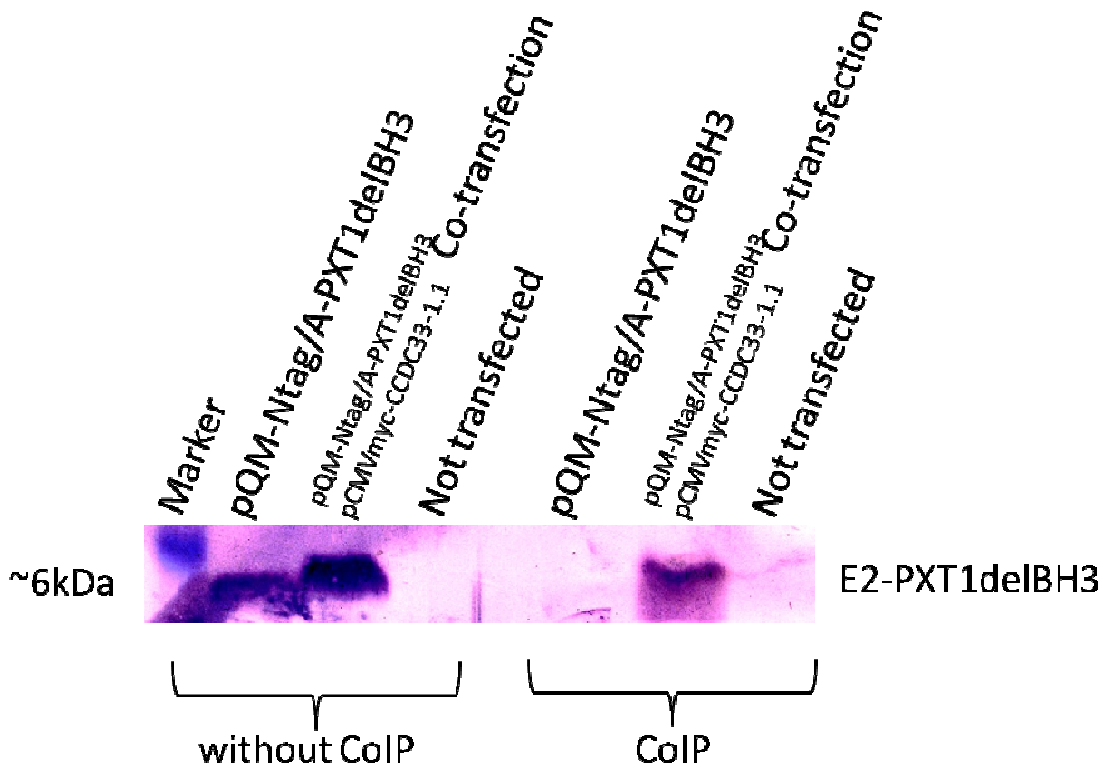

Figure 11. Coimmunoprecipitation of E2-PXT1delBH3 protein with anti-cMyc antibody. HeLa cells were transfected with either the pQM-Ntag/A-PXT1delBH3 (single transfection) or both pQM-Ntag/A-PXT1delBH3 and pCMVmyc-CCDC33-1.1 (co-transfection) constructs. Effective transfection was demonstrated prior to immunoprecipitation, the E2PXT1delBH3 fusion protein could be detected in protein lysate of single and co-transfected HeLa cells (the panel "without CoIP"). After coimmunoprecipitation with anti-cMyc antibody a single band was detected only in protein lysate of co-transfected cells (panel "CoIP").

Unfortunately, until the end of this work it was not possible to establish the coimmunoprecipitation assay in the opposite direction, namely immunoprecipitation with anti-E2 and the detection with anti-cMyc antibodies.

\subsubsection{Functional analysis of the PXT1 sequence responsible for the interaction with the CCDC33}

It has been demonstrated that the sequence of mouse PXT1 indispensable for the interaction with CCDC33 consists of four amino acids: leucine-alanine-prolinephenylalanine (LAPF) in position 26-30 (Kaczmarek, 2009). Kaczmarek has used a yeast- 
two-hybrid system and demonstrated that after deletion of LAPF motif the interaction with CCDC33 is abolished (Fig. 12 A, B). Next, the LAPF motif was mutated into GAPA sequence and this mutation also resulted in disruption of the interaction (Fig. 12 C, D) (Kaczmarek, 2009).

A
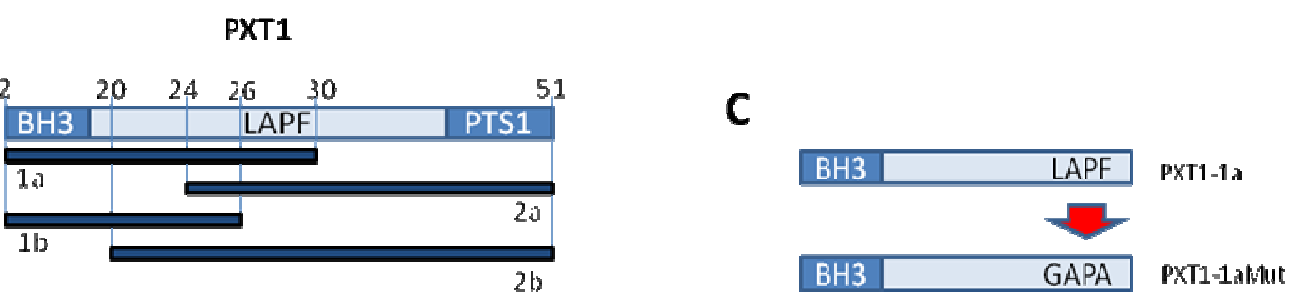

B
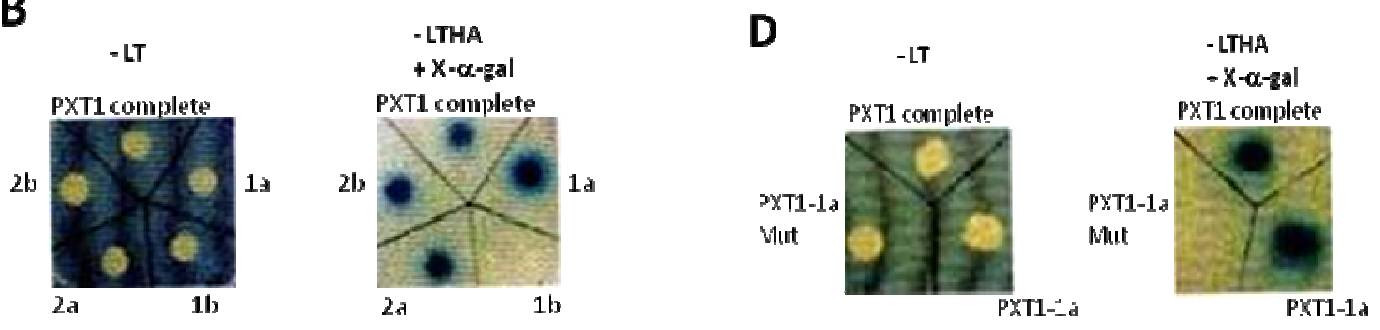

Figure 12.The analysis of the sequence of PXT1 involved in interaction with CCDC33. (A) PXT1 was divided into 4 parts and each was cloned into pGBKT7 vector. (B) Only the parts of PXT1 protein containing LAPF motif interacted with CCDC33. (C-D) The mutation of LAPF motif into GAPA abolished the PXT1-CCDC33 interaction (Kaczmarek, 2009, modified). The position of significant amino acids is given according to NCBI NP_700439.

It should be pointed out that Kaczmarek experiments were done using parts of PXT1 protein. Therefore, the aim of my work was the confirmation of the previous results using the entire protein. The pGBKT7-PXT1complete construct was used to mutate the LAPF motif into GAPG by site directed mutagenesis with Pxt1FGFP, Pxt1FGRP, Pxt1LGFP and Pxt1LGRP primers (Fig. 13 A). After PCR, bacterial cells were transformed and the construct pGBKT7-PXT1 mutated was verified by sequencing. Next, the analysis whether the mutation of LAPF motif influences the interaction of PXT1 and CCDC33 was performed by direct yeast-two-hybrid technique. Yeast were co-transfected with pGADT7-CCDC33 complete and either pGBKT7-PXT1 complete or pGBKT7PXT1 mutated. Transfection efficiency was monitored on -LT plates (Fig. 13 B), while 
the interaction was tested on -LTHA, + X- $\alpha$-gal plate (Fig. 13 C). Surprisingly, blue colonies of yeast co-transfected with pGADT7-CCDC33 complete and pGBKT7PXT1mutated GAPG constructs were growing on - LTHA, + X- $\alpha$-gal plate indicating that PXT1-GAPG mutant protein can still interact with CCDC33.

A

\begin{tabular}{|l|l|l|}
\hline BH3 & LAPF & PTS1 \\
\hline
\end{tabular}

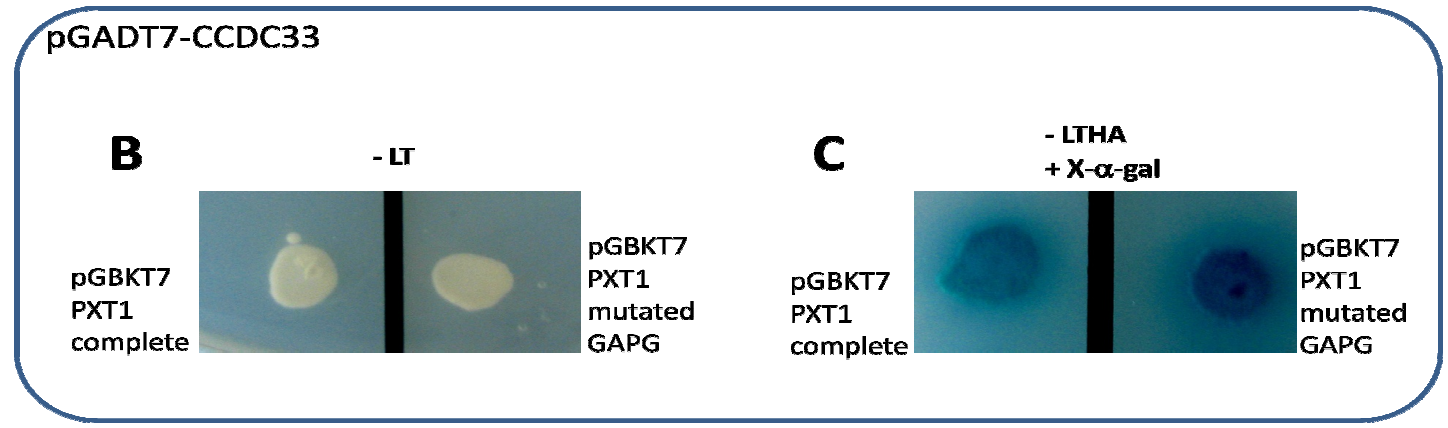

Figure 13. The analysis of the function of LAPF motif of the PXT1 for the interaction with CCDC33. (A) The pGBKT7-PXT1complete construct was used to mutate leucine and phenyloalanine into glicyne. (B) White colony growing on -LT plate confirmed the cotransfection of yeast with pGBKT7-PXT1 complete or pGBKT7-PXT1mutated GAPG with pGADT7-CCDC33. (C) Blue colonies growing on -LTHA, $+\mathrm{X}-\alpha$-gal plates indicate that both, wild type and mutated PXT1 proteins interact with CCDC33.

Next, the function of LAPF motif for the PXT1-CCDC33 interaction was analysed in mammalian cells. For this analysis the PXT1pEGFP fusion protein was expressed from the PXT1pEGFP construct. This construct contains the entire Pxt1 open reading frame cloned in frame into the pEGFP-C1 vector as described previously (Grzmil et al., 2007). To fuse the CCDC33 with dsRED marker protein a C-terminal part of the coding region of $C c d c 33$ gene (encoding amino acids 264 to 723) was amplified and cloned into pDsRed-Mono-N1 vector (Kaczmarek et al., 2009). The resulting CCDC33dsRED 
construct was used for the interaction study. The Pxt1pEGFP construct was used in site directed mutagenesis to introduce mutations into the sequence encoding the LAPF motif of the PXT1 protein. Using Pxt1FGFP, Pxt1FGRP, Pxt1LGFP and Pxt1LGRP primers the sequence CTGGCTCCTTTT encoding LAPF motif was mutated into GGGGCTCCTGGT encoding for GAPG. Subsequently, HeLa cells were transiently cotransfected with PXT1mutGAPGpEGFP or PXT1pEGFP and CCDC33dsRED constructs. As expected, in HeLa cells expressing PXT1pEGFP and CCDC33dsRED fusion proteins a co-localization of both proteins was observed, in contrast no co-localization was observed in the majority of cells expressing PXT1mutGAPGpEGFP and CCDC33dsRED fusion proteins (Fig. 14). Quantification revealed that $95 \%( \pm 5 \%)$ of cells co-transfected with PXT1pEGFP and CCDC33dsRED constructs demonstrated co-localization of both fusion proteins, while in only $35 \%( \pm 7 \%)$ of cells co-transfected with PXT1mutGAPGpEGFP and CCDC33dsRED constructs the co-localization was observed (Fig. 14 F). Quantification of co-localization events and Mann-Whitney U-test analysis of variations demonstrated that cells co-transfected with CCDC33dsRED and PXT1mutGAPGpEGFP developed significantly weaker co-localization as compared to cells co-transfected with CCDC33dsRED and PXT1EGFP fusion proteins only (Fig. 14 I, $\mathrm{p}<0.05)$.
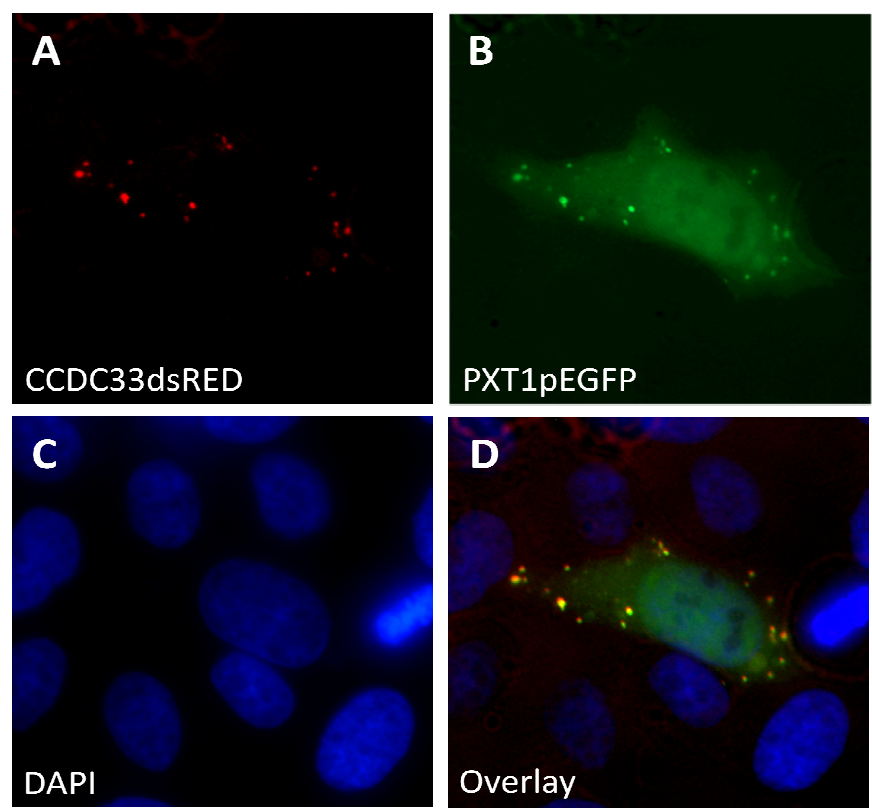

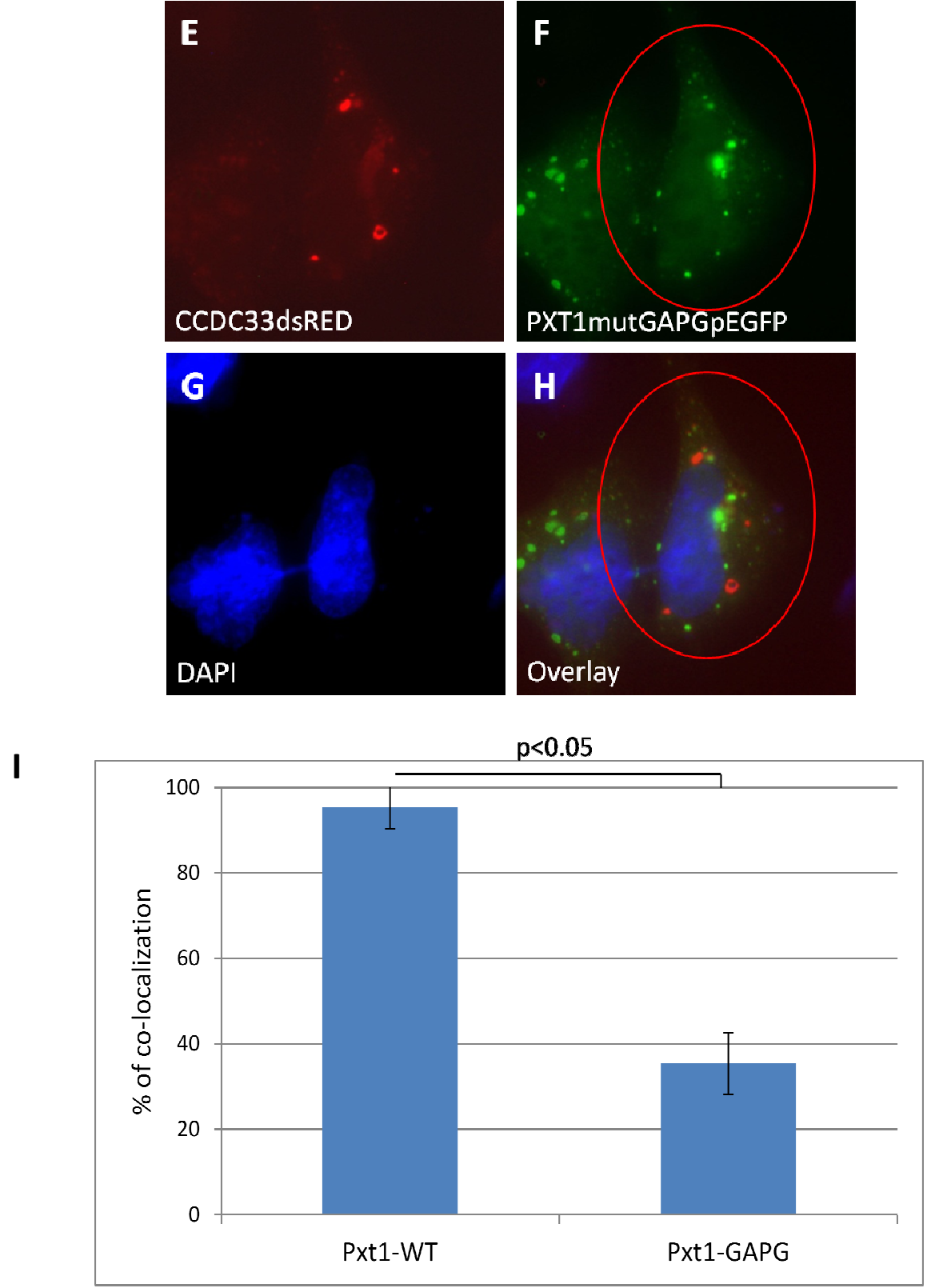

Figure 14. The analysis of LAPF motif of PXT1 and its role for the interaction with CCDC33 in HeLa cells. HeLa cells were transiently transfected with the CCDC33dsRED and either PXT1pEGFP or PXT1mutGAPGpEGFP. (A-D) Clear co-localization (yellow signal) of PXT1pEGFP (green signal) and CCDC33dsRED (red signal) fusion proteins can be observed, while the mutation of the LAPF motif into GAPG significantly disturbed the interaction of both proteins (E-H). Nuclei were counterstained with DAPI (blue signal). (I) Quantification of transiently transfected HeLa cells revealed that the mutation of the LAPF motif significantly reduced the interaction of PXT1mutGAPGpEGFP with CCDC33dsRED fusion proteins ( $36 \%$ cells demonstrated interaction of CCDC33dsRED with mutated PXT1 
and $92 \%$ cells demonstrated the interaction of wild type proteins). Bars represent the mean value for the percentage of cells with co-localization, whiskers represent standard deviation.

Since the mutation of LAPF motif into the GAPG did not completely abolish the PXT1-CCDC33 interaction, the next mutation was introduced. In this second round of site-directed mutagenesis with Pxt1APGGFP and Pxt1APGGRP primers and PXT1mutGAPGpEGFP construct as a template, the sequence GGGGCTCCTGGT was changed into GGGGGTGGTGGT sequence encoding GGGG motif. Then, HeLa cells were co-transfected with PXT1mutGGGGpEGFP and CCDC33dsRED constructs and the co-localization of both fusion proteins was analysed under the fluorescence microscope. The mutation of additional two amino acids from the LAPF motif didn't significantly decreased the PXT1-CCDC33 interaction as compared to the mutation of only two amino acids. As demonstrated in figure 15, $34 \%( \pm 6 \%)$ of co-transfected cells still demonstrate the co-localization of PXT1mutGGGGpEGFP and CCDC33dsRED fusion proteins. Mann-Whitney U-test analysis demonstrated that cells co-transfected with CCDC33dsRED and PXT1mutGGGGpEGFP presented significantly reduction of colocalization as compared to cells co-transfected with CCDC33dsRED and PXT1EGFP fusion protein only (Fig. $15 \mathrm{~F}, \mathrm{p}<0.05$ ).

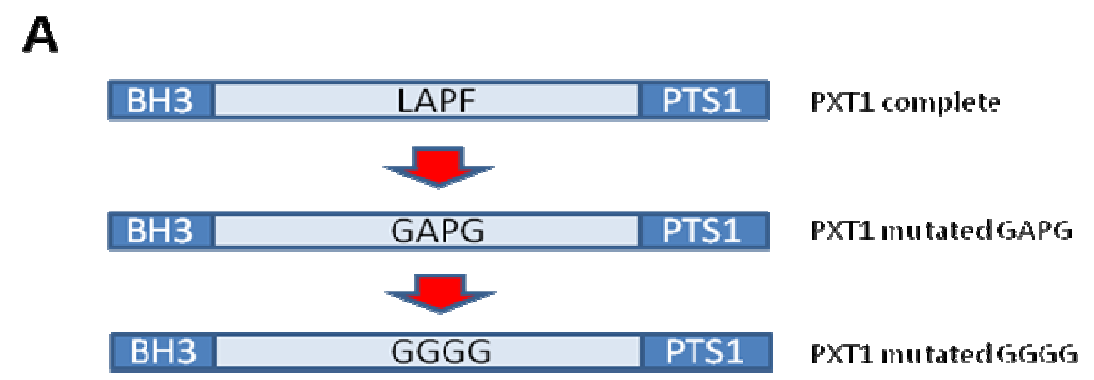



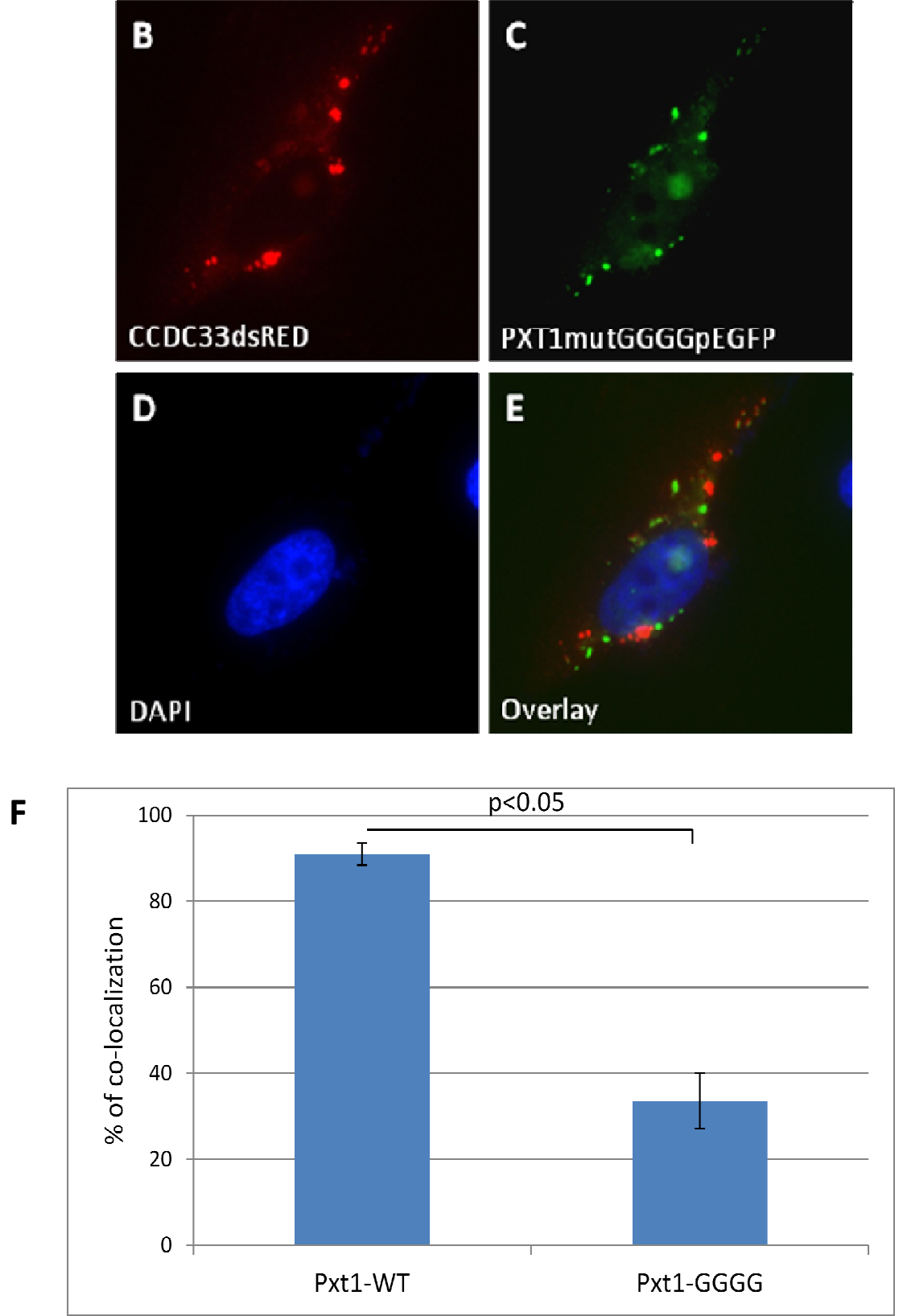

Figure 15. The analysis whether the mutation of LAPF motif into GGGG sequence completely abolish the PXT1-CCDC33 interaction in HeLa cells. (A) The sequence encoding the LAPF motif of the PXT1 protein was mutated into sequence encoding for GGGG motif. (B) The majority of cells expressing CCDC33dsRED (red signal) and (C) PXT1mutGgGGpEGFP (green signal) did not demonstrate the co-localization of both fusion proteins (E). (D) Nuclei were counterstained with DAPI. (F) Only $34 \%$ of cells cotransfected with Pxt1mutGgGGpEGFP and CCDC33dsRED constructs demonstrated the 
co-localization of both fusion proteins. Bars represent the mean value for the percentage of cells with co-localization, whiskers represent standard deviation.

\subsubsection{The analysis of the consequences of CCDC33-PXT1 interaction for PXT1 induced apoptosis}

To analyse whether the simultaneous overexpression of CCDC33 and PXT1 has any influence on apoptosis, HeLa cells were co-transfected with CCDC33dsRED construct (Kaczmarek, 2009) and one of the following constructs: PXT1pEGFP (Grzmil et al., 2007) or PXT1delBH3pEGFP (Kaczmarek et al., 2011). The last, PXT1delBH3pEGFP construct encodes the amino acids 12 to 52 of the mouse PXT1 protein (without the $\mathrm{BH} 3$ domain) fused with EGFP. For control HeLa cells were transfected with single constructs: CCDC33dsRED, PXT1pEGFP and PXT1delBH3pEGFP. After $24 \mathrm{~h}$ cells were fixed and mounted with medium containing DAPI and cell's cytomorphology was analysed. Cells were determined according to the characteristics of apoptosis: cell rounding, shrinkage, plasma membrane blebbing, apoptotic body formation and nuclear fragmentation (Alberts et al., 2008). This analysis demonstrated that the majority of cells, which overexpressed both, CCDC33dsRED and PXT1EGFP fusion proteins, did not demonstrate any signs of apoptosis (Fig. 16). Quantification of apoptotic events and ANOVA analysis of variation demonstrated that cells co-transfected with CCDC33dsRED and PXT1pEGFP developed significantly weaker apoptosis as compared to cells overexpressing PXT1EGFP fusion protein only (Fig. 17, p<0.0005). Noticeably, the apoptosis in cells co-transfected with CCDC33dsRED and PXT1pEGFP was not significantly different from the apoptosis observed in other controls. 

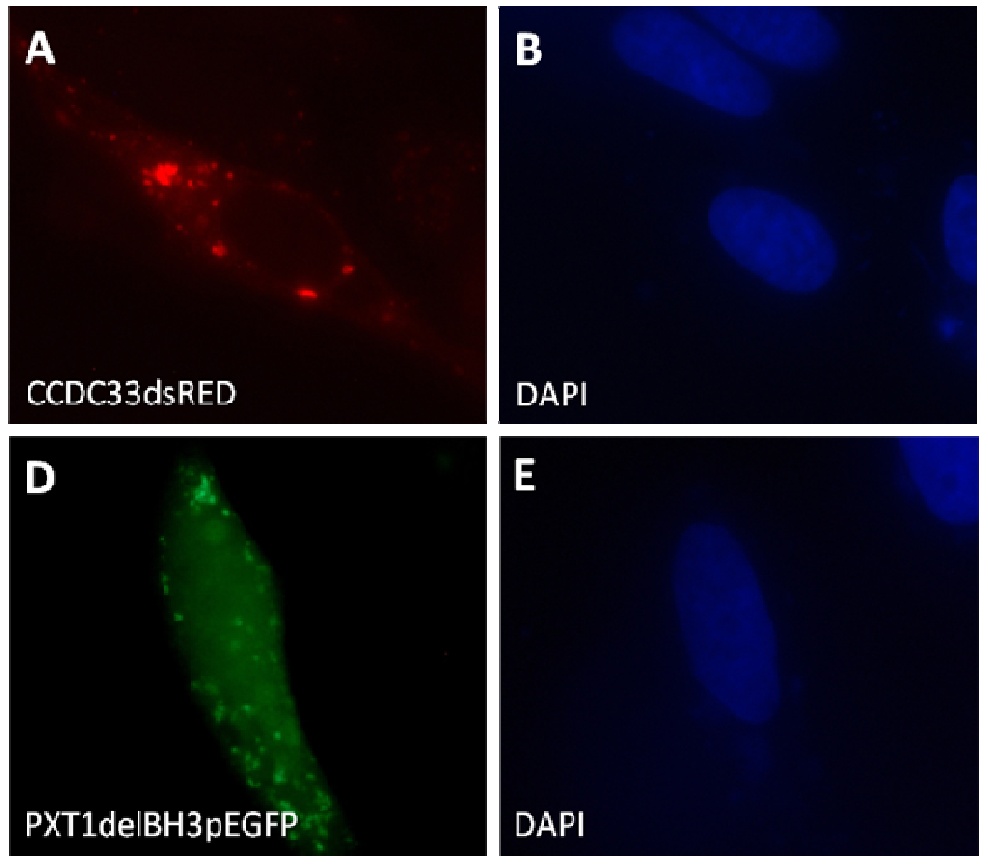

\section{Overlay}

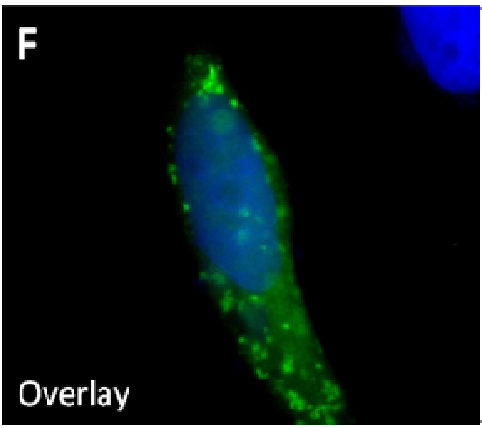

G
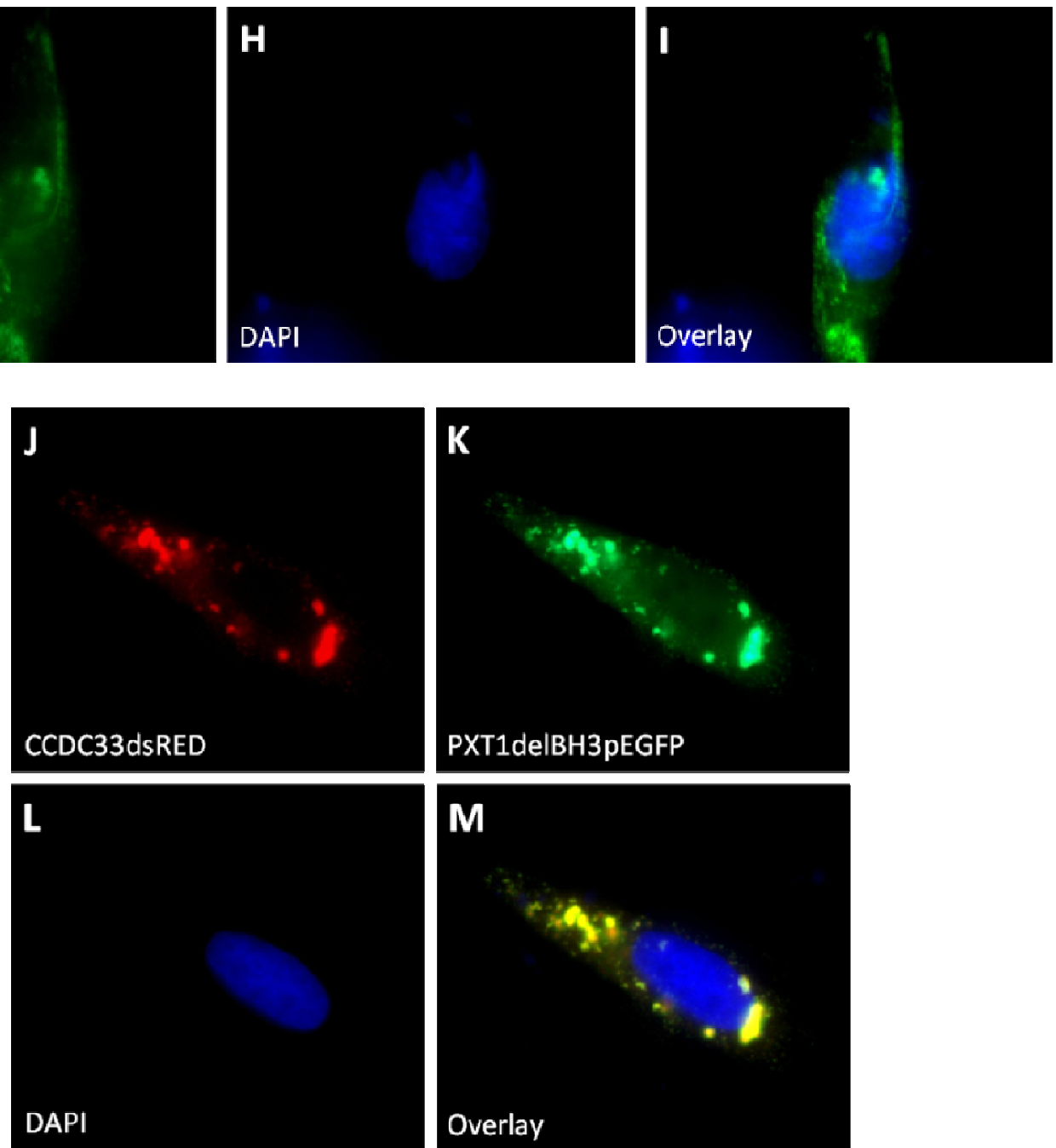

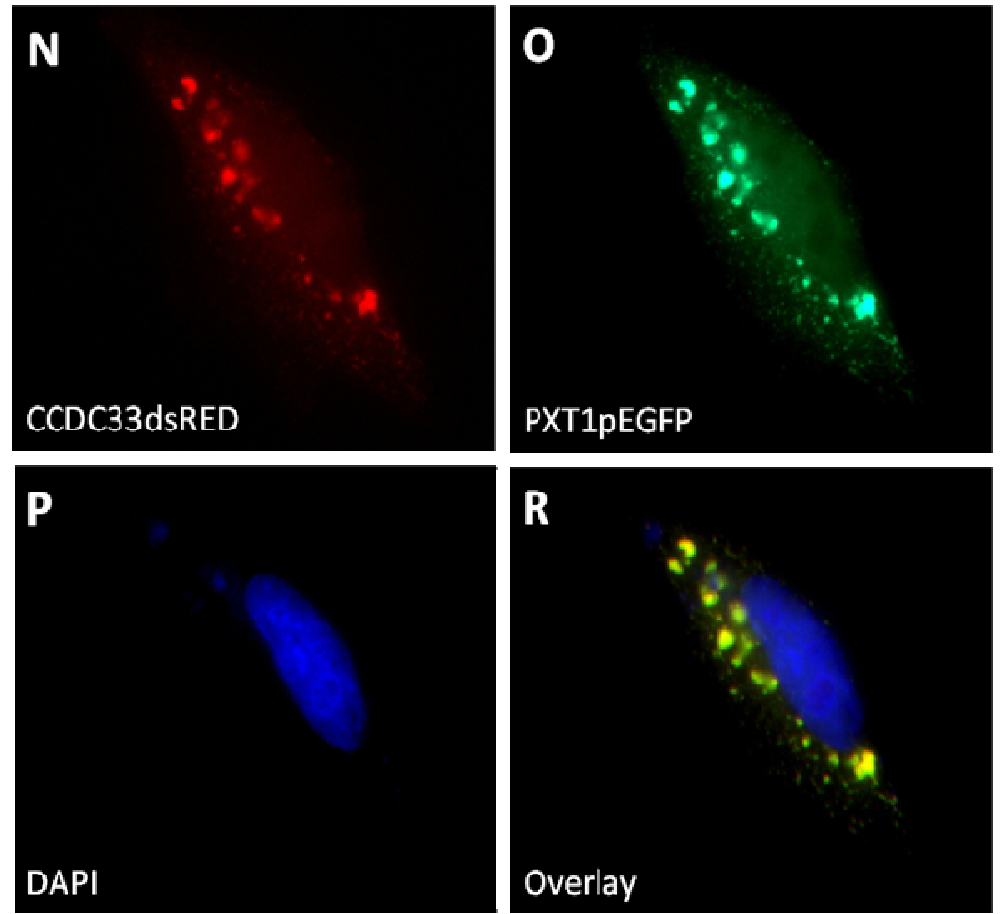

Figure 16. Transfections of HeLa cells with CCDC33dsRED, PXT1delBH3pEGFP and PXT1pEGFP constructs. The majority of cells with CCDCdsRED fusion protein (A-C, red fluorescence) and PXT1delBH3EGFP fusion protein (without the BH3 domain) (D-F, green fluorescence) demonstrated normal morphology. In contrast, cells overexpressing PXT1EGFP fusion protein (G-I) undergo apoptosis. Normal morphology was observed in cells co-transfected with CCDC33dsRED, PXT1delBH3pEGFP (J-M) and CCDC33dsRED, PXT1pEGFP(N-R). Nuclei were counterstained with DAPI (blue). This finding demonstrates that CCDC33 can suppress the pro-apoptotic activity of PXT1. 


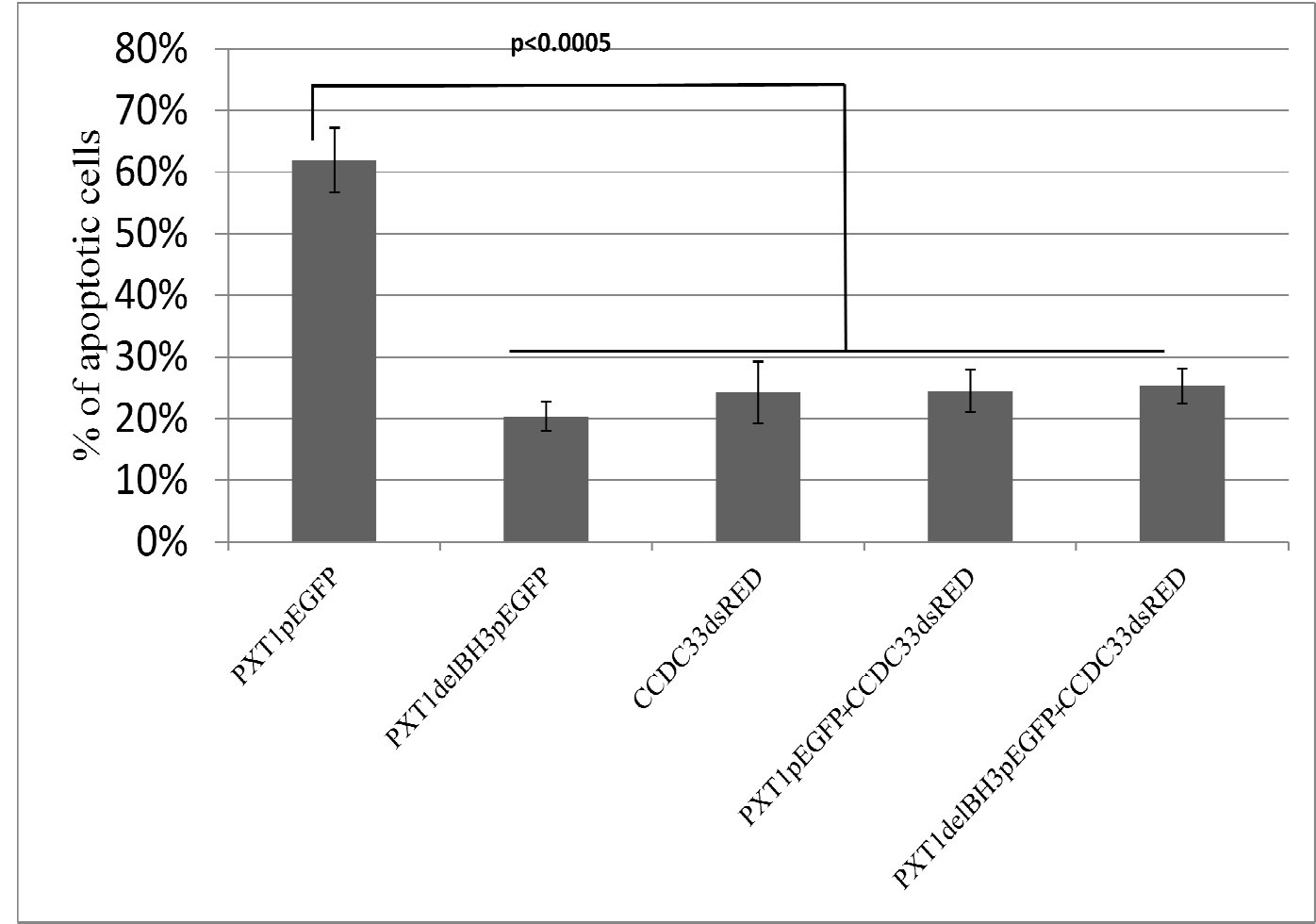

Figure 17. Quantification of apoptosis in HeLa cells transfected with CCDC33dsRED, PXT1delBH3pEGFP and PXT1pEGFP constructs. For each analysis 3 biological replicates were used. HeLa cells transfected with PXT1pEGFP construct only demonstrated significantly higher apoptosis as compared to control transfections. Apoptotic events in HeLa cells co-transfected with PXT1pEGFP and CCDC33dsRED (gray bar) were not different from the control transfections. Bars represent the mean value for the percentage of cells undergoing apoptosis, whiskers represent standard deviation.

\subsubsection{Generation of anti-CCDC33 antibody}

In order to analyse the expression of CCDC33 protein an attempt to generate antiCCDC33 antibody was undertaken. First, using the Protein-BLAST program the cDNA sequence was selected, which encodes part of the protein highly specific for the CCDC33. The chosen part of the $C c d c 33$ cDNA sequence consists of nucleotides 34-318 and is present in 3 different alternative splicing products. The selected sequence was amplified with Ccdc33MalEcoRIFP and Ccdc33MalPstIRP primers on the testicular cDNA as a template. In this RT-PCR reaction EcoRI and Pst 1 restriction sites were introduced on both ends of the product. Initially, the PCR product was cloned into pGEM-T Easy vector 
and verified by sequencing. Then, insert was isolated with EcoRI/PstI digestion and subcloned in frame into pMAL-c2x vector linearized with the same restriction enzymes. The CCDC33-pMAL vector encoding a CCDC33 protein fused with maltose binding protein (MBP) was introduced into E. coli strain BL21, then bacteria were induced by IPTG for the synthesis of the CCDC33MBP fusion protein. First, in a pilot experiment the time and temperature of the induction were checked. It could be determined that the optimal condition for protein production was $5 \mathrm{~h}$ induction by IPTG at $37^{\circ} \mathrm{C}$. Next, bacteria culture $(50 \mathrm{ml})$ was induced and after $5 \mathrm{~h}$ proteins were isolated. To control the protein production, isolated bacterial lysate was analysed in Western blot using anti-MBP Monoclonal HRP-conjugated antibody (1:40000). Blot was incubated in fresh prepared mixture of two substrates from Super Signal West Pico Chemiluminescent Substrate (Thermo Fisher Scientific) kit according to the manufacturer's instruction and exposed for 5-30 sec on X-ray films in X-ray cassette. The film was developed in X-Ray Automatic Processor Curix 60 (Agfa). Signal, $52 \mathrm{kDa}$ in size, representing the CCDC33MBP fusion protein was observed in protein extract of bacteria transformed with CCDC33pMAL construct while in control protein extract (from bacteria transformed with empty pMAL vector) a band of $42 \mathrm{kDa}$ was observed (Fig. $18 \mathrm{~A}$ ). The CCDC33MBP fusion protein was then purified from bacteria lysat using $0.45 \mu \mathrm{m}$ pores size filters and maltose column. After washing twice with column buffer, fusion protein was eluted with elution buffer I or II and dialysed in PBS overnight at $4{ }^{\circ} \mathrm{C}$ with Float-A-Lyzer G2 dialysis system (Spectra). After purification, the protein fraction was concentrated by centrifugation using CentrisartI MWCO 20000 (Sartorius) ultrafiltration system and controlled in polyacrylamid gel (Fig. 18 B). $500 \mu \mathrm{g}$ of protein was vigorously mixed with $500 \mu \mathrm{l}$ of Freud's Adjuvant. Two rabbits were then injected, one with denaturated and another with native CCDC33MBP fusion protein. 


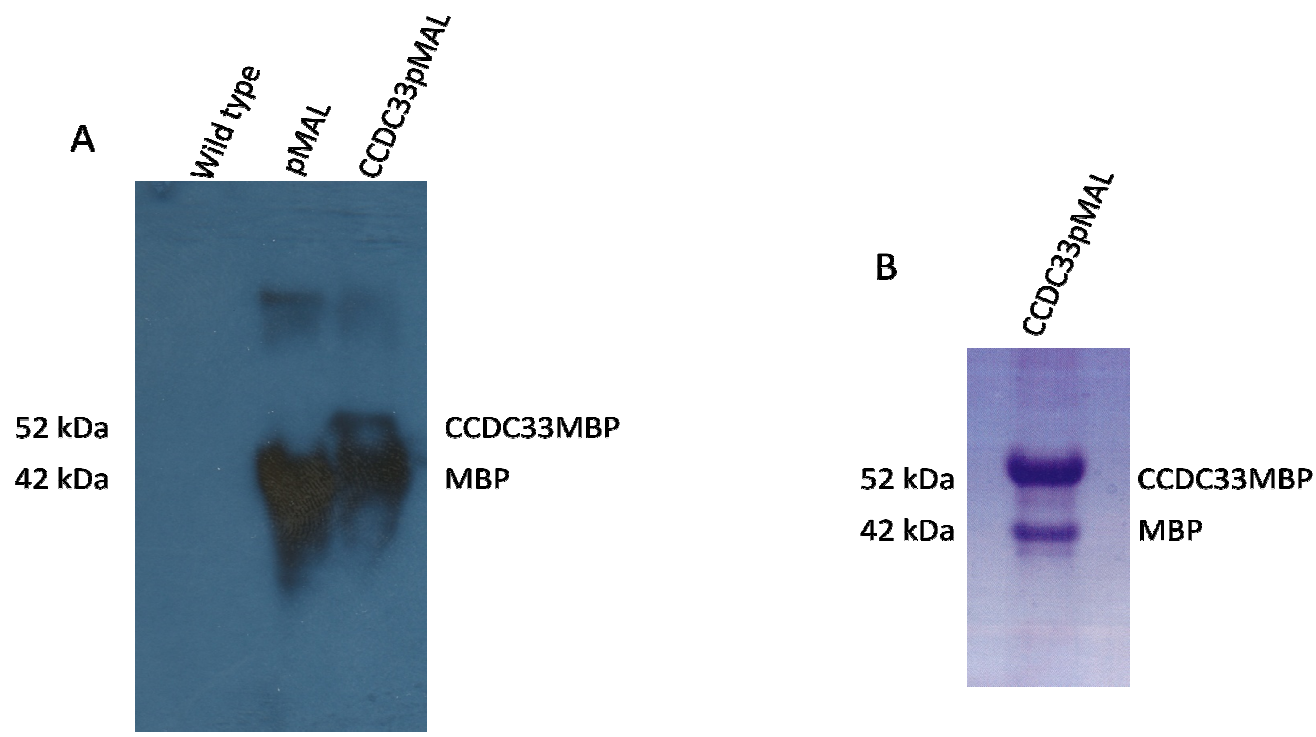

Figure 18. Western blot analysis of total protein samples isolated from IPTG induced cultures of $E$. coli BL21 strain used for CCDC33MBP fusion protein production. (A) AntiMBP antibody recognized the CCDC33MBP fusion protein of expected size $52 \mathrm{kDa}$ in the protein extract of induced bacterial cells transformed with CCDC33pMAL construct, while $42 \mathrm{kDa}$ signal representing the MBP was detected in protein extract of bacteria transformed with empty pMAL vector and CCDC33pMAL construct. (B) CCDC33MBP fusion protein was purified by maltose column, dialysed, concentrated and tested on SDS-gel. Both, MBP and CCDC33MBP are presented on gel, however CCDC33MBP fusion protein is much more abundant than MBP.

For purifciation of anti-CCDC33 antibody from rabbit's serum, the CCDC33GST fusion protein was generated. The same part of $C c d c 33$ cDNA (nucleotides 34-318) as used for generation of CCDC33MBP construct, was amplified with Ccdc33MalEcoRIFP and Ccdc33GSTPstIRP primers on testis cDNA. PCR product was cloned into pGEM-T Easy vector and sequenced. Then, insert was isolated with EcoRI and PstI enzymes and sub-cloned in frame into linearized pET-41a vector to generate the CCDC33GST construct. E. coli strain BL21 was transformed with the CCDC33GST construct. In a pilot experiment we have determined that the effective protein production can be obtained after $5 \mathrm{~h}$ of IPTG induction at $37^{\circ} \mathrm{C}$. To control the protein production, isolated bacterial lysate was analysed in Western blot using anti-Gluthatione-S-Transferase (1:1000) and anti- 
mouse HRP conjugated (1:5000) antibodies (Fig. 19). Blot was incubated in a mixture of two substrates from Super Signal West Pico Chemiluminescent Substrate (Thermo Fisher Scientific) kit according to the manufacturer's instruction and exposed for 5-30 sec on Xray films in X-ray cassette. The film was developed in X-Ray Automatic Processor Curix 60 (Agfa). Single signal, $46 \mathrm{kDa}$ in size, representing the CCDC33GST fusion protein was observed in protein extract of bacteria transformed with CCDC33pET-41a construct (Fig. 19). After producing the CCDC33GST fusion protein in the main culture, the fusion protein from the bacteria lysate was purified using sepharose column, dialysed with FloatA-Lyzer G2 dialysis system (Spectra) and concentrated with CentrisartI MWCO 20000 (Sartorius) ultrafiltration system. For anti-CCDC33 antibody purification, the purified CCDC33GST fusion protein was applied on the Hi-Trap column. Then, $10 \mathrm{ml}$ of the rabbit serum (2 times diluted in PBS), obtained from rabbit after immunisation with CCDC33MBP fusion protein, was loaded onto this column, washed with PBS and finally antibody was eluted with $3 \mathrm{ml}$ of Immunopure IgG Elution Buffer (Pierce) and neutralized with $3.5 \mu \mathrm{l}$ of $1 \mathrm{M}$ Tris/ $\mathrm{HCl} \mathrm{pH}$ 7.5. After elution, purified anti-CCDC33 antibody was used in further analyses.

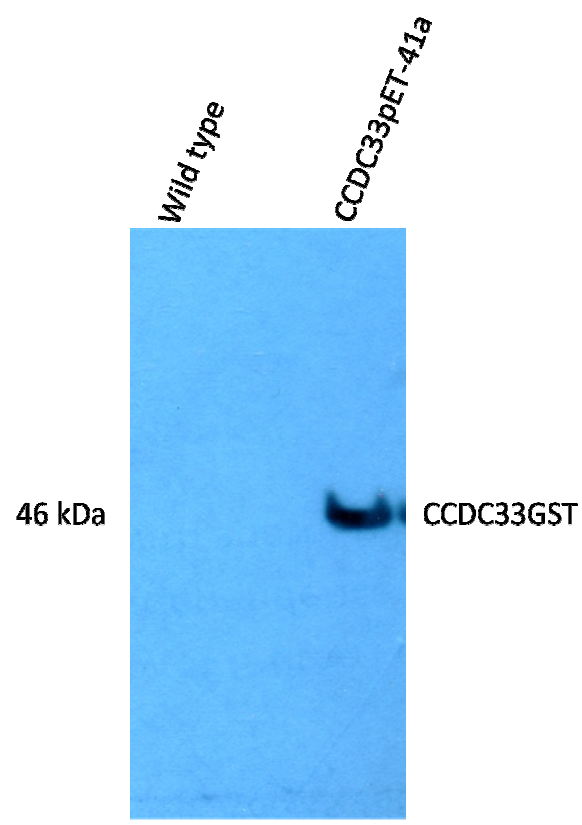

Figure 19. Western blot analysis of total protein sample from IPTG induced cultures of $E$. coli BL21 strain transformed with CCDC33GST construct. Anti-GST antibody detected the fusion protein, $46 \mathrm{kDa}$ in size, in the protein lysat of induced bacteria. 


\subsubsection{The analysis of the specificity of anti-CCDC33 antibody}

During the generation of the anti-CCDC33 antibody two commercial antibodies appeared available and have been purchased. Thus all together four different antiCCDC33 antibodies were tested: generated against the native CCDC33MBP fusion protein, against the denaturated CCDC33MBP fusion protein (both proteins containing amino acids 12-106), anti-mouse CCDC33 from Santa Cruz Biotech. (Kat. Number sc134633) (against amino acids: 408-637) and anti-human CCDC33 from Sigma (Kat. Number HPA038628) (against amino acids: 626-689) (Fig. 20). It should be noted that the region of amino acids 562-666 (NCBI ref.seq. AAH31684.1) of human CCDC33 demonstrates high similarity with amino acids 626-689 of the mouse CCDC33 (NCBI Ref. Seq. NP_083488), thus the one could expect the reactivity of antibody generated against human protein with mouse protein.

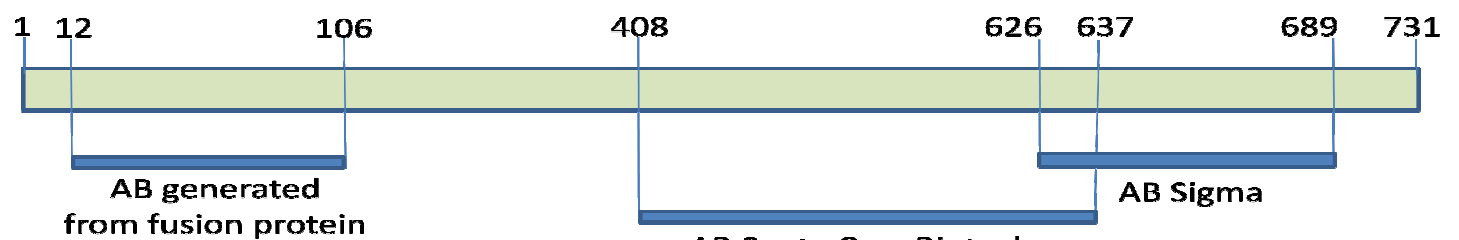

AB Santa Cruz Biotech.

Figure 20. Scheme of CCDC33 and localisation of epitopes for different anti-CCDC33 antibodies. Significant amino acids positions are given according to the NCBI Ref. Seq. NP_083488. AB - antibody.

To analyse whether the antibodies generated against the CCDC33MBP fusion protein can recognize CCDC33 protein, CCDC33ex6-8dsRED construct encoding amino acids 1-80 of mouse CCDC33 was generated. Fragment of $C c d c 33$ cDNA was amplified in PCR reaction with CCDC33-E6-8dsREDFP and CCDC33-E6-8dsREDRP primers. Next, purified PCR products were cloned into the pGEM-T Easy vector and sequenced. Then, appropriate inserts were isolated and sub-cloned in frame into pDsRed-MonomerN1 vector using EcoRI and BamHI restriction sites. Finally, constructs were verified by sequencing. To analyse antibodies purchased from Santa Cruz Biotechnology and from 
Sigma, CCDC33dsRED construct prepared by Kaczmarek (Kaczmarek et al., 2009), which encodes amino acids 264 to 723 , was used.

To check the reactivity and specificity of all the anti-CCDC33 antibodies HeLa cells were transfected with CCDC33ex6-8dsRED or CCDC33dsRED construct. Specificity was controlled in comparison to cells transfected with empty pDsRedMonomer-N1 (dsRED) vector. After fixation in 4\% paraformaldehyde with Tween 20, cells were probed with anti-CCDC33 antibody (for denaturated, native and Santa Cruz Biotech. antibody the dilution was 1:500 and for Sigma 1:50) and secondary anti-rabbitFITC conjugated antibody (1:500 or for Sigma 1:300). Nuclei were counterstained with DAPI. In figure 21 red signals represent both CCDC33dsRED fusion proteins or dsRED fusion protein and green signals recognizes the protein stained by particular antibody tested. As visualised in $\mathrm{C}, \mathrm{I}, \mathrm{O}$ and $\mathrm{U}$ all antibodies recognized the appropriate CCDC33dsRED fusion proteins (Fig. $21 \mathrm{C}$, I, O, U; overlay with DAPI) while no signal was observed in cells expressed the dsRED protein (Fig. 21 F, L, R, Y; overlay with DAPI).

\section{Anti-CCDC33 (native)}
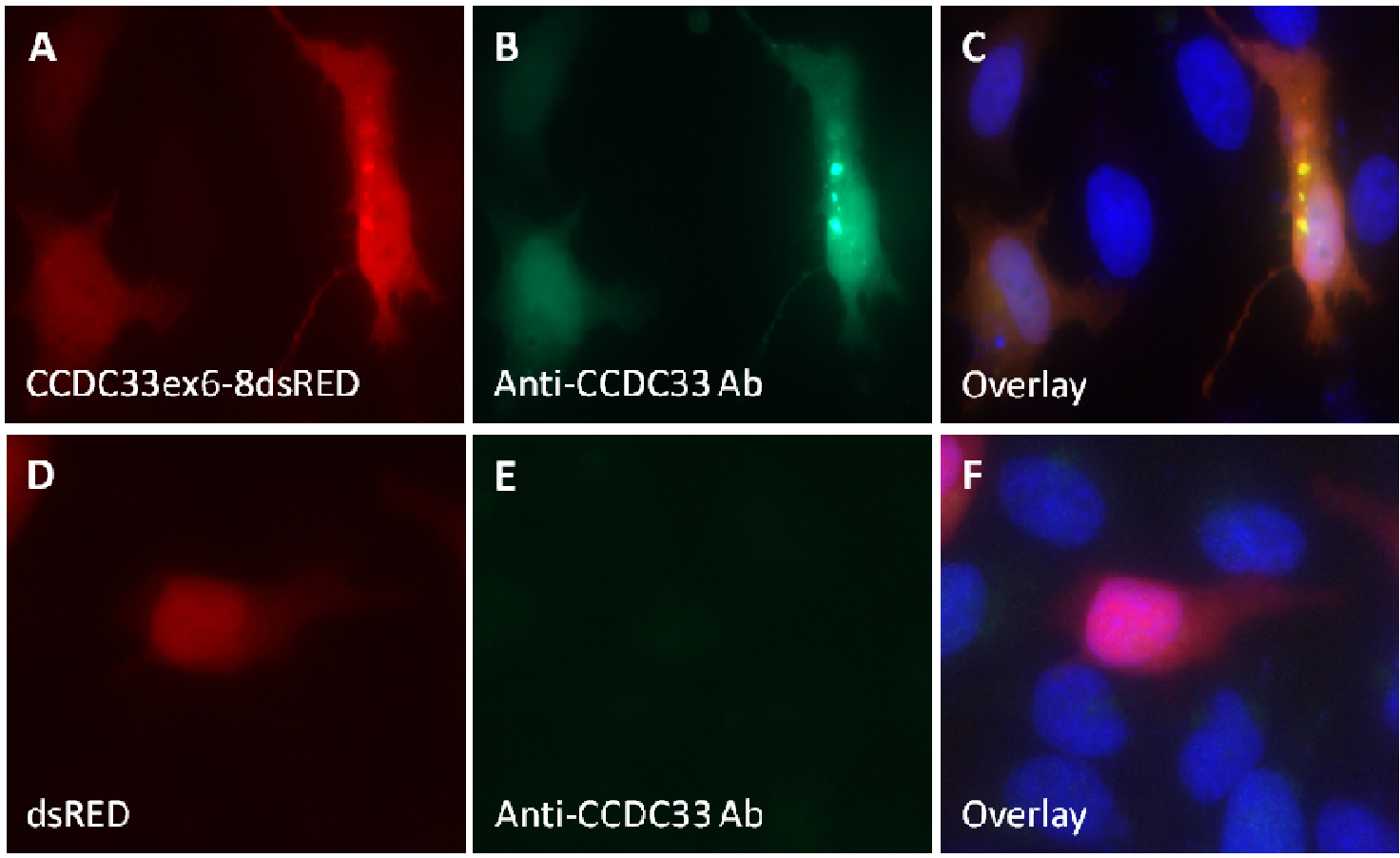
Anti-CCDC33 (denaturated)

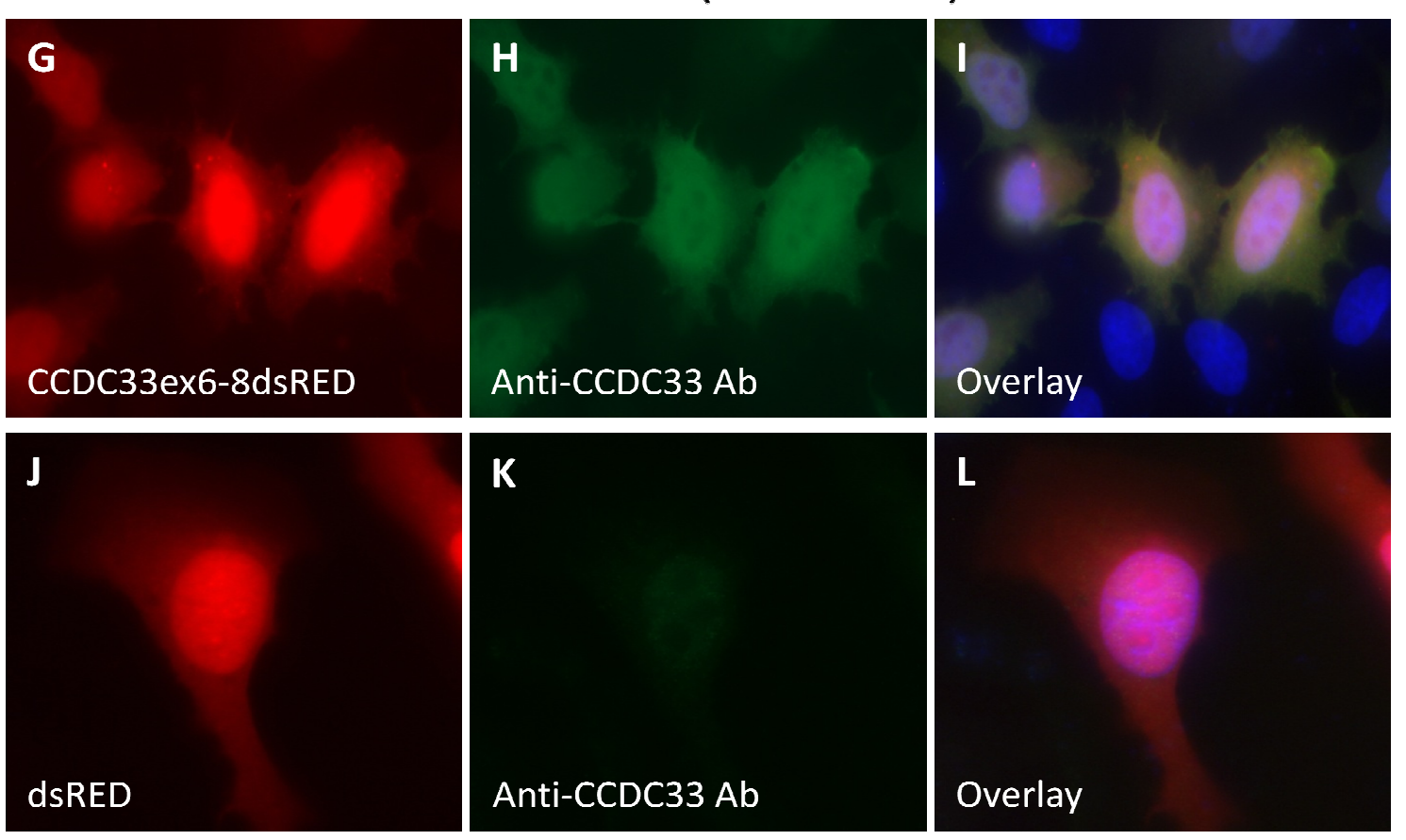

Anti-CCDC33 (Santa Cruz Biotech.)

\begin{tabular}{|l|l|l|l|}
\hline $\mathbf{M}$ & $\mathbf{N}$ & \\
\hline CCDC33dsRED & Anti-CCDC33 Ab & Overlay \\
\hline $\mathbf{P}$ & $\mathbf{Q}$ & $\mathbf{R}$ \\
\hline dsRED & Anti-CCDC33 Ab & Overlay \\
\hline
\end{tabular}


Nnti-human CCDC33 (Sigma)
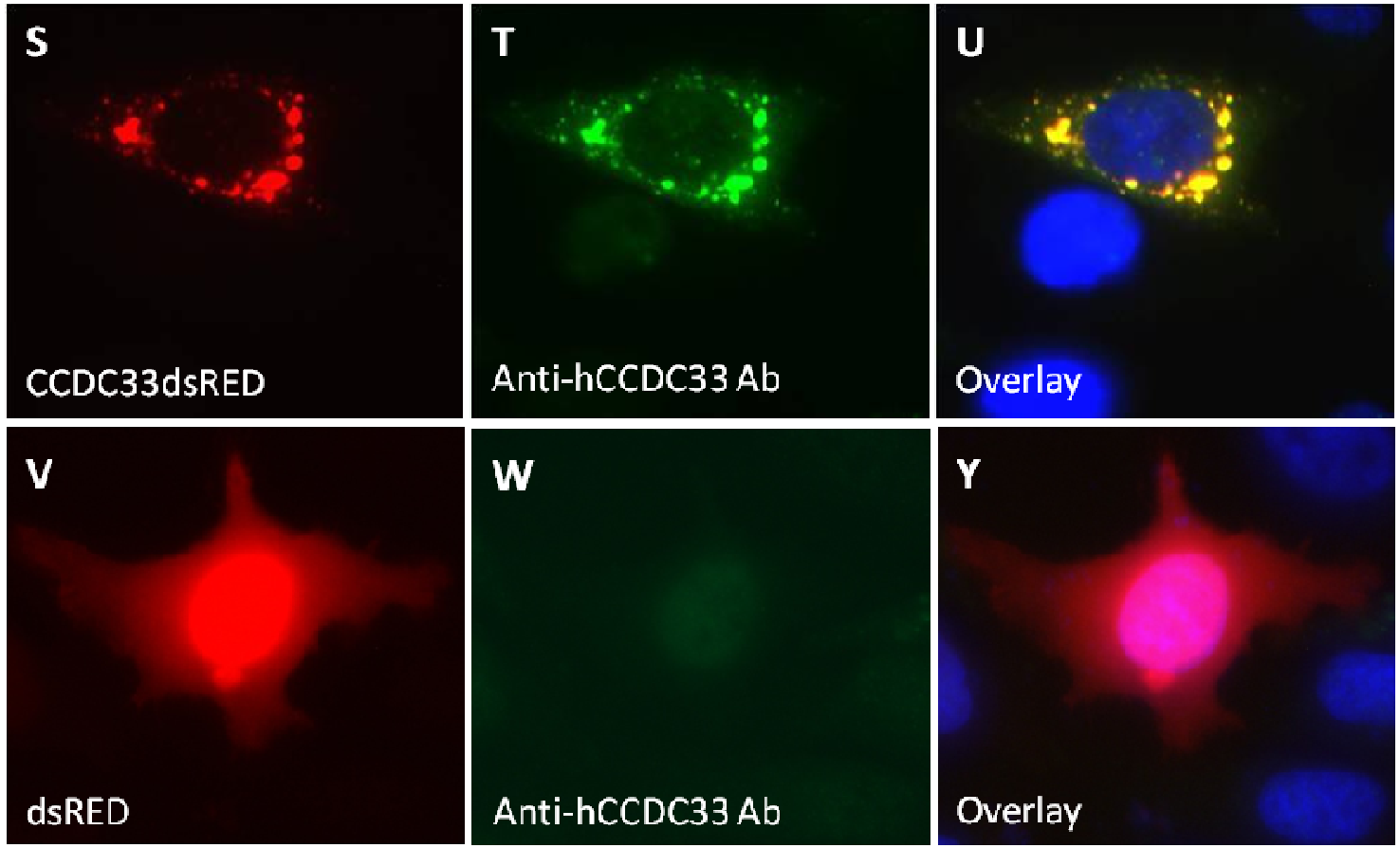

Figure 21. Analysis of different anti-CCDC33 antibodies. HeLa cells were transfected with CCDC33ex6-8dsRED to analyse the antibody generated against CCDC33-MBP fusion protein (A-C and G-I) and CCDC33dsRED (containing exons 14-24 of mouse Ccdc33 gene) to analyse both commercial antibodies. As a specificity control HeLa cells were transfected with empty pDsRed-Monomer-N1 vector (dsRED). After fixation cells were probed with rabbit anti-CCDC33 antibody and secondary anti-rabbit-FITC conjugated antibody. Red signals represent the CCDC33dsRED fusion protein, green signals the protein stained with antibody. Nuclei were counterstained with DAPI. As visualised in $\mathrm{C}, \mathrm{I}, \mathrm{O}$ and $\mathrm{U}$ all antibodies specifically recognize the CCDC33dsRED fusion protein while no signal is observed in cells expressing the dsRED protein $(F, L, R, Y)$.

To analyse translation of $C c d c 33 \mathrm{RNA}$, proteins were isolated from murine tissues with lysis buffer I - VII according to different protocols (protein isolation from tissue I, II and III described in part 2.2.13.1) and all anti-CCDC33 antibodies were tested by Western blot. Western blots incubated with antibodies generated against fusion protein showed, among others, band with size about $65 \mathrm{kDa}$, which could represnts CCDC33 (Fig. $22 \mathrm{~A}$ and B). But, every time, in different conditions of protein isolation (different buffers, 
centrifugation speed, sonication) and blotting (different types of membrane (PVDF or nitrocellulose), blocking solutions (BSA or Milk powder), different antibodies concentration or developing time, a lot of unspecific bands were also observed. Unfortunately, also for antibody from Santa Cruz Biotechnology (Fig. 22 C), it was not possible to optimize the Western blot condition to get specific signal. Therefore, these antibodies were not used for further analyses.
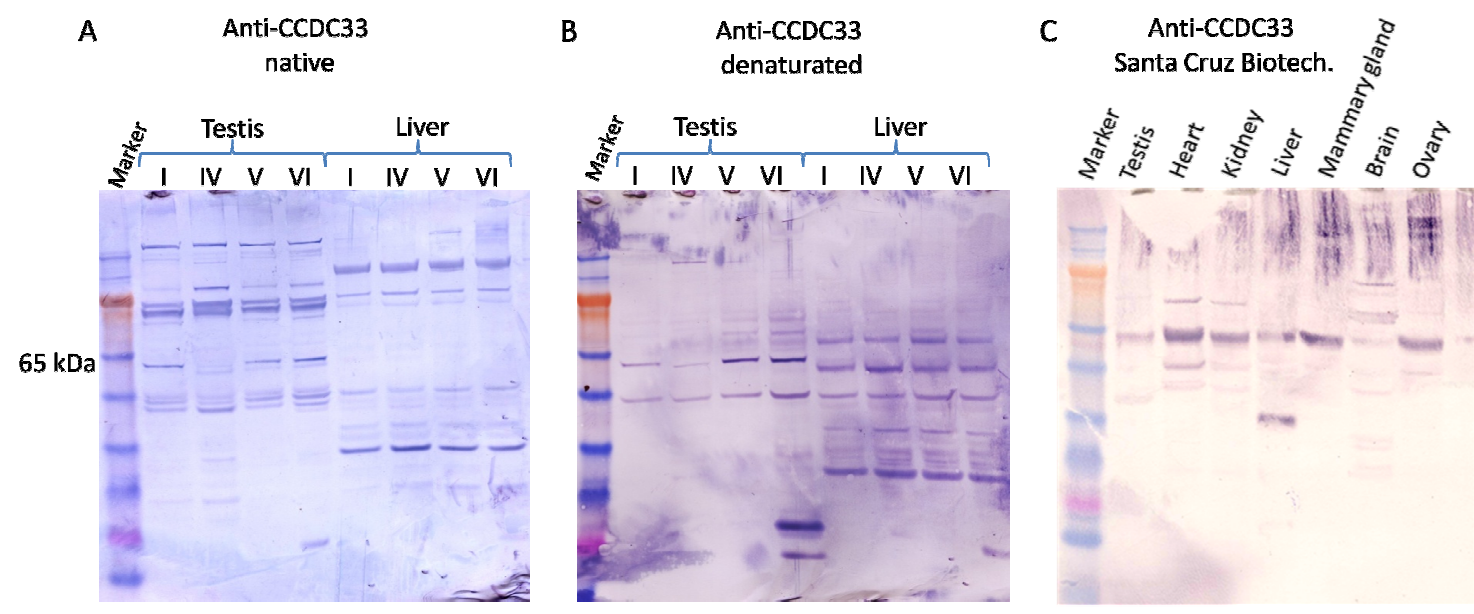

Figure 22. Examples of CCDC33 protein analysis with different anti-CCDC33 antibodies. Total proteins were isolated in different conditions: figures A and B: lysis buffer I; IV; V and VI, procedure II for protein isolation (2.2.13.1); figure C: lysis buffer I and procedure I for protein isolation. Then Western blots was incubated with anti-CCDC33 antibody produced from native (A) and denaturated (B) CCDC33MBP fusion protein and (C) with anti-CCDC33 obtained from Santa Cruz Biotechnology. In figure A and B, 65 kDa band could represents CCDC33. Since it was not possible to optimize the Western blot condition these antibodies were not used for further analyses.

Positive results were obtained only from protein isolated with buffer I/procedure I, subjected to SDS-page electrophoresis, blotted on nitrocellulose membrane and incubated with rabbit antibodies against human CCDC33 protein (Sigma, 1:1000) and anti-rabbit alkaline phosphatase conjugated secondary antibodies (1:5000). Single band around 65 $\mathrm{kDa}$, which represents CCDC33, was observed only in testis (Fig. 23 A). In proteins isolated from testis, brain, spleen and lung smaller band was obtained. This signal partially correlates with the expression pattern analysed by PCR with primers for exons 
23-24 (Fig. 23 B). This might suggest that this shorter form represents a product of alternative splicing, however further analyses are needed to confirm this hypothesis. Then human anti-CCDC33 antibody was used to analyse the expression of mouse CCDC33 protein during spermatogenesis. Proteins were isolated from testis of males at 10, 15, 16, 17, 18, 19, $20 \mathrm{dpp}$ and adult mice and tested in Western blot. Very weak expression of CCDC33 protein was detected at $16 \mathrm{dpp}$, in testes of older animals the CCDC33 expression was stronger (Fig. 23 C). The expression of $C c d c 33$ exons 23-24 was analysed by RT-PCR with primers CCDC33ex23F and CCDC33ex24R and RNA isolated from testes of animals at different ages post partum. Corresponding to the protein expression results, strong transcription of $C c d c 33$ was detected from $16 \mathrm{dpp}$. It should be noted that a very weak, almost undetectable expression was also observed in earlier stages (Fig. 23 D).
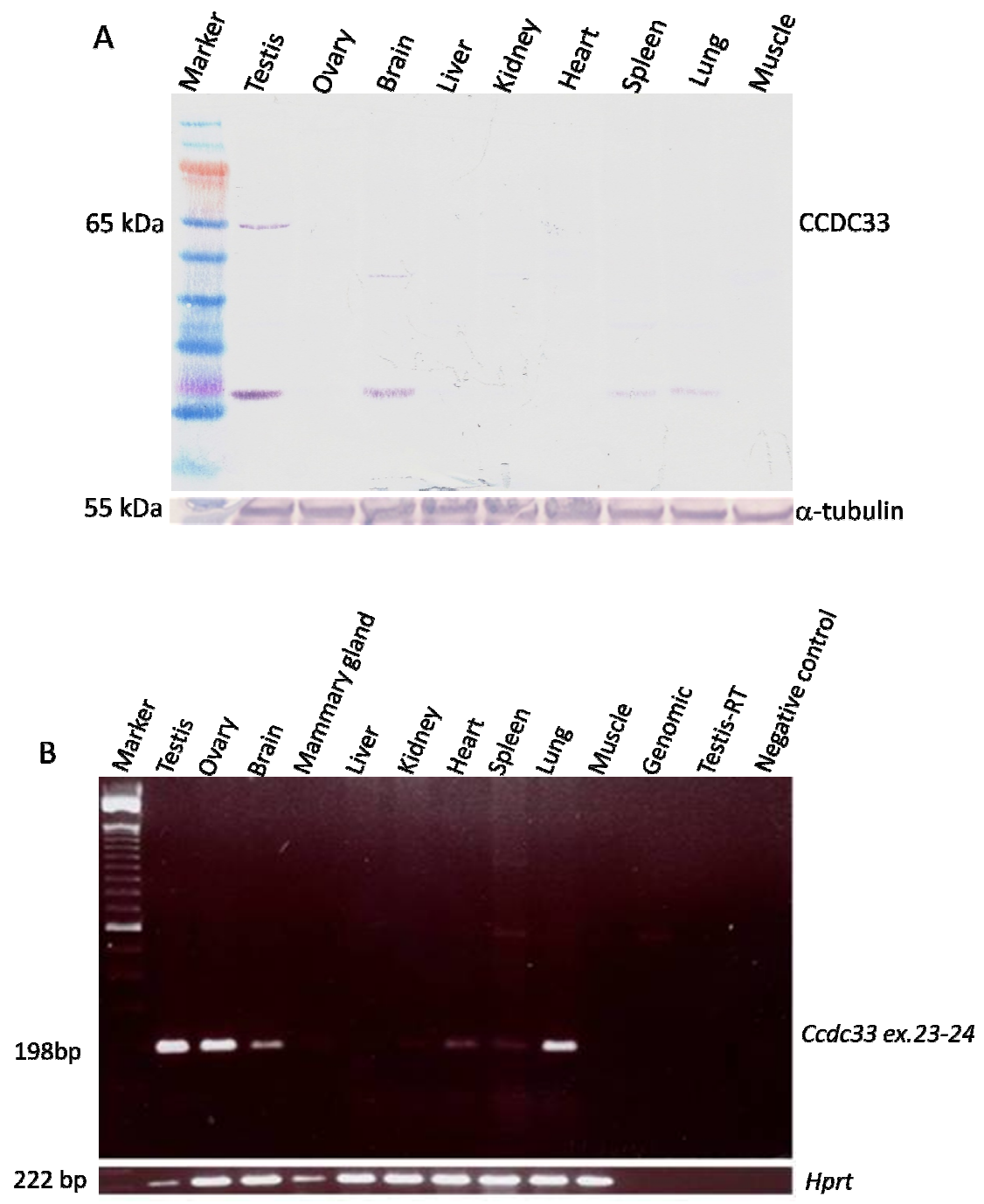
C

testis
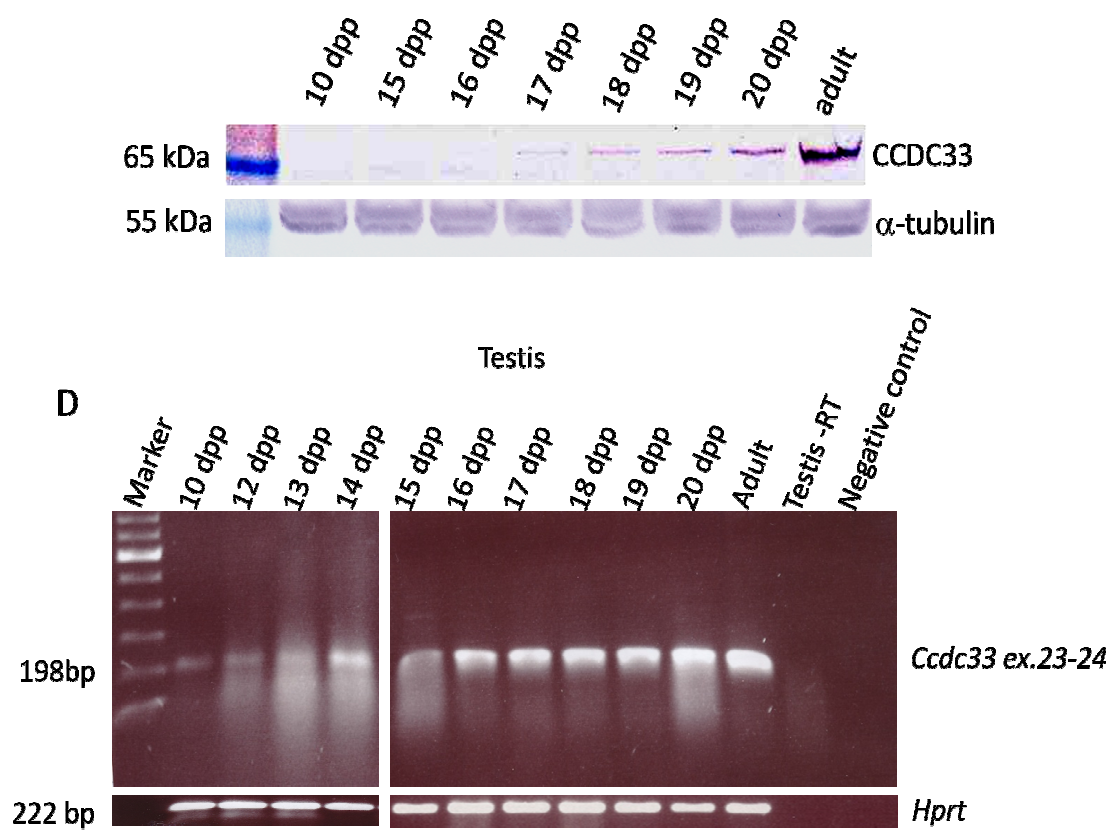

Figure 23. CCDC33 protein and mRNA analysis. (A) The long form of CCDC33 protein (65 kDa) was detected only in testis. Smaller band was detected in testis, brain, spleen and lung. The $C c d c 33$ transcript was also detected in these organs (B). (C) Mouse CCDC33 protein was detected in testis from 16 dpp. (D) Strong transcript of Ccdc33 (exons 23-24) was observed in testis isolated from mice at 16dpp and older. Protein quality was verified using anti- $\alpha$-tubulin antibody, cDNA quality was demonstrated by PCR reaction using Hprt specific primers. Testicular sample without the use of reverse transcriptase (-RT) was used to check $C c d c 33$ primer specificity.

Next, the immunohistochemistry with anti-CCDC33 antibody from Sigma was applied to analyse in which testicular cells of the mouse CCDC33 is present. Testes were isolated from males at 10 and $15 \mathrm{dpp}$ and from adult animals. Paraffin sections were immunostained as described in 2.2.15.4. After re-hydration in a decreasing ethanol series and washing in PBS, slides were boiled in a microwave two times for $5 \mathrm{~min}$ in $10 \mathrm{mM}$ sodium citrate pH6.0 and then incubated with a blocking solution containing $2 \%$ sheep serum and $5 \%$ triton X-100 in PBS for $1 \mathrm{~h}$ at RT. Then, slides were incubated with antiCCDC33 Sigma antibody (1:1000) overnight at $4^{\circ} \mathrm{C}$ and next day, after washing, slides were incubated with anti-rabbitCy3-conjugated antibody (1:1000) and mounted with DAPI. 
In adult testis a punctual pattern of red signals was observed in cytoplasm of spermatocytes whereas no staining was detected in testis of a male at $10 \mathrm{dpp}$ (Fig. 24). In the testis of $15 \mathrm{dpp}$ male early spermatocytes were stained (Fig. 24), however these signals seems to be not specific, because in Western blot experiment no positive signal was observed in proteins isolated from testis at $15 \mathrm{dpp}$ (Fig. $23 \mathrm{C}$ ).
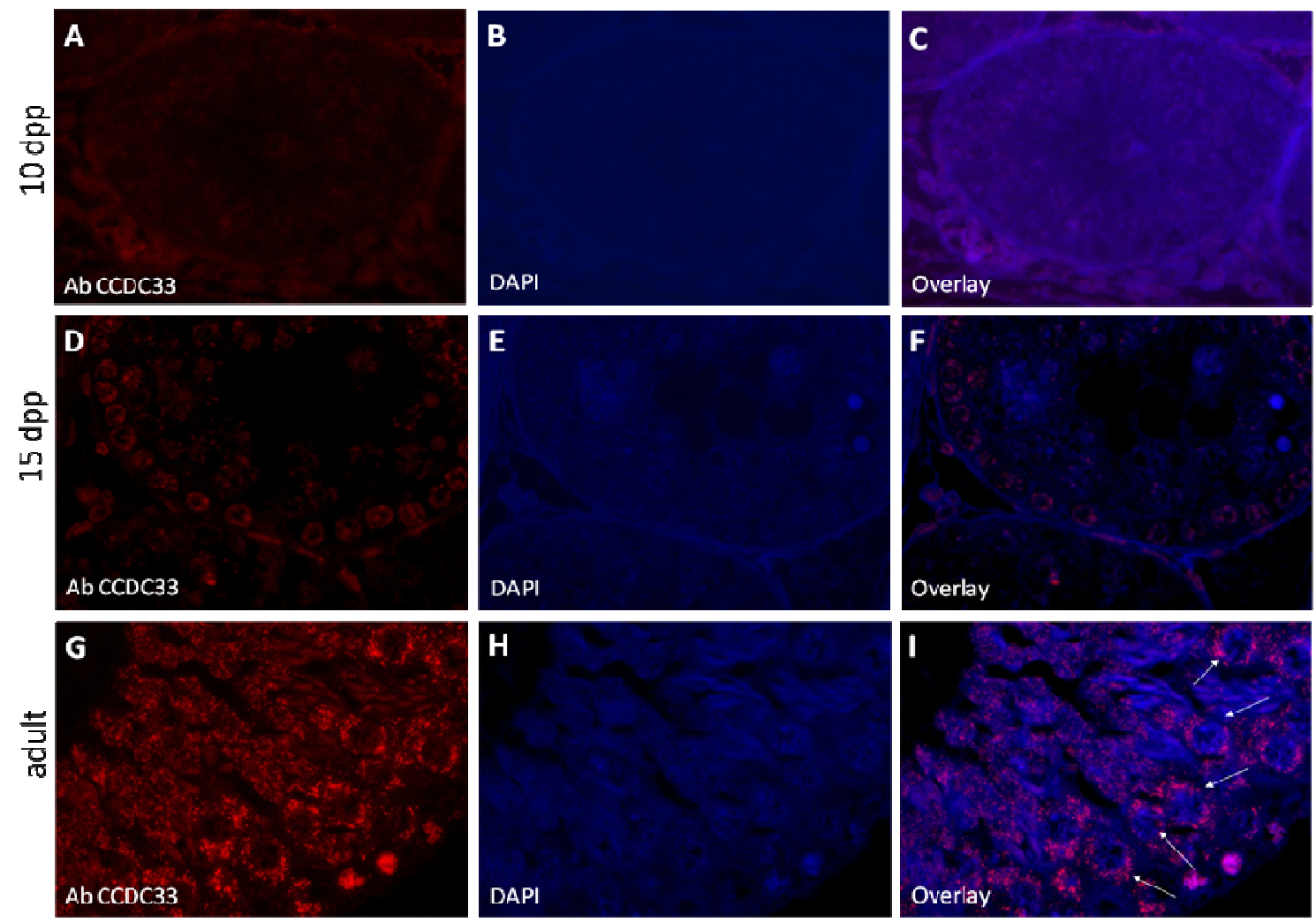

Figure 24. Immunohistochemistry of $10 \mathrm{dpp}$ (A-C), $15 \mathrm{dpp}$ (D-F) and adult (G-I) testis with anti-CCDC33 antibody. Red signals representing the CCDC33 protein were observed in late spermatocytes in adult testis (arrows), but no specific signals were observed in testis at 10 and 15 dpp.

\subsubsection{Generation of $C c d c 33$ - deficient mice}

To further analyse the function of mouse $C c d c 33$ gene, the knockout strategy was used to generate $C c d c 33$ deficient mouse using homologous recombined ES cells (C57bl) from Velocigene Regeneron Pharmaceuticals Inc. (2.2.17). In this recombinant ES-cell 
line exons 6 to 11 of mouse $C c d c 33$ (25398bp) are replaced by the neo cassette. These exons are present in three alternative splicing forms of $C c d c 33$ (Kaczmarek et al., 2009).

Before microinjection, the deletion in Ccdc33 gene was verified in ES cells by qPCR as described 2.2.17 using TDF; TDR and TUF, TUR primers. These primers are located upstream (TUF, TUR) and downstream (TDF, TDR) of the deleted genomic region. To determine the number of copies of exons 6-11 of the $C c d c 33$ gene present in the recombinant ES-cells the cT value of the $C c d c 33$ product was compared with the cT value for the mouse pelota homolog gene (Pelo) product amplified with PCR-Pelo-F and PCR-Pelo-R primers. The Pelo gene is present as a single copy in mouse genom (2 alleles) (Shamsadin et al., 2002), thus the ratio of cT value for $C c d c 33$ and cT value for Pelo should be 1 by wild type DNA and 0.5 in DNA with the deletion of one copy of Ccdc33 gene after homologous recombination.

DNA was isolated from ES cells as described in 2.2.1.1. qPCR confirmed that obtained ES cells contain indeed only one copy of the genomic region spanning exons 611 of the $C c d c 33$ gene as a result of homologous recombination (Fig. 25). These ES cells were injected into blastocysts derived from C57B1/6J mouse strain in Max Planck Institute for Experimental Medicine in Göttingen. The blastocysts were then transferred into pseudopregnant CD1 females.
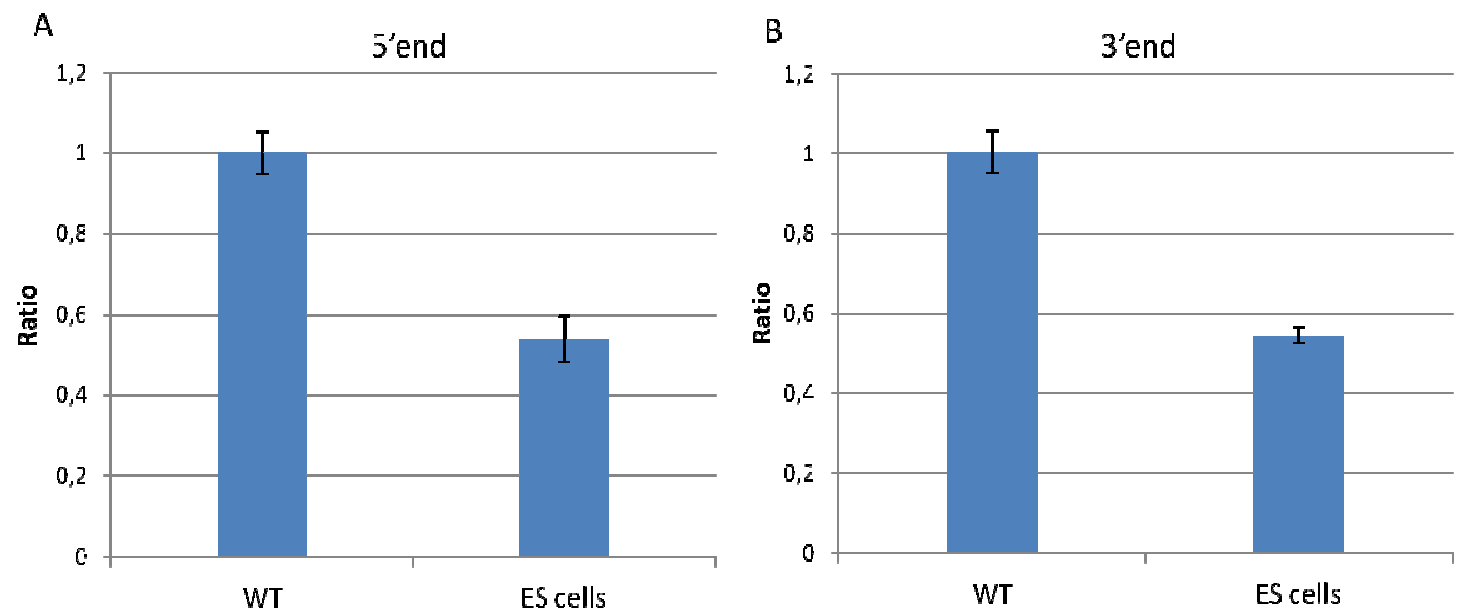

Figure 25. qPCR results of genotyping of homologous recombinant ES cells with the deletion within the Ccdc33 gene. While in wild type (WT) control the ratio of cT-Ccdc33 to cT-Pelo is close to 1 , in recombinant ES-cells the ratio is close to 0.5 , indicating that only one copy of Ccdc33 is present in the genome of these cells. (A) Genomic region located at the 5'end 
(primers TUF and TUR) and (B) 3'end (TDF and TDR) of the deleted sequence was analysed. Bars represent the mean value for the ratio, whiskers represent standard deviation.

The microinjection of recombinant ES-cells into blastocysts was performed 3 times. Together, I obtained 46 animals, which were genotyped by PCR with primers SDF, SD, NeoInF amplifying a 668 bp PCR product on wild (WT) type allele and a 400 bp product on recombinant $(\mathrm{KO})$ allele at the 5 ' region of the recombinant site and SU, SUR, LacInZRev primers, amplifying a 293 bp product on WT and 400 bp product on KO allele at the 3' end (Fig. 1). 4 male chimeras and 5 female chimeras were identified (Fig. 26).

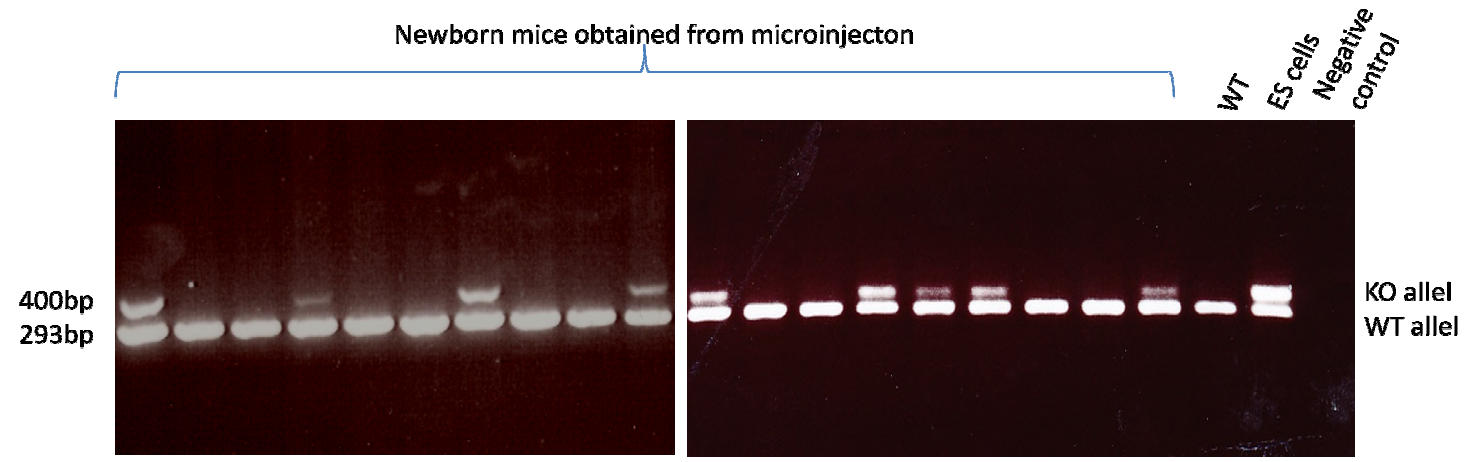

Figure 26. Sample of genotyping PCR of $C c d c 33$ chimeras. DNA isolated from mice obtained after microinjection was subjected to PCR genotyping. As a negative control DNA isolated from wild type mouse and as a positive control DNA of recombinant ES-cells was used. 9 chimeras were detected by PCR analysis.

First male chimera died with the age of 8 weeks, but three other male chimeras could be intercrossed with C57Bl females for a period of three months. During this time 14 pups were obtained from chimera nr 1 and 26 pups from chimera nr 2. All newborn animals were genotyped by PCR with the same primers as used for chimera genotyping, but none of them was heterozygous (sample of genotyping presented in figure 27 A-D). To further analyse whether the male chimeras can produce any sperm carying recombinant allele, both fertile male chimeras were crossed with wild type females and vaginal plug (VP) was daily checked. VP positive females were killed and spermatozoa 
were washed from the vagina and uterus. Sperm was stained with DAPI. DNA isolated from these sperm, was subjected to genotyping PCR reaction. In sperm of both male chimeras only the wild type PCR product was detected (Fig. 27 E-H). Thus we concluded that they do not transmit the recombinant allel.
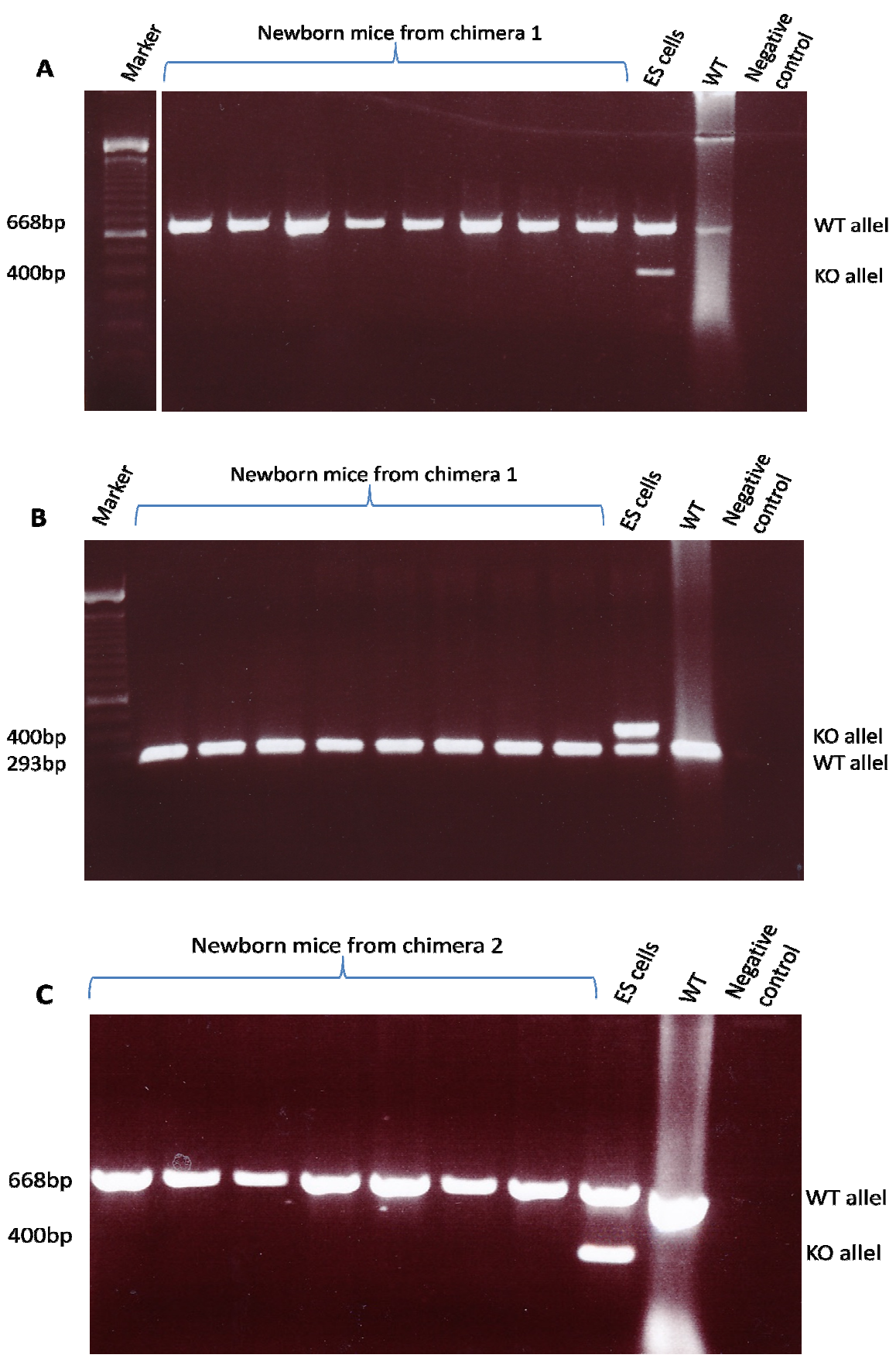

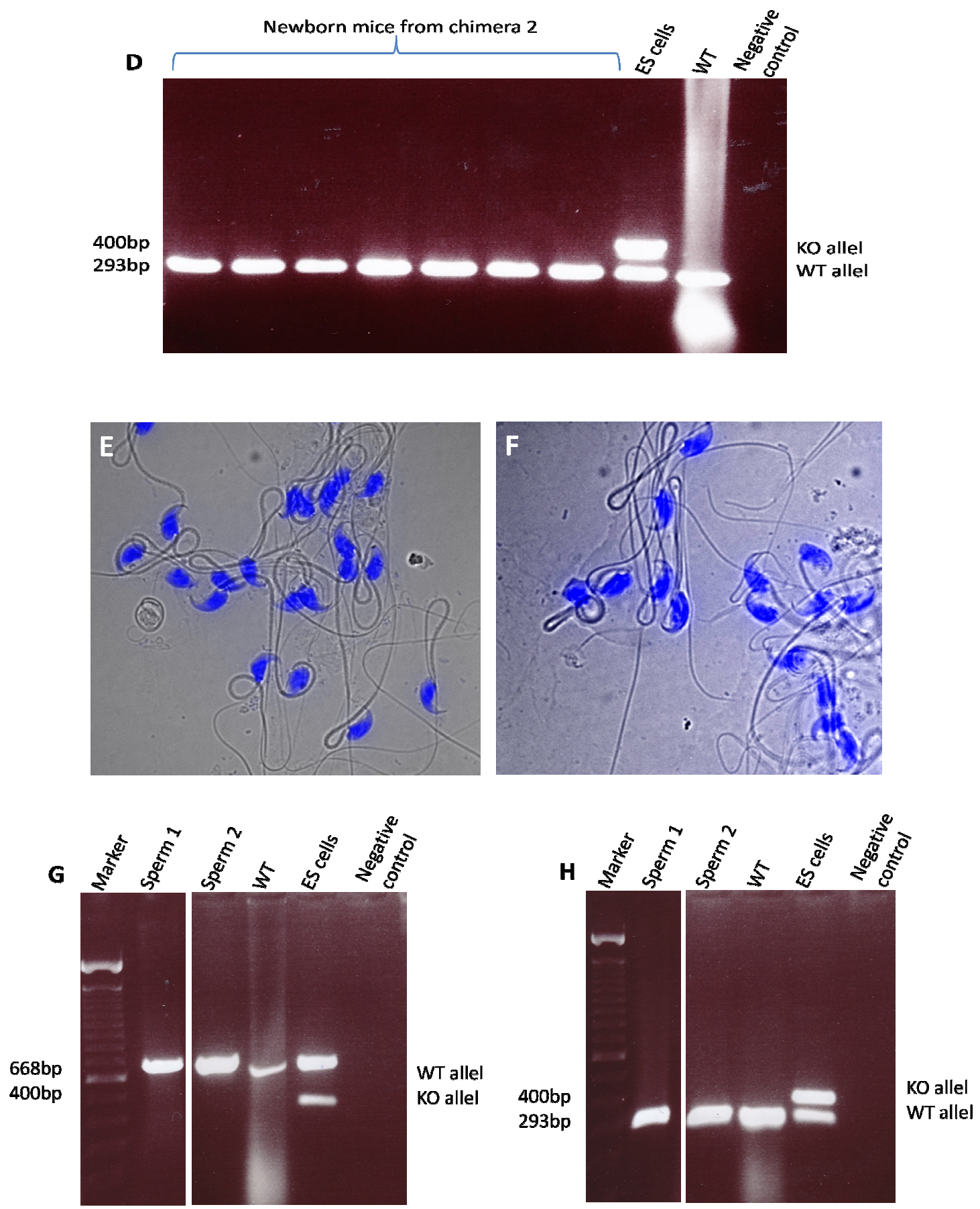

Figure 27. Offspring and spermatozoa analysis of two male chimeras. (A-D) Example of genotyping PCR results of pups obtained after breeding the male chimeras number 1 and 2 with wild type C57Bl female. (E-H) Spermatozoa isolated from vagina and uterus of a VP positive female mated with chimera 1 (E) or chimera 2 (F) were genotyped by PCR at the 5, and 3' end of the recombination site. Only the PCR product representig wild type allele was detected. As a positive control DNA isolated from recomabinant ES-cells was used. For 
negative control DNA from wild type mouse was analysed. Sperm 1, sperm 2 - spermatozoa isolated from the vagina and uterus of VP positive female mated with male chimera number 1 or number 2 , respectively.

Thereafter, two male chimeras (number 1 and 2) were killed and DNA isolated from different organs and from epididymal spermatozoa was genotyped by PCR. Genomic DNAs were isolated from testis, brain, liver, kidney, spleen and lung as described in 2.2.1.1. Sperm were isolated from epididymes as described in 2.2.18.1. Genotyping PCR was performed using SD-F; SD, NeoInF (Fig. 28 A) and SU, SU-R, LacInZRev (Fig. 28 B) primers. In all organs analysed, PCR products representing both, the wild type and the recombinant alleles, were observed. Also in epididymal spermatozoa a weak band, representing the recombinant allele was detected (Fig. $28 \mathrm{C}$ D). This finding suggests, that CCDC33-deficient spermatozoa are not able to reach uterus or the percentage of recombinant spermatozoa is very low.

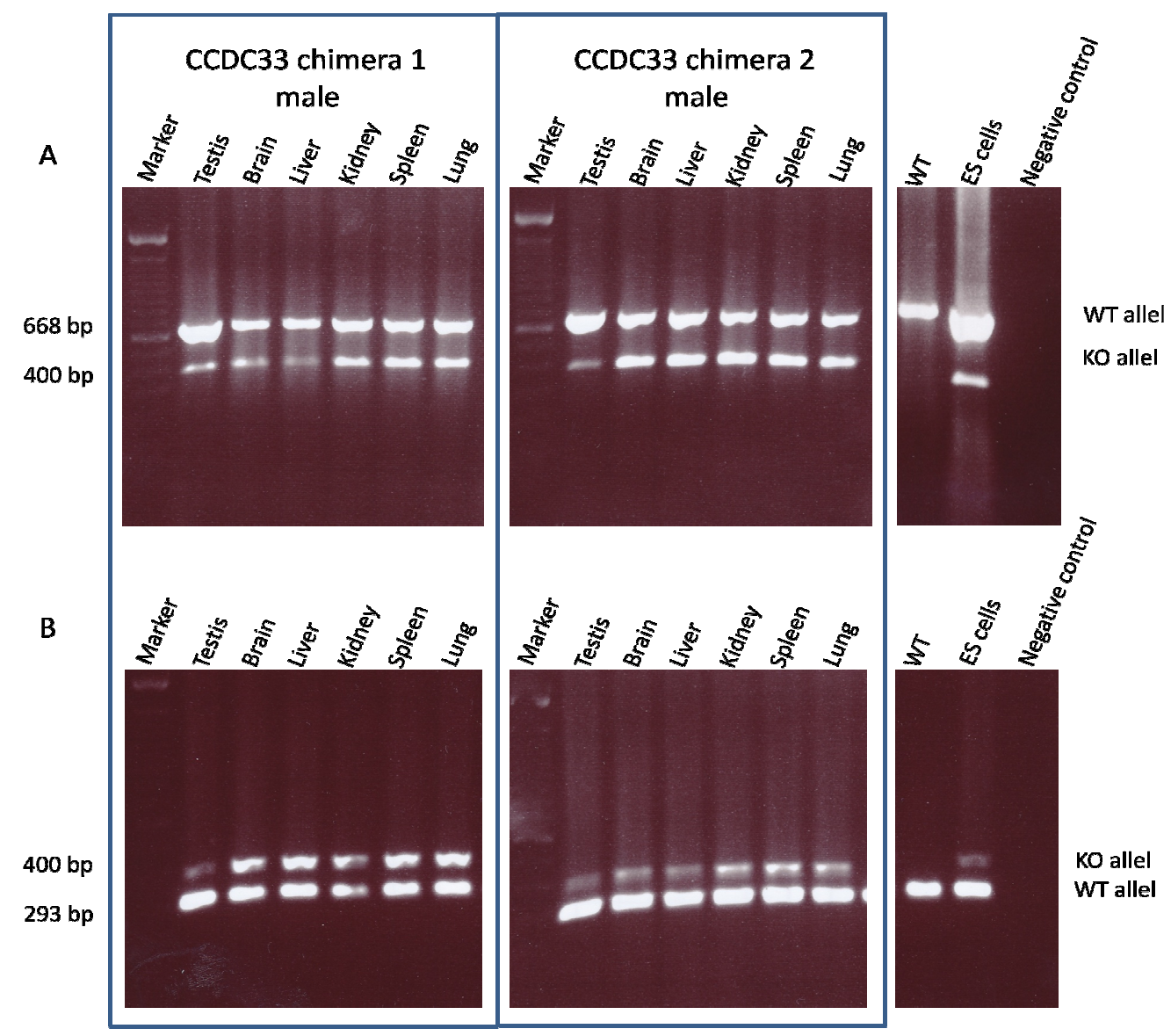



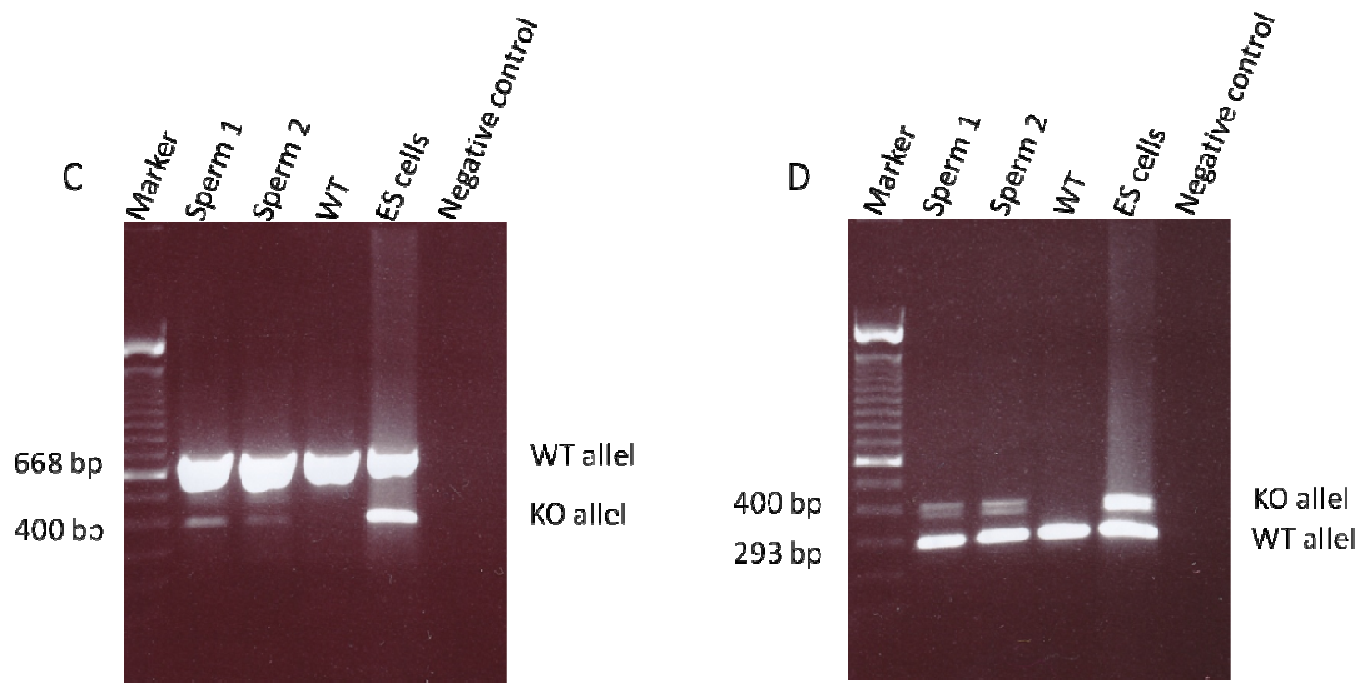

Figure 28. The analysis of chimerism in different organs and in spermatozoa isolated from epididymes of two male chimeras. (A) 3' and (B) 5' end genotyping PCR of organs isolated from male chimeras demonstrated that the recombinant allele could be detected in all organs analysed. (C) 3' and (D) and 5' end genotyping PCR of spermatozoa isolated from epididymis of both male chimeras revealed a weak product representing the knockout allel.

The third male chimera was infertile until the end of this work. Moreover, no vaginal plug was noticed after mating with wild type females. One possible explanation for its infertility is that this male has a high chimerism level in the testis, especial in germ cells and therefore is infertile.

Female chimeras were also mated with wild type males but no heterozygous pups were obtained. To check the chimerism of the female chimeras, genotyping PCR was applied on DNA isolated from skin, ovary, uterus, brain, muscle, kidney, liver and heart (Fig. 29 A-B). The chimerism was detected in all organs analysed. 

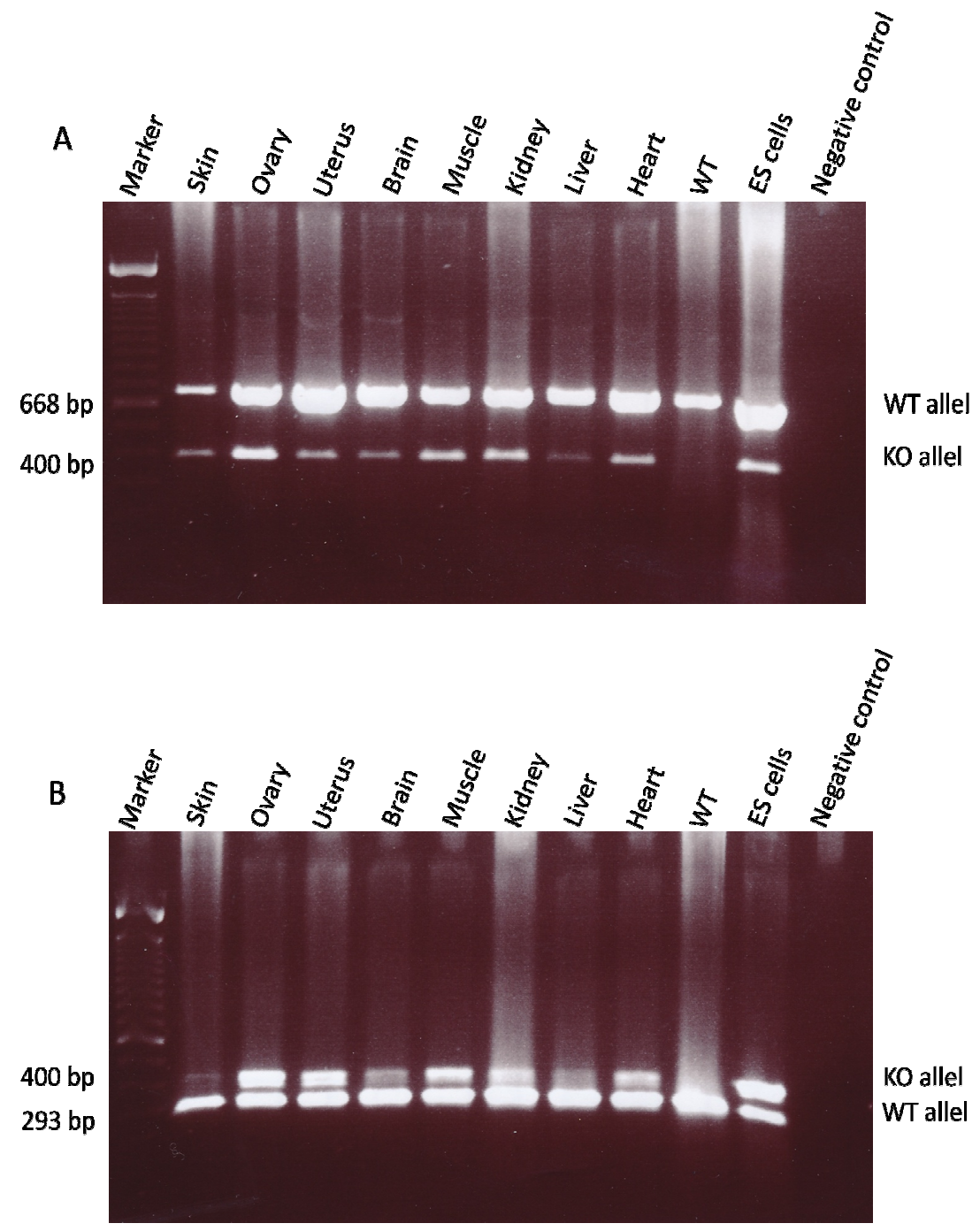

Figure 29. The analysis of chimerism in different organs of female chimera. The example of the genotyping PCR results at (A) 3' and (B) 5' end of the recombinant site in different organs.

3.2. The analysis of knockout mouse line with the disruption of 6 germ cell-specific genes

Genetic knockout is a common strategy to analyse gene function. However, it has been found that turning off a single gene not always leads to significant spermatogenesis disruption. Homozygous mutant males for following germ cell-specific genes: Tnp2 (Adham et al., 2001), Acr (Adham et al., 1997, Nayernia et al., 2002b), Histlhlt (Drabent 
et al., 2000), Theg (Mannan et al., 2003), Creb3l4 (Adham et al., 2005) and Tex 22 (Geisler, 2004) demonstrate normal fertility. Transition protein 2 gene (Tnp2) is located on mouse chromosome 16 and participates in replacement of histones and chromatin condensation in elongated spermatids. Subsequently TNP2 is replaced by protamine 1 and 2 (Reinhart et al., 1991; Engel et al., 1992). Histone cluster 1 (Histlhlt) gene, located on chromosome 13 is a linker histone, which replaces the somatic linker histones H1.1 and H1.2 in male germ cells during the meiotic prophase (Meistrich et al., 1985; Drabent et al., 1993). Testicular haploid expressed gene (Theg), located on chromosome 10, is expressed in spermatids and the expression of this gene is upregulated by factors from Sertoli cells (Nayernia et al., 1999; Mannan et al., 2003). Acrosin prepropeptide (Acr) gene is located on mouse chromosome 15 and the ACR protein was found in acrosome (Kremling et al., 1991). This protein is thought to be responsible for the proteolysis of zona pellucida of the oocyte (Howes et al., 2001; Honda et al., 2002). cAMP responsive element binding protein 3-like 4 (Creb3l4) gene, located on chromosome 3, encodes a protein which is a member of the CREB/ATF family of transcription factors (Stelzer and Don, 2002). This protein is especially active in response to a variety of stress conditions (Stirling and O'hare, 2006). Testis expressed gene 22 (Tex22), which is located on chromosome 12, encodes a protein believed to be involved in the biogenesis of acrosome and midpiece of mouse sperm (Neesen et al., 2002).

To analyse the function of these genes following multiple knockout lines were generated in the Institute of Human Genetics, University of Göttingen:

\begin{tabular}{llc} 
Line name & Knockouted gene(s) & Male fertility status \\
\hline 1xKO & Acr & fertile \\
2xKO & Acr/Tnp2 & fertile \\
3xKO & Acr/Tnp2/Hist1h1t & fertile \\
4xKO & Acr/Tnp2/Hist1h1t/Theg & fertile \\
5xKO & Acr/Tnp2/Hist1h1t/Theg/Creb3l4 & fertile \\
6xKO & Acr/Tnp2/Hist1h1t/Theg/Creb3l4/Tex22 & fertile/infertile
\end{tabular}

At the beginning of this work all lines were already available. A series of these multiple knockout lines was designed so, that in each line one additional male germ cell-specific 
gene is disrupted, from a line with single gene knockouted till a line with a disruption of 6 genes in a single animal. The fertility analysis, performed by breeding of homozygous males with wild type and homozygous females, revealed that males of $1 \mathrm{xKO}, 2 \mathrm{xKO}$, $3 \mathrm{xKO}, 4 \mathrm{xKO}$ and $5 \mathrm{xKO}$ demonstrated normal fertility. In the $6 \mathrm{xKO}$ line 24 males out of 107 were infertile. The fertility of fertile males of the line $6 x K O$ was normal, no significant reduction of the litter size in breeding homozygous males and females could be observed (Tab. 2). To determine whether the knockout of the sixth gene (Tex22) is a reason for male infertility, an additional multiple knockout line (generated before this work started) was analysed. In this line, called 4xKOa, four male germ cell-specific genes were disrupted (Acr/Tnp2/Hist1h1t/Tex22). Homozygous males and females were intercrossed and the normal fertility of mutant males was demonstrated (Tab. 2), thus we concluded, that male infertility of the $6 \mathrm{xKO}$ line is not direct consequence of the disruption of Tex22 gene, but rather cumulative effect of the disruption of six male germ cell-specific genes.

\begin{tabular}{|c|c|}
\cline { 2 - 2 } \multicolumn{1}{c|}{} & litter size \\
\hline wild type & $6.1+/-2.1$ \\
\hline 6xKO fertile & $5.86+/-1.9$ \\
\hline 4xKOa & $5.4+/-2.5$ \\
\hline
\end{tabular}

Table 2. Litter size analysis. Nine breeding pairs of fertile 6xKO males with females gave similar number of litters in comparison to wild type control. Data is given as mean +/- SD.

\subsubsection{The analysis of fertile and infertile males from $6 \times \mathrm{KO}$ line}

To further investigate the reason of the infertility of some homozygous males from $6 x \mathrm{KO}$ line, different fertility-relevant parameters were analysed. Because males from $1 \mathrm{xKO}, 2 \mathrm{xKO}, 3 \mathrm{xKO}, 4 \mathrm{xKO}$ and $5 \mathrm{xKO}$ lines demonstrated normal fertility, we compared the parameters of infertile males from $6 \mathrm{xKO}$ line to the parameters of fertile litter mates and to parameters of males from 5xKO line. As a control, wild type males from strains 129Sv, CD1 and C57B1 were used, because mice from multiple knockout lines have the hybrid background of these three inbred strains. 


\subsubsection{Testosterone level in peripheral blood}

Fertility may be affected by hormonal insufficiency, therefore the serum testosterone level of males from $6 x \mathrm{KO}$ infertile $(\mathrm{n}=8), 6 \mathrm{xKO}$ fertile (7), 5xKO (4) and wild type (6) was measured by radioimmunoassay as described in 2.2.18.4. The obtained results were very scattered in different groups. To reduce the data scatter, natural logarithm was calculated from testosterone concentration data and Kruskal-WallisANOVA analysis was performed. No significant difference between all tested animals was observed (Fig. 30).

Serum testosterone levels

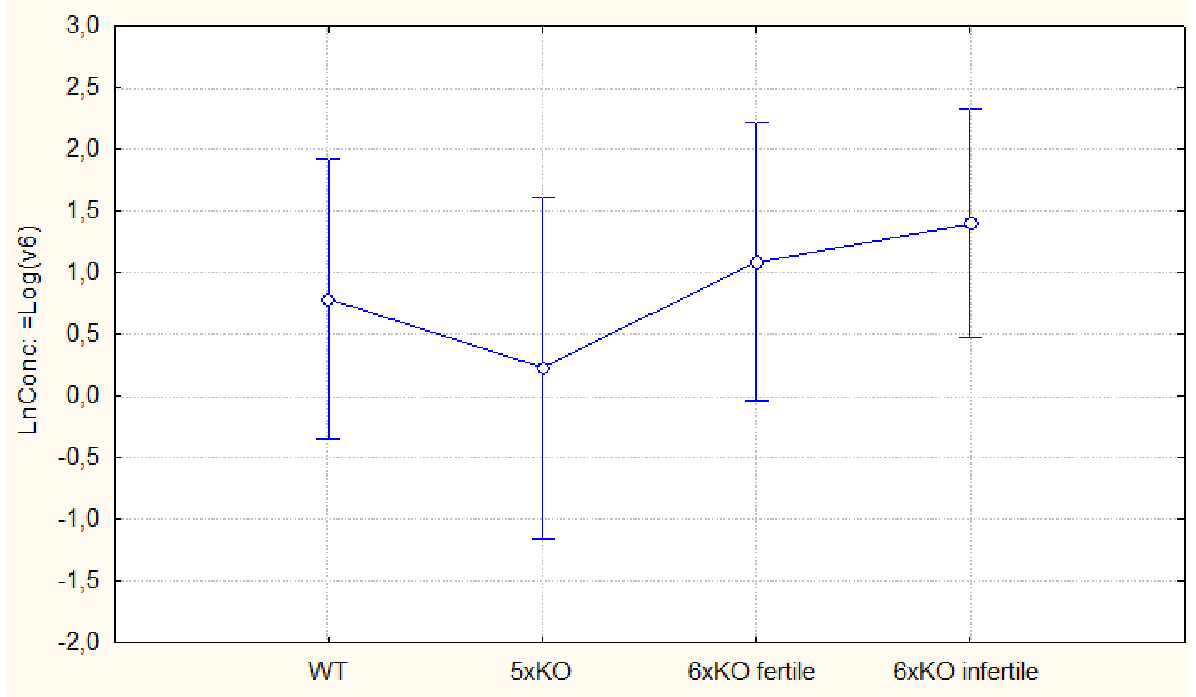

Figure 30. Serum testosterone levels from wild type, 5xKO, 6xKO fertile and infertile. Points indicate mean in each group, whiskers - standard deviation. Kruskal-Wallis-ANOVA analysis demonstrated that there is no significant difference in the concentration of testosterone between all groups analysed.

\subsubsection{Histological analysis of the testis from $6 \times \mathrm{KO}$ infertile males}

Testes of 6xKO infertile mice were isolated, fixed and stained with haematoxylin and eosin as described in 2.2.14.3. As a control, testes of $6 \mathrm{xKO}$ fertile, $5 \mathrm{xKO}$ and wild type males were analysed (not shown). As demonstrated on figure 31 histological analysis demonstrated that all stages of spermatogenesis are present in testis of infertile $6 \times \mathrm{KO}$ 
male, no obvious abnormalities can be noticed. This analysis was performed with cooperation with Prof. A. Meinhardt (Justus-Liebig-University of Giessen).

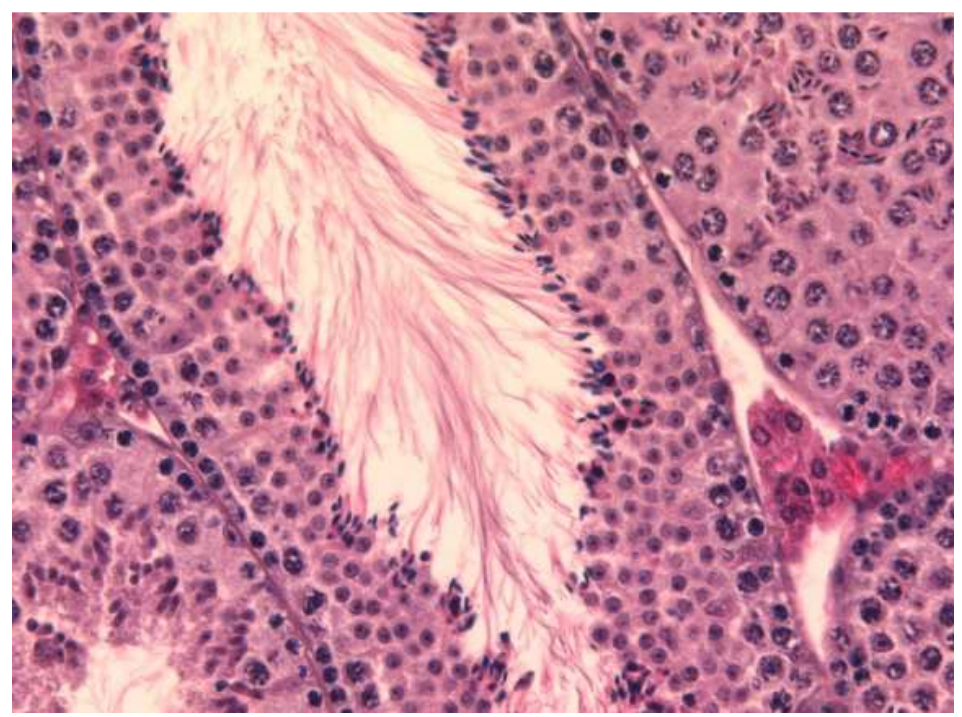

Figure 31. Section of testis of 6xKO infertile mouse stained by haematoxylin - eosin. The histological analysis revealed that all stages of spermatogenesis are present, no degeneration in germ cell epithelium was observed.

\subsubsection{The analysis of spermatozoa of $6 \times \mathrm{KO}$ infertile mice}

To further investigate the underlying cause of male infertility, different parameters of sperm from infertile males of $6 x \mathrm{KO}$ line were analysed. The number of spermatozoa from cauda epididymis was determined as described in 2.2.18.3. For this analysis 3 6xKO infertile, $3-6 x K O$ fertile and 3 - wild type males were used. ANOVA test was applied to analyse the data and no significant difference in the number of epididymal sperm could be observed between infertile and fertile males (Tab. 3). Next, 3 infertile males and 5 fertile males from $6 x \mathrm{KO}$ line and 4 wild type males were crossed with wild type females. After noticing of vaginal plug, females were sacrificed and the number of spermatozoa in uteri and oviducts was scored. Despite a high variation of the spermatozoa number between single animals of particular line, no significant difference could be observed between 6xKO infertile, 6xKO fertile and wild type males (Tab. 3). 


\begin{tabular}{|c|c|c|c|}
\hline \multirow{2}{*}{$\begin{array}{c}\text { Genotype } \\
\text { of mice }\end{array}$} & $\begin{array}{c}\text { Cauda epididymis } \\
\left(\mathbf{x 1 0}^{\mathbf{7}}\right)\end{array}$ & $\begin{array}{c}\text { Uterus } \\
\left(\mathbf{x 1 0}^{\mathbf{6}}\right)\end{array}$ & Oviduct \\
\cline { 2 - 4 } & $2.146+/-0.9(\mathrm{~N}=3)$ & $0.3+/-0.1(\mathrm{~N}=4)$ & $605+/-300(\mathrm{~N}=4)$ \\
\hline Wild type & $1.917+/-0.41(\mathrm{~N}=3)$ & $1.6+/-2.8(\mathrm{~N}=5)$ & $1014+/-1873(\mathrm{~N}=5)$ \\
\hline 6xKO fertile & $1.174+/-0.2(\mathrm{~N}=3)$ & $0.43+/-0.44(\mathrm{~N}=3)$ & $159+/-311(\mathrm{~N}=3)$ \\
\hline 6xKO infertile &
\end{tabular}

Table 3. Sperm analysis of mutant and control males. Spermatozoa number is given as mean +/- standard deviation.

Then, the motility of spermatozoa of wild type, 5xKO, 6xKO fertile and 6xKO infertile was measured using the computer assisted semen analysis (CASA) system (Hailton Throne CEROS software), as described in 2.2.18.3. Three animals from each line were analysed. Following parameters were evaluated: average path velocity (VAP, $\mu \mathrm{m} / \mathrm{s}$ ), curvilinear velocity (VCL, $\mu \mathrm{m} / \mathrm{s}$ ), straight line velocity (VSL, $\mu \mathrm{m} / \mathrm{s}$ ), straightness (STR, calculated as a ratio of VSL to VAP), beat cross frequency (BCF, $\mathrm{Hz}$ ) and amplitude of the lateral head displacement (ALH, $\mu \mathrm{m})$ (Fig. 32). Sperm were isolated in IVF medium and motility was analysed after $1.5 \mathrm{~h}$ capacitation in $37^{\circ} \mathrm{C}, 5 \% \mathrm{CO}_{2}$. Obtained results do not followed normal distribution, thus the non-parametric Kruskal-Wallis-ANOVA analysis was performed. The statistical analysis revealed that all velocities parameters (VAP, VCL, VSL) of sperm from 6xKO infertile were significantly reduced as compared to $6 \mathrm{xKO}$ fertile, $5 \mathrm{xKO}$ and wild type males and ALH of infertile 6xKO sperm was significant reduced as compared to fertile $6 \mathrm{xKO}$ and wild type, but was not significantly different from 5xKO. No significant differences were observed in BCF and STR (Fig. 32). 

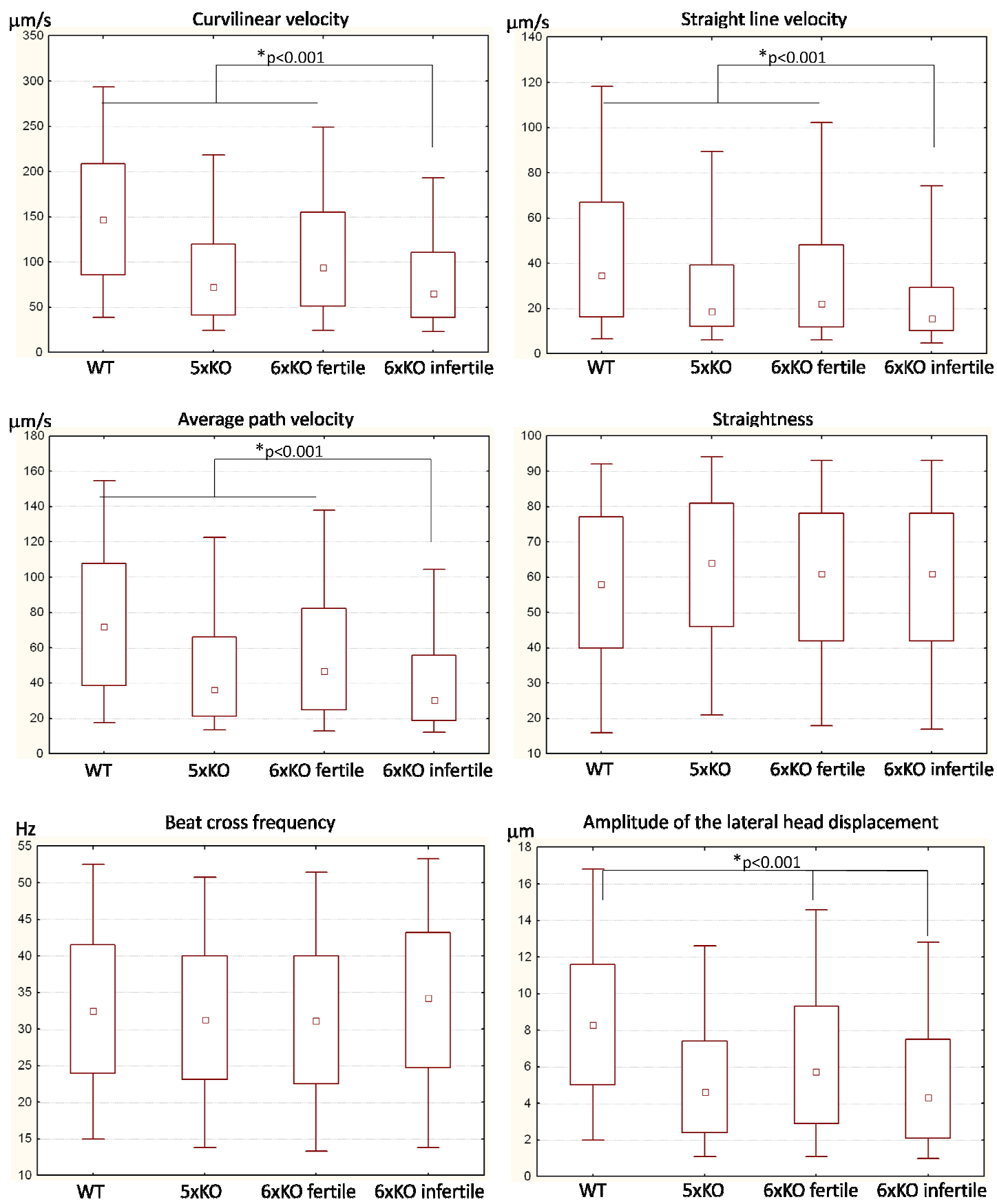

Figure 32. The analysis of sperm motility. Sperm of wild type, 5xKO, 6xKO fertile and 6xKO infertile were analysed with CASA system. For the average path velocity (VAP), curvilinear velocity (VCL) and straight line velocity (VSL), significant reductions were found in 6xKO infertile animals as compared to WT, 5xKO and 6xKO fertile. Amplitude of the lateral head displacement (ALH) of infertile 6xKO sperm was significantly reduced as compared to fertile 6xKO and wild type, but was not different from 5xKO. There were no significant differences in beat cross frequency (BCF) and straightness (STR) between 
analysed animals. Asterix $-\mathbf{p}<0.001$, points indicated median, bars $-25-75 \%$ percentile, whiskers $-5-95 \%$ percentile.

Next, the analysis of sperm head abnormalities was performed as described in 2.2.18.2. Sperm were isolated from 2 - wild type, 3 - 6xKO fertile and 3 - 6xKO infertile males and stained with $0.2 \%$ eosine Y. ANOVA analysis of variance was applied for data analyse. As compared to wild type, significantly increased number of abnormal spermatozoa from 6xKO fertile and 6xKO infertile males was observed $(10+/-2$ vs 47.2 +/- 5.2 and 57.2 +/- 6.1, respectively, p<0.001) (Fig. 33 A), but the difference between fertile and infertile 6xKO animals was not significant $(\mathrm{p}>0.05)$. Among abnormal spermatozoa different types of sperm head deformations were identified according to Styrna et al. 2003 (Fig. 33 B - G). Then, the morphology of sperm tails was analysed. After quantification it has been found, that $47 \%$ of sperm from $6 x \mathrm{KO}$ infertile, $31 \%$ of 6xKO fertile and $10 \%$ of wild type animal demonstrate a hairpin-like tail structure (Fig. $33 \mathrm{H})$. The ANOVA analysis revealed that 6xKO infertile sperm demonstrate significantly more abnormal sperm tails as compared to sperm of fertile $6 x \mathrm{KO}(\mathrm{p}<0.05)$ and wild type sperm $(\mathrm{p}<0.001)$.

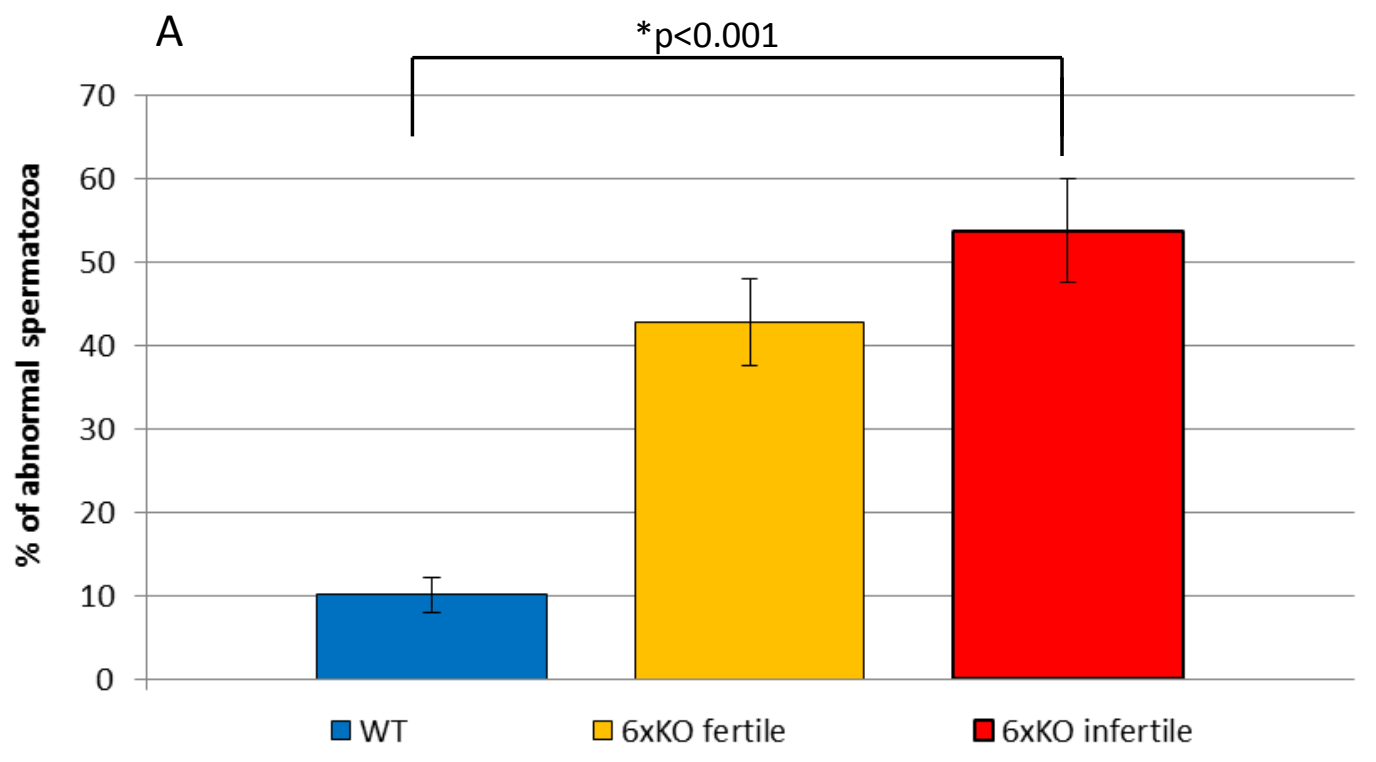



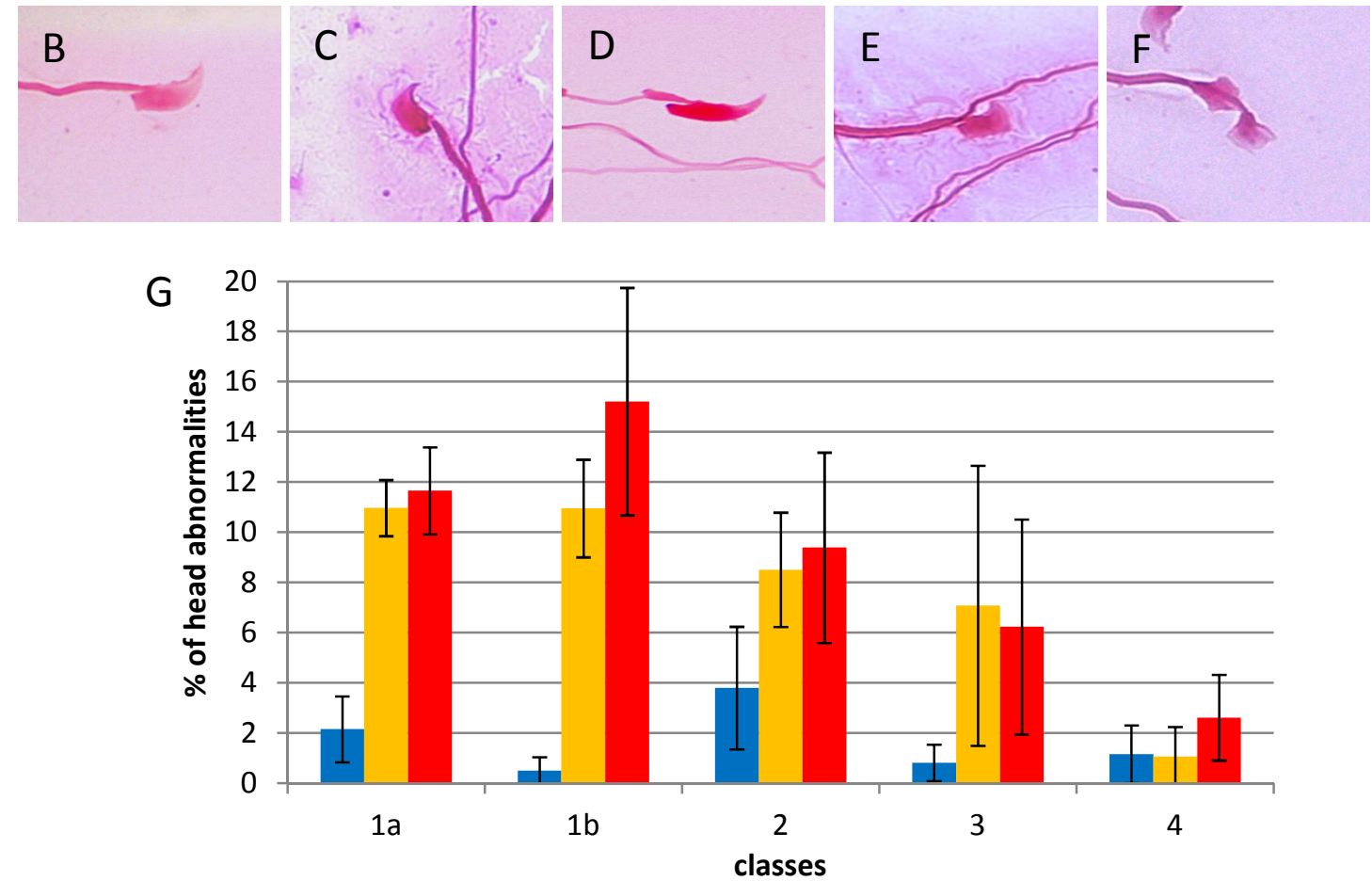

WT $\quad$ 6xKO fertile $\quad$ 6xKO infertile

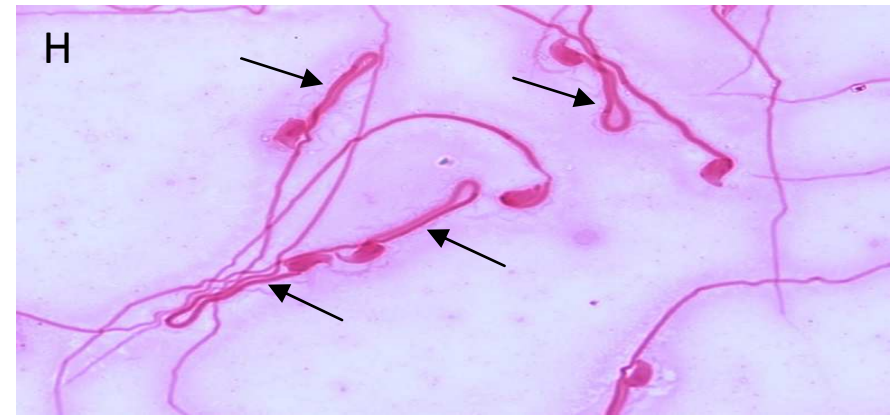

Figure 33. The analysis of sperm morphology. (A) The number of sperm with abnormal head was higher in 6xKO fertile and 6xKO infertile males as compared to wild type control. Asterix indicates $\mathbf{p}<0.001$, bars represent means, whiskers - standard deviation. (B-F) Examples of different abnormality classes from 6xKO infertile are given: B - class 1a; C class 1b, D - class 2, E - class 3, F - class 4 according to the classification of Styrna et al. 2003. (G) All classes could be observed in fertile and infertile males. (H) Typical view of spermatozoa from 6xKO infertile animal, arrows indicate the hairpin-like structures of the tail.

Next, the acrosome reaction was analysed in spermatozoa from $6 \mathrm{xKO}$ infertile animals. Sperm were treated with calcium ionophore A23187 and then, the number of 
acrosome reacted cells was scored (2.2.18.5). For this analysis sperm from $3-6 x K O$ infertile, 3 - 6xKO fertile and 3 wild type males were isolated. Data was analysed using ANOVA. The ability of spermatozoa of $6 x \mathrm{KO}$ infertile male to undergoes acrosome reaction was significantly reduced as compared to $6 \mathrm{xKO}$ fertile and wild type controls $(\mathrm{p}<0.001)$ (Fig. 34).

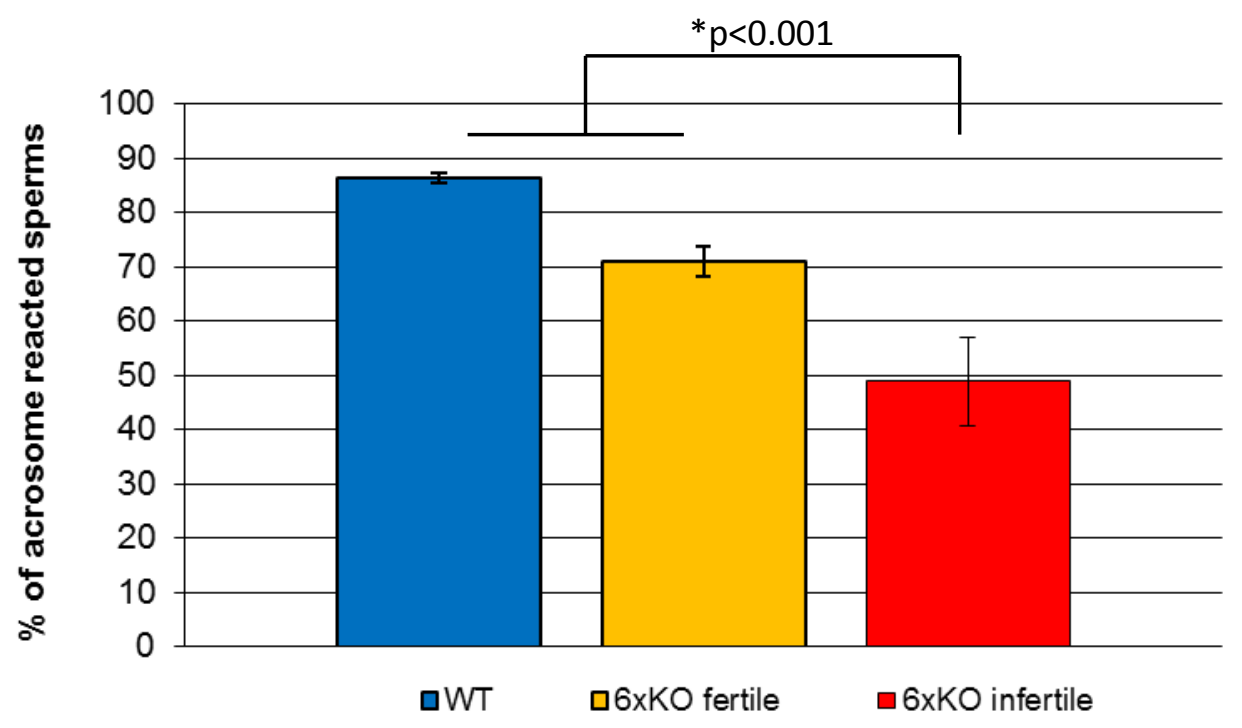

Figure 34. The analysis of acrosome reaction of spermatozoa from wild type, $6 \times K O$ fertile und 6xKO infertile animals. Acrosome reaction was significantly reduced in 6xKO infertile males as compared to 6xKO fertile and wild type males. Asterix indicates $\mathrm{p}<0.001$, column mean, whiskers - standard deviation.

\subsubsection{Transcriptome analysis of the testes of mice of $6 \times K O$ infertile and $5 \times K O$ fertile} lines, respectively

Normal fertility was observed in males from multiple knockout lines with one to five disrupted genes, but $22 \%$ of males with six knockouted genes are infertile. Therefore, one could assume, that some genes involved in male fertility control are differentially expressed in the testis of $5 \mathrm{xKO}$ fertile and $6 \mathrm{xKO}$ infertile animals. Therefore a single-channel transcriptome microarray using the Gene Chip Mouse Gene 1.0 ST Array (Affymetrix) technology was performed. This analysis was done in Microarray Facility, University of Göttingen accordingly to the manual of Gene Chip 
Whole Transcript (WT) Sense Target Labeling Assay (Affymetrix) (see 2.2.12). Two separate single-dye hybridizations were performed for each sample pair. To elucidate the total genes expression one sample from 5xKO fertile and second from 6xKO infertile male were compared. In each array control genes were included and used to estimate the relative expression levels and to correct the putative differences in RNA concentration. RNA was isolated from testes of five 5xKO fertile and four 6xKO infertile mice. 20986 genes were analysed on a single chip. After this experiment 55 genes were found to be down- or up-regulated in 6xKO infertile males as compared to 5xKO fertile (Tab. 4). For 41 genes the expression in testis was already known. The expressions of 10 genes were never tested in the testis and 4 genes were unknown.

\section{6 tested genes}

\begin{tabular}{|c|c|c|c|c|c|}
\hline \multicolumn{6}{|c|}{55 genes } \\
\hline \multicolumn{3}{|c|}{ Down-regulation } & \multicolumn{3}{|c|}{ Up-regulation } \\
\hline Symbol & NCBI Ref.Seq. & Fold & Symbol & NCBI Ref.Seq. & Fold \\
\hline 4933400A11Rik & NR_003635 & $-17,7$ & Ptpro & NM_011216 & 4,5 \\
\hline EG665933 & XR_031751 & $-14,6$ & H2afz & NM_016750 & 4,3 \\
\hline Tex22 & NM_029381 & $-5,8$ & Cpn1 & NM_030703 & 3,3 \\
\hline Slc26a10 & NM_177615.3 & $-3,5$ & A530064D06Rik & NM_001113556 & 2,5 \\
\hline EG547091 & ID-547091 & $-2,6$ & LOC669780 & XM_001474651 & 2,3 \\
\hline Sult1e1 & NM_023135 & $-2,1$ & 9230113P08Rik & XM_001477936 & 2,2 \\
\hline Ndufs5 & NM_001030274 & $-2,1$ & Zfp354b & NM_013744 & 2,0 \\
\hline Stat2 & NM_019963 & $-2,1$ & D10Bwg1379e & NM_001033258 & 2,0 \\
\hline Adh1 & NM_007409 & $-1,9$ & Serpina3n & NM_009252 & 1,9 \\
\hline Asah1 & NM_019734 & $-1,8$ & Pftk1 & NM_011074 & 1,8 \\
\hline EG632802 & XM_907438 & $-1,8$ & $\mathrm{Klb}$ & NM_031180 & 1,8 \\
\hline Ktn1 & NM_008477 & $-1,7$ & 9330182L06Rik & NM_172706 & 1,6 \\
\hline Hsd3b1 & NM_008293 & $-1,6$ & $\mathrm{BC} 030867$ & NM_153544 & 1,6 \\
\hline Kcnk2 & NM_010607 & $-1,6$ & Adam22 & NM_001007220 & 1,5 \\
\hline Slc7a2 & NM_001044740 & $-1,6$ & Ccdc144b & NM_178418 & 1,5 \\
\hline BC049715 & NM_178776 & $-1,6$ & Gm920 & XM_354882 & 1,5 \\
\hline Star & NM_011485 & $-1,6$ & Leng8 & NM_172736 & 1,5 \\
\hline Aldh1a7 & NM_011921 & $-1,6$ & EG625046 & XM_889589 & 1,4 \\
\hline AU021092 & NM_001033220 & $-1,5$ & Kif21b & NM_001039472 & 1,4 \\
\hline
\end{tabular}




\begin{tabular}{|c|c|c|c|c|c|} 
Ly6e & NM_008529 & $-1,5$ & Cyp2c44 & NM_001001446 & 1,4 \\
\hline Cyp11a1 & NM_019779 & $-1,5$ & Antxrl & NM_172808 & 1,4 \\
\hline 1700073E17Rik & NR_003625 & $-1,5$ & & & \\
\hline Gstk1 & NM_029555 & $-1,5$ & & & \\
\hline 9530002B09Rik & NM_023865 & $-1,5$ & & & \\
\hline Rwdd4a & NM_203507 & $-1,5$ & & & \\
\hline Folh1 & NM_016770 & $-1,5$ & & & \\
\hline Tmem176b & NM_023056 & $-1,4$ & & & \\
\hline 4930427A07Rik & NM_134041 & $-1,4$ & & & \\
\hline Foxo3 & NM_001128634 & $-1,4$ & & & \\
\hline Gpt2 & NM_173866 & $-1,4$ & & & \\
\hline Kcnab1 & NM_010597 & $-1,4$ & & & \\
\hline Slc30a2 & NM_001039677 & $-1,4$ & & & \\
\hline Mapkapk2 & NM_008551 & $-1,4$ & & & \\
\hline Als2 & NM_028717 & $-1,4$ & & & \\
\hline
\end{tabular}

Table 4. Comparison of transcriptome of fertile $5 \times \mathrm{KKO}$ and infertile $6 \times \mathrm{xKO}$ mice. 55 genes were found to be down- or up-regulated in $6 \times \mathrm{xKO}$ infertile males as compared to $5 \times \mathrm{XKO}$. Symbols of genes, their NCBI Ref. Seq and changes (in fold) between fertile 5xKO and infertile 6xKO are presented.

First, genes for which the expression in testis was not known, were selected and analysed with specific primers by RT-PCR. Unfortunately, it was not possible to design specific primers for all of the chosen 14 genes. To exclude any unspecific amplification through a genomic contamination, both primers were located in two different exons (Tab. 5). I have confirmed the testicular expression of all genes analysed, but only for $G m 7853$ gene exclusive testis expression was found (Fig. 35). The quality of cDNAs was demonstrated with Hprt specific primers (Fig. 35). 
Results

\begin{tabular}{|c|c|c|c|}
\hline Symbol & Name & Primers & Exons \\
\hline A530064D06Rik & RIKEN cDNA & mGene25F & $2-4$ \\
& A530064D06 & mGene25R & \\
\hline D10Bwg1379e & DNA segment, Chr 10, & mGene28F & $5-9$ \\
& Brigham \& Women's & mGene28R & \\
& Genetics 1379 & & \\
\hline 9330182L06Rik & RIKEN cDNA 9330182L06 & mGene27F & $10-13$ \\
& mGene27R & \\
\hline Slc26a10 & solute carrier family 26, & mGene20F & $4-6$ \\
& member 10 & mGene20R & \\
\hline Gm7853 & predicted gene 7853 & mGene4F & $1-2$ \\
& & mGene9R & \\
\hline
\end{tabular}

Table 5. Analysis of expression of unknown genes. Name of primers and its localisation in exons are presented.

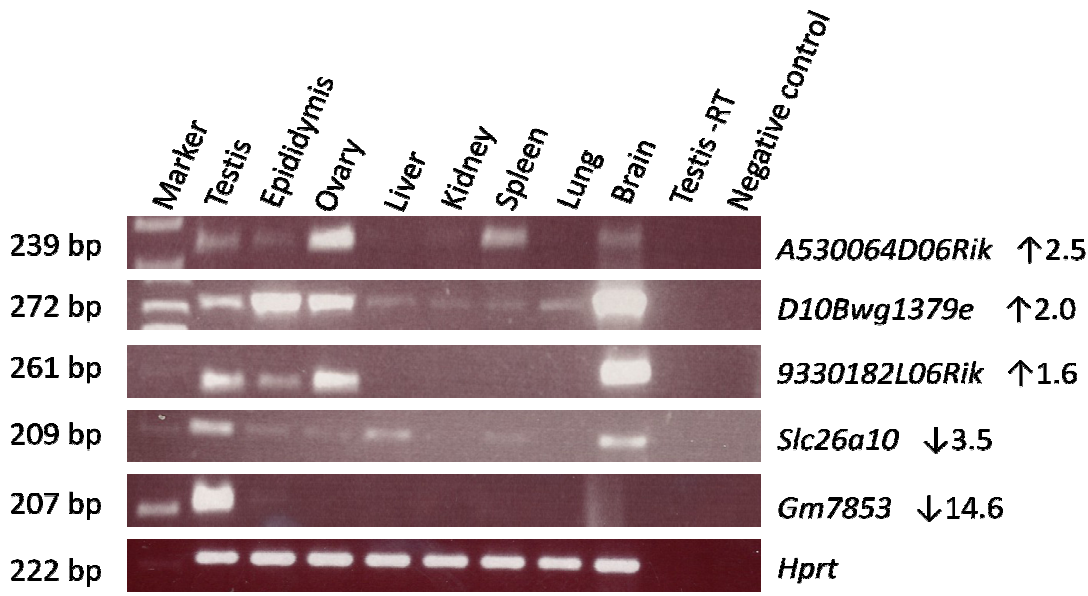

Figure 35. RT-PCR analysis of genes from transcriptome with unknown expression in the testis. RT-PCR demonstrates that all genes analysed are expressed in the testis, but except for the Gm7853 gene the expression was not restricted to the testis. Arrows and numbers next to gene's names indicate the fold of up- or down-regulation.

Next, the quantitative Real time RT-PCR (qRT-PCR) technique (2.2.5) was used to confirm transcriptome results. The expression levels of the following genes was 
analysed using specific primers: RIKEN cDNA 4933400A11 gene (4933400A11Rik), RIKEN cDNA $1700073 E 17$ gene (1700073E17Rik), NADH dehydrogenase (ubiquinone) $\mathrm{Fe}-\mathrm{S}$ protein 5 gene (Ndufs5), sulfotransferase family $1 \mathrm{E}$, member 1 gene (Sult1e1) and protein tyrosine phosphatase, receptor type, $O$ gene (Ptpro) (Tab. 6). In this analysis testis of two 5xKO fertile and two 6xKO infertile males were used. After normalization with cT value for Hprt expression level, the expression of all genes analysed was compared between 5xKO and 6xKO infertile animals. As demonstrated in figure $36 \mathrm{~A}$ the qRT-PCR analysis confirmed the transcriptome results for 4933400A11Rik, Ndufs5 and Ptpro. Expression level of 1700073E17Rik and Sult1el genes was not significantly lower in 6xKO infertile as compared to 5xKO (Mann-Whitney U test).

\begin{tabular}{|c|c|c|c|}
\hline Symbol & Name & Primers & Exons \\
\hline 4933400Al1Rik & RIKEN cDNA 4933400A11 & $\begin{array}{l}\text { mGene5F } \\
\text { mGene5R }\end{array}$ & $2-3$ \\
\hline 1700073E17Rik & RIKEN cDNA $1700073 E 17$ & $\begin{array}{l}\text { mGene17F } \\
\text { mGene17R }\end{array}$ & $1-2$ \\
\hline$N d u f s 5$ & $\begin{array}{c}\text { NADH dehydrogenase } \\
\text { (ubiquinone) Fe-S protein } 5\end{array}$ & $\begin{array}{l}\text { Ndufs5FP } \\
\text { Ndufs5RF }\end{array}$ & $1-2$ \\
\hline Sult1e1 & $\begin{array}{c}\text { sulfotransferase family } 1 E \text {, } \\
\text { member } 1\end{array}$ & $\begin{array}{l}\text { Sult1e1F } \\
\text { Sult1e1R }\end{array}$ & $2-4$ \\
\hline Ptpro & $\begin{array}{c}\text { protein tyrosine phosphatase, } \\
\text { receptor type, } O\end{array}$ & $\begin{array}{l}\text { PtproFP } \\
\text { PtproRP }\end{array}$ & $9-11$ \\
\hline
\end{tabular}

Table 6. Confirmation of transcriptome by qRT-PCR. Name of primers and their localisations in exons are given.

The expression of the 4933400A11Rik gene demonstrated the strongest downregulation in the testis of $6 \mathrm{xKO}$ infertile mice. The expression of this gene was almost not detectable in qRT-PCR array in the testis of 6xKO infertile male while similar expression level was observed in wild type, 5xKO and 6xKO fertile testes (Fig. 36 B). Next, the RT- 
PCR with mGene5F and mGene5R primers was used to verify the hypothesis that this gene is not expressed in the testis of $6 x \mathrm{KO}$ infertile males. As demonstrated in figure 36 $\mathrm{C}$ no PCR product was observed in the testes of $6 \mathrm{xKO}$ infertile animals. cDNA quality was tested with Hprt, Sdha and Tbp specific primers.

A

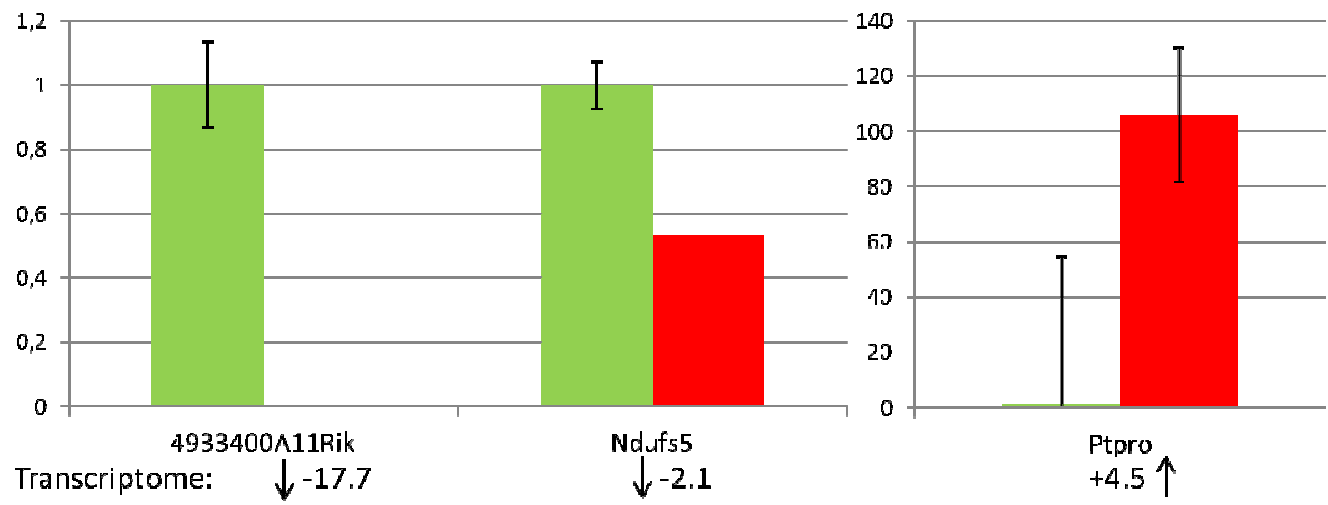

5xKO $\square \times K O$ infertile
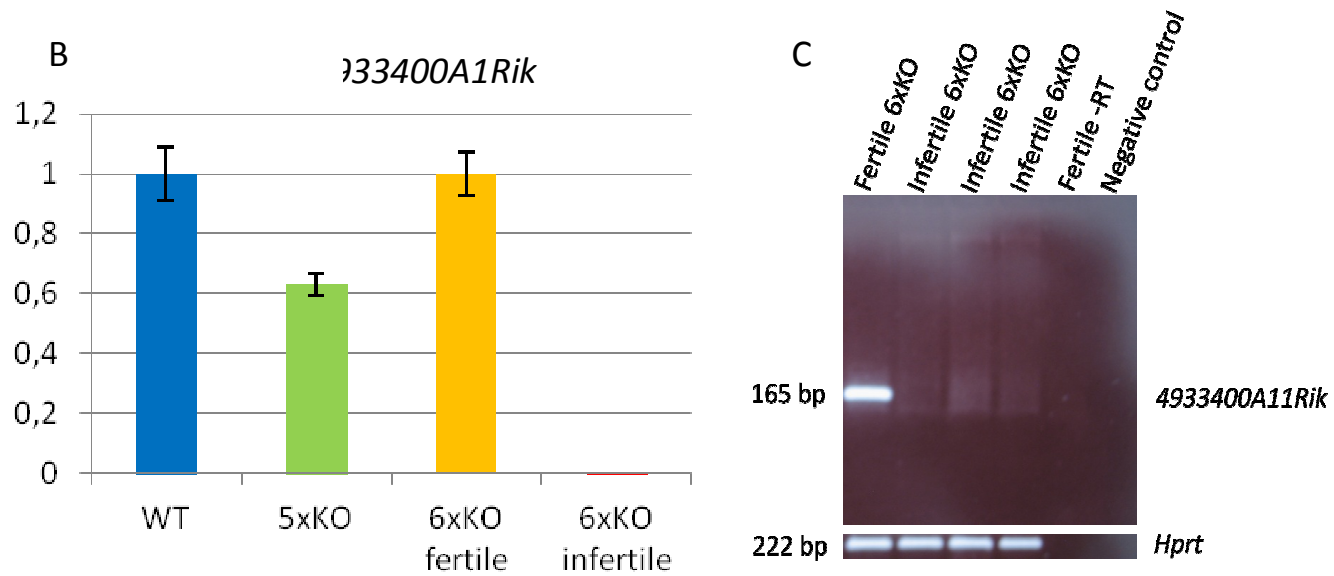

Figure 36. Confirmation of transcriptome array by qPCR. (A) Expression levels of 4933400A11Rik, Ndufs5 and Ptpro were tested in the testis of 5xKO and 6xKO infertile mice and transcriptome results could be confirmed in this analysis. Arrows and numbers next to gene's names indicate the fold of up- or down-regulation. (B) The analysis of expression level of the strongest down-regulated gene, 4933400A11Rik in testis of wild type, 5xKO, 6xKO fertile and 6xKO infertile males revealed, that this gene is no longer expressed in the testis of 6xKO infertile males. (C) RT-PCR product was not observed in the testes of 6xKO infertile animals. cDNA quality was tested with $\mathrm{Hprt}$, Sdha and Tbp specific primers. 


\subsubsection{Analysis of 4933400A11Rik expression}

The 4933400A11Rik gene is expressed in the testis of 5xKO fertile males, but not in testis of $6 x \mathrm{KO}$ infertile males. Therefore this gene was selected for further characterization. Besides the sequence in NCBI data base there was no information about this gene. To analyse the expression of 4933400A11Rik gene in different tissues, the RTPCR technique with mGene5F and mGene5R primers was applied. To exclude any unspecific amplification resulting from genomic contamination, both primers were located in two different exons, namely exon 2 and 3. The RT-PCR product $165 \mathrm{bp}$ in size could became amplified on cDNA obtained from wild type testis and epididymis, but not from ovary, liver, kidney, spleen, lung, brain and cerebellum. cDNA quality was controlled by RT-PCR with Hprt specific primers (Fig. 37 A). Then, the RT-PCR product was isolated from gel, cloned into pGEM-T easy vector and sequenced to confirm its specificity. Next, qRT-PCR reaction with the same primers as for RT-PCR, was used to analyse the expression level of this gene in testis and epididymis. For control cDNA of ovary, brain, cerebellum and kidney was used. This analysis demonstrated that 4933400A11Rik gene is highly expressed in testis, while the expression in epididymis is on a very low level. No expression could be detected in other organs (Fig. 37 B). To confirm the qRT-PCR result a Northern blot was hybridized with ${ }^{32} \mathrm{P}$-labelled $332 \mathrm{bp}$ 4933400A11Rik cDNA probe. The cDNA probe was generated by PCR amplification of testis cDNA with mGene5Fsonda and mGene5R (nucleotides 27-358) primers, PCR product was then cloned into pGEM-T Easy, sequenced and isolated with EcoRI restriction enzyme. RNA quality was controlled by rehybridization of the membrane with $\beta$-actin cDNA probe. The $1.7 \mathrm{~kb}$ transcript of 4933400AllRik gene was detected only in testis (Fig. $37 \mathrm{C}$ ). Taken together, this gene is highly expressed in testis, low amount of transcript is also detectable in epididymis, but not in other organs. 


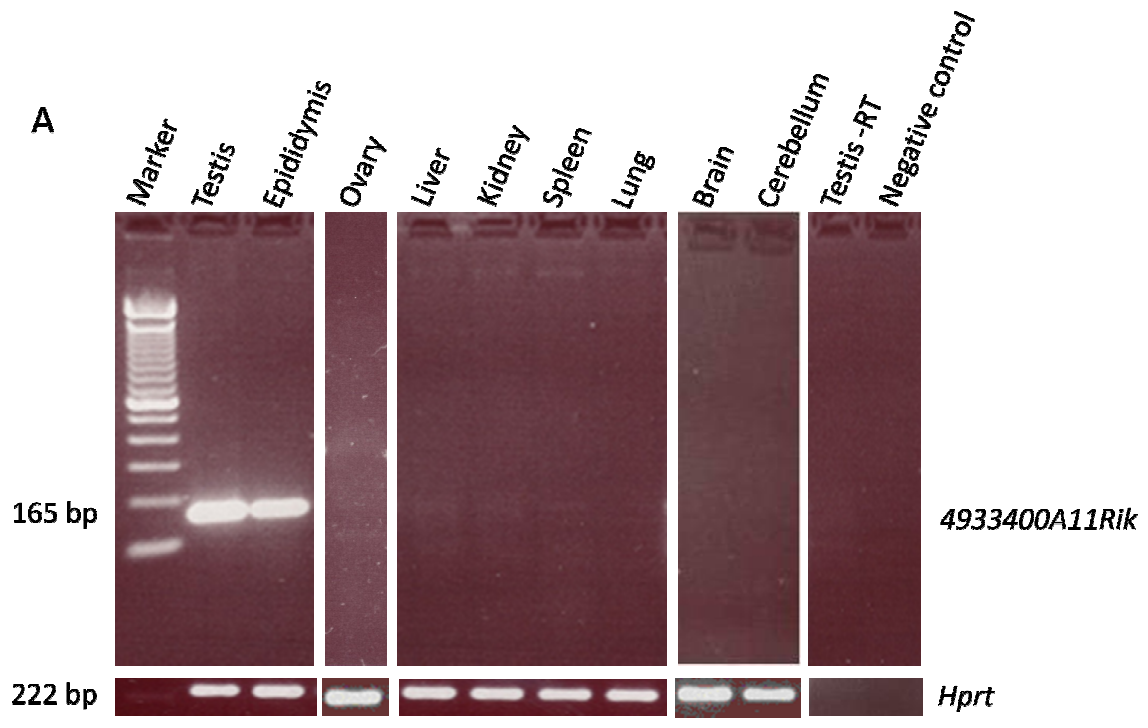

B

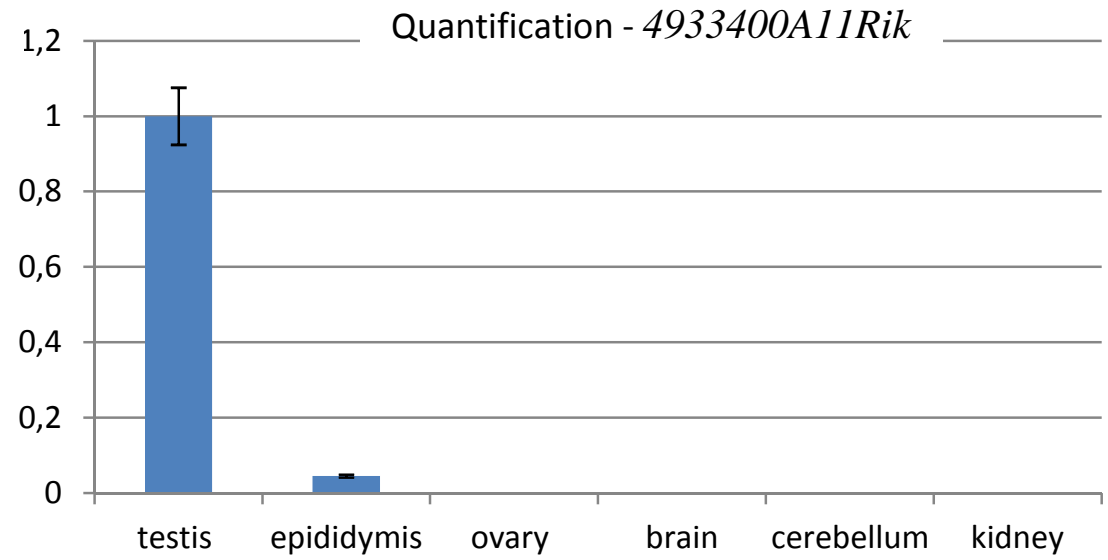




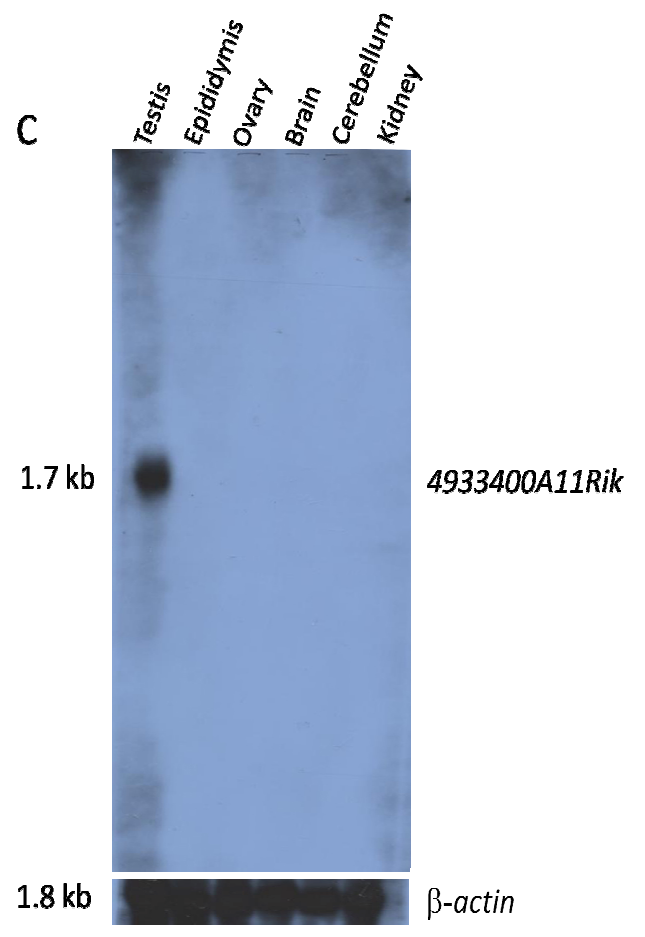

Figure 37. Expression analysis of the 4933400A11Rik gene. (A) RT-PCR analysis of 4933400A11Rik expression in different organs of adult wild type mouse with mGene5F and mGene5R primers. RT-PCR product was detected only in testis and epididymis. (B) qRTPCR and (C) Northern blot analyses demonstrated that 4933400A11Rik gene is expressed in testis. Only low amount of transcript was detectable in epididymis in qRT-PCR. RNA quality was tested by RT-PCR with Hprt primers (A) or by re-hybridization with mouse $\beta$ actin probe (C).

Next, the expression of 4933400A11Rik gene in different spermatogenesis stages was analysed by RT-PCR. The 165 bp product representing 4933400A11Rik transcript was detected from the 16th dpp (Fig. 38 A). Next, 4933400A11Rik expression was analysed in testes of mutants with spermatogenesis arrest at different stages. For this analysis following mutants were used: $W / W^{\nu}$ without any germ cells in the testis, $T \mathrm{fm} / \mathrm{y}$ with spermatogenesis arrest at the primary spermatocyte stage. Insl $3^{-/-}$- spermatogenesis is arrested at the stage of pachytene spermatocytes, olt/olt and $q k / q k$ - spermatogenesis is arrested at spermatid stage. After RT-PCR, the $165 \mathrm{bp}$ band was observed in all mutants analysed but not in $W / W^{v}$ (Fig. $38 \mathrm{~B}$ ). Thus it can be concluded that the expression of 4933400Al1Rik is restricted to germ cells. To further prove this hypothesis cDNA of 
Leydig (MA-10) and Sertoli cell lines (15P-1 and Sc11) were used for RT-PCR amplification with 4933400A11Rik primers. No expression was detected in either of cell lines tested confirming the germ cell-specific expression of 4933400A11Rik gene (Fig. 38 B).
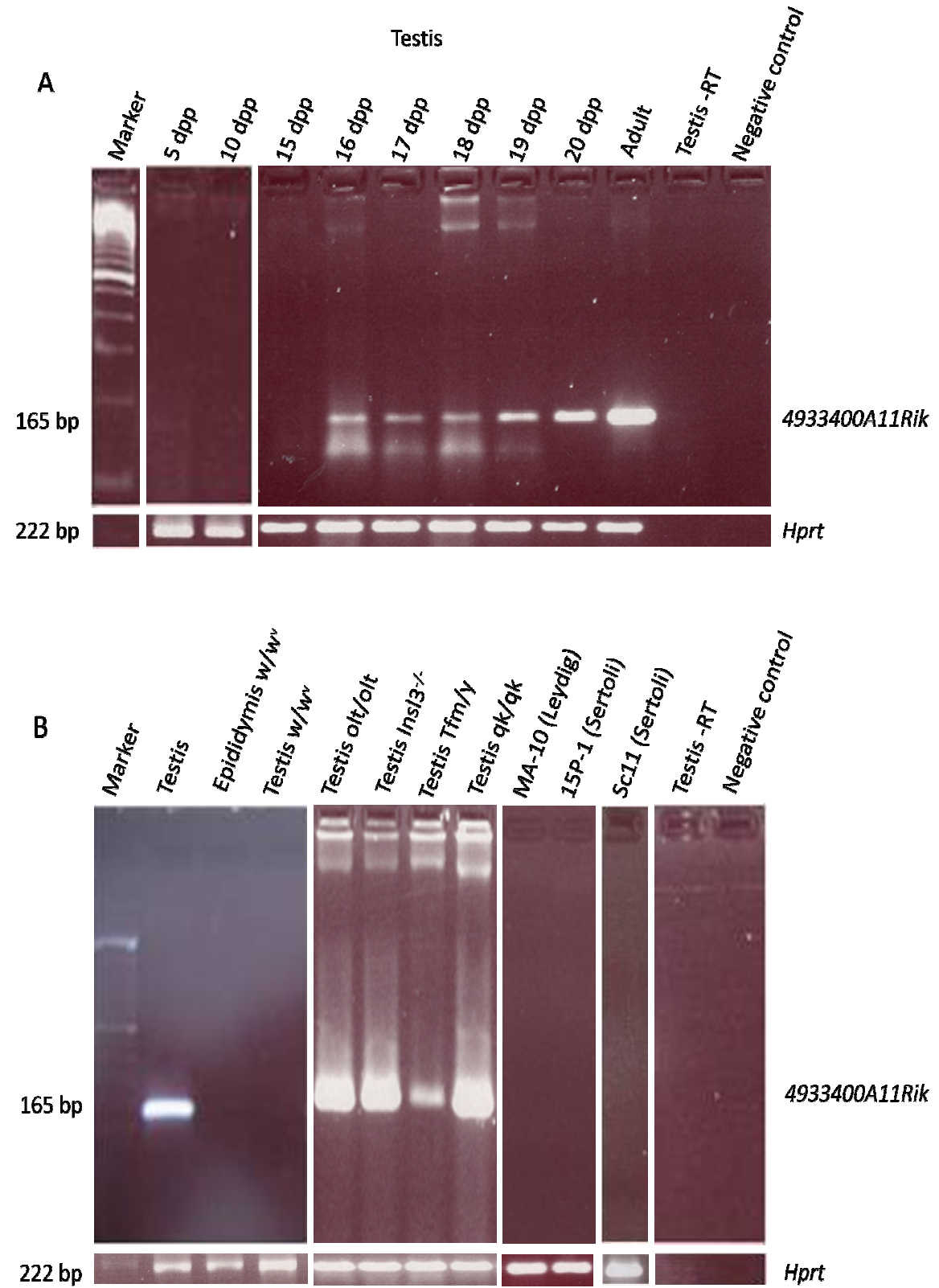

Figure 38. Analysis of expression of 4933400A11Rik in testis from males at different age post partum (A) and from different mutant males (B). The expression of 4933400A11Rik starts at $16 \mathrm{dpp}$. The expression is not detected in $W / W^{v}$ mutants and also not in somatic cell lines 
(MA-10, 15P-1 and Sc11). The expression was observed in olt/olt; $q \mathrm{k} / q \mathrm{k} ; \mathrm{Tfm} / \mathrm{y}$ and $\mathrm{Insl3}^{-/-}$ mutant mice. cDNA quality was proven by RT-PCR with $H$ prt specific primers.

In 2007 about 70 putative iRNAs were known in human sperm and 15 of them specifically inhibit genes that are only active during early embryonic development (Boerke et al., 2007). Because it is known that sperm RNAs could be important in sperm motility, fertilisation or early zygotic and embryonic development (Atlas-White et al., 2000; Ibrahim et al., 2000; Poon et al., 2000; Poon et al., 2002; Ostermeier et al., 2004; deMateo et al., 2011), we checked whether 4933400Al1Rik transcript is present in spermatozoa. To avoid any contamination of epididymal cells spermatozoa were isolated from the uterus of plugged females. In addition mRNA was isolated from epididymis of 20 dpp old male, which has no spermatozoa in the epididymis. A 165 bp 4933400Al1Rik PCR product was observed in spermatozoa isolated from uterus, but not in the epididymis of 20 dpp old male. For control uterus cDNA was also used (Fig. 39 A). This result indicates that 4933400A11Rik transcript is present in spermatozoa and that epididymis does not express this gene. To exclude the possibility that the epididymal expression is initiated by the spermatozoa migration, adult male was castrated and epididymes were isolated three weeks after castration. After preparing RNA and cDNA synthesis, RT-PCR with 4933400AllRik specific primers was performed (Fig. 39 B). This experiment demonstrated that also in epididymis of adult male, without any spermatozoa, the 4933400A11Rik gene is not expressed. 

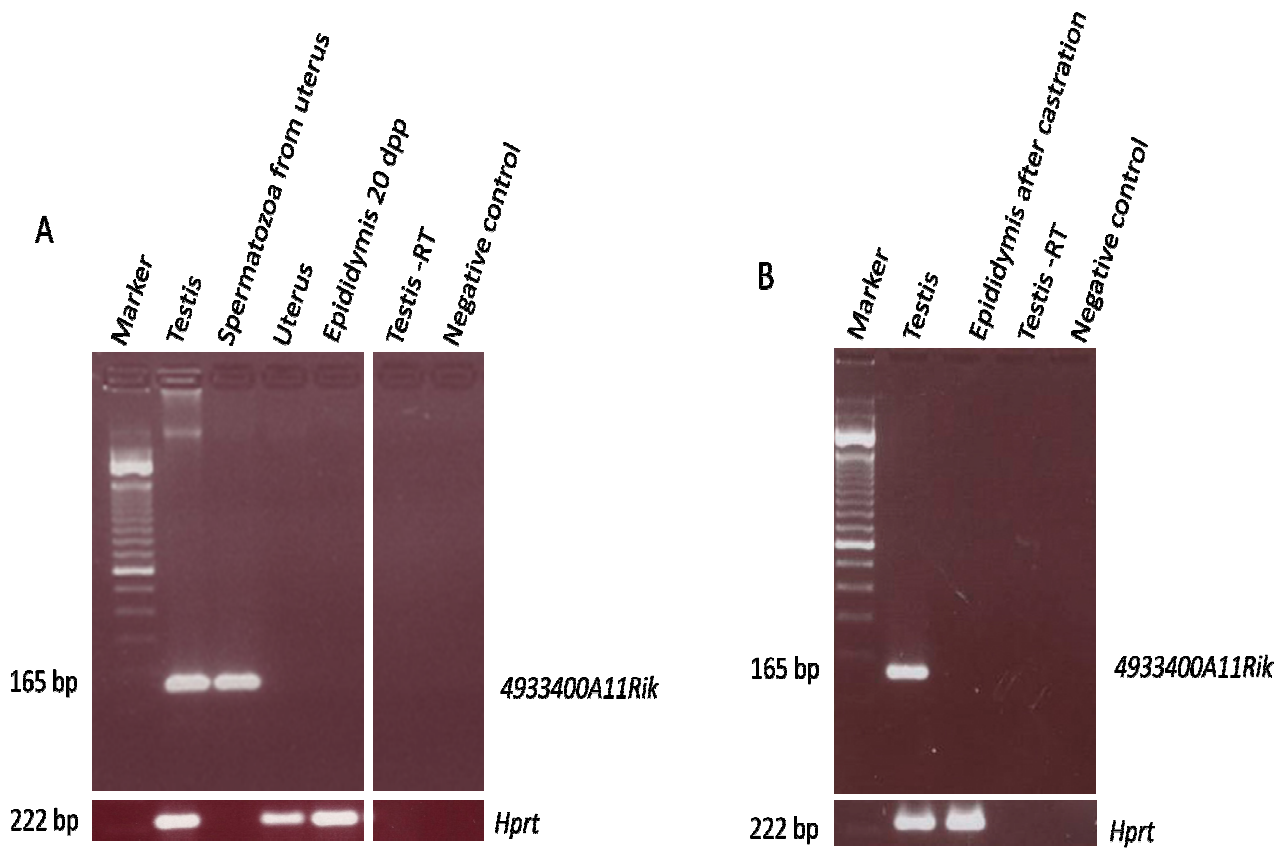

Figure 39. Analysis whether the 4933400A11Rik is present in spermatozoa or is expressed in epididymis. (A) After RT-PCR with 4933400A11Rik specific primers a 165 bp product was observed in spermatozoa isolated from the uterus, but not in epididymis of 20 days old male. (B) No expression of 4933400A11Rik was observed in epididymis of adult male three weeks after castration. cDNA quality was demonstrated by RT-PCR with Hprt primers.

\subsubsection{Analysis whether sperm of $6 \mathrm{xKO}$ infertile males are able to fertilize oocyte}

To check this hypothesis, first early embryonic development was analysed. Five $6 \mathrm{xKO}$ infertile and five $6 \mathrm{xKO}$ fertile males were mated with superovulated wild type females and vaginal plug (VP) was noticed to check whether the copulation had occurred. $48 \mathrm{~h}$ after mating, oocytes/embryos were isolated from VP positive females and fixed in 4 $\%$ paraformaldehyde. In the breeding of $6 \mathrm{xKO}$ fertile males with wild type females $35 \%$ embryos were at 2-cell stage (Fig. $40 \mathrm{~A}$ ). In contrast, in the breeding of $6 \times \mathrm{KO}$ infertile males with wild type females 2-cell stage embryos were not observed (Fig. 40 B). 

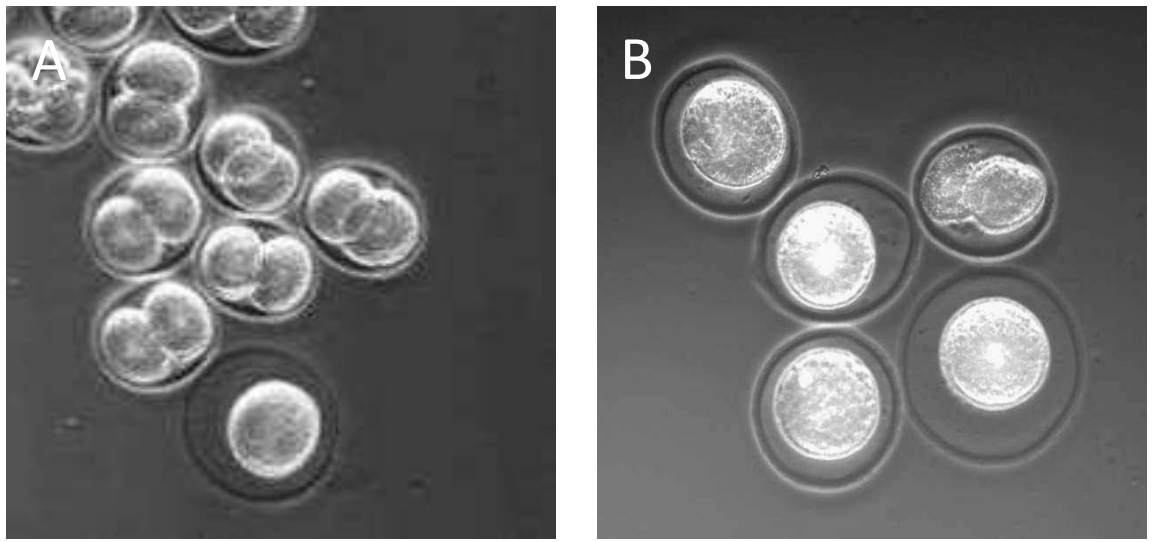

Figure 40. Analysis of oocytes $48 \mathrm{~h}$ after mating. Superovulated wild type females were mated with 6xKO fertile and 6xKO infertile males. About $48 \mathrm{~h}$ after mating, oocytes/embryos were isolated and fixed in $4 \%$ paraformaldehyde. (A) From breeding of fertile 6xKO $35 \%$ of embryos were at 2-cell stage, while from breeding of 6xKO infertile (B) 2-cell stage were not observed.

To further determine whether sperm of $6 \mathrm{xKO}$ infertile males are able to penetrate the oocyte, males were mated with superovulated wild type females and oocytes were examined for the presence of 2 pronuclei. But first it was necessary to determine the right time for oocyte isolation. 5 wild type males were mated with superovulated females and $24 \mathrm{~h}$ after hCG administration oocytes were isolated, fixed in $4 \%$ paraformaldehyde and stained with DAPI as described 2.2.18.8. The examination for the presence of 2 pronuclei was done under fluorescence microscope. 9 from 43 oocytes $(21 \%)$ demonstrated 2 pronuclei (Fig. 41 A). Next, five 6xKO fertile males were mated with superovulated females and oocytes were isolated from VP positive females at different times after hCG administration: 24, 26, 29, 31, 32, 34, 41 and 45 h. As demonstrated in table 7, it was impossible to determine any time point in which significant number of oocyte demonstrated 2 pronuclei. At each time point analysed the proportion of oocyte demonstrating 2 pronuclei was under $8 \%$ which is not enough to perform statistical significant analysis (Fig. 41 B). We concluded that the fertilization process of spermatozoa of 6xKO fertile male is prolonged in time, therefore it will not be possible to determine a single time point optimal for oocyte preparation. We assume that also for $6 \mathrm{xKO}$ infertile males it will not be possible to determine the right time for oocyte isolation. Therefore we have stopped this analysis. 

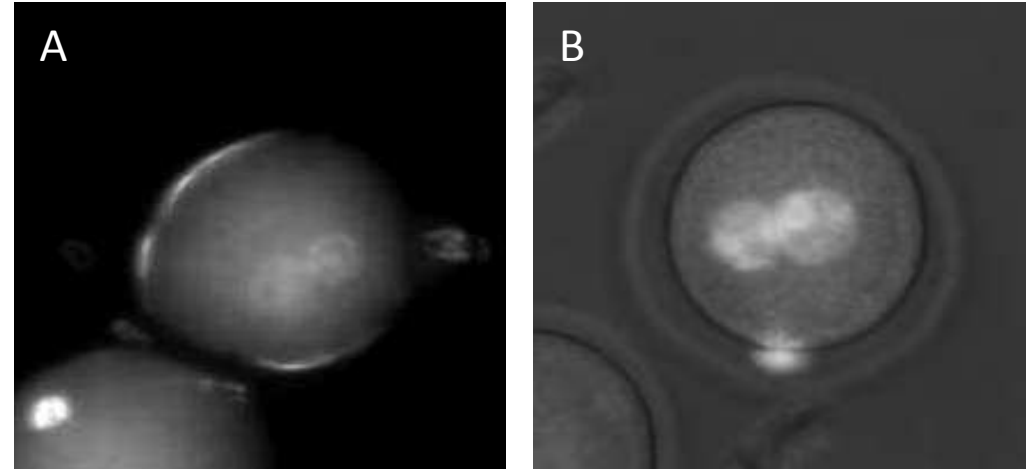

Figure 41. Analysis of oocytes $24 \mathrm{~h}$ after fertilization. Superovulated wild type females were mated with wild type (A) and 6xKO fertile (B) males. $24 \mathrm{~h}$ after mating, oocytes/embryos were isolated, fixed in $4 \%$ paraformaldehyde and stained with DAPI. From breeding of wild type mice $21 \%$ of oocytes with 2 pronuclei (A), while from breeding of $6 x \mathrm{KO}$ fertile males about $3 \%$ were observed.

\begin{tabular}{|c|c|c|c|c|c|c|c|c|}
\hline $\begin{array}{c}\text { Isolation time } \\
\text { after hCG } \\
\text { administration }\end{array}$ & $24 \mathrm{~h}$ & $26 \mathrm{~h}$ & $29 \mathrm{~h}$ & $31 \mathrm{~h}$ & $32 \mathrm{~h}$ & $34 \mathrm{~h}$ & $41 \mathrm{~h}$ & $45 \mathrm{~h}$ \\
\hline 2-cell stage & 1 & 0 & 3 & 1 & 4 & 4 & 6 & 37 \\
\hline 1-cell stage & 69 & 132 & 33 & 45 & 21 & 25 & 41 & 73 \\
\hline 2 pronuclei & 2 & 0 & 3 & 1 & 2 & 0 & 1 & 2 \\
\hline degenerated & 4 & 18 & 5 & 3 & na & na & 7 & 20 \\
\hline total & 76 & 150 & 44 & 50 & 27 & 29 & 55 & 132 \\
\hline
\end{tabular}

Table 7. Analysis of 2 pronuclei stage oocytes isolated from females mated with 6xKO fertile males. Oocytes were isolated at different time points after hCG administration, and stained with DAPI and examined under fluorescence microscope. Four different stages were determined: degenerated oocytes, 1-cell, 2 pronuclei stage and 2-cell stage. na - not analysed. 


\subsubsection{In vitro fertilization}

It was not possible to analyse in vivo whether spermatozoa of $6 \mathrm{xKO}$ infertile males have the ability to penetrate the oocyte, therefore an in vitro approach was applied. First, to optimize the IVF conditions, sperm were isolated from wild type and fertile $6 \mathrm{xKO}$ males and incubated for $6 \mathrm{~h}$ with zona pellucida (ZP) intact oocytes isolated from superovulated wild type females. After incubation oocytes were washed two times and incubated overnight at $37^{\circ} \mathrm{C}$ in $5 \% \mathrm{CO}_{2}$. Next day fertilization ratio was analysed under the microscope. I have found that while $50 \%$ of oocytes incubated with wild type spermatozoa developed to 2-cell stage embryos, only $8.9 \%$ of oocytes incubated with sperm from 6xKO fertile male reached the 2-cell stage (Tab. 8).

\begin{tabular}{|l|c|c|c|c|c|c|c|}
\cline { 2 - 9 } \multicolumn{1}{c|}{} & \multicolumn{7}{c|}{ IVF - oocyte with zona pellucida } \\
\cline { 2 - 9 } \multicolumn{1}{c|}{} & 1-cell stage & $\%$ & 2-cell stage & $\%$ & degenerated & $\%$ & total \\
\hline WT & 14 & 17.3 & 41 & 50.6 & 26 & 32.1 & 81 \\
\hline 6xKO fertile & 102 & 65.0 & 14 & 8.9 & 41 & 26.1 & 157 \\
\hline
\end{tabular}

Table 8. IVF with sperm of wild type and 6xKO fertile mice. The number of oocytes fertilized with sperm of 6xKO fertile male, which developed to the 2-cell stage, is strongly reduced as compared to oocytes incubated with sperm of wild type control.

Because the fertilization success of $6 x \mathrm{KO}$ fertile males in IVF assay was very low, this experiment was not continued for $6 \mathrm{xKO}$ infertile animals. Instead IVF approach using oocytes without ZP was undertaken. Spermatozoa were isolated from $6 \times \mathrm{KO}$ infertile, 6xKO fertile and wild type animals. ZP was removed from oocytes with thyroid acid and $7 \mathrm{~h}$ after IVF oocytes were examined for the presence of 2 pronuclei (Fig. $42 \mathrm{~A}$ ). As demonstrated in table 9, sperm of $6 \mathrm{xKO}$ infertile male were able to penetrate ZP-free oocyte and the number of oocytes demonstrating 2 pronuclei was similar for $6 \mathrm{xKO}$ fertile and wild type males. From all the fertilization experiments we can conclude that the sperm of 6xKO infertile male can enter oocyte after removing of ZP. However, according to the phenotype it seems probable that sperm of $6 \mathrm{xKO}$ infertile males are not able to penetrate ZP intact oocytes. 

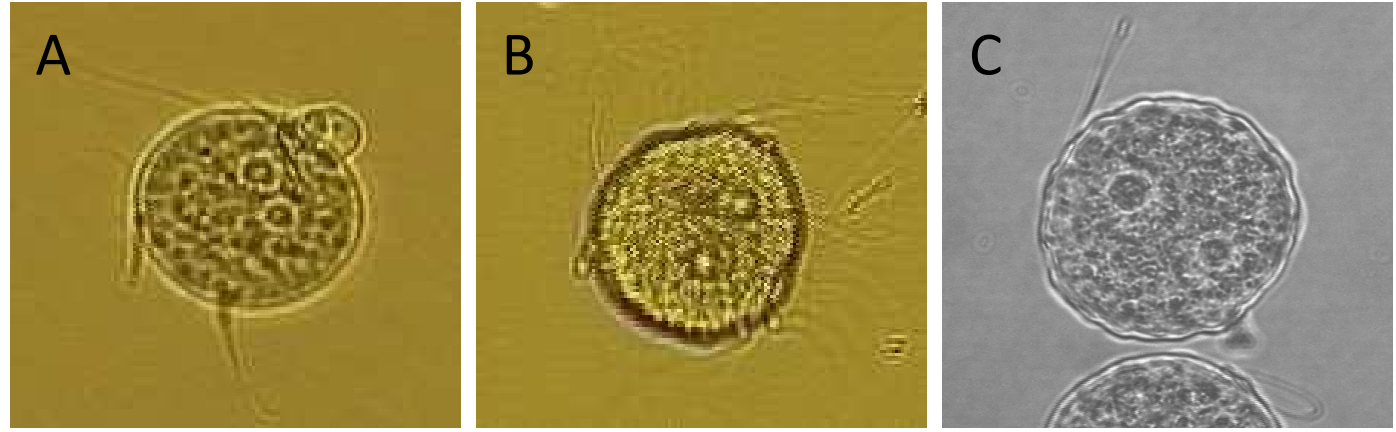

Figure 42. IVF analysis using oocytes without zona pellucida. (A) After incubation with sperm of 6xKO infertile male, the number of oocytes demonstrating 2 pronuclei was similar to that of oocytes incubated with sperm of $(B) 6 \times K O$ fertile and $(C)$ wild type males.

\begin{tabular}{|l|c|c|c|c|c|c|c|}
\cline { 2 - 9 } \multicolumn{1}{c|}{} & \multicolumn{7}{c|}{ IVF - oocyte zona pellucida free } \\
\cline { 2 - 9 } \multicolumn{1}{c|}{} & 2 pronuclei & $\%$ & 1 -cell stage & $\%$ & degenerated & $\%$ & total \\
\hline WT & 60 & 66.7 & 10 & 11.1 & 20 & 22.2 & 90 \\
\hline 6xKO fertile & 27 & 56.3 & 18 & 37.5 & 3 & 6.3 & 48 \\
\hline 6xKO infertile & 15 & 65.2 & 4 & 17.4 & 4 & 17.4 & 23 \\
\hline
\end{tabular}

Table 9. IVF analysis using oocytes without zona pellucida. After $7 \mathrm{~h}$ of incubation with sperm of 6xKO infertile, 6xKO fertile and wild type control males, oocytes were examined microscopically for the presence of 2 pronuclei. No difference in number of 2 pronuclei between oocytes incubated with sperm of all tested males could be found.

\subsubsection{Generation of $4933400 A 11$ Rik knockout mouse}

4933400A11Rik belongs to a capping protein alpha subunit family. Genes from this family encode the alpha subunit of the barbed-end actin binding protein, which regulates growing of actin filaments. To analyse the role of $4933400 A 11 R i k$, we started to generate a knockout mouse line using a commercially available vector (2.2.17).

4933400A11Rik gene is localized in intron of midlinel gene (Midl) on the mouse chromosome X (Fig. 43). Complete open reading frame of 4933400A11Rik is located in 3th exon. Our strategy was to delete only exon 3 of $4933400 A 11$ Rik gene to avoid any disturbance of Midl gene. 


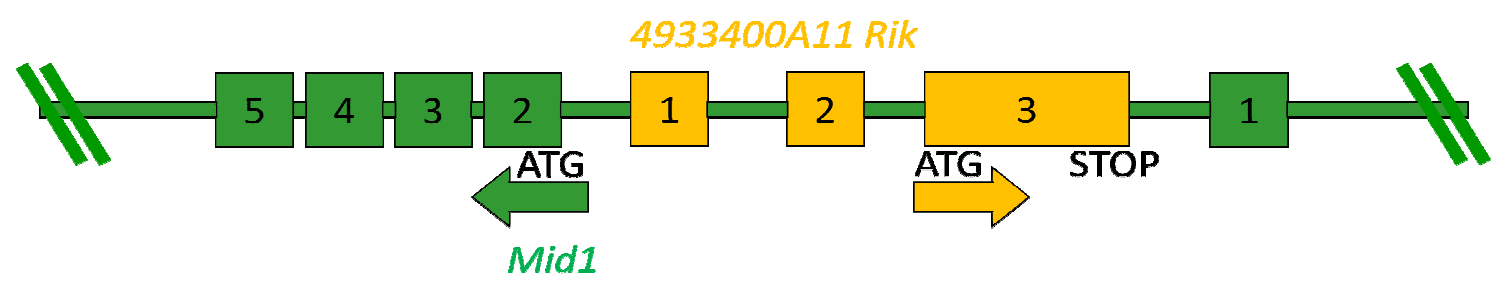

Figure 43. Scheme of 4933400A11 Rik gene structure and localization in first intron of Mid1 gene. Arrows indicate direction of transcription, green/orange boxes represent exons of Mid1/4933400A11 Rik genes, respectively.

Knokcout vector linearized with AsiSI enzyme $(50 \mu \mathrm{g})$ was electroporated by Prof. Adham into embryonic stem cells (C57bl) (2.2.17.1). Electroporated cells were plated on fibroblast layer and after 10 days of selection with neomycine, drug-resistant clones were picked into two 24-wells plate. Genomic DNA was isolated from cells from one 24-well plate (2.2.1.1) and tested with PCR and Southern blot (2.2.11) for homologous recombinantion. First, by PCR with primers mGene5A-F, mGene5-R and mGene5A-R, amplifying a 575 bp product of WT-allel and 233 bp product of KO-allele clones were selected, that contained the knockout vector (Fig. 44 A). For control, WT and KO PCR products were sequenced.

Next, to control a ES-cell clone after homologous recombination, a Southern blot was performed with 3' external probe (Fig. 2). DNA isolated from electroporated ES cells, that contained a KO-vector DNA, was digested with BglII restriction enzyme. Southern blot membrane was hybridized with ${ }^{32}$ P-labelled 870 bp external probe generated by PCR with Sth-3KOMPF5 and Sth-3KOMPR3 primers. This probe was cloned into pGEM-T Easy vector, sequenced and isolated with EcoRI restriction enzyme. As demonstrated in figure $44 \mathrm{~B}$, this probe detects a $15 \mathrm{~kb}$ band representig recombinant allel and $10.5 \mathrm{~kb}$ band corresponding to wild type allel. After Southern blot analysis one homologous recombinant ES-clone was identified (Fig. 44 B). ES-cells of this clone were used for microinjection into blastocysts derived from C57bl/6J mice in the Max Planck Institute for Experimental medicine in Goettingen (2.2.17.2). After 2 attempts of microinjection 23 mice were born and the chimerism was tested by PCR as described in 2.2.17.3. Unfortunately all of the tested animals demonstrated only WT allel (example of 
genotyping PCR results is given in figure $44 \mathrm{C}$ ). Till the end of this work it was not possible to get any chimera.

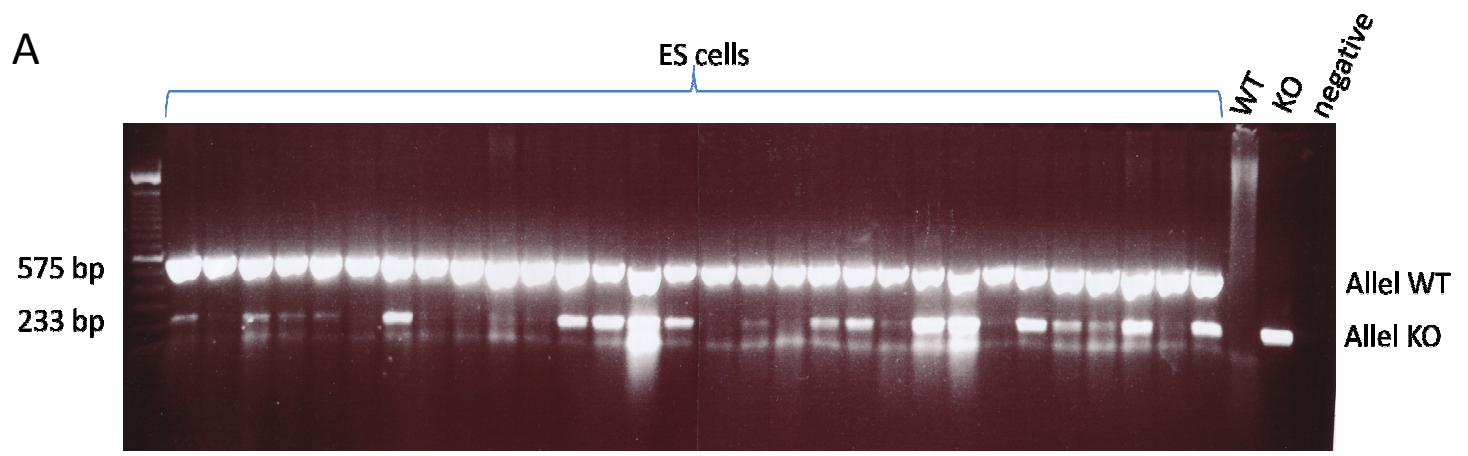

B
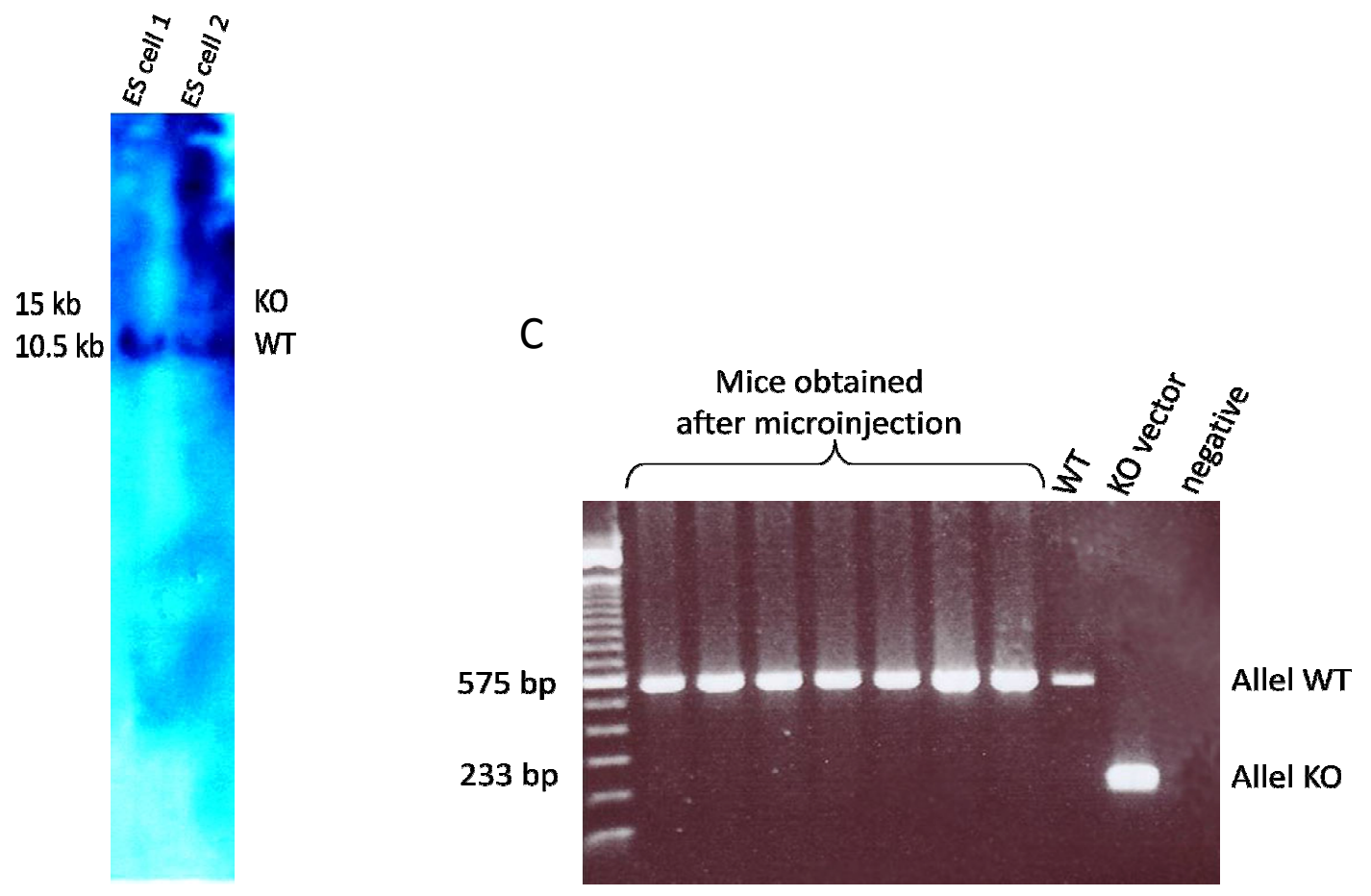

Figure 44. Analysis of ES cells electroporated with 4933400A11Rik KO vector. (A) PCR test of ES cells after electroporation to detect which of them incorporated the KO vector in the genome. (B) Southern blot analysis to detect homologous recombinant ES-cells. 3'external probe recognized a $15 \mathrm{~kb}$ band of recombinant allel and a $10.5 \mathrm{~kb}$ band of WT allel. (C) Genotyping PCR of newborn mice obtained after microinjection. No chimeras could be detected. 


\subsubsection{Analysis of 4933400A11RIK protein}

In order to analyse 4933400A11RIK protein an attempt to generate antibodies against this protein was undertaken. First, using Blast-Protein program a sequence unique for 4933400A11Rik gene was selected. The 4933400A11RIK belongs to the capping protein alpha subunit family and only short peptide of 14 amino acids: MANRKDKASDEKKI (aa 1-14) was found to be specific for this protein. This peptide was used to generate antibody by the Gene Script Company.

To test the specificity of generated antibody, a Western blot with proteins isolated from testis, epididymis and liver was performed. The membrane was incubated with rabbit anti-4933400A11RIK (1:1000) and with anti-rabbit alkaline phosphatase conjugated (1:5000) antibodies. Two bands were observed in testis and epididymis (Fig. $45 \mathrm{~A})$. The $45 \mathrm{kDa}$ band is unspecific because this band is also detected in liver while RTPCR analysis demonstrated that there is no expression of 4933400A11Rik gene in this organ (Fig. $45 \mathrm{~A}$ ). The $27 \mathrm{kDa}$ band observed in epididymis correspond to the predicted size of 4933400A11RIK protein. The $55 \mathrm{kDa}$ band observed in testis is two times bigger that the predicted size of 4933400A11RIK, thus it could represent a dimer of this protein. For control Western blot was incubated with rabbit serum collected before immunization (serum " 0 ") and with antibody pre-absorbed with peptide used for production of this antibody. In all Western blots the same proteins were used. No signals were observed in both control hybridizations indicating the specificity of produced antibody (Fig. $45 \mathrm{~A}$ ).

As demonstrated before (Fig. 36), the expression of 4933400A11Rik gene was not detectable by RT-PCR in testis of 6xKO infertile mouse. Therefore, Western blot with protein isolated from testis of $6 \mathrm{xKO}$ fertile and $6 \mathrm{xKO}$ infertile males was performed to check whether the $55 \mathrm{kDa}$ band observed in wild type testis indeed represents the 4933400A11RIK protein. Protein electorophoresis was performed longer than earlier, so proteins became better separated. While RT-PCR confirmed that in all 6xKO infertile animals tested the 4933400A11Rik gene is not expressed (Fig. 45 C) antibody recognized the same $55 \mathrm{kDa}$ band in testes of all males (Fig. $45 \mathrm{~B}$ ). This clearly indicates that this band does not represent the 4933400A11RIK protein. Thus we concluded that generated antibody cannot be used in Western blot. 


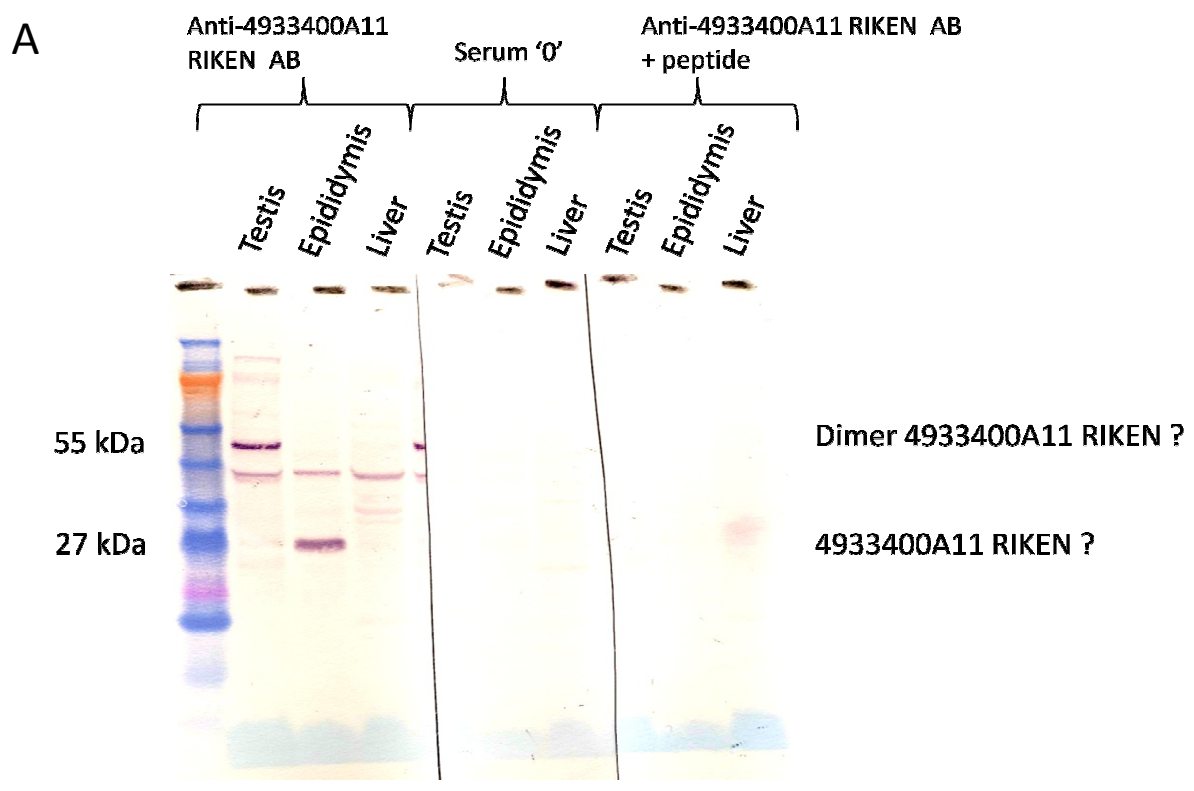

B

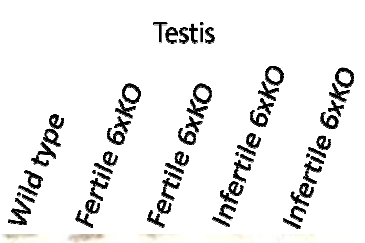

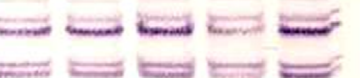
4933400A11 RIKEN ?
C

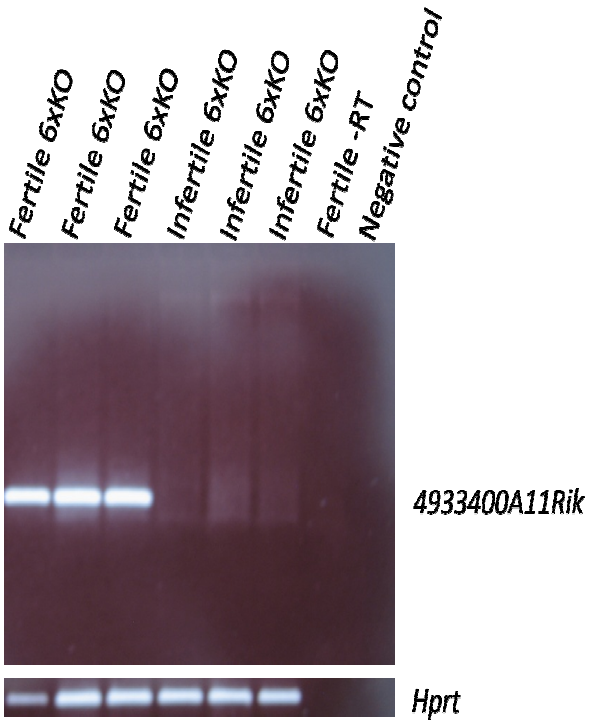

Figure 45. Analysis of anti-4933400A11RIK antibody. (A) Western blot analysis of protein isolated from wild type testis, epididymis and liver. Rabbit anti-4933400A11Rik and secondary anti-rabbit alkaline phosphatase conjugated antibodies recognized a 55kDa band in testis and a $27 \mathrm{kDa}$ band in epididymis. The epididymal $27 \mathrm{kDa}$ band correspond to the predicted size of 4933400A11RIK protein while 55kDa band observed in testis might represent a dimer. As a control Western blot incubated with serum "0" and with antibody pre-absorbed with peptide used for rabbit immunization was performed. (B) Western blot analysis of testis of $6 \times \mathrm{KO}$ fertile and infertile mice revealed that the $55 \mathrm{kDa}$ band is not 
specific for the 4933400A11RIK protein since this band is detected in the testis of 6xKO infertile males while RT-PCR (C) demonstrated no expression of this gene in this organ. RNA quality was demonstrated by PCR with Hprt-specific primers.

\subsubsection{Anti-4933400A11RIK antibody test in immunostaining of transiently tranfected cells}

To determine whether the anti-4933400A11RIK antibody generated by the Gene Script company can be used for detection of 4933400A11RIK protein in the cell, 4933400A11RikdsRED fusion protein was generated. Entire coding region of 4933400A11Rik gene was amplified with Gene5HindRedF and Gene5KpnRedR primers, cloned into pGEM-T Easy vector and verified by sequencing. PCR product without any mutation was digested with HindIII and $K p n I$ restriction enzymes and sub-cloned into HindIII/KpnI linearized pDsRED-monomer-N1 vector. In this construct the 4933400A11RikdsRED fusion protein is expressed under the control of CMV IE promoter (human cytomegalovirus immediate early promoter), kanamycin resistance gene was used to screen for a positive bacteria clone (Fig. 46).

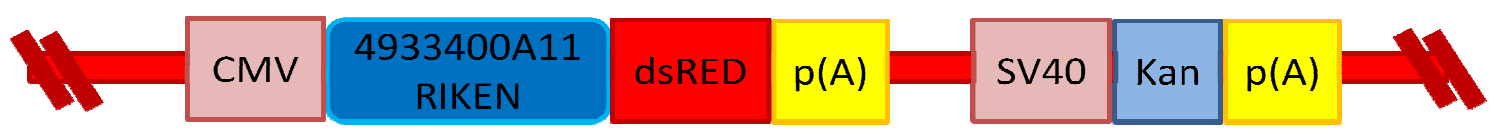

Figure 46. Schematic representation of 4933400A11RikdsRED fusion construct. CMV CMV IE promoter (human cytomegalovirus immediate early promoter), 4933400A11RIKEN - complete ORF of tested gene, dsRED - dsRed-monomer domain, p(A) - polyadenylation signal, SV40 - SV40 early promoter, Kan - kanamycin resistant cassette.

After purification with Midi Plasmid Kit (Invitrogen) construct DNA was transiently transfected into cultured $\mathrm{HeLa}$ and GC-4 cells using lipofectamine as described in section 2.2.16.2. For a control transfection dsRED vector without any insert was used. After $24 \mathrm{~h}$ cells were fixed and immunostained with rabbit anti4933400A11RIK (1:5000) and secondary anti-rabbit-FITC (1:500) antibodies. Nuclei were counterstained with DAPI. Red signals representing the 4933400A11RikdsRED fusion protein was observed mainly in the nucleus of transfected HeLa and GC-4 cells 
Results

(Fig. 47 A, G) but no green fluorescence overlapping with red signals could be observed (Fig. 47 C, I).

HeLa cells

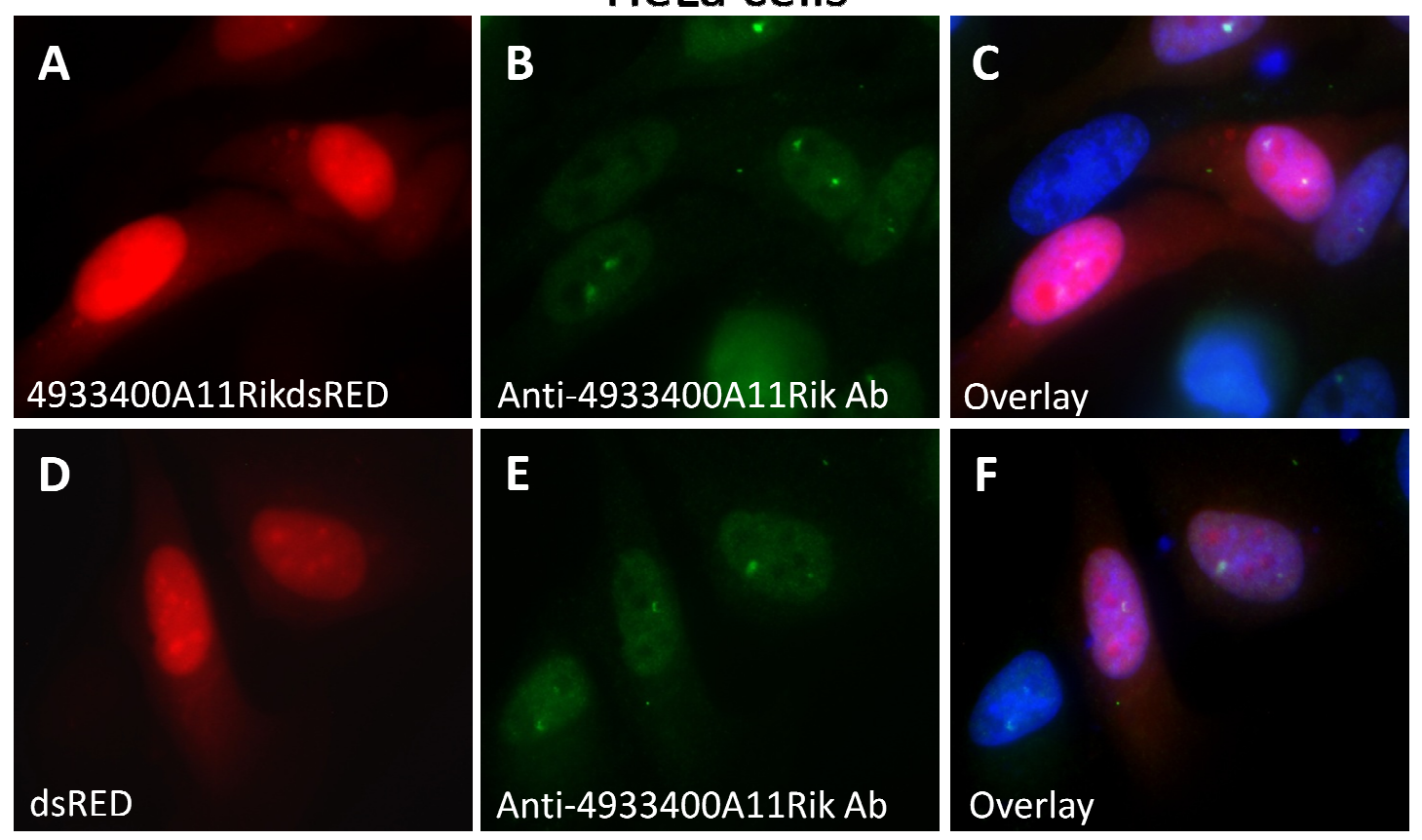

\section{GC-4 cells}

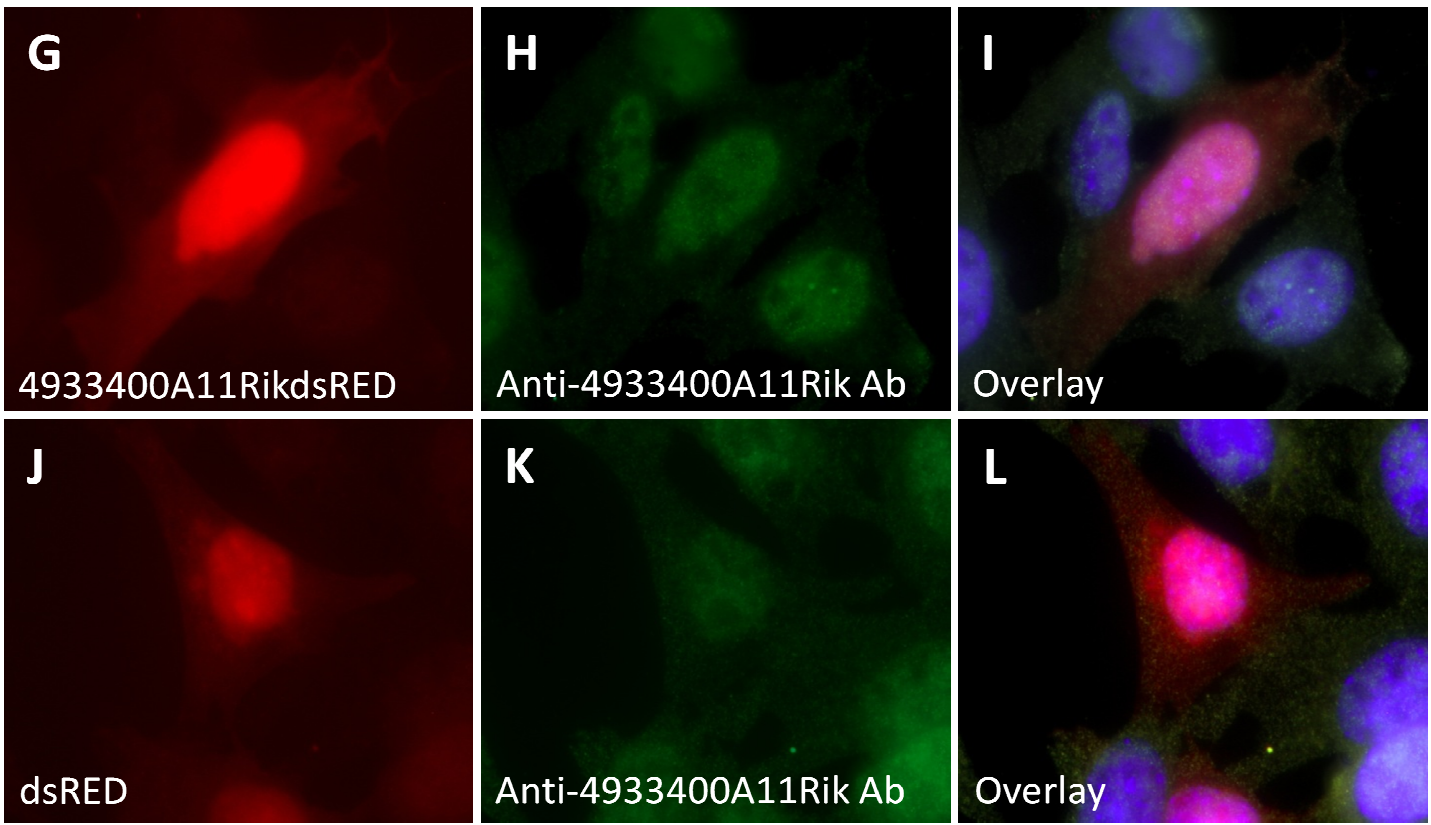

Figure 47. Immunostaining of HeLa (A-F) and GC-4 (G-L) cells transiently transfected with 4933400A11RikdsRED construct with anti-4933400A11RIK antibody. HeLa and GC-4 cells 
were transfected with 4933400A11RikdsRED construct (A-C and G-I) and with empty dsRED vector for control (D-F and J-L). Immunostaining was performed with anti4933400A11Rik and anti-rabbit-FITC antibodies. Nuclei were counterstained with DAPI. No green fluorescence overlapping with red signals was observed, indicating that anti4933400A11RIK antibody did not react with 4933400A11RIKdsRED fusion protein.

As demonstrated in figure 47 the sub-cellular localization of 4933400A11RIKdsRED protein and used for control dsRED protein, was similar. Thus we concluded that when dsRED was fused to the C-terminal end of the 4933400A11RIK protein the sub-cellular localization of 4933400A11RIK was disturbed. Therefore another construct, encoding a 4933400A11RIK with EGFP protein fused to the N-terminal end, was generated. Entire ORF of 4933400A11Rik was amplified with primers Gene5HindEGFPF and Gene5KpnRedR introducing HindIII and KpnI restriction sites to the PCR product and cloned into pGEM-T Easy vector. Next, the sequence was analysed for mutations and finally the insert was sub-cloned into pEGFP-C1vector linearized with HindIII and KpnI enzymes. This fusion protein was also expressed under the control of CMV IE promoter (human cytomegalovirus immediate early promoter) (Fig. 48).

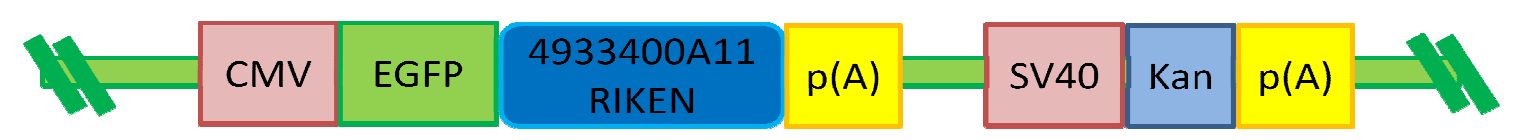

Figure 48. Schematic representation of 4933400A11RikpEGFP fusion construct. CMV CMV IE promoter (human cytomegalovirus immediate early promoter), 4933400A11RIK complete ORF of tested gene, EGFP - green fluorescent protein domain, p(A) polyadenylation signal, SV40 - SV40 early promoter, Kan - kanamycin resistant cassette.

HeLa cells were transfected with 4933400A11RikpEGFP or with empty pEGFP using lipofectamine. Cells cultured for $24 \mathrm{~h}$ were fixed and immunostained with rabbit anti-4933400A11RIK (1:10000) and anti-rabbit-Cy3 (1:500) antibodies and mounted with DAPI. Green fluorescence of 4933400A11RikpEGFP fusion protein was observed in cytoplasm (Fig. 49 A). Clear overlapping of green and red signals, representing anti4933400A11RIK antibody was observed (Fig. 49 B, C). In cells transfected with pEGFP 
vector no co-localization of green and red fluorescence was observed (Fig. 49 D-F) indicating that the antibody staining of 4933400A11RikpEGFP fusion protein is specific.
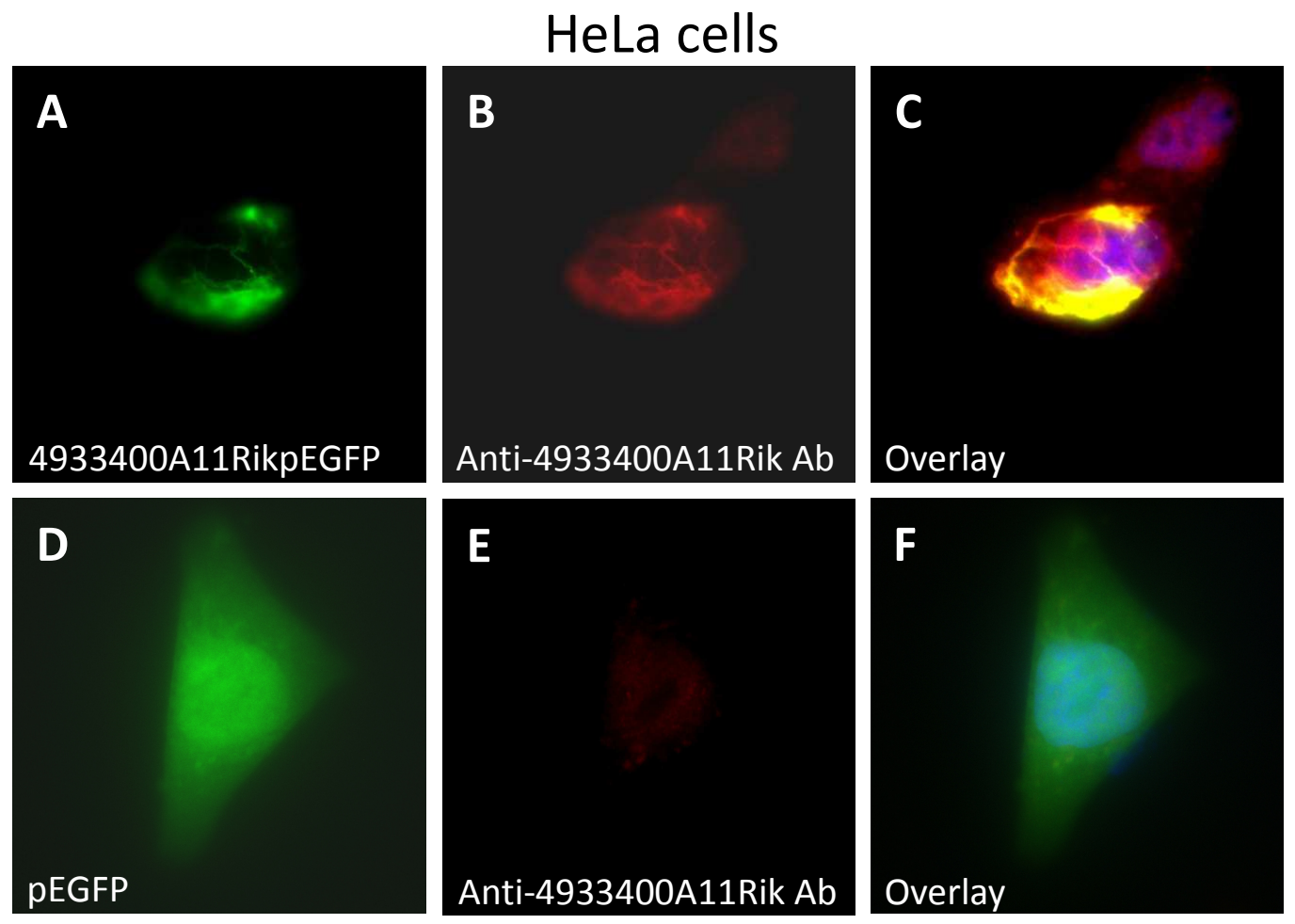

Figure 49. Immunostaining of HeLa cells (A-F) transfected with 4933400A11RikpEGFP construct with anti-4933400A11Rik antibody. HeLa cells were transfected with 4933400A11RikpEGFP (A-C) and with empty pEGFP (D-F) vectors. Immunostaining was performed with rabbit anti-4933400A11RIK and anti-rabbit-Cy3 antibodies. Co-localization of green and red fluorescence $(C)$ indicates that anti-4933400A11RIK antibody react with 4933400A11RikpEGFP fusion protein.

\subsubsection{Sub-cellular localization of mouse 4933400A11RIK protein}

As demonstrated in figure 49 A-C the 4933400A11RikpEGFP fusion protein is localized in cytoplasm and the signal pattern resembles the cytoskeleton. As mentioned before, 4933400A11RIK protein belongs to the actin capping protein family. To verify whether this protein is a member of this family, a co-localization of 4933400A11RikpEGFP fusion protein with F-actin capping protein subunit alpha-1 (CAPZA1) was analysed. HeLa cells were transfected with 4933400A11RikpEGFP 
construct and for control with empty pEGFP vector using lipofectamine. After fixation, cells were immunostained with rabbit anti-CAPZA1 (1:10000) and secondary anti-rabbitCy3 (1:500) antibodies. Nuclei were counterstained with DAPI. Partial co-localization of 4933400A11RikpEGFP and CAPZA1 was detected (Fig. 50 A-C) in the cytoplasm of transfected cells. In contrast, no co-localization of pEGFP protein with F-actin capping protein subunit alpha-1 could be detected (Fig. 50 D-F). This result indicates that mouse 4933400A11Rik gene encodes a protein from the actin capping protein family.
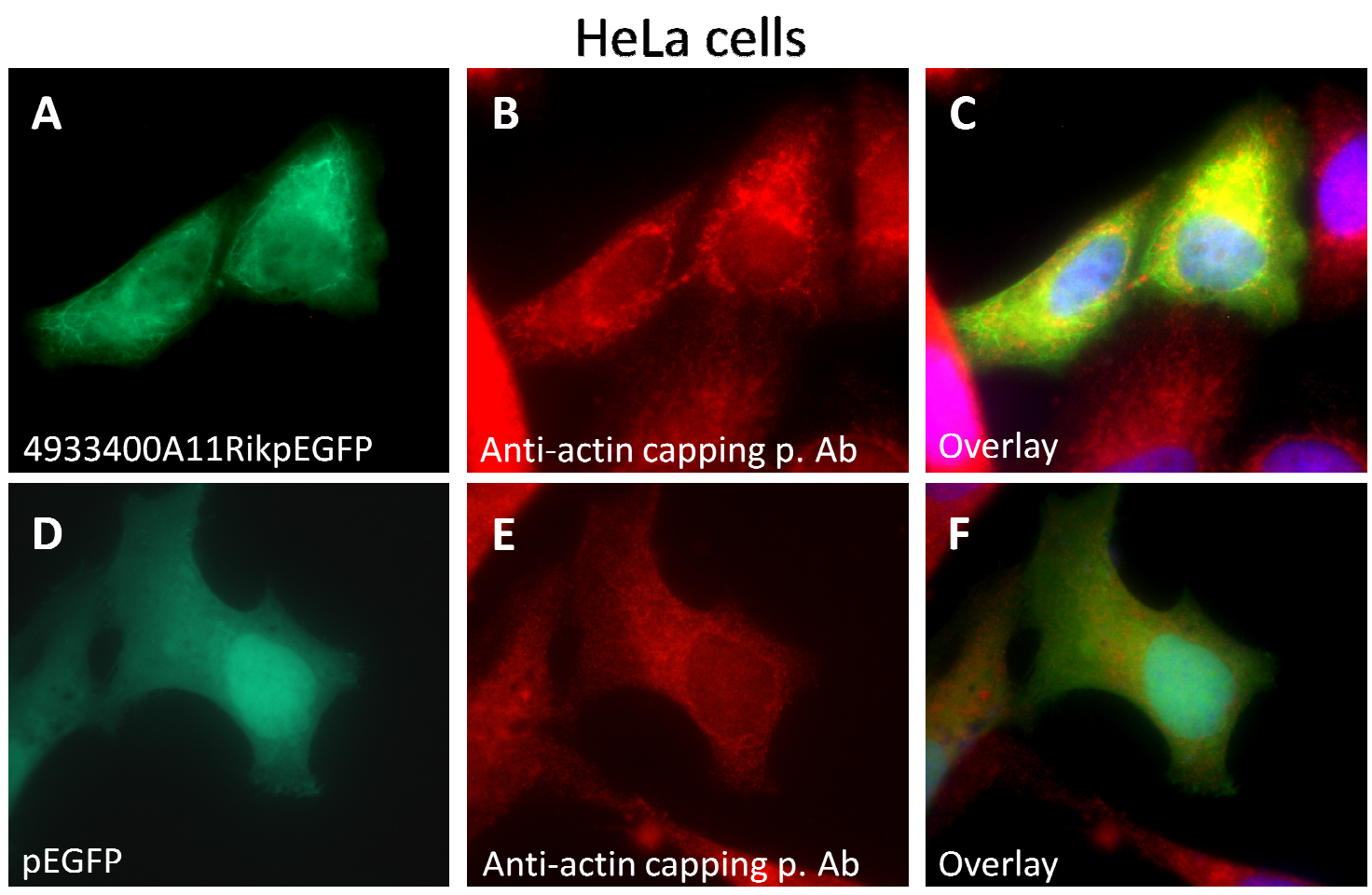

Figure 50. Immunostaining of HeLa cells (A-F) transfected with 4933400A11RikpEGFP construct with anti-F-actin capping protein subunit alpha-1 antibody. HeLa cells were transfected with 4933400A11 RikpEGFP (A) and with empty pEGFP (D). Immunostaining was performed with rabbit anti-F-actin capping protein subunit alpha-1 and anti-rabbitCy3 antibodies (B, E). Partial co-localization of 4933400A11 RikpEGFP protein with F-actin capping protein subunit alpha-1 was observed (C) while no co-localization was detected in control transfection $(\mathbf{F})$. 


\section{DISCUSSION}

\subsection{Analysis of the CCDC33 protein}

\subsubsection{Identification of domains in $\mathrm{CCDC33}$ and PXT1 responsible for protein- protein interaction}

Coiled coil domain containing 33 (CCDC33) protein contains three coiled coil domains, which are known as important elements in protein-protein interactions (Talbot and Hodges, 1982; Naik et al., 2001; Frank et al., 2002; Singh and Hitchcock-DeGregori, 2003; Mason and Arndt, 2004; Iwai et al., 2008; Mason, 2009). Therefore, one could expect that at least one of them is involved in interaction with PXT1. However, using the yeast-two-hybrid technique we could demonstrate that CCDC33 interacts with PXT1 through another domain. The deletion of even all coiled coil domains did not influence the interaction with PXT1. The analysis of evolutionary conserved amino acids sequence and the deletion of the part containing leucine-glycine-valine-serine-leucine-prolineleucine (LGVSLPL) was found to disturb CCDC33-PXT1 interaction, suggesting that this motif plays an important role in this interaction. All these amino acids are often present in domains involved in protein-protein interactions (Padmanabhan and Baldwin, 1994; Kobe, 1996; Williamson, 1994; Doyle et al., 1996; Kajava, 1998; Lim et al., 2002; Nedura et al., 2007; Rotem et al., 2008; Pelish et al., 2010). LGVSLPL motif, together with some surrounding amino acids, is similar to leucine rich repeat domain (LR). LR structure is responsible for the interactions between such proteins as flagellar outer dynein arm light chain (LC1) and the dynein motor domain (Wu et al., 2000); two U2 small nuclear ribonucleoproteins A' and B' (Scherly et al., 1990); RNase inhibitor with angiogenin and RNase A (Chen et al., 1997) or fibroblast growth factor (FGF) with fibronectin-leucine-rich transmembrane (FLRT) protein family (Karaulanov et al., 2006). The leucine rich domains are generally 20-29 residues long and contain a conserved 11residue segment with the consensus sequence containing leucines, valines, isoleucines or phenylalanines separated by 1-3 other amino acids (Buchanan et al. 1997; Kajava, 1998; Kobe and Kajava, 2001). In the detected region of CCDC33 protein, 5 leucines and 2 valines are similar as in LR domain. Isoleucine or phenylalanine are not present, but 
additional proline and glycine, which are also characteristic for some other domains of LR family, such as RL-like or bacterial LR (Kobe and Deisenhofer, 1994 and 1995a/b; Kajava, 1998; Kobe and Kajava, 2001), have similar order in CCDC33.

In the PXT1 protein LAPF amino acid motif was further detected as important part for binding with the BAG6 (BCL2-associated athanogene 6 also known as BAT3) protein (Kaczmarek et al., 2011). In the direct yeast two-hybrid system it was demonstrated that the mutation of $\mathrm{L}$ into $\mathrm{G}$ and $\mathrm{F}$ into $\mathrm{A}$ in a construct containing amino acids 2-30 of PXT1 completely abolishes the PXT1-BAG6 interaction, suggesting that the LAPF motif is the core of the PXT1 domain which interacts with BAG6 (Kaczmarek, 2009; Kaczmarek et al. 2011). The same LAPF motif was demonstrated to be responsible for the interaction with CCDC33, however only a part of PXT1 protein was used in this analysis (Kaczmarek, 2009). In order to verify this finding, we used a construct containing complete open reading frame of Pxtl gene. Deletion of the LAPF motif or substitution into GGGG sequence strongly, but not completely, reduced the interaction of CCDC33 and PXT1, confirming that this motif also takes part in the CCDC33-PXT1 interaction. Since PXT1 interacts with BAG6 and CCDC33 using the same motif, we can speculate that both interacting proteins might compete to bind with PXT1. Further understanding of this mechanism can bring more information about the control of PXT1 pro-apoptotic activity.

\subsubsection{CCDC33 can inhibit pro-apoptotic activity of PXT1 in spermatocytes}

PXT1 is a first peroxisomal protein containing a functional BH3-like domain (Kaczmarek et al., 2011): this domain is known to trigger apoptosis (Lomonosova and Chinnadurai, 2008). The exclusive expression of Pxt1 gene in the male germ cells is an evidence that this gene is involved in apoptosis control during spermatogenesis (Grzmil et al., 2007). Transgenic males overexpressing PXT1 showed strongly enhanced germ cells apoptosis (Kaczmarek et al., 2011). Overexpression of PXT1 initiates cytomorphological alterations typical for apoptosis: nuclear fragmentation, plasma membrane blebbing, cell rounding and shrinkage (Mund et al., 2003; Alberts et al., 2008; Nozawa et al., 2009). Interaction of BAG6 and PXT1 regulates the PXT1-induced apoptosis (Kaczmarek, 2009; Kaczmarek et al., 2011). 
The expression of $C c d c 33$ and Pxt1 starts from $15 \mathrm{dpp}$ in postnatal mouse testis the stage when primary spermatocytes are present (Grzmil et al., 2007; Kaczmarek et al., 2009). I have demonstrated that the CCDC33 protein can be detected from $16 \mathrm{dpp}$ in spermatocytes and germ cells at later stages of spermatogenesis. HeLa cells cotransfected with constructs expressing Cccd33 and Pxt1 demonstrated co-localization of CCDC33 and PXT1 in cytoplasm and reduced apoptosis as compared to the cells transfected with Pxt1 construct alone. This finding may suggest that physical binding of both proteins inhibits PXT1-induced apoptosis. However, it remains unclear whether BAG6 and CCDC33 protect cells from PXT1 induced apoptosis by the same or two different pathways.

The interaction of CCDC33 and PXT1 as well as the expression pattern of Ccdc33 implicate that this gene might be involved in the control of male gametes production. Spermatogenesis is a precisely controlled biological process in which germ stem cells differentiate into spermatozoa. Programmed cell death is a normal and very important event in this process. About $75 \%$ of developing germ cells undergo apoptosis in mammalian testis. This process is regulated by various factors (Fig. 51). An early wave of germ cell apoptosis keeps proper balance between germ cells and supporting Sertoli cells (Blanco-Rodriguez, 1998; Print and Loveland, 2000; Carmell et al., 2002; Shaha et al., 2010). 


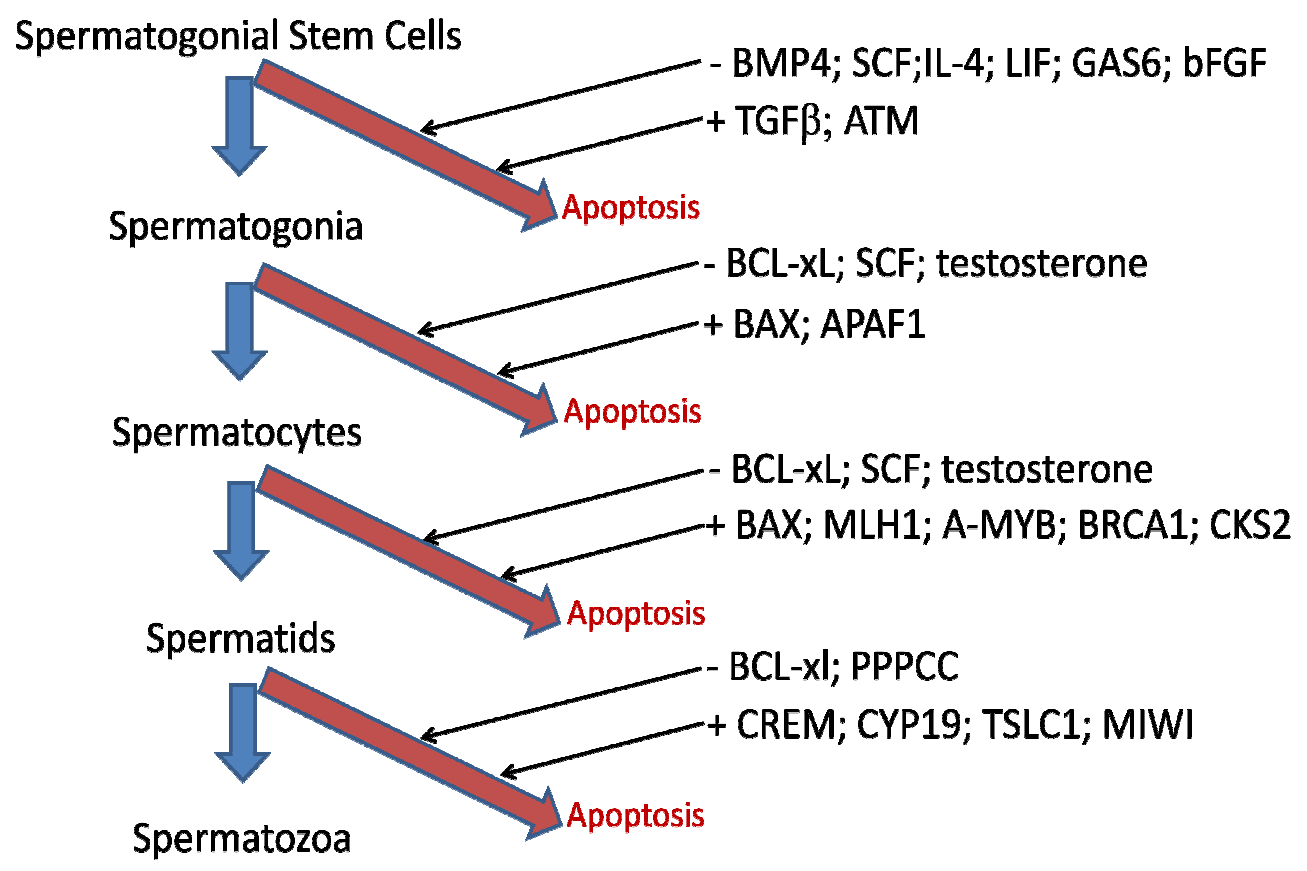

Figure 51. Regulation of apoptosis during spermatogenesis. Samples of proteins, which promotes "+" and inhibits "_" apoptosis are presented (Blanco-Rodriguez, 1998; Print and Loveland, 2000; Shaha et al., 2010; modified).

Development of spermatocytes is regulated by proteins which belong to the Bcl-2 family (BAX, BCL-xL, BIK, BIM) (Sattler et al., 1997; Garrison et al., 2011). BAX and BCL-xL belong to one signalling pathway, which is essential for male germ cell homeostasis. BCL-xL promotes cell survival, and BAX promotes apoptosis of spermatocytes (Rucker et al., 2000; Shaha et al., 2010). BAX-deficient mice exhibit reduced germ cell death during spermatogenesis, leading to an increase in the number of atypical premeiotic germ cells, abnormalities in structure of seminiferous tubules and infertility (Knudson et al., 1995). Mice deficient in BCL-xL present increased apoptosis of germ cells and a complete lack of spermatozoa (Sertoli-cell-only phenotype) (Print $e t$ al., 1998; Ross el al., 1998; Song et al., 2011). Mice lacking other proteins from Bcl-2 family, namely BIK and BIM, are also infertile with reduced testicular cell content. The testes of bik-/-bim-/- males exhibit increased numbers of spermatogonia and spermatocytes and no spermatozoa, which suggests that spermatogenesis fails because supporting Sertoli cells are crowded (Coultas et al., 2005). The dysregulation of genes 
from both pro- and anti-apoptotic groups leads to fertility problems clearly demonstrating how important the balance of apoptotic regulators for spermatogenesis is (Shaha et al., 2010; Vergara et al., 2011). The strongest expression of Ccdc33 was found in round spermatids (Dastig et al., 2011), which suggests that CCDC33 can be an important regulator of apoptosis in post-meiotic cells; however, this protein might also play a certain role in pre-meiotic spermatocytes. In order to better understand the function of this gene, it is important to prepare $C c d c 33$ knockout mice. One can expect a higher apoptosis rate in $\mathrm{Ccdc} 33^{-/}$mice.

In my work I have generated 4 male $C c d c 33$ chimeras. In spermatozoa isolated from epididymides of 2 chimeric males, recombinant allel could be detected, but when spermatozoa of the same 2 males were washed from uteri of plugged females I was unable to detect the recombinant allele. Moreover, all offspring were genotyped as wild type. This observation suggests that the viability of sperm harbouring the recombinant allele is reduced and the allele do not overcome the selection mechanisms during transport. More chimeras should be analysed to assess whether recombinant sperm are present in Vas deferens.

\subsection{Analysis of knockout mouse line with the disruption of 6 germ cell-specific genes}

\subsubsection{Males from $6 x \mathrm{KO}$ line are infertile}

Gene knockout technology is a powerful tool for analysing the function of genes. Using this technique, the function of many genes involved in spermatogenesis was identified and the genes were acknowledged as essential for male fertility. Mutations in the Kit gene (kit oncogene and the mutations are known as white spotting - W) affect the proliferation and differentiation of spermatogonial stem cells, and $W / W^{v}$ mutant mice are lacking germ cells (de Rooij and de Boer, 2003). The deletion of Dmc1 (DMC1 dosage suppressor of mckl homolog, meiosis-specific homologous recombination) or Syce3 (synaptonemal complex central element protein 3) blocks synapses initiation and results in the arrest of the first meiotic division (Pittmann et al., 1998; Schramm et al., 2011). Mice with the disruption of olt (oligotriche) and qk (quaking) genes demonstrated spermatogenesis arrest at the spermatid stage (Bennett et al., 1971; Moutier, 1976). 
However, it has been found that null mutations in a single germ cell specific gene does not always lead to significant spermatogenesis disruption; therefore, such genes were referred to as "non-essential" (McMillan et al., 2002; Kaneko et al., 2010). In order to examine the synergistic function of these non-essential proteins in spermatogenesis and during fertilization, multiple knockout mice were established. Double-knockout mice lacking two sperm serine proteases, ACR and PRSS21 (protease serine 21), are subfertile. The mutant epididymal sperm exhibited the inability to undergo acrosomal exocytosis on the zona pellucida (ZP) surface and to penetrate through the ZP. They were also defective in penetration through the cumulus matrix to reach the ZP (Kawano et al., 2010). In Prnp/Prnd (prion protein/prion protein dublet) double mutant mice spermatozoa developed normally, but fertilization ratio was decreased. Most of the mutant sperm were unable to undergo acrosomal reaction and when sometimes spermatozoon was able to fertilize oocyte, the embryonic development failed at an early stage as a result of oxidative DNA damage (Paisley et al., 2004).

Non-essential genes: Acr, Tnp2, Hist1h1t, Theg, Creb3l4, Tex22 and Smcp were analysed in the Institute of Human Genetics. Heterozygous/homozygous double knockout mice Histlhla/Smcp, Hist1h1t/Smcp, Tnp2/Smcp and Acr/Smcp are subfertile, while double homozygous mutants are nearly infertile. In Histlhla-/-/Smcp-/- the migration of spermatozoa is disturbed in female genital tract; in Hist1h1t-/-/Smcp-/- spermatozoa show head abnormalities; in Tnp2-/-/Smcp-/- the motility of spermatozoa's is affected; and in Acr-/-/Smcp-/- the sperm-oocyte interaction is impaired (Nayernia et al., 2003b). Triple knockout mice of Acr/H1.1/Smcp, Acr/Tnp2/Smcp, Tnp2/H1.1/Smcp, Acr/Hist1h1t/Smcp and Tnp2/Hist1h1t/Smcp (Smcp, sperm mitochondria-associated cysteine-rich protein) exhibit drastic reductions in fertility on mixed genetic backgrounds due to defects in sperm motility correlated with reduced migration in the female reproductive tract. They also show decreased fertilization due to defects in the adhesion of sperm to the zona pellucida (Nayernia et al., 2005). Double knockout mice for only Acr, Tnp2, Histlh1t, Theg, Creb3l4 or Tex22 genes were found to be viable and fertile. Therefore, the question arises: how many of these six non-essential male germ cell expressed genes are dispensable for sperm differentiation and function. To answer this question, several knockout lines deficient for 1, 2, 3, 4, 5 and 6 of these genes in a single animal were generated on the mixed CD-1 $\times$ C57Bl/6J $\times 129 / \mathrm{Sv}$ background. Males with mutated 1, 2, 
3, 4 and 5 genes are fertile and they exhibit normal sperm parameters, clearly demonstrating the functional redundancy of these proteins in male mouse fertility (Adham et al., 2001; Adham et al., 1997; Adham et al., 2005; Drabent et al., 2000; Geisler, 2004; Mannan et al., 2003; Nayernia et al., 2002a; Nayernia et al., 2003b; data not published). $20 \%$ of males from the line with all six genes Acr, Tnp2, Hist1h1t, Theg, Creb3l4 and Tex22 mutated are infertile. These findings demonstrate that multiple knockout lines can be a very good tool to investigate cumulative effects of non-essential genes in spermatogenesis, they also suggest that male fertility involves synergistic interactions of genes controlling male fertility.

In order to further study the underlying cause for the male infertility in the $6 \mathrm{xKO}$ line, various fertility-relevant parameters were analysed. Increased number of spermatozoa with abnormal head and reduction of sperm motility was observed in $6 \mathrm{xKO}$ males. After mating with wild type female $6 \mathrm{xKO}$ sperm needed noticeably longer to fertilize oocyte as compared to wild type sperm. However, in the case of fertile $6 x \mathrm{KO}$ males these changes in sperm quality did not significantly influence the litter size. It should be noted that sperm motility and morphology might not be very important for fertility under laboratory conditions, but they may have a significant function in nature (Gomendio and Roldan, 2008); therefore, we cannot exclude that in competition with wild type males, reproduction success of 6xKO mutants may be reduced.

The competition of sperm from various individuals is a well known phenomenon (Clark, 2002; Stockley, 2004; Dean et al., 2006). The sperm competition in knockout mice was also analysed to discover gene function. For example, polycystin-1 knockout mice are fertile in unrestricted mating trials, but they exhibit lower reproductive success when competing with wild-type males in sequential mating trials and in artificial insemination of mixed-sperm populations (Sutton et al. 2008). Sperm from triple mutant mice Tnp-22-/-/Acr-/-/H1.1-/- exhibit selective disadvantages in the presence of Acrdeficient sperm and authors suggested that some sperm proteins are essential for competition (Nayernia et al., 2003). Moreover, it was observed that abnormal spermatozoa are eliminated by passing the utero-tubular junction, suggesting that female reproductive tracts play also an important role in the selection of male gametes migrating towards eggs (Kotarska and Lenartowicz, 2011). We have observed that in the infertile males from $6 \mathrm{xKO}$ line sperm parameters were significantly worse as compared to the 
fertile animals or wild type animals. We believe that this is an effect of both genetic background and the inactivation of six germ cells-specific genes.

\subsubsection{A11RIK protein may be responsible for the infertility of $6 \times \mathrm{KO}$ mice males}

In order to examine more thoroughly which genes might be involved in the infertility of $6 \mathrm{xKO}$ males, we performed transcriptome assay and compared the expression of genes in the testes of 5xKO fertile and 6xKO infertile animals.

The transcriptomes of mouse type A spermatogonia, pachytene spermatocytes and round spermatids determined by sequencing of the respective SAGE (Serial Analysis of Gene Expression) libraries showed that cell-specific transcripts constitute 12-19.5\% of the transcriptome. The components of the protein biosynthetic machinery are highly expressed in spermatogonia, transcription factors in spermatocytes, whereas proteins involved in chromosome remodelling are prominent in spermatids (Wu et al., 2004). In 2006, over 2700 of novel transcripts were identified in purified mouse germ cells (Chan et $a l ., 2006)$. By means of computational analyses it was possible to identify the clusters of co-regulated genes, cell-specific promoter modules, cell-specific biological processes and "preferential" biological networks in various germ cell types in testis. In these transcriptome analyses the new role of cytochrome c oxidase in germ cells apoptosis was discovered (Chan et al., 2006). NF-kappaB (nuclear factor kappaBetta), SP1 (trans-acting transcription factor1), AP-1 (activator protein 1) and EGR (nerve growth factor) were identified as transcription regulators in spermatogenesis by transcriptome analysis. Novel promoter elements such as the EBOX (E-box binding factor) in spermatogonia-specific genes were detected, whereas GATA (GATA binding factor) in spermatocyte-specific genes and GKLF (gut-enrichted Krueppel-like binding factor) in spermatides-specific genes were observed (Lee et al., 2006; Lee et al., 2009). Classifications and clustering according to developmental transcriptional patterns during spermatogenesis $(7,10,12,14$ and 17 day post partum, representing distinct meiotic stages) showed that on postnatal day 14 (representing the early pachytene stage of spermatocytes) about $40 \%$ of genes have the highest expression and the activity of about $30 \%$ was found to be specifically suppressed at this stage (Waldman Ben-Asher et al., 2010). cDNA microarray from testes 
at 6 to $10 \mathrm{dpp}$ identified thousands of differential expressed genes, which expression patterns have critical period for spermatogenesis (Liu et al., 2011).

From 55 genes differentially expressed in 6xKO infertile males as compared to $5 \mathrm{xKO}$, we selected the strongest down-regulated gene, the 4933400A11Rik, for further analysis. In wild type mice, 4933400A11Rik is expressed in germ cells. The 4933400A11Rik mRNA was detected from $16 \mathrm{dpp}$, when primary spermatocytes are produced, until mature spermatozoa. However, it is not clear whether mRNAs detected in spermatozoa are a result of the expression of genes or are residual molecules which were not degraded during spermatogenesis. In human testes and spermatozoa, a set of common transcripts was identified in microarray experiments. The authors implicated that these mRNAs might play certain roles in fertilization and embryonic development (Ostermeier et al., 2002). 70 putative RNAs were identified in human sperm, and it was demonstrated that 15 of them specifically inhibit genes which are active exclusively during early embryonic development (Boerke et al., 2007). The comparison microarray experiment of spermatozoal mRNAs with oocyte mRNAs revealed no overlaps, suggesting that spermatozoa provide novel transcripts distinct from those of the oocyte. Moreover, the series of transcripts from spermatozoa are also found in zygotes, which indicate that spermatozoal mRNAs may be necessary for sustaining zygotic or embryonic viability before or after the activation of the embryonic genome (Ostermeier et al., 2002).

In murine and porcine spermatozoa, mRNAs of the Clu (Clusterin), Prm1(Protamine1) and Prm2 (Protamine2) genes were identified, which may be delivered to the oocyte during fertilization; they may also contribute to zygotic and early embryonic development (Ibrahim et al., 2000; Poon et al., 2000; Poon et al., 2002; Cho et al., 2003; Ostermeier et al., 2004; Kempisty et al., 2008; deMateo et al., 2011). The nuclei of sperm without these mRNAs were found to be less resistant to chemical disruption than the nuclei of wild type sperm. Moreover, failure of development of embryos after ICSI with sperm without protamine was greater than when wild type sperm was used. The deficiency of Prm2 also correlates with infertility in men (Oliva, 2006).

Transforming growth factor $\beta$ (TGF $\beta$ ), which is expressed in chicken sperm, is one of the factors involved in fertility, probably by maintaining the sperm survivability in the hen oviduct (Das et al., 2006; Das et al., 2007). However, TGF $\beta$ could be synthesized by sperm until ejaculation. The question whether it is still synthesized, even 
during travelling in oviduct has not been answered untill now. It is known that sperm may influence some gene expressions and secretory proteomic profiles in the reproductive tract that may be related to sperm transport and selection (Fazeli et al., 2004; Georgiu et al., 2005). All genes which are expressed in sperm cells but not in oocytes are suggested to be required in the early zygote for the organization of DNA, pronuclear formation, oocyte activation or the establishment of imprinting in early embryos (Ostermeier et al., 2004; Boerke et al., 2007). Transcripts that are specific for male germ cells may also play certain role in the differentiation of embryonic stem cells (Geijsen et al., 2004; Surani, 2004).

In order to answer the question whether 4933400A11Rik gene influence fertility, 4933400A11Rik knockout mice should be generated. In my work I used a ready-made construct for 4933400A11Rik gene knockout to delete only exon 3 of 4933400A11Rik (contains complete open reading frame). It is necessary to limit the size of deletion, because 4933400A11Rik gene is located in the first intron of midlinel gene (Mid1). The deletion of the exon 3 of 4933400A11Rik gene only should not influence the midline1 expression, as the codon start of Midl is located in its exon 2 (compare Figure 2). The knockout of Midl (deletion of exon 2 only) showed brain anatomical defect, similar to that observed in patients with Opitz G/BBB Syndrome. This defect correlates with motor coordination and procedural learning impairments. The fertility of Midl mutant mice is normal. The $\mathrm{Midl}^{-/ Y}$ mice are fertile and born at the expected Mendelian ratio (Fontanella et al., 2008; Lancioni et al., 2010). Phosporylated MID1 (by Plo-1 kinase) influences the timing of myosin II recruitment and in this way regulates mitosis and cytokinesis (McCollum, 2010; Almonacid et al., 2011). MID1 is associated with the microtubules (MTs) and regulates the level of MT-associated phosphatase 2A (PP2A) (Aranda-Orgillés et al., 2008; Aranda-Orgillés et al., 2011). Unfortunately, until the end of my work it was impossible to obtain 4933400A11Rik chimeras.

\subsubsection{A11Rik protein might regulate germ cells cytoskeleton}

4933400A11RIK protein has similar sequence as proteins that belong to the actin filament capping protein family. Furthermore, the 4933400A11RIK co-localises with F- 
actin capping protein subunit alpha-1. Proteins from this family are known to control the process of cytoskeleton growth by the regulation of actin filaments reorganization.

Actin is a $45 \mathrm{kDa}$ ATP-binding protein present in the cell in two forms: as monomeric G-actin and polymeric F-actin. G-actin can polymerize into filaments of Factin, $7 \mathrm{~nm}$ in diameter, which form the cell cytoskeleton (Alberts et al., 2008; Carlsson, 2010). Each actin molecule can bind one ATP molecule. After binding to actin filament, ATP is hydrolyzed to ADP + Pi. Additional energy is not necessary for this incorporation of monomers into the filaments, however, ATP connection to monomeric actin molecule can increase the rate of polymerization (Pollard and Cooper, 1986). Typical actin filament has two ends: the fast-growing barbed end (+ end) capped with ATP-actin, and the slowgrowing pointing end (- end) capped with ADP-actin. Due to the fact that ADP-actin has lower affinity to the filament than ATP-actin, on the barbed end ATP-actin monomers are added faster and the filament is growing, whereas on the pointing end of the filament ADP-actin monomers are lost. This process is known as treadmilling and it is presented in Figure 52 (Alberts et al., 2008).

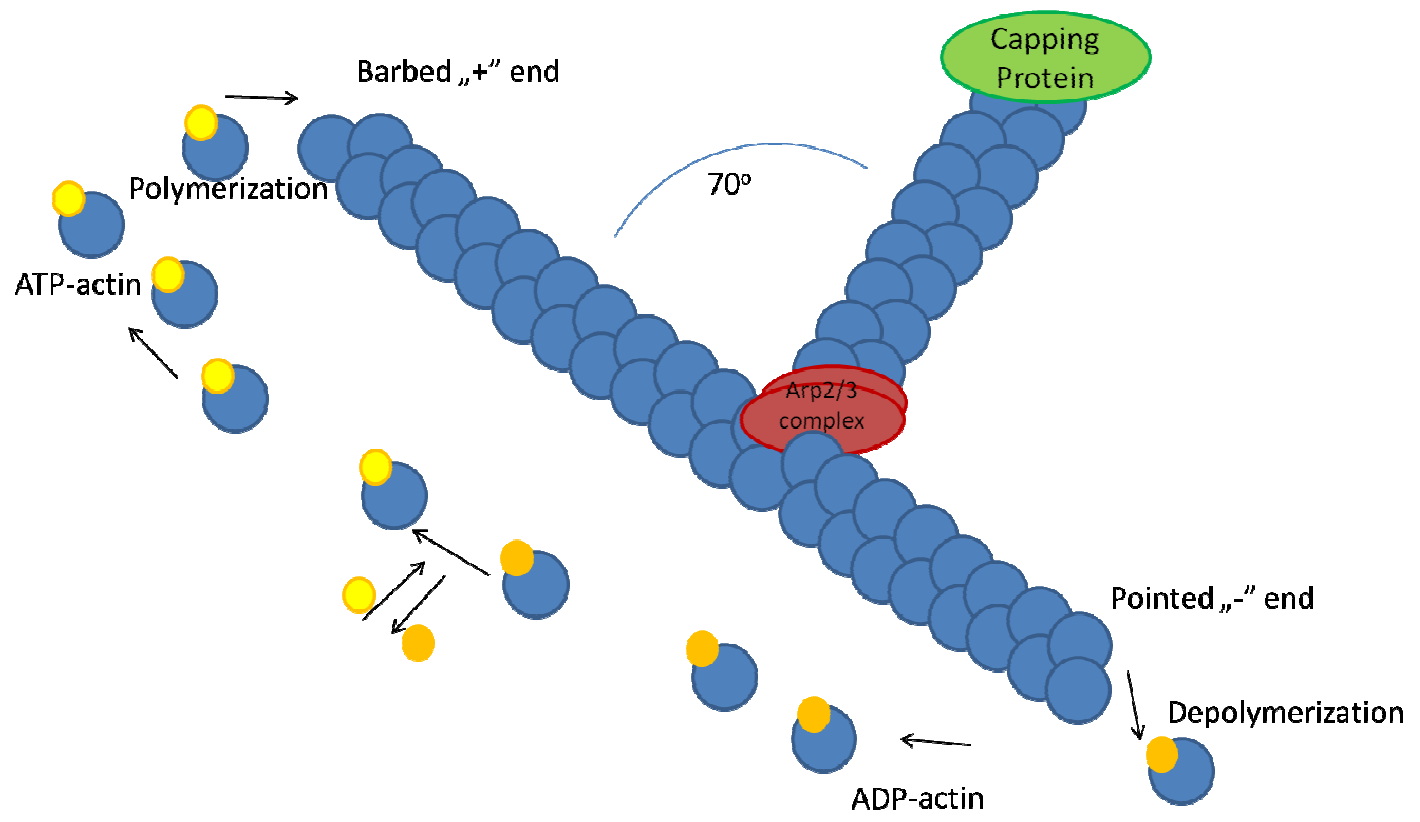

Figure 52. Growing of actin filaments. ATP-actin subunits preferentially bind to the fast growing barbed "+"end of an actin filament, although they can also bind to the pointed "_" end. Upon binding to the end of a filament, an actin subunit hydrolyzes its bound ATP into ADP and phosphate (Pi). Active Arp2/3 (actin related protein2/3 homolog) complex binds to 
the side of an existing filament and nucleates new filament growth towards the cell membrane. Actin capping protein regulates the elongation of actin filaments by blocking barbed ends (Schafer, 2004; Nicholson-Dykstra et al., 2005; Lowery and van Vactor, 2009; Kim et al., 2010; modified).

The rearrangements of actin cytoskeleton are precisely regulated by a large number of proteins known as actin binding proteins (DiNubile et al., 1995; Röhrig et al., 1995; Sun et al., 1999; Bear et al., 2002; Nyakern-Meazza et al., 2002; Pollard et al., 2000; Pollard and Beltzner, 2002; Pring et al., 2003; Taoka et al., 2003; Zigmond et al., 2003; Disanza et al., 2004; Harris et al., 2004; Yang et al., 2005; Canton et al., 2005; Bhattacharya et al., 2006; Canton et al., 2006; Dai et al., 2006; Romero et al., 2007; Benz et al., 2009; Pottiez et al., 2009; Cheng and Mruk, 2011; Galkin et al., 2011; Thomson et al., 2011; Teng et al., 2012) and by other proteins, such as cofilin1 (Cfl1), destrin (ADF), gelsolin (GSN), ARP 2/3 (Sun et al., 1999; Pollard et al., 2000; Pollard and Beltzner, 2002; Pottiez et al., 2009; Galkin et al., 2011; Teng et al., 2012). There are three mechanisms of action: by binding to the filament and protecting it from capping protein, by binding to capping protein (CP) and inhibiting its capping activity, or by uncapping. When proteins from barbed-end actin capping family are located at the barbed end of actin filaments, their growing of these filaments is stopped and they remain short (Fig. 52) (DiNubile et al., 1995; Yang et al., 2005; Bhattacharya et al., 2006). Capping proteins are inhibited for example by CARMIL (Yang et al., 2005), myotrophin/V-1 (Taoka et al., 2003; Bhattacharya et al., 2006), PLEKHO1 (Canton et al., 2005; Canton et al., 2006) and phosphoinositides molecules (Kim et al., 2007; Shewan et al., 2011; Ueno et al., 2011), whereas Formins interact with fast growing actin filaments and protect the new filament's barbed ends from capping (Pring et al., 2003; Zigmond et al., 2003; Harris et al., 2004; Romero et al., 2007). Due to the fact that the network of proteins which regulates the growth of actins cytoskeleton is complicated, one may suggest that this cellular structure is very dynamic during cell life. 4933400A11RIK may be a new protein, which regulate the reorganisation of germ cells actin cytoskeleton. 


\subsubsection{Disregulation of germ cells actin cytoskeleton reorganisation may be the underlying cause of male infertility in 6xKO mice}

Actin cytoskeleton is important in the development of germ cell and in mature spermatozoa (Brener et al., 2003; Vogl et al., 2008; Kopera et al., 2010; Rotkopf et al., 2011). In spermatids, actin exists mainly in its filamentous form (Vogl, 1989). In the final stages of spermiogenesis and in spermatozoa the depolymerization process dominates and mainly G-actin monomolecules are present (Howes et al., 2001). During the capacitation of sperm, second increase in actin polymerization was observed till acrosome reaction; when F-actin have to be again depolymerised to allow the activation of the outer acrosomal membrane. The disregulation of polymerization/depolymerization of actin filaments influences reduction fertility. The inhibition of actin polymerization by cytochalasin B or D or by actin antibodies blocks sperm capacitation and reduces the in vitro fertilization rate by the disorder of acrosome reaction and through preventing the sperm from incorporation into ooctes cytoplasm, as well as by the inhibition of DNA decondensation during fertilization (Tilney et al., 1983; Castellani-Ceresa et al., 1993; Forer and Pickett-Heaps, 1998; Liu et al., 2002; Kumakiri et al., 2003). Latrunculin A or B inhibits post-testicular sperm maturation and blocks sperm motility in the epididymal spermatozoa of tammar wallabies, which suggests the role of actin in the development of the sperm tail (Forer and Pickett-Heaps, 1998; Lim et al., 2002; Lin et al., 2002). CAPZA3 plays certain role in maintaining polymerized actin during spermiogenesis (Geyer et al., 2009). The dispersion of actin is necessary for the acrosome reaction. The inhibition of actin depolymerization in spermatozoa by calcium ionophore influences fertility reduction (Spungin et al., 1995). Gelsolin, which is presented in the spermatozoa head from some mammalian species, is responsible for the depolymerization of F-actin prior to acrosome reaction (Cabello-Agueros et al., 2003). Mice lacking the testis-specific serine kinase 6 (TSSK6) similar to mice with disturbed IZUMO1 (izumo sperm-egg fusion 1) are incapable to fuse with the egg (Inoue et al., 2005; Sosnik et al., 2009). Moreover, the cooperation of actin polymerization and changing localisation of IZUMO1 seems to be necessary during acrosome process (Miranda et al., 2009; Sosnik et al., 2010). All studies mentioned above evidence that actin cytoskeleton and its reorganization are very important during spermatogenesis and fertilization. We suggest 
that the absence of the 4933400A11Rik gene, which belongs to actin capping protein family, can disregulate sperm cytoskeleton and can be responsible for the infertility of 6xKO male mice.

\subsection{Future perspective}

In the present study the first insights into the physiological role of CCDC33 protein as an anti-apoptotic regulator of spermatogenesis is presented. In order to confirm this thesis, it is necessary to produce $C c d c 33$ knockout mice. If this mutant male mice will be fertile, it is possible to generate double knockout mice $C c d c 33-/-P x t 1-/-$. In the present thesis it was discovered that CCDC33protect cells from PXT1 induced apoptosis. Consequently, the analysis of pathways which play certain role in this process is the next step in analysing this issue.

An alternative way to analyse the role of CCDC33 protein might be the analysis of the function of its coiled coil domains. In this work I have demonstrated that coiled coil domains of CCDC33 are not involved in the interaction with PXT1. However, coiled coils build specific three-dimensional structures which are very well known from proteinprotein interactions. They have been found in proteins which regulate the activity of transcription factors and which are involved in cell growth and proliferation, as well as in the development of cartilage and bone (Talbot and Hodges, 1982; Frank et al., 2002; Singh and Hitchcock-DeGregori, 2003; Mason and Arndt, 2004; Mason et al., 2006; Iwai et al., 2008; Mason, 2009; Worrall et al., 2011). The analysis of coiled coil domains in CCDC33 protein can help to identify new interaction partners of this protein and then new functions of CCDC33 protein during spermatogenesis.

In order to study the role of the 4933400A11Rik gene, we started to generate conditional knockout mice. Until now, no knockout of actin capping protein has been analysed. Unfortunately, till the end of my work no 4933400A11Rik chimeras have been obtained; therefore, in the future the generation of 4933400A11Rik knockout mice should be continued.

The rescue experiment may also confirm the role of this gene in male fertility. It is known that sperm cells incubated with particular RNA molecules can transfer this RNA to the oocyte during IVF procedure (Zini and Agarwal, 2011). The question whether the 
4933400AllRik mRNA is necessary for the early embryo, an attempt can be made in which sperm from infertile 6xKO mice (without 4933400A11Rik mRNA) are incubated with 4933400A11Rik transcripts and then used in IVF assay. The determination of the early embryonic development ( 2 pronuclei and 2-cell stage) would give more information on the role of this gene after sperm penetration into the oocyte. 


\section{SUMMARY}

Since most cases of male infertility remain idiopathic, analysis of the mechanism in which genes are involved in spermatogenesis control might help to better understand the reasons. This thesis consists of 2 parts concerning 2 different aspects of human fertility research. The first project concerns the analysis of coiled coil domain containing 33 (CCDC33) protein and its role as an interaction partner of peroxisomal testis specific 1 (PXT1). In the second project we have analyzed the phenotype and determined the cause of males infertility from a multiple knockout mouse line with six knockouted genes: Tnp2, Hist1h1t, Theg, Acr, Creb3l4 and Tex22.

In the first part of the thesis, domains in CCDC33 and PXT1, which take part in mutual interaction were identified. Interaction between these proteins was detected by Kaczmarek (Kaczmarek, 2009). We showed that not coiled coil domains are important in CCDC33 interaction with PXT1, but an amino acid sequence which is similar to sequence presented in leucine rich domain. By mutagenesis of sequence in PXT1 we detected amino acids important for interaction of PXT1 and CCDC33. PXT1 is a first peroxisomal protein containing a functional BH3-like domain, which is known to trigger apoptosis. Based on co-transfections of HeLa cell experiments, we demonstrated co-localization of CCDC33 and PXT1 in cytoplasm. Moreover, cells with co-localization of both proteins presented reduction of apoptosis level as compared to the cells transfected with PXT1 construct only. This finding may suggest that physical binding of both proteins inhibits PXT1-induced apoptosis. By Western blot and immunohistochemistry, we showed that CCDC33 protein is localized in testes and during spermatogenesis since the stage of spermatocytes. The interaction of CCDC33 and PXT1 as well as the expression pattern of both genes implicate that $C c d c 33$ might be involved in the control of spermatogenesis. We suggest that CCDC33 might be new peroxisomal protein, which regulate apoptosis during spermatogenesis. However, further studies, including analysis of CCDC33 knockout mouse models, will be necessary to determine whether $C c d c 33$ is essential for male fertility.

In the second part of the thesis, analysis of knockout mouse line with the disruption of 6 germ cell-specific genes are described. In about $20 \%$ of mice infertility 
was observed. In both, fertile and infertile 6xKO males, increased number of spermatozoa with abnormal head and reduction of sperm motility were found. After mating with wild type female $6 x K O$, sperm needed noticeably longer to fertilize oocyte as compared to wild type sperm. Differences in phenotype of 6xKO mutant mice are an effect of both genetic background and the inactivation of six germ cells-specific genes. In order to examine more thoroughly which genes might be involved in the infertility of $6 \mathrm{xKO}$ males, we performed transcriptome assay and compared the expression of genes in the testes of $5 \mathrm{xKO}$ fertile and $6 \mathrm{xKO}$ infertile animals. We identified and characterised a new gene 4933400Al1Rik, which may be responsible for the infertility of 6xKO mice males. In wild type mice, 4933400A11Rik is expressed in germ cells. The 4933400A11Rik mRNA was detected from $16 \mathrm{dpp}$, when primary spermatocytes are produced, until mature spermatozoa. However, it is not clear whether mRNAs detected in spermatozoa are a result of the expression of genes or are residual molecules which were not degraded during spermatogenesis. 4933400A11RIK has sequence similar to the actin filament capping protein family. We demonstrated that the 4933400A11RIK co-localises with Factin capping protein subunit alpha-1. Proteins from this family are known to control the process of cytoskeleton growth by the regulation of actin filaments reorganization. Disregulation of germ cells actin cytoskeleton reorganization may be the underlying cause of male infertility in 6xKO mice, because 4933400A11Rik gene is expressed in testis of fertile $6 \mathrm{xKO}$, but not presented in infertile $6 \mathrm{xKO}$ males. In order to answer the question whether 4933400A11Rik gene influences fertility, 4933400A11Rik knockout mice should be generated. The rescue experiment may also confirm the role of this gene in male fertility.

In conclusion, the data presented in this thesis provide interesting insights into the potential function of CCDC33 in regulation of spermatogenesis. We present also cumulative effects of 6 germ cell-specific genes and of new gene, 4933400A11Rik, which might be important in fertility research. 


\section{REFERENCES}

Adham I.M., Eck T.J., Mierau K., Müller N., Sallam M.A., Paprotta I., Schubert S., Hoyer-Fender S., Engel W. (2005) Reduction of spermatogenesis but not fertility in Creb314-deficient mice. Mol Cell Biol. 25:7657-7664.

Adham I.M., Nayernia K., Burkhardt-Gottges E., Topaloglu O., Holstein A.F., Engel W. (2001) Teratozoospermia in mice lacking the transition protein 2 (Tnp2). Mol Hum Reprod. 7:513-520.

Adham I.M., Nayernia K., Engel W. (1997) Spermatozoa lacking acrosin protein show delayed fertilization. Mol Reprod Dev. 46:370-376.

Alberts K., Johnson A., Lewis J., Raff M., Walter P. (2008) Molecular biology of the cell. Garland Science Verlag, New York.

Almonacid M., Celton-Morizur S., Jakubowski J.L., Dingli F., Loew D., Mayeux A., Chen J.S., Gould K.L., Clifford D.M., Paoletti A. (2011) Temporal control of contractile ring assembly by Plo1 regulation of myosin II recruitment by Mid1/anillin. Curr Biol. 21:473-479.

Altschul S., Madden T., Schaffer A., Zhang J., Zhang Z., Miller W., Lipman D. (1997) Gapped BLAST and PSI-BLAST: a new generation of protein database search programs. Nucleic Acids Res. 25:3389-3402.

Aranda-Orgillés B., Aigner J., Kunath M., Lurz R., Schneider R., Schweiger S. (2008) Active transport of the ubiquitin ligase MID1 along the microtubules is regulated by protein phosphatase 2A. PLoS One. 3:e3507.

Aranda-Orgillés B., Rutschow D., Zeller R., Karagiannidis A.I., Köhler A., Chen C., Wilson T., Krause S., Roepcke S., Lilley D., Schneider R., Schweiger S. (2011) Protein phosphatase 2A (PP2A)-specific ubiquitin ligase MID1 is a sequence-dependent regulator of translation efficiency controlling 3-phosphoinositide-dependent protein kinase-1 (PDPK-1). J Biol Chem. 286:3994539957.

Atlas-White M., Murphy B.F., Baker H.W. (2000) Localisation of clusterin in normal human sperm by immunogold electron microscopy. Pathology. 32:258-261.

Baes M., Gressens P., Baumgart E., Carmeliet P., Casteels M., Fransen M., Evrard P., Fahimi D., Declercq P.E., Collen D., van Veldhoven P.P., Mannaerts G.P. (1997) A mouse model for Zellweger syndrome. Nat Genet. 17:49-57. 
Baes M. (2000) Mouse models for peroxisome biogenesis disorders. Cell Biochem Biophys. $32: 229-37$.

Baumgart E., Schad A., Volkl A., Fahimi H.D. (1997) Detection of mRNAs encoding peroxisomal proteins by non-radioactive in situ hybridization with digoxigenin-labelled cRNAs. Histochem Cell Biol. 108:371-379.

Bear J.E., Svitkina T.M., Krause M., Schafer D.A., Loureiro J.J., Strasser G.A., Maly I.V., Chaga O.Y., Cooper J.A., Borisy G.G., Gertler F.B. (2002) Antagonism between Ena/VASP proteins and actin filament capping regulates fibroblast motility. Cell. 109:509-521.

Bennett W.I., Gall A.M., Southard J.L., Sidman R.L. (1971) Abnormal spermiogenesis in quaking, a myelin-deficient mutant mouse. Biol Reprod. 5:30-58.

Benz P.M., Blume C., Seifert S., Wilhelm S., Waschke J., Schuh K., Gertler F., Münzel T., Renné T. (2009) Differential VASP phosphorylation controls remodeling of the actin cytoskeleton. J Cell Sci. 122:3954-3965.

Bhattacharya N., Ghosh S., Sept D., Cooper J.A. (2006) Binding of myotrophin/V-1 to actincapping protein: implications for how capping protein binds to the filament barbed end. J Biol Chem. 281:31021-31030.

Birnboim H.C., Doly J. (1979) A rapid alkaline extraction procedure for screening recombinant plasmid DNA. Nucleic Acids Res. 7:1513-1523.

Blanco-Rodríguez J. (1998) A matter of death and life: the significance of germ cell death during spermatogenesis. Int J Androl. 21:236-248.

Boerke A., Dieleman S.J., Gadella B.M. (2007) A possible role for sperm RNA in early embryo development. Theriogenology. 68:Suppl.1:147-155.

Bradford M.M. (1976) A rapid and sensitive method for the quantitation of microgram quantities of protein utilizing the principle of protein-dye binding. Anal Biochem. 7:248-254.

Brener E., Rubinstein S., Cohen G., Shternall K., Rivlin J., Breitbart H. (2003) Remodeling of the actin cytoskeleton during mammalian sperm capacitation and acrosome reaction. Biol Reprod. 68:837-845.

Brennemann W., Kohler W., Zierz S., Klingmuller D. (1997) Testicular dysfunction in adrenomyeloneuropathy. Eur J Endocrinol. 137:34-39.

Brites P., Mooyer P.A., El Mrabet L., Waterham H.R., Wanders R.J. (2008) Plasmalogens participate in very-long-chain fatty acid-induced pathology. Brain. 132:482-92. 
Brites P., Motley A.M., Gressens P., Mooyer P.A., Ploegaert I., Everts V., Evrard P., Carmeliet P., Dewerchin M., Schoonjans L., Duran M., Waterham H.R., Wanders R.J., Baes M. (2003) Impaired neuronal migration and endochondral ossification in Pex7 knockout mice: a model for rhizomelic chondrodysplasia punctata. Hum Mol Genet. 12:2255-2267.

Buchanan S., Gay N.J. (1996) Structural and functional diversity in the leucine-rich repeat family of proteins. Prog Biophys Mol Biol. 65:1-44.

Cabello-Agüeros JF, Hernández-González EO, Mújica A. (2003) The role of F-actin cytoskeleton-associated gelsolin in the guinea pig capacitation and acrosome reaction. Cell Motil Cytoskeleton. 56:94-108.

Canton D.A., Olsten M.E., Kim K., Doherty-Kirby A., Lajoie G., Cooper J.A., Litchfield D.W. (2005) The pleckstrin homology domain-containing protein CKIP-1 is involved in regulation of cell morphology and the actin cytoskeleton and interaction with actin capping protein. Mol Cell Biol. 25:3519-3534.

Canton D.A., Olsten M.E., Niederstrasser H., Cooper J.A., Litchfield D.W. (2006) The role of CKIP-1 in cell morphology depends on its interaction with actin-capping protein. J Biol Chem. 281:36347-35359.

Carlsson A.E. (2010) Actin dynamics: from nanoscale to microscale. Annu Rev Biophys. 39:91110.

Carmell M.A., Girard A., van de Kant H.J., Bourc'his D., Bestor T.H., de Rooij D.G., Hannon G.J. (2007) MIWI2 is essential for spermatogenesis and repression of transposons in the mouse male germline. Dev Cell.12:503-514.

Carninci P., Hayashizaki Y. (1999) High-efficiency full-length cDNA cloning. Methods Enzymol. 303:19-44.

Castellani-Ceresa L, Mattioli M, Radaelli G, Barboni B, Brivio MF. (1993) Actin polymerization in boar spermatozoa: fertilization is reduced with use of cytochalasin D. Mol Reprod Dev. 36:203-211.

Chan W.Y., Lee T.L., Wu S.M., Ruszczyk L., Alba D., Baxendale V., Rennert O.M. (2006) Transcriptome analyses of male germ cells with serial analysis of gene expression (SAGE). Mol Cell Endocrinol. 250:8-19.

Chen C.Z., Shapiro R. (1997) Site-specific mutagenesis reveals differences in the structural bases for tight binding of RNase inhibitor to angiogenin and RNase A. Proc Natl Acad Sci USA. 94:1761-1766. 
Cheng C.Y., Mruk D.D. (2011) Regulation of spermiogenesis, spermiation and blood-testis barrier dynamics: novel insights from studies on Eps8 and Arp3. Biochem J. 435:553-562.

Cho C., Jung-Ha H., Willis W.D., Goulding E.H., Stein P., Xu Z., Schultz R.M., Hecht N.B., Eddy E.M. (2003) Protamine 2 deficiency leads to sperm DNA damage and embryo death in mice. Biol Reprod. 69:211-217.

Clark A.G. (2002) Sperm competition and the maintenance of polymorphism. Heredity (Edinb). $88: 148-53$.

Coultas L., Bouillet P., Loveland K.L., Meachem S., Perlman H., Adams J.M., Strasser A. (2005) Concomitant loss of proapoptotic BH3-only Bcl-2 antagonists Bik and Bim arrests spermatogenesis. EMBO J. 24:3963-3973.

Dai H., Huang W., Xu J., Yao B., Xiong S., Ding H., Tang Y., Liu H., Wu J., Shi Y. (2006) Binding model of human coactosin-like protein with filament actin revealed by mutagenesis. Biochim Biophys Acta. 1764:1688-1700.

Das S.C., Isobe N., Nishibori M., Yoshimura Y. (2006) Expression of TGFb-isoforms and their receptors in utero-vaginal junction of hen oviduct in presence or absence of resident sperm with reference to sperm storage. Reproduction. 132:781-790.

Das S.C., Isobe N., Yoshimura Y. (2007) Changes in the mRNA expressions of sperm transforming growth factor beta-isoforms and their receptors with reference to fertility during in vitro storage of fowl semen. The Journal of Poultry Science. 44:189-197.

Dastig S., Nenicu A., Otte D.M., Zimmer A., Seitz J., Baumgart-Vogt E., Lüers G.H. (2011) Germ cells of male mice express genes for peroxisomal metabolic pathways implicated in the regulation of spermatogenesis and the protection against oxidative stress. Histochem Cell Biol. $136: 413-425$.

Dean M.D., Ardlie K.G., Nachman M.W. (2006) The frequency of multiple paternity suggests that sperm competition is common in house mice (Mus domesticus). Mol Ecol.15:4141-4151.

de Mateo S., Ramos L., de Boer P., Meistrich M., Oliva R. (2011) Protamine 2 precursors and processing. Protein Pept Lett. 18:778-785.

de Rooij D.G., de Boer P. (2003) Specific arrests of spermatogenesis in genetically modified and mutant mice. Cytogenet Genome Res. 103:267-276. 
DiNubile M.J., Cassimeris L., Joyce M., Zigmond S.H. (1995). Actin filament barbed-end capping activity in neutrophil lysates: the role of capping protein-beta 2. Mol Biol Cell. 6:16591671.

Disanza A., Carlier M.F., Stradal T.E., Didry D., Frittoli E., Confalonieri S., Croce A., Wehland J., Di Fiore P.P., Scita G. (2004) Eps8 controls actin-based motility by capping the barbed ends of actin filaments. Nat Cell Biol. 6:1180-1188.

Doyle D.A., Lee A., Lewis J., Kim E., Sheng M., MacKinnon R. (1996) Crystal structures of a complexed and peptide-free membrane protein-binding domain: molecular basis of peptide recognition by PDZ. Cell. 85:1067-1076.

Drabent B., Bode C., Bramlage B., Doenecke D. (1996) Expression of the mouse testicular histone gene H1t during spermatogenesis. Histochem Cell Biol. 106:247-251.

Drabent B., Bode C., Doenecke D. (1993) Structure and expression of the mouse testicular H1 histone gene (H1t). Biochim Biophys Acta. 1216:311-313.

Drabent B., Saftig P., Bode C., Doenecke D. (2000) Spermatogenesis proceeds normally in mice without linker histone H1t. Histochem Cell Biol. 113:433-442.

El-Alfy M., Azzi L., Lessard J., Lavergne E., Pelletier M., Labrie C. (2006) Stage-specific expression of the Atce1/Tisp40alpha isoform of CREB3L4 in mouse spermatids. J Androl. 27:686-694.

Engel W., Keime S., Kremling H., Hameister H., Schlüter G. (1992) The genes for protamine 1 and 2 (PRM1 and PRM2) and transition protein 2 (TNP2) are closely linked in the mammalian genome. Cytogenet Cell Genet. 61:158-159.

Fan C.Y., Pan J., Chu R., Lee D., Kluckman K.D., Usuda N., Singh I., Yeldandi A.V., Rao M.S., Maeda N., Reddy J.K. (1996) Hepatocellular and hepatic peroxisomal alterations in mice with a disrupted peroxisomal fatty acyl-coenzyme A oxidase gene. J Biol Chem. 271:24698-710.

Fawcett D.W., Burgos M.H. (1960) Studies on the fine structure of the mammalian testis. The human interstitial tissue. Am J Anat. 107:245-269.

Fazeli A., Affara N.A., Hubank M., Holt W.V. (2004) Sperm-induced modification of the oviductal gene expression profile after natural insemination in mice. Biol Reprod.71:60-65.

Figueroa C., Kawada M.E., Veliz L.P., Hidalgo U., Barros C., Gonzalez S., Santos M.J. (2000) Peroxisomal proteins in rat gametes. Cell Biochem Biophys. 32:259-268. 
Fontanella B., Russolillo G., Meroni G. (2008) MID1 mutations in patients with X-linked Opitz G/BBB syndrome. Hum Mutat. 29:584-594.

Forer A., Pickett-Heaps J.D. (1998) Cytochalasin D and latrunculin affect chromosome behaviour during meiosis in crane-fly spermatocytes. Chromosome Res. 6:533-549.

Foresta C., Zuccarello D., Garolla A., Ferlin A. (2008) Role of hormones, genes, and environment in human cryptorchidism. Endocr Rev. 29:560-580.

Frank S., Schulthess T., Landwehr R., Lustig A., Mini T., Jenö P., Engel J., Kammerer R.A. (2002) Characterization of the matrilin coiled-coil domains reveals seven novel isoforms. J Biol Chem. 277:19071-19079.

Galkin V.E., Orlova A., Kudryashov D.S., Solodukhin A., Reisler E., Schröder G.F., Egelman E.H. (2011) Remodeling of actin filaments by ADF/cofilin proteins. Proc Natl Acad Sci U S A. 108:20568-20572.

Garrison S.P., Phillips D.C., Jeffers J.R., Chipuk J.E., Parsons M.J., Rehg J.E., Opferman J.T., Green D.R., Zambetti G.P. (2012) Genetically defining the mechanism of Puma- and Biminduced apoptosis. Cell Death Differ. 19:642-649.

Geijsen N., Horoschak M., Kim K., Gribnau J., Eggan K., Daley G.Q. (2004) Derivation of embryonic germ cells and male gametes from embryonic stem cells. Nature. 427:148-154.

Geisler S. (2004) Molekulare und phänotypische Analyse bei Tep22-defizienten Mäusen. Diplomarbeit. Institute of Human Genetics, Goettingen.

Georgiou A.S., Sostaric E., Wong C.H., Snijders A.P., Wright P.C., Moore H.D., Fazeli A. (2005) Gametes alter the oviductal secretory proteome. Mol Cell Proteomics. 4:1785-1796.

Geyer C.B., Inselman A.L., Sunman J.A., Bornstein S., Handel M.A., Eddy E.M. (2009) A missense mutation in the Capza3 gene and disruption of F-actin organization in spermatids of repro32 infertile male mice. Dev Biol. 330:142-152.

Gomendio M., Roldan E.R. (2008) Implications of diversity in sperm size and function for sperm competition and fertility. Int J Dev Biol.52:439-447.

Grzmil P., Boinska D., Kleene K.C., Adham I., Schlüter G., Kämper M., Buyandelger B., Meinhardt A., Wolf S., Engel W. (2008) Prm3, the fourth gene in the mouse protamine gene cluster, encodes a conserved acidic protein that affects sperm motility. Biol Reprod. 78:958-967. 
Harris E.S., Li F., Higgs H.N. (2004) The mouse formin, FRLalpha, slows actin filament barbed end elongation, competes with capping protein, accelerates polymerization from monomers, and severs filaments. J Biol Chem. 279:20076-20087.

Honda A., Siruntawineti J., Baba T. (2002a) Role of acrosomal matrix proteases in sperm-zona pellucida interactions. Hum Reprod Update. 8:405-412.

Honda A., Yamagata K., Sugiura S., Watanabe K., Baba T. (2002b) A mouse serine protease TESP5 is selectively included into lipid rafts of sperm membrane presumably as a glycosylphosphatidylinositol-anchored protein. J Biol Chem. 277:16976-16984.

Howes E, Pascall JC, Engel W, Jones R. (2001) Interactions between mouse ZP2 glycoprotein and proacrosin; a mechanism for secondary binding of sperm to the zona pellucida during fertilization. J Cell Sci. 114:4127-4136.

Huyghe S., Schmalbruch H., De Gendt K., Verhoeven G., Guillou F., Van Veldhoven P.P., Baes M. (2006) Peroxisomal multifunctional protein 2 is essential for lipid homeostasis in Sertoli cells and male fertility in mice. Endocrinology. 147:2228-2236.

Ibrahim N.M., Gilbert G.R., Loseth K.J., Crabo B.G. (2000) Correlation between clusterinpositive spermatozoa determined by flow cytometry in bull semen and fertility. J Androl. 21:887894.

Inoue N., Ikawa M., Isotani A., Okabe M. (2005) The immunoglobulin superfamily protein Izumo is required for sperm to fuse with eggs. Nature. 434:234-238.

Iwai A., Hijikata M., Hishiki T., Isono O., Chiba T., Shimotohno K. (2008) Coiled-coil domain containing 85B suppresses the $\beta$-catenin activity in a p53-dependent manner. Oncogene. 27:15201526.

Kaczmarek K. (2009) On the functional analysis of murine peroxisomal testis specific 1 (Pxt1) gene. Dissertation. Institute of Human Genetics, Goettingen.

Kaczmarek K., Niedzialkowska E., Studencka M., Schulz Y., Grzmill P. (2009) Ccdc33 a predominantly testis expressed gene encodes a putative peroxisomal protein. Cytogenet Genome Res. 126:243-252.

Kaczmarek K., Studencka M., Meinhardt A., Wieczerzak K., Thoms S., Engel W., Grzmil P. (2011) Overexpression of peroxisomal testis-specific 1 protein induces germ cell apoptosis and leads to infertility in male mice. Mol Biol Cell. 22:1766-79.

Kajava A.V. (1998) Structural diversity of leucine-rich repeat proteins. J Mol Biol. 277:519-527. 
Kaneko K.J., Kohn M.J., Liu C., DePamphilis M.L. (2010) The acrosomal protein Dickkopf-like 1 (DKKL1) is not essential for fertility. Fertil Steril. 93:1526-1532.

Karaulanov E.E., Bottcher R.T., Niehrs C. (2006) A role for fibronectin-leucine-rich transmembrane cell-surface proteins in homotypic cell adhesion. EMBO Rep. 7:283-290.

Kawano N., Kang W., Yamashita M., Koga Y., Yamazaki T., Hata T., Miyado K., Baba T. (2010) Mice lacking two sperm serine proteases, ACR and PRSS21, are subfertile, but the mutant sperm are infertile in vitro. Biol Reprod. 83:359-369.

Kemp S., Wanders R.J. (2007) X-linked adrenoleukodystrophy: very long-chain fatty acid metabolism, $\mathrm{ABC}$ half-transporters and the complicated route to treatment. Mol Genet Metab. 90:268-276.

Kempisty B., Antosik P., Bukowska D., Jackowska M., Lianeri M., Jaśkowski J.M., Jagodziński P.P. (2008) Analysis of selected transcript levels in porcine spermatozoa, oocytes, zygotes and two-cell stage embryos. Reprod Fertil Dev. 20:513-518.

Kim K., McCully M.E., Bhattacharya N., Butler B., Sept D., Cooper J.A. (2007) Structure/function analysis of the interaction of phosphatidylinositol 4,5-bisphosphate with actincapping protein: implications for how capping protein binds the actin filament. J Biol Chem. 282:5871-5879.

Kim T., Cooper J.A., Sept D. (2010) The interaction of capping protein with the barbed end of the actin filament. J Mol Biol. 404:794-802.

Knudson C.M., Tung K.S., Tourtellotte W.G., Brown G.A., Korsmeyer S.J. (1995) Bax-deficient mice with lymphoid hyperplasia and male germ cell death. Science.70:96-99.

Kobe B. (1996) Leucines on a roll. Nat Struct Biol. 3:977-980.

Kobe B., Deisenhofer J. (1994) The leucine-rich repeat: a versatile binding motif. Trends Biochem Sci. 19:415-421.

Kobe B., Deisenhofer J. (1995a) A structural basis of the interactions between leucine-rich repeats and protein ligands. Nature. 374:183-186.

Kobe B., Deisenhofer J. (1995b) Proteins with leucine-rich repeats. Curr Opin Struct Biol. 5:409416.

Kobe B., Kajava A.V. (2001) The leucine-rich repeat as a protein recognition motif. Curr Opin Struct Biol. 11:725-732. 
Kopera I.A., Bilinska B., Cheng C.Y., Mruk D.D. (2010) Sertoli-germ cell junctions in the testis: a review of recent data. Philos Trans R Soc Lond B Biol Sci. 365:1593-1605.

Kotarska K., Lenartowicz M. (2011) Sperm migration and selection in the reproductive tract of female mice is mostly affected by male genotype. Folia Biol (Krakow). 59:71-75.

Kremling H., Keime S., Wilhelm K., Adham I.M., Hameister H., Engel W. (1991) Mouse proacrosin gene: nucleotide sequence, diploid expression, and chromosomal localization. Genomics. 11:828-834.

Kumakiri J., Oda S., Kinoshita K., Miyazaki S. (2003) Involvement of Rho family G protein in the cell signaling for sperm incorporation during fertilization of mouse eggs: inhibition by Clostridium difficile toxin B. Dev Biol. 260:522-535.

Lancioni A., Pizzo M., Fontanella B., Ferrentino R., Napolitano L.M., De Leonibus E., Meroni G. (2010) Lack of Mid1, the mouse ortholog of the Opitz syndrome gene, causes abnormal development of the anterior cerebellar vermis. J Neurosci. 30:2880-2887.

Lee T.L., Alba D., Baxendale V., Rennert O.M., Chan W.Y. (2006) Application of transcriptional and biological network analyses in mouse germ-cell transcriptomes. Genomics. 88:18-33.

Lee T.L., Cheung H.H., Claus J., Sastry C., Singh S., Vu L., Rennert O., Chan W.Y. (2009) GermSAGE: a comprehensive SAGE database for transcript discovery on male germ cell development. Nucleic Acids Res. 37:891-897.

Lester L.B., Coghlan V.M., Nauert, B., Scott J.D. (1996) Cloning and characterization of a novel A-kinase anchoring protein. AKAP 220, association with testicular peroxisomes. J Biol Chem. 271:9460-9465.

Lim I.A., Hall D.D., Hell J.W. (2002) Selectivity and promiscuity of the first and second PDZ domains of PSD-95 and synapse-associated protein 102. J Biol Chem. 277:21697-21711.

Lin M., Hess R., Aitken R.J. (2002) Induction of sperm maturation in vitro in epididymal cell cultures of the tammar wallaby (Macropus eugenii): disruption of motility initiation and sperm morphogenesis by inhibition of actin polymerization. Reproduction. 124:107-117.

Liu D.Y., Martic M., Clarke G.N., Grkovic I., Garrett C., Dunlop M.E., Baker H.W. (2002) An anti-actin monoclonal antibody inhibits the zona pellucida-induced acrosome reaction and hyperactivated motility of human sperm. Mol Hum Reprod. 8:37-47. 
Liu T., Yu B., Luo F., Zhang X., Wu S., Liu L., Wu Y. (2011) Gene expression profiling of rat testis development during the early post-natal stages. Reprod Domest Anim. doi:10.1111/j.14390531.2011.01950.x

Lomonosova E., Chinnadurai G. (2008) BH3-only proteins in apoptosis and beyond: an overview. Oncogene. 27:Suppl.:1:2-19.

Lowery L.A., van Vactor D. (2009) The trip of the tip: understanding the growth cone machinery. Nat Rev Mol Cell Biol. 10:332-343.

Luers G.H., Nenicu A., Baumgart-Vogt E.. (2009) Peroxisomes are essential for regular spermatogenesis. In: Glander H.J., Grunewald S., Paasch U. Biology of male germ cells. Shaker Verlag, Aachen.

Luers G.H., Schad A., Fahimi H.D., Volkl A., Seitz J. (2003) Expression of peroxisomal proteins provides clear evidence for the presence of peroxisomes in the male germ cell line GC1spg. Cytogenet Genome Res. 103:360-365.

Luers G.H., Thiele S., Schad A., Volkl A., Yokota S., Seitz J. (2006). Peroxisomes are present in murine spermatogonia and disappear during the course of spermatogenesis. Histochem Cell Biol. 125:693-703.

McMillan R., Christians E., Forster M., Xiao X.Z., Connell P., Plumier J.C., Zuo X.X., Richardson J., Morgan S., Benjamin I.J. (2002) Heat shock transcription factor 2 is not essential for embryonic development, fertility, or adult cognitive and psychomotor function in mice. Mol Cell Biol. 22:8005-8014.

Mannaerts G.P., van Veldhoven P.P. (1993) Metabolic role of mammalian peroxisomes. In: Gibson G, Lake B. Peroxisomes: biology and importance in toxicology and medicine. Taylor \& Francis Verlag, London.

Mannan A., Lücke K., Dixkens C., Neesen J., Kämper M., Engel W., Burfeind P. (2000) Alternative splicing, chromosome assignment and subcellular localization of the testicular haploid expressed gene (THEG). Cytogenet Cell Genet. 91:171-179.

Mannan A., Nayernia K., Mueller C., Burfeind P., Adham I.M., Engel W. (2003) Male mice lacking the Theg (testicular haploid expressed gene) protein undergo normal spermatogenesis and are fertile. Biol Reprod. 69:788-796.

Mason J.M. (2009) Electrostatic contacts in the activator protein-1 coiled coil enhance stability predominantly by decreasing the unfolding rate. FEBS J. 276:7305-7318. 
Mason J.M., Arndt K.M. (2004) Coiled Coil Domains: stability, specificity, and biological implications. Chem Bio Chem. 5:170-176.

Mason J.M., Schmitz M.A., Müller K.M., Arndt K.M. (2006) Semirational design of Jun-Fos coiled coils with increased affinity: Universal implications for leucine zipper prediction and design. Proc Natl Acad Sci USA. 103:8989-8994.

McCollum D. (2010) Cytokinesis: ER keeps Mid1 in the middle. Curr Biol. 20:484-486.

Meistrich M., Bucci L.R., Trostle-Weige P.K., Brock W.A. (1985) Histone variants in rat spermatogonia and primary spermatocytes. Dev Biol. 112:230-240.

Miranda P.V., Allaire A., Sosnik J., Visconti P.E. (2009) Localization of low-density detergentresistant membrane proteins in intact and acrosome-reacted mouse sperm. Biol Reprod. 80:897904.

Morgulis A., Coulouris G., Raytselis Y., Madden T.L., Agarwala R., Schäffer A.A. (2008) Database indexing for production MegaBLAST searches. Bioinformatics. 24:1757-1764.

Moutier R. (1975) New mutations causing sterility restricted to the male in rats and mice. In: Antikatzides T., Erichsen S., Spiegel A. The laboratory animal in the study of reproduction, Fischer Verlag, Stuttgart.

Mund T., Gewies A., Schoenfeld N., Bauer M.K., Grimm, S. (2003) Spike, a novel BH3-only protein, regulates apoptosis at the endoplasmic reticulum. Faseb J. 17:696-698.

Naik R.R., Kirkpatrick S.M., Stone M.O. (2001) The thermostability of an alpha-helical coiledcoil protein and its potential use in sensor applications. Biosens Bioelectron. 16:1051-1057.

Nayernia K., Adham I.M., Burkhardt-Göttges E., Neesen J., Rieche M., Wolf S., Sancken U., Kleene K., Engel W. (2002a) Asthenozoospermia in mice with targeted deletion of the sperm mitochondrion-associated cysteine-rich protein (Smcp) gene. Mol Cell Biol. 22:3046-3052.

Nayernia K., Adham I.M., Shamsadin R., Müller C., Sancken U., Engel W. (2002b) Proacrosindeficient mice and zona pellucida modifications in an experimental model of multifactorial infertility. Mol Hum Reprod. 8:434-440.

Nayernia K, Drabent B, Adham IM, Möschner M, Wolf S, Meinhardt A, Engel W. (2003a) Male mice lacking three germ cell expressed genes are fertile. Biol Reprod. 69:1973-1978.

Nayernia K., Drabent B., Meinhardt A., Adham I.M., Schwandt I., Müller C., Sancken U., Kleene K.C., Engel W. (2005) Triple knockouts reveal gene interactions affecting fertility of male mice. Mol Reprod Dev. 70:406-416. 
Nayernia K., Meinhardt A., Drabent B., Adham I.M., Müller C., Steckel M., Sancken U., Engel W. (2003b) Synergistic effects of germ cell expressed genes on male fertility in mice. Cytogenet Genome Res. 103:314-320.

Nayernia K., von Mering M.H., Kraszucka K., Burfeind P., Wehrend A., Köhler M., Schmid M., Engel W. (1999) A novel testicular haploid expressed gene (THEG) involved in mouse spermatidsertoli cell interaction. Biol Reprod. 60:1488-1495.

Neduva V., Russell R.B. (2007) Proline-Rich Regions in Transcriptional Complexes: Heading in Many Directions. Sci STKE. 369:pe1.

Neesen J., Hartwich T., Brandhorst G., Aumuller G., Gläser B., Burfeind P., Mendoza-Lujambioa I. (2002) Tep22, a novel testicular expressed gene, is involved in the biogenesis of the acrosome and the midpiece of the sperm tail. Biochem Biophys Res Commun. 297:737-748.

Nenicu A., Luers G.H., Kovacs W., David M., Zimmer A., Bergmann M., Baumgart-Vogt E. (2007) Peroxisomes in human and mouse testis: differential expression of peroxisomal proteins in germ cells and distinct somatic cell types of the testis. Biol Reprod. 77:1060-1072.

Nicholson-Dykstra S., Higgs H.N., Harris E.S. (2005) Actin dynamics: growth from dendritic branches. Curr Biol. 15:346-357.

Nozawa K., Fritzler M.J., Takasaki Y., Wood M.R., Chan E.K. (2009). Co-clustering of Golgi complex and other cytoplasmic organelles to crescentic region of half-moon nuclei during apoptosis. Cell Biol Int. 33:148-157.

Nyakern-Meazza M., Narayan K., Schutt C.E., Lindberg U. (2002) Tropomyosin and gelsolin cooperate in controlling the microfilament system. J Biol Chem. 277:28774-28779.

Oliva R. (2006) Protamines and male infertility. Hum Reprod Update.12:417-435.

Ostermeier G.C., Dix D.J., Miller D., Khatri P., Krawetz S.A. (2002) Spermatozoal RNA profiles of normal fertile men. Lancet. 360:772-777.

Ostermeier G.C., Miller D., Huntriss J.D., Diamond M.P., Krawetz S.A. (2004) Reproductive biology: delivering spermatozoan RNA to the oocyte. Nature. 429:154.

Padmanabhan S., Baldwin R.L. (1994) Helix-stabilizing interaction between tyrosine and leucine or valine when the spacing is i,i+4. J Mol Biol. 241:706-713.

Paisley D., Banks S., Selfridge J., McLennan N.F., Ritchie A.M., McEwan C., Irvine D.S., Saunders P.T., Manson J.C., Melton D.W. (2004) Male infertility and DNA damage in Doppel knockout and prion protein/Doppel double-knockout mice. Am J Pathol. 164:2279-2288. 
Pelisch F., Gerez J., Druker J., Schor I., Muñoz M.J., Risso G., Petrillo E., Westman B.J., Lamond A.I., Arzt E., Srebrow A. (2010) The serine/arginine-rich protein SF2/ASF regulates protein sumoylation. Proc Natl Acad Sci. 107:16119-16124.

Pittman D.L., Cobb J., Schimenti K.J., Wilson L.A., Cooper D.M., Brignull E., Handel M.A, Schimenti J.C. (1998) Meiotic prophase arrest with failure of chromosome synapsis in mice deficient for Dmc1, a germline-specific RecA homolog. Mol Cell.1:697-705.

Pollard T.D., Beltzner C.C. (2002) Structure and function of the Arp2/3 complex. Curr Opin Struct Biol. 12:768-74.

Pollard T.D., Blanchoin L., Mullins R.D. (2000) Molecular mechanisms controlling actin filament dynamics in nonmuscle cells. Annu Rev Biophys Biomol Struct. 29:545-576.

Pollard T.D., Cooper J.A. (1986) Actin and actin-binding proteins. A critical evaluation of mechanisms and functions. Annu Rev Biochem. 55:987-1035.

Poon S., Easterbrook-Smith S.B., Rybchyn M.S., Carver J.A., Wilson M.R. (2000) Clusterin is an ATP-independent chaperone with very broad substrate specificity that stabilizes stressed proteins in a folding-competent state. Biochemistry. 39:15953-15960.

Poon S., Rybchyn M.S., Easterbrook-Smith S.B., Carver J.A., Pankhurst G.J., Wilson M.R. (2002) Mildly acidic pH activates the extracellular molecular chaperone clusterin. J Biol Chem. 277:39532-39540. Erratum in: J Biol Chem. (2002) 277:47964.

Pottiez G., Sevin E., Cecchelli R., Karamanos Y., Flahaut C. (2009) Actin, gelsolin and filamin-A are dynamic actors in the cytoskeleton remodelling contributing to the blood brain barrier phenotype. Proteomics. 9:1207-1219.

Powers J.M. (1985) Adreno-leukodystrophy (adreno-testiculo-leukomyelo-neuropathic-complex). Clin Neuropathol. 4:181-199.

Powers J.M., Schaumburg H.H. (1981) The testis in adreno-leukodystrophy. Am J Pathol. 102:9098.

Pring M., Evangelista M., Boone C., Yang C., Zigmond S.H. (2003) Mechanism of formininduced nucleation of actin filaments. Biochemistry. 42:486-496.

Print C.G., Loveland K.L. (2000) Germ cell suicide: new insights into apoptosis during spermatogenesis. Bioessays. 22:423-430. 
Print C.G., Loveland K.L., Gibson L., Meehan T., Stylianou A., Wreford N., de Kretser D., Metcalf D., Kontgen F., Adams J.M., Cory S. (1998) Apoptosis regulator bcl-w is essential for spermatogenesis but appears otherwise redundant. Proc Natl Acad Sci USA. 95:12424-12431.

Qi H., Fillion C., Labrie Y., Grenier J., Fournier A., Berger L., El-Alfy M., Labrie C. (2002) AIbZIP, a novel bZIP gene located on chromosome 1q21.3 that is highly expressed in prostate tumors and of which the expression is up-regulated by androgens in LNCaP human prostate cancer cells. Cancer Res. 62:721-733.

Reddy J., Svoboda, D. (1972) Microbodies (peroxisomes) identification in interstitial cells of the testis. J Histochem Cytochem. 20:140-142.

Reinhart N., Kremling H., Luerssen H., Adham I.M., Engel W. (1991) Characterization of a gene encoding a basic protein of the spermatid nucleus, TNP2, and its close linkage to the protamine genes in the bull. Biol Chem Hoppe Seyler. 372:431-436.

Reisse S., Rothardt G., Volkl A., Beier, K. (2001) Peroxisomes and ether lipid biosynthesis in rat testis and epididymis. Biol Reprod. 64:1689-1694.

Rodemer C., Thai T.P., Brugger B., Kaercher T., Werner H., Nave K.A., Wieland F., Gorgas K., Just W.W. (2003) Inactivation of ether lipid biosynthesis causes male infertility, defects in eye development and optic nerve hypoplasia in mice. Hum Mol Genet. 12:1881-1895.

Romero S., Didry D., Larquet E., Boisset N., Pantaloni D., Carlier M.F. (2007) How ATP hydrolysis controls filament assembly from profilin-actin: implication for formin processivity. $\mathbf{J}$ Biol Chem. 282:8435-8445.

Ross A.J., Waymire K.G., Moss J.E., Parlow A.F., Skinner M.K., Russell L.D., MacGregor G.R. (1998) Testicular degeneration in Bclw-deficient mice. Nat Genet. 18:251-256.

Rotem S., Katz C., Benyamini H., Lebendiker M., Veprintsev D., Rüdiger S., Danieli T., Friedler A. (2008) The structure and interactions of the proline-rich domain of ASPP2. J Biol Chem. 283:18990-18999.

Rotkopf S., Hamberg Y., Aigaki T., Snapper S.B., Shilo B.Z., Schejter E.D. (2011) The WASpbased actin polymerization machinery is required in somatic support cells for spermatid maturation and release. Development. 138:2729-2739.

Rozen S., Skaletsky H. (2000) Primer3 on the WWW for general users and for biologist programmers. In: Krawetz S, Misener S. Bioinformatics Methods and Protocols: Methods in Molecular Biology. Humana Press, Totowa. 
Röhrig U., Gerisch G., Morozova L., Schleicher M., Wegner A. (1995) Coactosin interferes with the capping of actin filaments. FEBS Lett. 374:284-286.

Rucker E.B. $3^{\text {rd }}$, Dierisseau P., Wagner K.U., Garrett L., Wynshaw-Boris A., Flaws J.A., Hennighausen L. (2000) Bcl-x and Bax regulate mouse primordial germ cell survival and apoptosis during embryogenesis. Mol Endocrinol. 14:1038-1052.

Sattler M., Liang H., Nettesheim D., Meadows R.P., Harlan J.E., Eberstadt M., Yoon H.S., Shuker S.B., Chang B.S., Minn A.J., Thompson C.B., Fesik S.W. (1997) Structure of Bcl-xL-Bak peptide complex: recognition between regulators of apoptosis. Science. 275:983-986.

Sambrook J., Fritsch E.F., Maniatis T. (1989) Molecular cloning: a laboratory manual (2 $2^{\text {nd }}$ edition). Cold Spring Habour, New York.

Sarg B., Chwatal S., Talasz H., Lindner H.H. (2009) Testis-specific linker histone H1t is multiply phosphorylated during spermatogenesis. Identification of phosphorylation sites. J Biol Chem. 284:3610-3618.

Schafer D.A. (2004) Cell biology: Barbed ends rule. Nature. 430:734-735.

Scherly D., Dathan N.A., Boelens W., van Venrooij W.J., Mattaj I.W. (1990) The U2B" RNP motif as a site of protein-protein interaction. EMBO J. 9:3675-3681.

Schramm S., Fraune J., Naumann R., Hernandez-Hernandez A., Höög C., Cooke H.J., Alsheimer M., Benavente R. (2011) A novel mouse synaptonemal complex protein is essential for loading of central element proteins, recombination, and fertility. PLoS Genet. 7:e1002088.

Shaha C., Tripathi R., Mishra D.P. (2010) Male germ cell apoptosis: regulation and biology. Philos Trans R Soc Lond B Biol Sci. 365:1501-1515.

Shamsadin R., Adham I.M., Engel W. (2002) Mouse pelota gene (Pelo): cDNA cloning, genomic structure, and chromosomal localization. Cytogenet Genome Res. 97:95-99.

Shewan A., Eastburn D.J., Mostov K. (2011) Phosphoinositides in cell architecture. Cold Spring Harb Perspect Biol. 3:a004796.

Singh A., Hitchcock-DeGregori S.E. (2003) Local destabilization of the tropomyosin coiled coil gives the molecular flexibility required for actin binding. Biochemistry. 42:14114-14121.

Song G., Wang W., Hu T. (2011) p53 facilitates BH3-only BID nuclear export to induce apoptosis in the irrepairable DNA damage response. Med Hypotheses. 77:850-852. 
Sosnik J., Miranda P.V., Spiridonov N.A., Yoon S.Y., Fissore R.A., Johnson G.R., Visconti P.E. (2009) Tssk6 is required for Izumo relocalization and gamete fusion in the mouse. J Cell Sci. 122:2741-2749.

Sosnik J., Buffone M.G., Visconti P.E. (2010) Analysis of CAPZA3 localization reveals temporally discrete events during the acrosome reaction. J Cell Physiol. 224:575-580.

Spungin B., Margalit I., Breitbart H. (1995) Sperm exocytosis reconstructed in a cell-free system: evidence for the involvement of phospholipase $\mathrm{C}$ and actin filaments in membrane fusion. $\mathrm{J}$ Cell Sci. 108:2525-2535.

Stelzer G., Don J. (2002) Atce1: a novel mouse cyclic adenosine 3',5'-monophosphate-responsive element-binding protein-like gene exclusively expressed in postmeiotic spermatids. Endocrinology. 143:1578-1588.

Stirling J., O'hare P. (2006) CREB4, a transmembrane bZip transcription factor and potential new substrate for regulation and cleavage by S1P. Mol Biol Cell. 17:413-426.

Stockley P., Preston B.T. (2004) Sperm competition and diversity in rodent copulatory behaviour. J Evol Biol. 17:1048-1057.

Styrna J., Kilarski W., Krzanowska H. (2003) Influence of the CBA genetic background on sperm morphology and fertilization efficiency in mice with a partial $\mathrm{Y}$ chromosome deletion. Reproduction. 126:579-588.

Sun H.Q., Yamamoto M., Mejillano M., Yin H.L. (1999) Gelsolin, a multifunctional actin regulatory protein. J Biol Chem. 274:33179-33182.

Surani M.A. (2004) Stem cells: How to make eggs and sperm. Nature. 427:106-107.

Sutton K.A., Jungnickel M.K., Florman H.M. (2008) A polycystin-1 controls postcopulatory reproductive selection in mice. Proc Natl Acad Sci USA.105:8661-8666.

Talbot J., Hodges R.S. (1982) Tropomyosin: a model protein for studying coiled-coil and alphahelix stabilization. Acc Chem Res. 15:224-230.

Taoka M., Ichimura T., Wakamiya-Tsuruta A., Kubota Y., Araki T., Obinata T., Isobe T. (2003) $\mathrm{V}-1$, a protein expressed transiently during murine cerebellar development, regulates actin polymerization via interaction with capping protein. J Biol Chem. 278:5864-5870.

Teng B., Lukasz A., Schiffer M. (2012) The ADF/Cofilin-pathway and actin dynamics in podocyte injury. Int J Cell Biol. 2012:320531. 
Thomson D.M., Ascione M.P., Grange J., Nelson C., Hansen M.D. (2011) Phosphorylation of VASP by AMPK alters actin binding and occurs at a novel site. Biochem Biophys Res Commun. 414:215-219.

Tilney L.G., Bonder E.M., Coluccio L.M., Mooseker M.S. (1983) Actin from Thyone sperm assembles on only one end of an actin filament: a behavior regulated by profilin. J Cell Biol. 97:112-124.

Tseden K., Topaloglu O., Meinhardt A., Dev A., Adham I.M., Müller C., Wolf S., Böhm D., Schlüter G., Engel W., Nayernia K. (2007) Premature translation of transition protein 2 mRNA causes sperm abnormalities and male infertility. Mol Reprod Dev. 74:273-279.

Ueno T., Falkenburger B.H., Pohlmeyer C., Inoue T. (2011) Triggering actin comets versus membrane ruffles: distinctive effects of phosphoinositides on actin reorganization. Sci Signal. 4:ra87.

Vergara S.P., Lizama C., Brouwer-Visser J., Moreno R.D. (2011) Expression of BCL-2 family genes in germ cells undergoing apoptosis during the first wave of spermatogenesis in the rat. Andrologia. 43:242-247.

Vogl A.W. (1989) Distribution and function of organized concentrations of actin filaments in mammalian spermatogenic cells and Sertoli cells. Int Rev Cytol. 119:1-56.

Vogl A.W., Vaid K.S., Guttman J.A. (2008) The Sertoli cell cytoskeleton. Adv Exp Med Biol. 636:186-211.

Waldman Ben-Asher H., Shahar I., Yitzchak A., Mehr R., Don J. (2010) Expression and chromosomal organization of mouse meiotic genes. Mol Reprod Dev. 77:241-248.

Wanders R.J. (2000) Peroxisomes, lipid metabolism and human disease. Cell Biochem Biophys. 32:89-106.

Wanders R.J., Waterham H.R. (2006) Biochemistry of mammalian peroxisomes revisited. Annu Rev Biochem. 75:295-332.

Williamson M.P. (1994) The structure and function of proline-rich regions in proteins. Biochem J. 297:249-260.

Worrall J.A., Mason J.M. (2011) Thermodynamic analysis of Jun-Fos coiled coil peptide antagonists. FEBS J. 278:663-672. 
Wu S.M., Baxendale V., Chen Y., Pang A.L., Stitely T, Munson P.J., Leung M.Y., Ravindranath N., Dym M., Rennert O.M., Chan W.Y. (2004) Analysis of mouse germ-cell transcriptome at different stages of spermatogenesis by SAGE: biological significance. Genomics. 84:971-981.

Wu H., Maciejewski M.W., Marintchev A., Benashski S.E., Mullen G.P., King S.M. (2000) Solution structure of a dynein motor domain associated light chain. Nat Struct Biol. 7:575-579.

Wu W., Shen O., Qin Y., Niu X., Lu C., Xia Y., Song L., Wang S., Wang X. (2010) Idiopathic male infertility is strongly associated with aberrant promoter methylation of methylenetetrahydrofolate reductase (MTHFR). PLoS One. 5:e13884.

Wu Y.H., Shih S.F., Lin J.Y. (2004) Ricin triggers apoptotic morphological changes through caspase-3 cleavage of BAT3. J Biol Chem. 279:19264-19275.

Yan W., Samson M., Jégou B., Toppari J. (2000) Bcl-w forms complexes with Bax and Bak, and elevated ratios of $\mathrm{Bax} / \mathrm{Bcl}-\mathrm{w}$ and $\mathrm{Bak} / \mathrm{Bcl}-\mathrm{w}$ correspond to spermatogonial and spermatocyte apoptosis in the testis. Mol Endocrinol. 14:682-699.

Yang C., Pring M., Wear M.A., Huang M., Cooper J.A., Svitkina T.M., Zigmond S.H. (2005) Mammalian CARMIL inhibits actin filament capping by capping protein. Dev Cell. 9:209-221.

Yang J. (2010) Molecular modeling of human BAD, a pro-apoptotic Bcl-2 family member, integrating glycolysis and apoptosis. Protein Pept Lett. 17:206-220.

Zhao M., Shirley C.R., Yu Y.E., Mohapatra B., Zhang Y., Unni E., Deng J.M., Arango N.A., Terry N.H., Weil M.M., Russell L.D., Behringer R.R., Meistrich M.L. (2001) Targeted disruption of the transition protein 2 gene affects sperm chromatin structure and reduces fertility in mice. Mol Cell Biol. 21:7243-7255.

Zigmond S.H., Evangelista M., Boone C., Yang C., Dar A.C., Sicheri F., Forkey F., Pring M. (2003) Formin leaky cap allows elongation in the presence of capping proteins. Curr Biol. 13:1820-1823.

Zini A., Agarwal A. (2011) Sperm chromatin: biological and clinical applications in male infertility and assisted reproduction. Springer Verlag, New York.

Zini A., Schlegel P.N. (1996) Catalase mRNA expression in the male rat reproductive tract. J Androl. 17:473-80. 


\section{Acknowledgements}

I would like to express my gratitude to Prof. Dr. med. Dr. h.c. Wolfgang Engel for the chance he gave me, to do my PhD study in the Institute of Human Genetics and for valuable scientific discussions, his excellent guidance and advice, patience and financial support.

I am very grateful to Dr. P. Grzmil for supervision of the project, constructive comments and help in the preparation of this thesis.

I sincerely thank Prof. Dr. S. Hoyer-Fender for being my co-referee. I would like to thank Prof. Dr. I. Adham, Prof. Dr. A. Meinhardt, Prof. Dr. H. Jarry and Prof. Dr. H. Michelmann for friendly and productive cooperation.

I would like to thank Dr. G. Salinas-Riester, L. Opitz and S. Luthin for their help in performance and analysis of transcriptional profiling experiments.

I would like to express special thanks to Dr. U. Fünfschilling, Dr. R. Hahnewald, Dr. K. Pantakani, Dr. J. Nolte and Dr. F. Nitzki for their scientific cooperation, advice and comments.

Special thanks go to my students: Claudia, Ralf and Bojan for the manual support, questions, discussions and friendship. I am grateful to Johanna, Janine, Christian, Christina, Tina, Nicole, Lorenz and to U. Lenz and S. Bergmann for a technical advice and supports in my project and to $S$. Wolf and A. Zigan and all workers of Animal Facility for care of my mice.

I am thankful for good and friendly atmosphere in our lab created by Tseku, Yvonne, Katrina, Agneta and Neele and all other colleges from Institute which I have met during my work. I would like to point out: Anna, Chiru, Joanna, Karina, Marta, Ogi, Penelope, Sandra, Saskia, Simone, Xinghbo, Rovena, Daria, Sascha, Henning.

The warmest thanks go to all people who help me in my life in Goettingen: Ewa and Radek, Bożenka and Mathias, Ozii and Kazik, Ola, Isabell, Lukasz... Thank you for everything!

A very special acknowledgement to my Parents, Grandmother, aunt Krystyna, Piotrek, Gosia and Jaś, Wojtek, Ewelina and Ania, Aneta, Basia and Jurek, Ewa. Thank you for the faith in my abilities, smiles, good words and support, what helped me to overcome the most stressful und difficult moments of my PhD.

A lot of thanks to my Sweetheart - Lilka. Your smile restored my hope.

Most of all I would like to thank my Wife Monika. Thank you for Your love, unlimited patience and friendship - it is the best I have received in my life. Only You know how important it is for me, that You firmly hold our kite. 


\section{Curriculum Vitae}

\section{Personal information}

Surname/First Name

Address

E-mail

Date and place of birth

Nationality

\section{Work experience}

03/2009 to present

03/2007-02/2009

$11 / 2006-02 / 2007$

$10 / 2005-06 / 2007$

\section{Education}

$06 / 2007$

$10 / 2004-06 / 2007$

$10 / 2002$ - 06/2007

$09 / 1998-06 / 2002$

\section{WIECZERZAK, KRZYSZTOF}

Albrecht-Thaer-Weg 22a/2 37075 Göttingen

krzyswie@interia.pl

06 July 1983 - Cracow, Poland

Polish
Georg-August-University Göttingen, Instiute of Human Genetic, $\mathrm{PhD}$ studies

Polish Academy of Sciences, Institute of Pharmacology, Cracow, Poland, Department of Biochemistry

Scientific worker, PhD studies

Polish Academy of Sciences, Institute of Pharmacology

Trainee in Department of Biochemistry

Jagiellonian University, Cracow, Poland

Trainee in molecular genetics laboratory in Department Genetics and Evolutionary

\section{Jagiellonian University}

Master Science Degree in Biology

Major in: Molecular Genetics

Jagiellonian University, Pedagogical Department

Biology and chemistry teacher's courses and practices

Jagiellonian University, Faculty of Biology and Earth Sciences. Study in Biology

Nowodworski High School (no. I), Cracow, Poland 


\section{Publications}

Kaczmarek K., Studencka M., Meinhardt A., Wieczerzak K., Thoms S., Engel W., Grzmil P. (2011) Overexpression of peroxisomal testis-specific 1 protein induces germ cell apoptosis and leads to infertility in male mice. Mol Biol Cell. 22:1766-1779.

Lenartowicz M., Starzyński R., Wieczerzak K., Krzeptowski W., Lipiński P., Styrna J. (2011) Alterations in the expression of the Atp7a gene in the early postnatal development of the mosaic mutant mice (Atp7a mo-ms) - An animal model for Menkes disease. Gene Expr Patterns. 11:41-47.

Lenartowicz M., Wieczerzak K., Krzeptowski W., Dobosz P., Grzmil P., Starzyński R., Lipiński P. (2010) Developmental changes in the expression of the Atp7a gene in the liver of mice during the postnatal period. J Exp Zool A Ecol Genet Physiol. 313:209-217.

Wieczerzak K., Witarski T., Kowalska M., Nawrat D., Roman A., Bielawski A., Nalepa I. (2008) Effect of cocaine on responsiveness of alpha(1)-adrenergic receptors in rat cerebral cortex: modulation by GABA-mimetic drugs. Pharmacol Rep. 60:980-984. 